\title{
Simultaneous evaluation of multiple PEMS using an engine dynamometer emissions test cell
}

\author{
Thomas G. McConnell \\ West Virginia University
}

Follow this and additional works at: https://researchrepository.wvu.edu/etd

\section{Recommended Citation}

McConnell, Thomas G., "Simultaneous evaluation of multiple PEMS using an engine dynamometer emissions test cell" (2007). Graduate Theses, Dissertations, and Problem Reports. 4318.

https://researchrepository.wvu.edu/etd/4318

This Thesis is protected by copyright and/or related rights. It has been brought to you by the The Research Repository @ WVU with permission from the rights-holder(s). You are free to use this Thesis in any way that is permitted by the copyright and related rights legislation that applies to your use. For other uses you must obtain permission from the rights-holder(s) directly, unless additional rights are indicated by a Creative Commons license in the record and/ or on the work itself. This Thesis has been accepted for inclusion in WVU Graduate Theses, Dissertations, and Problem Reports collection by an authorized administrator of The Research Repository @ WVU. For more information, please contact researchrepository@mail.wvu.edu. 
Simultaneous Evaluation of Multiple PEMS Using an Engine Dynamometer Emissions Test Cell

\author{
Thomas G. McConnell
}

Thesis submitted to the College of Engineering and Mineral Resources at West Virginia University in partial fulfillment of the requirements for the degree of

\author{
Master of Science \\ in \\ Mechanical Engineering
}
Mridul Gautam, Ph.D., Chair
W. Scott Wayne, Ph.D.
Benjamin C. Shade, Ph.D.

Department of Mechanical and Aerospace Engineering Morgantown, West Virginia 2007

Keywords: Diesel Emissions, Emissions Testing, Mobile Systems, PEMS, In-Use Testing 


\begin{abstract}
Portable emission measurement systems (PEMS) are taking center stage as in-use testing programs are getting underway. EPA-mandated manufacturer-run in-use testing programs require a PEMS, and currently there is one commercially available and widely used, the SEMTECH-D built by Sensors, Inc. The SEMTECH-D was first unveiled in 2002, and numerous software and hardware upgrades have given way to the SEMTECHDS. The manufacturer claims this system is fully compatible with all new Code of Federal Regulations (CFR) including part 1065 subpart $\mathrm{J}$ (which addresses field testing and PEMS). Yet, while West Virginia University (WVU) was using the SEMTECH-D during the summer of 2005, problems were encountered that prompted further insight into its performance. A ten month study ensued to study SEMTECH-D's behavior compared to an EPA certified engine test cell on the campus of WVU at Morgantown, WV. After multiple test days, exhaust configurations, and comparisons to both the heavy-duty engine dynamometer laboratory (compliant with CFR40 Part 86 Subpart N) at WVU, and another PEMS, the SEMTECH-D was found to consistently exhibit high discrepancies. Over a twenty minute Federal Test Procedure (FTP) transient test the total $\mathrm{NO}_{\mathrm{X}}$ mass emitted error was as high as $25 \%$, while the $\mathrm{CO}_{2}$ total mass emitted error was as high as $15 \%$ compared to the engine dynamometer laboratory.
\end{abstract}




\section{Acknowledgments}

My time at West Virginia University has allowed me to work with a lot of talented and motivated people. My interest in emissions engineering started when Dr. Wayne hired me as an hourly during the summer of 2003, and I appreciate him allowing me to travel and get a glimpse of the testing being conducted by WVU. After graduation, Dr. Gautam hired me as a graduate student, and my real education in emission engineering began. Dr. Gautam you have exposed me to in-use emissions testing and have given me a very broad knowledge base on which to start my career in industry. I would like to thank you, Dr. Gautam, for guiding me through this process.

While conducting tests with MEMS and SEMTECH, Ben Shade was always willing to answer questions and help, even though his own dissertation was looming over him. Also, when it came time for me to construct tests and eventually write my thesis I could always count on Ben for suggestions and help.

I would not have had this topic had our 2005 SEMTECH In-Use crew not have banded together and found problems in the field. Petr Sindler, Josh Flaugher, Robin Ames, and I spent many late nights installing SEMTECH on vehicles, and then countless hours troubleshooting. And when I was conducting comparison tests at the ERC, I knew that I could ask one of you guys to help out. Big bubbles, no troubles!

Pop, you and Callee have scientific minds that have inspired me to learn and work hard. Callee, I got a good taste of research in academia when Molly and I helped you with the cows and fish oil during your masters.

Elise, your writing abilities and interest in my research have motivated me to produce a quality document. I know that I got annoyed when you would bring up the ' $\mathrm{T}$ ' word, but you kept me on track by doing so, and I know that you are sincerely interested. Thanks everyone for your support! 
Table of Contents

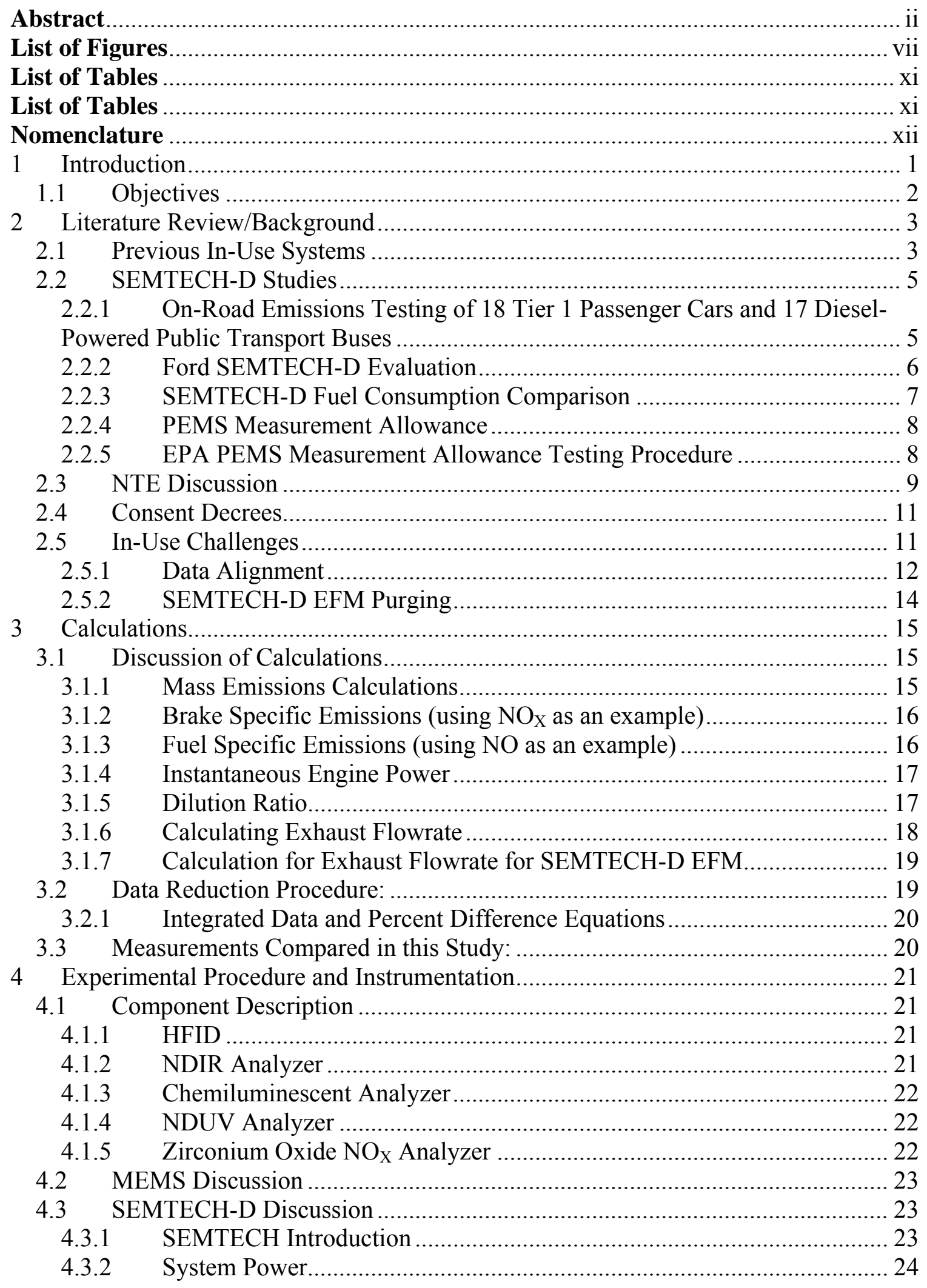




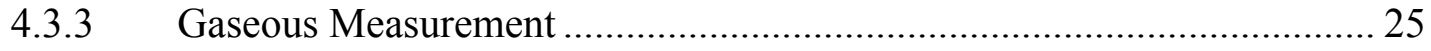

4.3.4 Sampling Frequency/Engine Communication .................................... 26

4.3.5 SEMTECH EFM............................................................................... 26

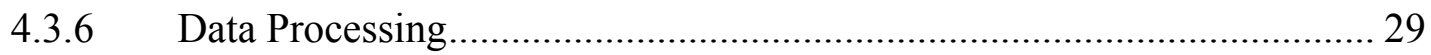

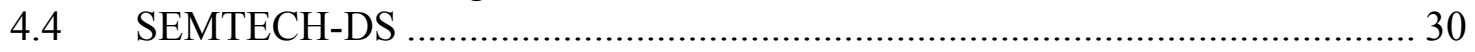

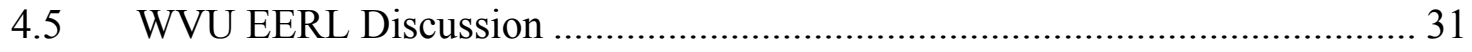

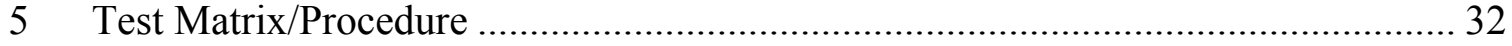

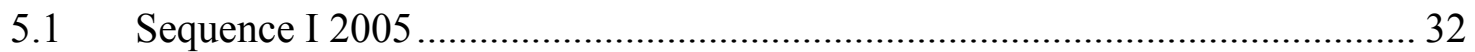

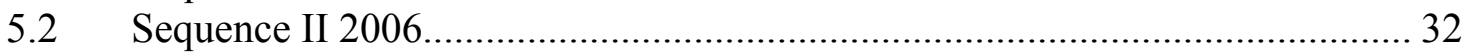

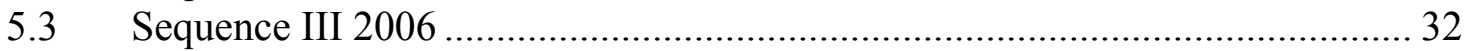

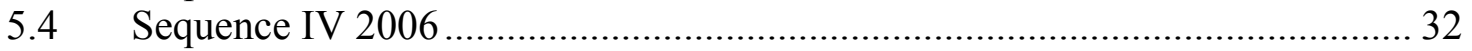

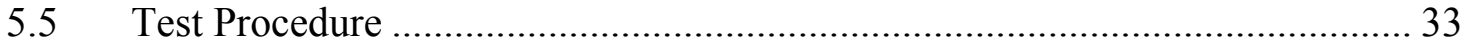

5.6 Test Cell Setup ........................................................................................ 33

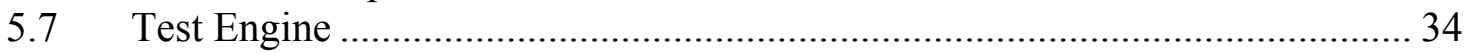

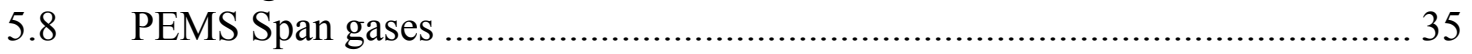

5.8.1 The SEMTECH-D was spanned with the following concentrations: ....... 35

5.8.2 The MEMS span bottle used had the following concentrations: .............. 35

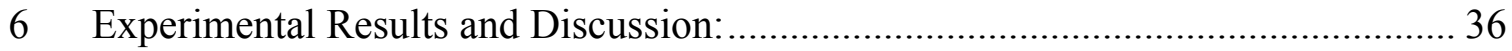

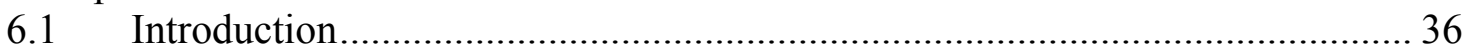

6.2 Laboratory Performance/Consistency .................................................... 36

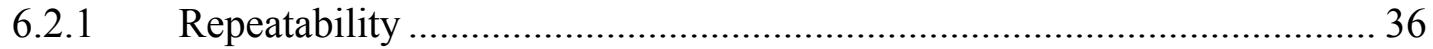

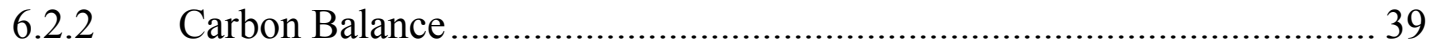

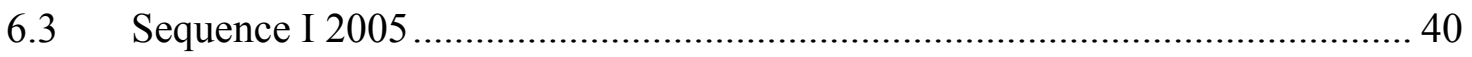

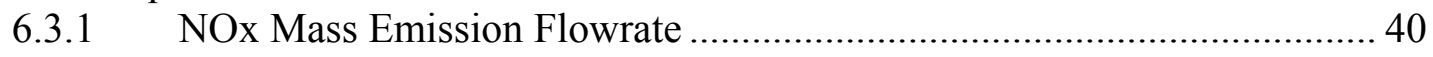

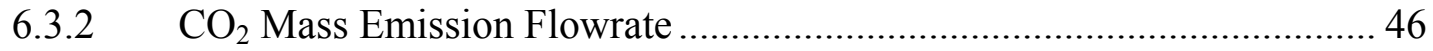

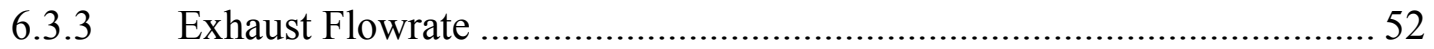

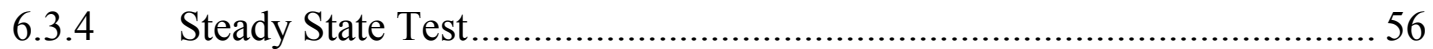

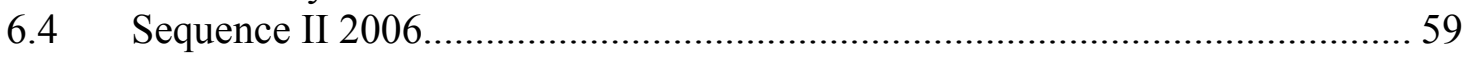

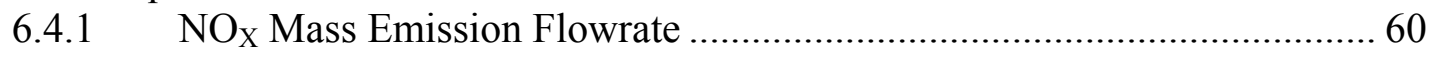

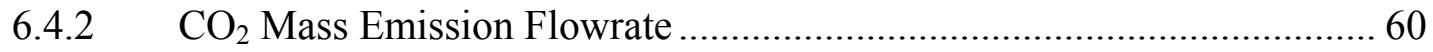

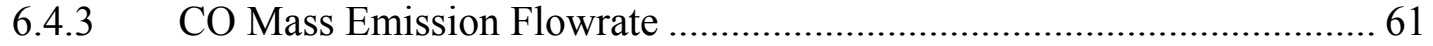

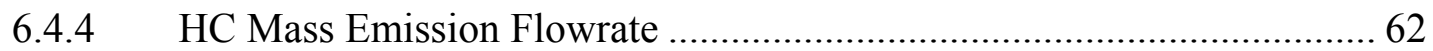

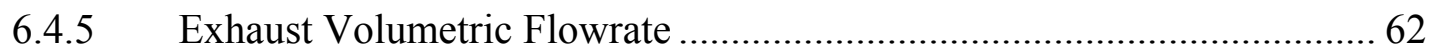

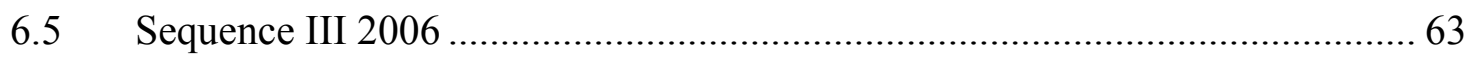

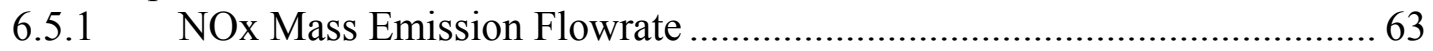

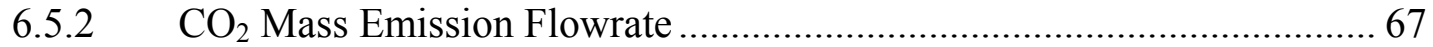

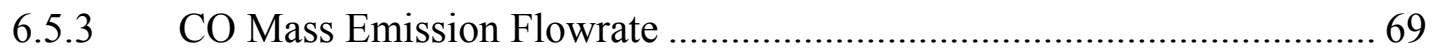

6.5.4 HC Mass Emission Flowrate ........................................................... 71

Exhaust Flowrate ............................................................................ 73

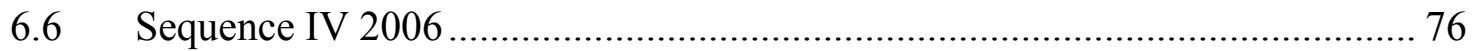

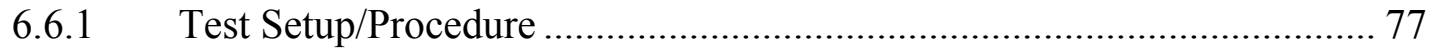

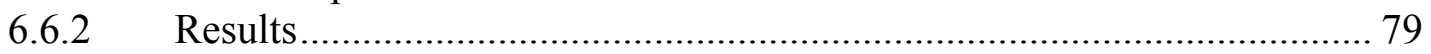

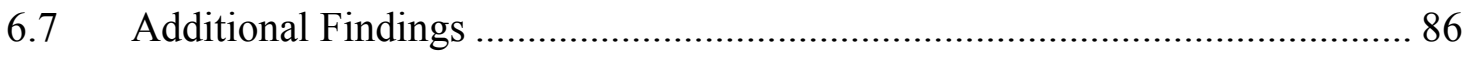

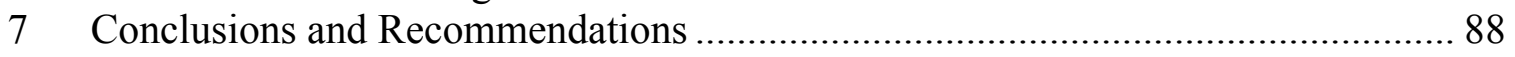

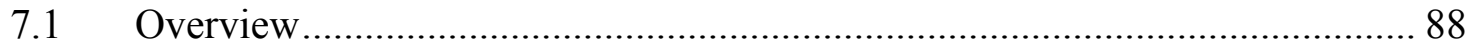

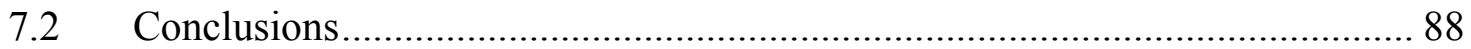




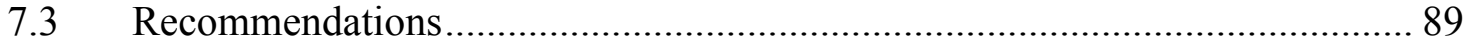

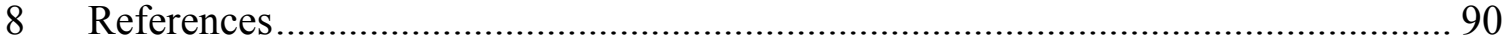

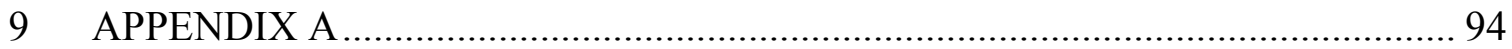

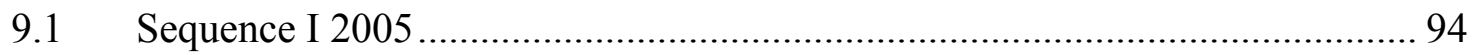

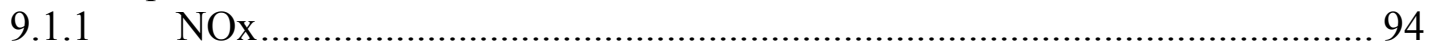

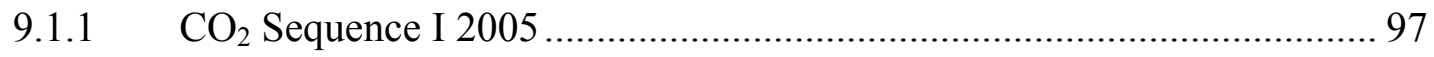




\section{List of Figures}

Figure 2.1 Engine Operation Points for FTP with NTE region .................................. 10

Figure 2.2 Improperly Aligned Data....................................................................... 13

Figure 2.3 Properly Aligned Data ............................................................................. 14

Figure 4.1 SEMTECH-D Front Panel [23] .............................................................. 24

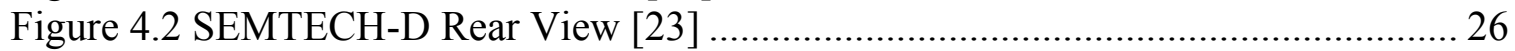

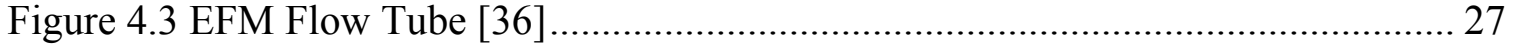

Figure 4.4 SEMTECH-D EFM Flow Tube Cross Section [36] ..................................... 28

Figure 4.5 SEMTECH EFM Electronics Box [36] ..................................................... 29

Figure 4.6 SEMTECH-D Post Processor ................................................................... 30

Figure 5.1 SEMTECH-D test setup inside EERL...................................................... 34

Figure 6.1 Average laboratory $\mathrm{NO}_{\mathrm{X}}$ values from hot-start FTP tests using reference fuel.

Error bars represent one standard deviation for each data set. Note the expanded axis.

Figure 6.2 Average laboratory $\mathrm{CO}_{2}$ values from hot-start FTP tests using reference fuel.

Error bars represent one standard deviation for each data set. Note the expanded axis.

Figure 6.3 Average laboratory $\mathrm{CO}$ values from hot-start FTP tests using reference fuel.

Error bars represent one standard deviation for each data set. Note the expanded axis.

Figure 6.4 Average laboratory emission values from hot-start FTP tests using reference fuel.

Figure 6.5 EERL Fuel Consumption Percent Difference (consumed vs. recovered) ...... 40

Figure 6.6 PEMS and laboratory NOx mass emission flowrate traces for FTP E00840_01.

Figure 6.7 Total $\mathrm{NO}_{\mathrm{X}}$ Mass for Sequence I 2005 testing. SEMTECH\#1 did not capture E00840 03.

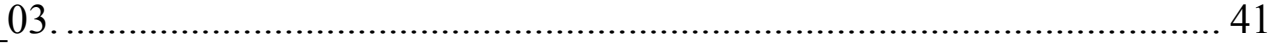

Figure 6.8 Laboratory versus SEMTECH\#1 averaged FTP $\mathrm{NO}_{\mathrm{X}}$ mass emissions rate.... 42

Figure 6.9 Laboratory versus SEMTECH\#2 averaged FTP $\mathrm{NO}_{\mathrm{X}}$ mass emissions rate.... 43

Figure 6.10 SEMTECH-D\#1 repeatability, FTP 1 versus FTP $2 \mathrm{NO}_{\mathrm{X}}$ mass emissions rate.

44

Figure 6.11 SEMTECH-D\#2 repeatability, FTP 1 versus FTP $2 \mathrm{NO}_{\mathrm{X}}$ mass emissions rate.

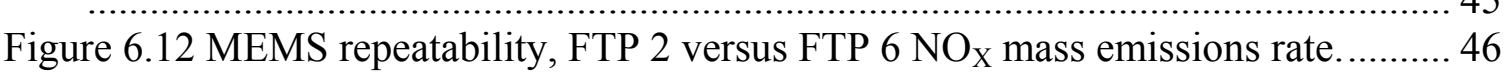

Figure 6.13 PEMS and laboratory $\mathrm{CO}_{2}$ mass emission flowrate traces for FTP E00840 01.

Figure $6.14 \overline{\mathrm{CO}_{2}}$ mass emission totals for Sequence I 2005 testing. E00840_03 was not

captured by SEMTECH\#1 ..................................................................... 48

Figure 6.15 Laboratory versus SEMTECH\#1 averaged FTP $\mathrm{CO}_{2}$ mass emissions rate. . 48

Figure 6.16 Laboratory versus SEMTECH\#2 averaged $\mathrm{FTP} \mathrm{CO}_{2}$ mass emissions rate. . 49

Figure 6.17 SEMTECH-D\#1 repeatability, FTP 1 versus FTP $2 \mathrm{CO}_{2}$ mass emissions rate.

Figure 6.18 SEMTECH-D\#2 repeatability, FTP 1 versus FTP $2 \mathrm{CO}_{2}$ mass emissions rate.

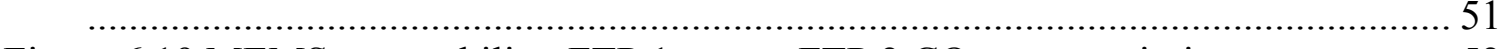

Figure 6.19 MEMS repeatability, FTP 1 versus FTP $2 \mathrm{CO}_{2}$ mass emissions rate........... 52 
Figure 6.20 Exhaust volumetric totals from Sequence I 2005 testing. SEMTECH\#1 did

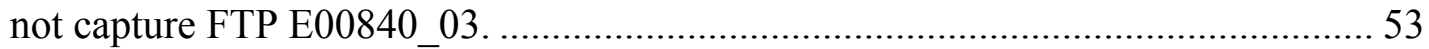

Figure 6.21 Laboratory versus SEMTECH\#1 averaged FTP exhaust flowrate................ 54

Figure 6.22 Laboratory versus SEMTECH\#2 averaged FTP exhaust flowrate................ 54

Figure 6.23 Multiple system exhaust flowrate trace.................................................. 55

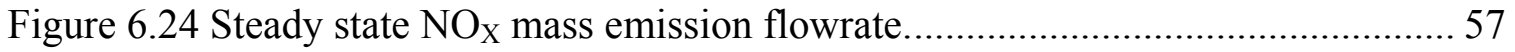

Figure 6.25 Steady state $\mathrm{CO}_{2}$ mass emission flowrate. ............................................5

Figure 6.26 Exhaust volumetric flowrate.................................................................. 58

Figure 6.27 SEMTECH-D raw steady-state exhaust flow rate traces. ............................ 59

Figure 6.28 Average $\mathrm{NO}_{\mathrm{X}}$ mass emission totals. Error bars represent one standard deviation for each day of testing. Percent difference calculation made using Laboratory as standard.

Figure 6.29 Average $\mathrm{CO}_{2}$ mass emission totals. Error bars represent one standard deviation for each day of testing. Percent difference calculations made using Laboratory as reference.

Figure 6.30 Average CO mass emission totals. Error bars represent one standard deviation for each day of testing. Percent difference calculations made using Laboratory as reference.

Figure 6.31 Average HC mass emission totals. Error bars represent one standard deviation for each day of testing. Percent difference calculations made using laboratory as reference.

Figure 6.32 Average exhaust volumetric flowrate totals. Error bars represent one standard deviation for each day of testing. Percent difference calculations made using Laboratory as reference.

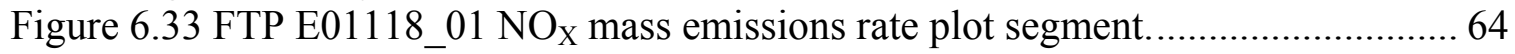

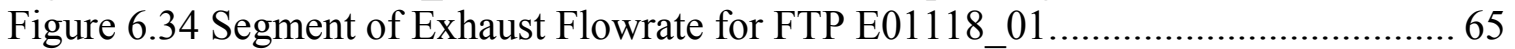

Figure 6.35 System agreement for FTP Sequence E01118 $\overline{N O}_{\mathrm{X}}$ mass emissions rate.... 65 Figure 6.36 Average NOx mass emission totals. Error bars represent one standard deviation for each day of testing. Percent difference calculations made using Laboratory as reference. 66

Figure 6.37 Segment of E01118_01 NOx plot with SEMTECH mass emissions calculated using ECU fuel flowrate. Complete test shown in Appendix A Figure 9.8............ 67

Figure 6.38 Segment of FTP E01118_01 $\mathrm{CO}_{2}$ mass emission plot. Complete plot shown in APPENDIX A Figure 9.9.

Figure 6.39 Average $\mathrm{CO}_{2}$ mass emission totals. Error bars represent one standard deviation for each day of testing. Percent difference calculations made using Laboratory as reference.

Figure 6.40 System agreement for FTP Sequence E01118 $\mathrm{CO}_{2}$ mass emissions rate...... 69 Figure 6.41 Segment of CO mass emission comparison for FTP E01118_01. Complete

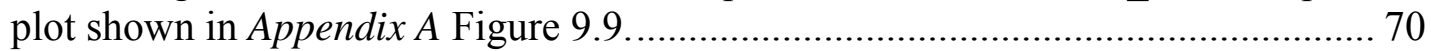

Figure 6.42 System agreement for FTP Sequence E01118 CO mass emissions rate...... 70 Figure 6.43 Average CO mass emission totals. Error bars represent one standard deviation for each day of testing. Percent difference calculations made using

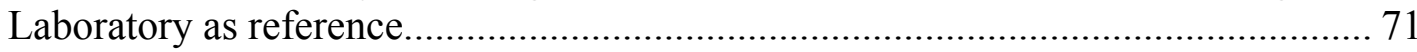

Figure 6.44 Segment of HC mass emission comparison for FTP E01118_01............... 72 Figure 6.45 System agreement for FTP Sequence E01118 HC mass emissions rate...... 72 
Figure 6.46 Average HC mass emission totals. Error bars represent one standard deviation for each day of testing. Percent difference calculations made using Laboratory as reference.

Figure 6.47 Segment of FTP E01118_01 exhaust flowrate plot. Complete trace shown in

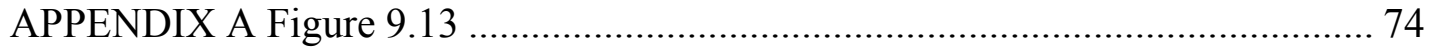

Figure 6.48 System agreement for FTP Sequence E01118 exhaust flowrate.................. 74

Figure 6.49 Average exhaust volumetric totals. Error bars represent one standard deviation for each day of testing. Percent difference calculations made using

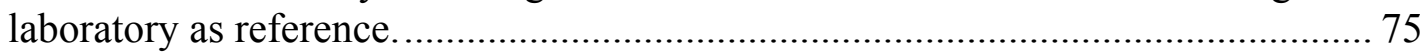

Figure 6.50 Calibration Verification Test............................................................... 78

Figure 6.51 Segment of FTP E01361_03 $\mathrm{NO}_{\mathrm{X}}$ mass emission flowrate plot. Complete

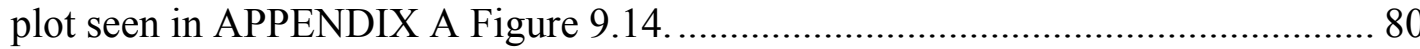

Figure 6.52 Average $\mathrm{NO}_{\mathrm{X}}$ mass emission totals. Error bars represent one standard deviation for each day of testing. Percent difference calculations made using laboratory as reference............................................................................ 80

Figure 6.53 Segment of FTP E01361_03 $\mathrm{CO}_{2}$ mass emission plot. Complete plot seen in

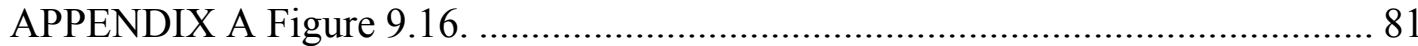

Figure 6.54 Average $\mathrm{CO}_{2}$ mass emission totals. Error bars represent one standard deviation for each day of testing. Percent difference calculations made using laboratory as reference............................................................................. 81

Figure 6.55 Segment of FTP E01361_03 CO mass emission plot. Complete plot seen in

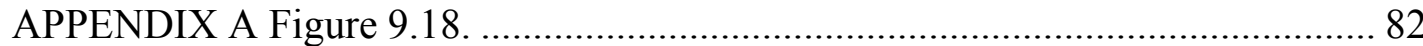

Figure 6.56 Average CO mass emission totals. Error bars represent one standard deviation for each day of testing. Percent difference calculations made using

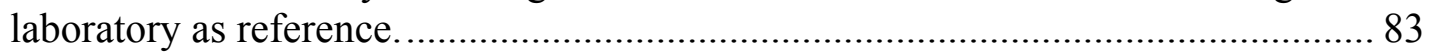

Figure 6.57 Segment of FTP E01361_03 HC Plot. Complete plot seen in .................... 83 Figure 6.58 Average $\mathrm{HC}$ mass emission totals. Error bars represent one standard deviation for each day of testing. Percent difference calculations made using laboratory as reference............................................................................ 84

Figure 6.59 Segment of FTP E01361_03 exhaust flowrate plot. Complete plot seen in

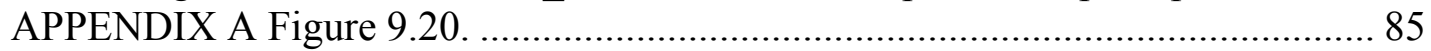

Figure 6.60 Average exhaust volumetric totals. Error bars represent one standard deviation for each day of testing. Percent difference calculations made using

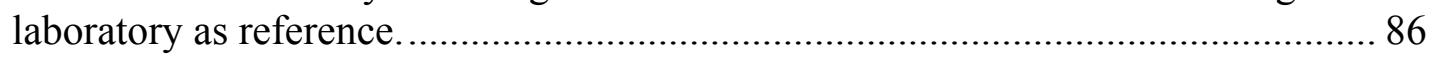

Figure 6.61 FTP NTE engine operating region and NTE segments from FTP E01357_01.

Figure 9.1 Time Aligned Data from Multiple PEMS …............................................... 95

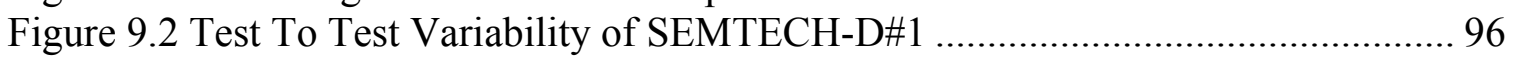

Figure 9.3 Test To Test Variability of SEMTECH-D \#2 ............................................ 96

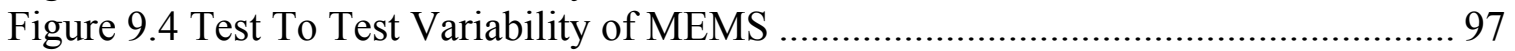

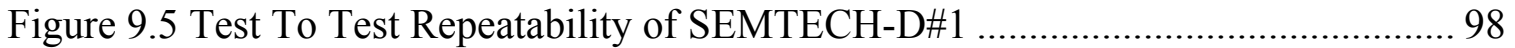

Figure 9.6 Test To Test Repeatability of SEMTECH-D\#2 .......................................... 98

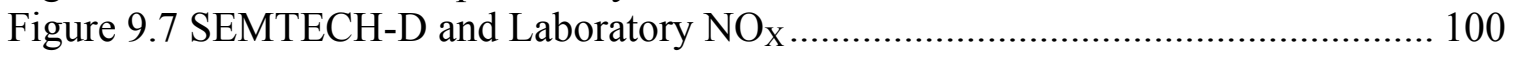

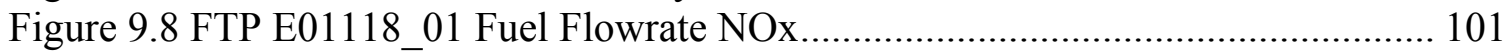

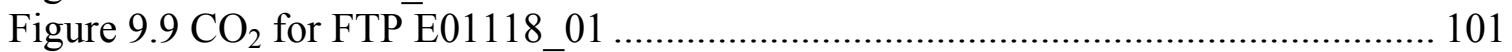

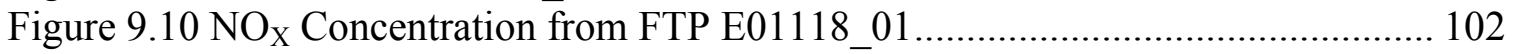


Figure 9.11 Segment of Figure 9.10

Figure 9.12 Time Aligned Averaged Laboratory vs. Averaged SEMTECH-D E01118 103

Figure 9.13 Exhaust Flowrate from a FTP................................................................ 103

Figure 9.14 $\mathrm{NO}_{\mathrm{X}}$ Mass Emission from FTP E01361_03 ............................................ 104

Figure 9.15 Time Aligned Averaged Laboratory vs. Averaged SEMTECH-D E01357 105

Figure 9.16 $\mathrm{CO}_{2}$ Mass Emission for FTP E01361_03 ........................................... 105

Figure 9.17 Time Aligned Averaged Laboratory vs. Averaged SEMTECH-D E01357 106

Figure 9.18 CO Mass Emission for FTP E01361 03 ................................................... 106

Figure 9.19 HC Mass Emission for FTP E01361_03 ................................................ 107

Figure 9.20 Exhaust Flowrate for FTP E01361_03 .................................................. 107 


\section{List of Tables}

Table 2.1 Ford SEMTECH-D Span Gas Concentrations........................................... 7

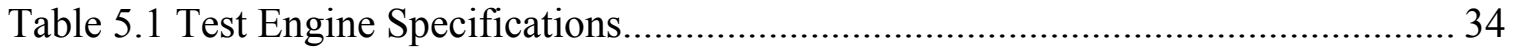

Table 5.2 SEMTECH-D Span Gases ......................................................................... 35

Table 5.3 MEMS Span Gases ................................................................................. 35

Table 6.1 PEMS Integrated $\mathrm{NO}_{\mathrm{X}}$ Mass Percent Differences Compared to Laboratory ... 46

Table $6.2 \mathrm{CO}_{2}$ Integrated Percent Differences Compared to Laboratory ........................ 52

Table 6.3 Exhaust Flowrate Integrated Percent Differences. ...................................... 56

Table 6.4 Sequence I 2005 steady-state test errors compared to the laboratory............... 56

Table 6.5 Audit Test ............................................................................................ 78

Table 6.6 Sequence IV 2006 Percent Differences Compared to Laboratory................... 79

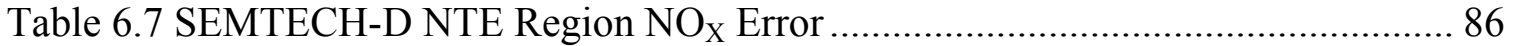

Table 9.1 Complete Statistics from Sequence I, 2005 ................................................ 94

Table 9.2 Complete results from Sequence I 2006 .................................................... 99

Table 9.3 Sequence III 2006 Complete Results....................................................... 100

Table 9.4 August 2006 Percent Differences Compared to Laboratory.......................... 104 


\section{Nomenclature}

\begin{tabular}{|c|c|}
\hline CATI & Clean Air Technologies, Incorporated \\
\hline CFR & Code of Federal Regulations \\
\hline $\mathrm{CO}$ & Carbon Monoxide \\
\hline $\mathrm{CO}_{2}$ & Carbon Dioxide \\
\hline $\mathrm{EC}$ & Electrochemical Sensor \\
\hline $\mathrm{ECU}$ & Engine Control Unit \\
\hline EERL & Engine and Emissions Research Laboratory \\
\hline EFM & Electronic Flow Meter \\
\hline EPA & Environmental Protection Agency \\
\hline FTP & Federal Test Procedure \\
\hline $\mathrm{HC}$ & Hydrocarbons \\
\hline HFID & Heated Flame Ionization Detector \\
\hline MEMS & Mobile Emissions Measurement System \\
\hline NESCAUM & Northeast States for Coordinated Air Use Management \\
\hline NDIR & Non-Dispersive Infrared \\
\hline NDUV & Non-Dispersive Ultraviolet \\
\hline NMHC & Non-Methane Hydrocarbons \\
\hline $\mathrm{NO}$ & Nitric Oxide \\
\hline $\mathrm{NO}_{2}$ & Nitrogen Dioxide \\
\hline $\mathrm{NO}_{\mathrm{X}}$ & Oxides of Nitrogen \\
\hline NTE & Not To Exceed \\
\hline PM & Particulate Matter \\
\hline ppm & Parts Per Million \\
\hline ROVER & Real-Time On-Road Vehicle Emissions Recorder \\
\hline scfm & Standard Cubic Feet Per Minute \\
\hline SEMTECH-D & Sensors Emission Technology Diesel \\
\hline SwRI & Southwest Research Institute \\
\hline $\mathrm{THC}$ & Total Hydrocarbons \\
\hline WVU & West Virginia University \\
\hline
\end{tabular}




\section{Introduction}

Heavy-duty diesel emissions have come under increasing scrutiny by governmental agencies and the public since 1998. Since the early 1990s, the United States Environmental Protection Agency (US EPA) and the European Union (EU) have been placing tougher requirements on both on-road and off-road heavy-duty diesel engine emissions.

In early June 2005, the EPA signed a rule implementing an in-use regulatory testing program for heavy-duty diesel engines [1]. This regulation requires engine manufacturers to measure gaseous and particulate matter (PM) emissions in real-world driving situations using a portable emissions measurement system (PEMS). Regulations will take full effect in 2007. However, an EPA mandated pilot program was started for the 2005 and 2006 model year engines. The program required that carbon monoxide (CO), hydrocarbons $(\mathrm{HC})$, oxides of nitrogen $\left(\mathrm{NO}_{\mathrm{X}}\right)$ including nitrogen monoxide and dioxide (NO and $\mathrm{NO}_{2}$, respectively), and PM emissions be monitored on-board with a PEMS. Compliance for the in-use program will be determined using current 30 second window not-to-exceed (NTE) criteria (see Section 2.3).

Analyzers used for portable emissions systems are off-shoots of 'garage grade' analyzers. These analyzers are considerably smaller, cheaper, and less accurate than laboratory grade analyzers. Given the accuracy, repeatability, and response characteristics of analyzers used in PEMS, and the constraints associated with engine control unit (ECU) broadcast, it is imperative that a measurement allowance be determined to account for limitations associated with in-use testing. The EPA contracted Southwest Research Institute (SwRI) to carry out testing to determine how much error is associated with a measurement from a PEMS, specifically Sensors' SEMTECH-D. The PEMS were to be delivered on August 15, 2005, and the testing was to be done and a report delivered by November of 2006 [2].

In early 2005, as manufacturers were ramping up for the pilot program, the only system commercially available was Sensors' SEMTECH-D. West Virginia University (WVU) purchased a SEMTECH-D to conduct in-use tests for a study funded by Cummins, Inc. Later, WVU also later received a second SEMTECH-D from Cummins to conduct comparison tests. Initial flooded probe tests proved the SEMTECH-D to be 
reliable for steady state sampling. Throughout the summer of 2005, WVU tested numerous vehicles for 'in-use' emissions. Results from these tests were inconsistent and warranted an investigation into the system's performance. In the fall of 2005 , the opportunity arose to install WVU's SEMTECH-D along with the aforementioned manufacturer's unit in the WVU Engine and Emissions Research Laboratory (EERL) test cell at WVU, which will be referred to as the laboratory for the remainder of this document. A series of Federal Test Procedure (FTP) tests were conducted, as well as a seven-mode steady-state test. During the testing it was found that discrepancies in total $\mathrm{NO}_{\mathrm{X}}$ mass emissions were greater than $20 \%$ when compared to the laboratory. These large errors prompted a ten month investigation, which is reported in this document.

\subsection{Objectives}

Given the fact that SEMTECH-D is a widely used commercially available system, it is important that measurement errors for mass emissions be determined. Portable systems, probably due to size constraints and operating conditions, have proven to be less accurate than laboratory-grade equipment. The primary objective of this study was to evaluate the performance of a commercially available PEMS against the WVU heavyduty engine Code of Federal Regulation (CFR) 40 Part 86 compliant FTP test cell. Secondly, the goal is to monitor the accuracy and repeatability of the PEMS under transient and steady state operation of a heavy-duty diesel engine compared to the WVU test cell. Finally, the objective is to determine a range of error for gaseous emissions measurements from the PEMS. 


\section{Literature Review/Background}

A thorough review of previous portable systems was conducted in order to understand different technologies that have been used. Also, testing procedures and guidelines were documented for complete understanding.

\subsection{Previous In-Use Systems}

In-use emissions testing is not a new concept. In 1982, Caterpillar built a portable bag collection system to measure fuel specific $\mathrm{NO}_{\mathrm{X}}$ from diesel engines [3]. Ten years later in 1992, SwRI created another integrated bag system that could measure undiluted $\mathrm{CO}, \mathrm{NO}_{\mathrm{X}}$, carbon dioxide $\left(\mathrm{CO}_{2}\right), \mathrm{O}_{2}$, and $\mathrm{PM}$ separately with a mini dilution tunnel. The drawbacks to this system were that it could only test vehicles with automatic transmissions, and it could not be used for continuous monitoring of emissions, since it used an integrated bag for sampling [4].

Over the next few years General Motors (GM) and Ford each came out with emissions systems for gasoline engines. The GM system used a Horiba infrared-based analyzer for $\mathrm{CO}_{2}, \mathrm{HC}, \mathrm{CO}$, and $\mathrm{NO}$. Exhaust flow measurements were made with a Kurz flow meter [5]. The Ford system measured $\mathrm{CO}_{2}, \mathrm{HC}, \mathrm{CO}$, and $\mathrm{NO}_{\mathrm{X}}$. An infrared analyzer was used to measure concentrations of $\mathrm{CO}_{2}, \mathrm{HC}, \mathrm{CO}$, and $\mathrm{O}_{2}$, while a nondispersive ultraviolet detector was used for $\mathrm{NO}_{\mathrm{X}}$. The Ford system was within 3\% difference for $\mathrm{CO}_{2}$, while the $\mathrm{NO}_{\mathrm{X}}$ measurement was $10 \%$ off of a laboratory grade analyzer [6].

Marine emissions were tested by the Coast Guard in 1997 using a system capable of measuring $\mathrm{CO}_{2}, \mathrm{HC}, \mathrm{CO}, \mathrm{NO}, \mathrm{NO}_{2}$, and $\mathrm{SO}_{2}$. A Shortridge Instruments Electronic Flowhood provided airflow measurements $[7,8]$.

In 1997 the University of Pittsburgh used an analyzer from OTC SPX to measure $\mathrm{CO}_{2}, \mathrm{HC}, \mathrm{CO}, \mathrm{NO}_{\mathrm{X}}$, and $\mathrm{O}_{2}$ from natural gas-fueled vans [9]. Exhaust flowrate came from ECM fuel and intake air flows. The same year, the Flemish Institute for Technological Research created a system to measure diluted emissions from gasoline and diesel-fueled vehicles. The system incorporated a non-dispersive infrared (NDIR) for CO and $\mathrm{CO}_{2}$, a heated flame ionization detector (HFID) for $\mathrm{HC}$, and a chemiluminescent analyzer for $\mathrm{NO}_{\mathrm{X}} \cdot \mathrm{NO}_{\mathrm{X}}$ and $\mathrm{CO}_{2}$ results were reported to be within $10 \%$ of a laboratory 
grade analyzer. A calculated exhaust flowrate came from ECM fuel, engine speed, and lambda values [9].

The Northeast States for Coordinated Air Use Management (NESCAUM), the U.S. Generating Co., US EPA, the Manufacturers of Emission Control Association, and the Massachusetts Department of Environmental Protection used an onboard system to test $\mathrm{CO}_{2}, \mathrm{HC}, \mathrm{CO}$, and $\mathrm{NO}_{\mathrm{X}}$ on diesel-fueled off-road vehicles. Results compared to an engine laboratory found $\mathrm{NO}_{\mathrm{X}}$ to be $12 \%$ off, and the carbon balance calculation was $9 \%$ off [10].

The US EPA created a system called ROVER (Real-Time On-Road Emissions Recorder) in 1999. The system was capable of measuring $\mathrm{CO}_{2}, \mathrm{HC}, \mathrm{CO}, \mathrm{NO}$ using an Andros microbench. The exhaust flowrate was measured using an Annubar differential pressure device [11].

Ford along with WPI-Microprocessor, Inc. created a new portable system called PREVIEW (Portable Real-Time Emission Vehicular Integrated Engineering Workstation). Ultraviolet and infrared-based analyzers were used to measure $\mathrm{CO}_{2}, \mathrm{HC}$, $\mathrm{CO}, \mathrm{NO}_{\mathrm{X}}$. Comparisons to lab grade analyzers were very good for $\mathrm{CO}_{2}$ and $\mathrm{NO}_{\mathrm{X}}$ (both less than $2 \%$ difference) [12].

In 2000, Horiba, Ltd. and NGK Insulators, Ltd. created an on-board system to measure $\mathrm{NO}_{\mathrm{X}}$ for diesel engines. The system used zirconium oxide sensors to measure $\mathrm{NO}_{\mathrm{X}}$ concentrations. Intake air was measured using a Karman vortex volumetric flowmeter. Results were favorable with $\mathrm{NO}_{\mathrm{X}}$ mass measurements within $4 \%$ agreement of the laboaratory [13].

Clean Air Technologies International, Inc. (CATI) released an on-board mass exhaust measurement emissions monitoring system with $\mathrm{NO}_{\mathrm{X}}, \mathrm{CO}_{2}$, and qualitative $\mathrm{PM}$ abilities in 2001 [14]. Exhaust flowrate was indirectly calculated using intake air and mass balance equations. An NDIR analyzer was used for $\mathrm{HC}, \mathrm{CO}$, and $\mathrm{CO}_{2}$. Electrochemical cells were used for $\mathrm{NO}$ and $\mathrm{O}_{2} . \mathrm{NO}_{2}$ was estimated from $\mathrm{NO}$ measurements, knowing that $\mathrm{NO}_{2}$ comprises less than $5 \%$ of total $\mathrm{NO}_{\mathrm{X}}$ in nonaftertreatment equipped diesel engines. Flow and concentration alignment problems caused errors to be as high as $25 \%$ for $\mathrm{NO}$ and $\mathrm{CO}_{2}$. Authors concluded that the use of a 'minimized' system sacrificed the accuracy. 
In 2001, Engine, Fuel, and Emissions Engineering, Inc. created a "Ride-Along Vehicle Emission Measurement" (RAVEM) system. The system utilizes a partial flow dilution system capable of measuring $\mathrm{CO}, \mathrm{CO}_{2}, \mathrm{NO}_{\mathrm{X}}$, and PM. NDIR detection was used for $\mathrm{CO}$ and $\mathrm{CO}_{2}$, while chemiluminesence was used for $\mathrm{NO}_{\mathrm{X}}$. Particulate matter was collected on a $37 \mathrm{~mm}$ filter. The system diluted a portion of the exhaust stream, as compared to a typical laboratory tunnel. Results for $\mathrm{CO}_{2}$ and $\mathrm{NO}_{\mathrm{X}}$ have been presented as system repeatability over a driving cycle within $6 \%$ and within $10 \%$ for PM [15].

In 2002, Horiba Instruments Inc. created an onboard system capable of measuring $\mathrm{CO}, \mathrm{CO}_{2}, \mathrm{HC}$, and $\mathrm{NO}_{\mathrm{X}}$. It utilized a static Pitot tube to provide a real-time measurement of the exhaust mass flowrate, which was related to mileage. A heated NDIR was used for $\mathrm{HC}, \mathrm{CO}$, and $\mathrm{CO}_{2}$, while $\mathrm{NO}_{\mathrm{X}}$ was measured with a zirconium oxide $\left(\mathrm{ZrO}_{2}\right)$ sensor. In 2004, the Horiba On-Board Measurement System (OBS 1000) was compared to the WVU MEMS system and the WVU engine laboratory. The conclusions were that the $\mathrm{NO}_{\mathrm{X}}$ measurements were up to $11 \%$ different, and $\mathrm{CO}_{2}$ concentrations were within $3 \%$. [16],[17].

In 2002 Sensors Inc. also unveiled their on-board emission system, the first generation SEMTECH (see Section 4.3) [18]. The following year, Sensors, Inc. announced a five year cooperative agreement with Ford to develop the next generation SEMTECH-G and SEMTECH-D [19].

In 2005, Horiba Instruments Inc. released a paper discussing the latest on-board system; the OBS 2200. The system used partial-vacuum FID, chemiluminescence detection, and NDIR analyzers [20]. All analyzers were heated and placed upstream of the sample pump. The heated NDIR also measures water to quantify water interference with other analyzers. Exhaust flowrate measurement was achieved with a dual pressure transducer pitot tube system [20]. It was concluded that this PEMS analyzers and flow meter meet the linearity check requirements [20].

\section{$2.2 \quad$ SEMTECH-D Studies}

\subsubsection{On-Road Emissions Testing of 18 Tier 1 Passenger Cars and 17 Diesel- Powered Public Transport Buses}

In 2001, the US EPA awarded Sensors, Inc. with a contract to conduct on-road tests of gasoline powered passenger vehicles and heavy-duty diesel equipped vehicles 
[21]. SEMTECH-G was used for the gasoline vehicles, and the SEMTECH-D tested the diesel engines. The difference between the two systems was the measurement of HC and the exclusion of an $\mathrm{NO}_{2}$ measurement with the SEMTECH-G. The SEMTECH-G measures HC with NDIR, while the SEMTECH-D uses a HFID. The buses were equipped with Detroit Diesel Corporation (DDC) Series 50 engines, and one had a Series 40 engine. The exhaust flowrate was not measured; hence mass emissions were computed from ECM fuel flowrate data. $\mathrm{CO}_{2}$ results were consistent with a $4.4 \%$ difference on average and a standard deviation of $20.2 \mathrm{~g} / \mathrm{bhp}-\mathrm{hr}$ for the family of engines. $\mathrm{NO}_{\mathrm{X}}$ data resulted in a standard deviation of $0.89 \mathrm{~g} / \mathrm{bhp}-\mathrm{hr}$ and a $17 \%$ difference for the DDC Series 50 family [21]. This data does not provide any comparisons to a trusted machine, but it shows SEMTECH to be consistent.

Correlation testing was also performed at three different locations, including Caterpillar and two unnamed Sensors, Inc. customer locations. Both steady-state and transient FTP correlation tests were captured. Steady-state correlations were very good and standard errors were well within acceptable limits (i.e. CO:17 parts per million (ppm), $\left.\mathrm{NO}_{\mathrm{X}}: 7 \mathrm{ppm}, \mathrm{THC}: 3 \mathrm{ppm}\right)$. Transient mass results were within $2.5 \%$ for all constituents when compared to a Horiba MEXA 7100 stationary laboratory analyzer. The $\mathrm{NO}_{X}$ mass emission result was reported to exactly match the MEXA [21].

In order to validate the performance of the complete system, the authors suggested using a root mean square equation [21]. The three quantities needed for a complete picture are: 1) gas concentration, 2) exhaust mass flowrate, and 3) ECM torque. With these errors, one can insert them into the following equation to understand the overall system performance.

System Error $=\sqrt{(\text { concentration error })^{2}+(\text { flow error })^{2}+(\text { ECM torque error })^{2}}$

\subsubsection{Ford SEMTECH-D Evaluation}

In 2005, Ford Motor Company addressed the accuracy of SEMTECH-D analyzers

[22]. Raw concentrations were compared to modal measurements from the chassis dynamometer test facility at Ford. The test vehicles were light-duty passenger cars with 1.8 and 2.0 liter turbocharged engines with oxidation catalysts. The test cycle comprised 
of phase one through three of the heavy-duty Federal Test Procedure (FTP) Urban Driving Dynamometer Schedule (UDDS) test cycle.

Table 2.1 Ford SEMTECH-D Span Gas Concentrations

\begin{tabular}{|l|l|l|}
\hline Gaseous Species & Concentration Used & Concentration Recommended \\
\hline Propane & $1000 \mathrm{ppm}$ & $200-300 \mathrm{ppm}$ \\
\hline $\mathrm{CO}$ & $20,000 \mathrm{ppm}$ & $1200-1400 \mathrm{ppm}$ \\
\hline $\mathrm{CO}_{2}$ & $15.0 \%$ & $12-14 \%$ \\
\hline $\mathrm{NO}$ & $1500 \mathrm{ppm}$ & $1500-2000 \mathrm{ppm}$ \\
\hline $\mathrm{NO}_{2}$ & $500 \mathrm{ppm}$ & $200-300 \mathrm{ppm}$ \\
\hline
\end{tabular}

*Italics signifies span gas out of limits

Table 2.1 lists the span gas concentrations, which were used for the testing, and manufacturer recommended concentrations. Concentrations in Italics denote that the gas concentration recommendation by Sensors, Inc. was exceeded [23].

The authors concluded that the measurement of $\mathrm{CO}_{2}, \mathrm{THC}$, and $\mathrm{NO}_{\mathrm{X}}$ were well within $+/-5 \%$ of the concentrations reported by the test cell analyzers. Also, transient CO emissions were possible above the 200ppm level. This paper did not address the performance of the electronic flow meter for exhaust flowrate measurements.

\subsubsection{SEMTECH-D Fuel Consumption Comparison}

The US EPA and SwRI collaborated to conduct fuel consumption testing on heavy-duty road tractors [24]. The scope of the testing was to study fuel saving strategies such as fuel efficient tires and aerodynamic fairings. At the same time Sensors, Inc. installed a SEMTECH-D on the test vehicles to collect emissions data for the comparison of gravimetric fuel measurements versus carbon balance calculations. Two vehicles were tested with modifications and compared to a control vehicle. The carbon balance using SEMTECH-D emissions measurements was calculated using SAE Standard J1094a [25].

Results from this study found that the variability of SEMTECH-D fuel usage measurements was similar to gravimetric measurements with a coefficient of variance of $3.26 \%$ versus $2.98 \%$. The authors concluded that PEMS can be used for J1321 test procedures. 


\subsubsection{PEMS Measurement Allowance}

In June 2003, the US EPA and Engine Manufacturers Association (EMA) agreed to an outline of a manufacturer operated in-use heavy-duty vehicle NTE testing program. This program was a result of a law suit filed by the EMA and other individual engine manufacturers against the EPA [2]. The suit targeted the not-to-exceed (NTE) emissions standards [2]. The outline stated that the EPA, CARB, and EMA were to determine an emission accuracy margin for in-use PEMS. The need for this error band was expressed by the engine manufacturers before the in-use program becomes fully enforceable [2] in 2007.

“Test Plan to Determine PEMS Measurement Allowances for the Gaseous Emissions Regulated under the Manufacturer-Run Heavy-Duty Diesel Engine In-Use Testing Program" [26] states the following:

The computer model statistically combines many sources of PEMS and lab error, which are nearly impossible to capture simultaneously in a single test. The model will use statistics to apply the errors in a way that simulates actual running of a PEMS in-use. The model will also consider only the portion of error that is attributable to PEMS, and it will subtract the error that is already tolerated in an emissions lab today. The model will also calculate and validate results according to 40 CFR Part 1065.

The errors refer to the way that the laboratory and the PEMS react to varying conditions, such as environmental changes or vibrations.

\subsubsection{EPA PEMS Measurement Allowance Testing Procedure}

The US EPA, California Air Resources Board (CARB), and EMA agreed on a procedure to determine the measurement allowance for PEMS. The measurement allowance establishes the error associated with using a PEMS and adjusts emission regulations accordingly [26]. The measurement allowance is only applied to $\mathrm{NO}_{\mathrm{X}}, \mathrm{CO}$, and non-methane hydrocarbons (NMHC). The actual determination was to be done using a computer model. The model was to capture all sources of error, both from the PEMS and the stationary laboratory, then subtract outside errors leaving the PEMS total error. 
The test plan outlined the following procedure for testing a PEMS for the measurement allowance program [26]:

1) Measure raw as well as CVS-dilute emissions

2) Measure engine inlet airflow through use of LFE or equivalent

3) Measure instantaneous fuel consumption and torque

4) Ensure purging of the DPF system as often as needed in order to ensure negligible impact on emissions variability

5) Capture ECM broadcast channels and other common diagnostic channels, as recommended by engine manufacturer(s), to ensure proper engine operation

6) Do not measure PM.

7) Stabilization time $=120$ seconds. Data acquisition $=30$ seconds, after stabilization. Dwell time between points $=30$ seconds (total time per point $=180 \mathrm{sec} .=3 \mathrm{~min}$ )

8) Zero and span PEMS at beginning of day following manufacturer's guidelines. Do not re-span PEMS analyzers again during the day, unless PEMS manufacturer provides a way to do this automatically, so it is realistic with real-life in-use testing practices. Re-zeroing should be allowed if and only if done automatically by the PEMS for the same reasons.

9) Zero and spanning of the instrument laboratory analyzer can be repeated as often as laboratory common practices.

10) Perform carbon balance checks on CVS emissions data to ensure data quality

11) Always power off PEMS equipment at end of each day. Re-start start-up process every day.

The Italics items were followed during the acquisition of the data presented in this document. Zeroing and spanning was performed in between tests on the PEMS, unlike the guideline stating this was to be done only once a day. This ensures repeatable data from test to test.

\section{$2.3 \quad$ NTE Discussion}

Not-to-exceed testing procedures resulted from the Consent Decrees between the United States EPA and the engine manufacturers [27],[28]. This testing scheme ensures that the engine's emissions are controlled over the entire range of speeds and loads 
experienced in use. The lug curve of the engine determines the NTE zone, and it is bounded by the following and represented in Figure 2.1:

- Torque upper boundary: lug curve

- Torque lower boundary: $30 \%$ of maximum torque

— Engine speed lower limit: $\mathrm{n}_{15}=\mathrm{n}_{10}+0.15\left(\mathrm{n}_{\mathrm{hi}}-\mathrm{n}_{\mathrm{lo}}\right)$

- Engine speed upper limit: $\mathrm{n}_{\mathrm{hi}}=$ engine speed (above rated speed) at $70 \%$ of maximum power

- $\mathrm{n}_{\mathrm{lo}}=$ engine speed (below rated speed) at $50 \%$ of maximum power

— Power Boundary: 30\% maximum power

When the engine is running in the described region, the emissions are averaged over a thirty second period. Then these values are compared to FTP emission levels that were found when the engine was certified. Engine compliance is determined by the emissions not exceeding 1.25 times the respective emission limit.

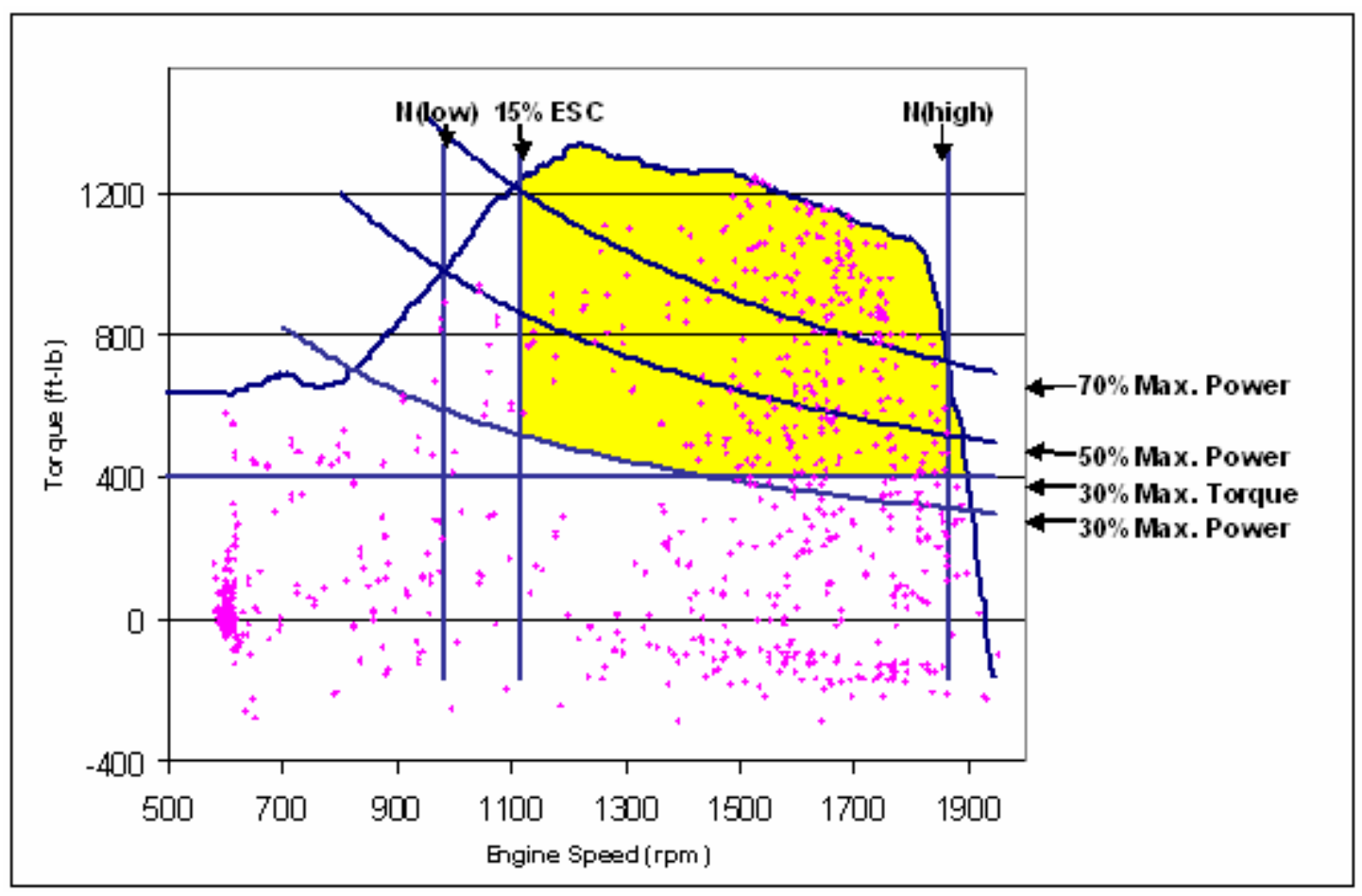

Figure 2.1 Engine Operation Points for FTP with NTE region

The previously mentioned heavy-duty transient FTP cycle has three segments where the engine is operating continuously, for at least 30 seconds, in the NTE zone. These three periods are the only segments of time where NTE compliance can be determined. The 
first segment occurs 625 seconds into the test and provides 28 thirty second windows. The second and third windows occur at 723 and 799 seconds, and provide 10 and 23 windows, respectively.

\subsection{Consent Decrees}

In October of 1998, the US EPA, CARB, and the EMA, which represents the six major U.S. diesel engine manufacturers agreed to a one billion dollar settlement resulting from over polluting the air. The government charged the engine manufacturers with creating engine control strategies that evaded pollution regulations. Under certain operating conditions the engine controller employed strategies that appeared to defeat the emissions control system on the engine. Per example, at highway cruising speeds (steady state behavior) the ECU switched from an 'urban' setting to a 'highway' calibration. The highway calibration resulted in advanced injection timing that led to improved fuel economy and increased power, but at the cost of high $\mathrm{NO}_{\mathrm{X}}$ emissions. As a result of this settlement, the engine manufacturers were required to engage in an increased level of emission reduction research, compliance testing on current products, and pay fines to the United States.

\subsection{In-Use Challenges}

There are many places where measurement and operating errors can occur during an in-use test. Presented below is a summary of these situations [29].

- Different data sampling frequencies for analyzers

- Analyzer drift over multi-hour tests.

- Condensation of water in measurement lines

- Condensation in the differential pressure lines

- Soot in differential pressure lines

- Inertial effects on pressure measurement devices

- Leaks in sampling lines

- Sample filter effectiveness over long tests

- Problems with ambient weather measurement devices

- ECU communication lapses 
There are also known factors that effect an engine's emissions and power output [30] as listed below:

- Fuel composition

- Fuel temperature

- Intake air temperature

- Intercooler temperature

- Intake restriction and exhaust depression

- Engine wear

Fuel composition can have very great effects on emissions. $\mathrm{NO}_{\mathrm{X}}$ creation can vary by as much as $12 \%$ depending on fuel characteristics [31] and PM can vary by as much as $50 \%$. CO and $\mathrm{HC}$ can also vary by as much as $40 \%$ and $17 \%$, respectively.

Environmental changes can create variances in emissions nearly identical to those mentioned for fuel [31]. These contributions will weigh heavily as emission limits continue to decrease.

\subsubsection{Data Alignment}

The time aligning of data from the different analyzers, communication devices, and flow measurement signals is an important step in the testing process. As stated in the SEMTECH-D user manual, time shifts as small as 2-3 seconds can cause significant errors [23]. These errors stem from different exhaust configurations. Each vehicle's exhaust system varies in length, therefore resulting in longer or shorter travel times for the exhaust through the PEMS and flow measurement system. For instance, improperly aligned data will result in electronic flow meter (EFM) flowrates not matching up with gas concentrations, and $\mathrm{NO}_{\mathrm{X}}$ values will be well under or over the actual mass emission flowrate. Time alignment is done by plotting the $\mathrm{CO}_{2}$ measurement with either the fuel flowrate or the exhaust flowrate, and visually aligning the signals. To be more precise, the two signals can be multiplied together and summed. Then, as the signals are aligned properly, the sum will reach a maximum. 


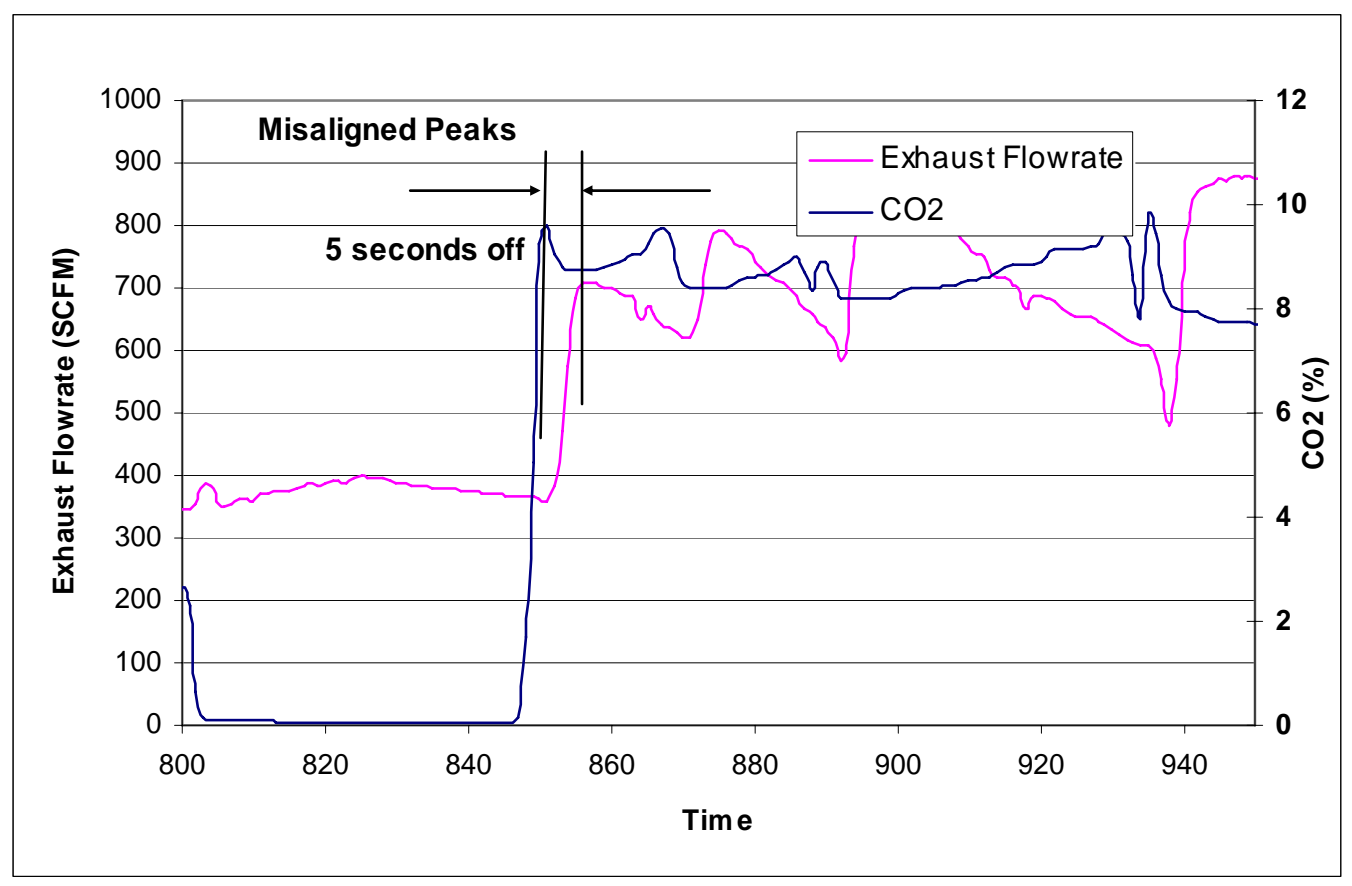

Figure 2.2 Improperly Aligned Data

Figure 2.2 illustrates a set of data that are not properly aligned. When the second-bysecond data is multiplied together, the highlighted peaks (not being aligned) are not multiplied to one another, and this creates a smaller number than if they were. Once all matching points are aligned, multiplied, and summed, the plot in Figure 2.3 will result in a total larger than Figure 2.2, signifying proper alignment. To expedite this process, an Excel spreadsheet is used to plot $\mathrm{CO}_{2}$. Then the exhaust flowrate time stamp is modified (either $+\mathrm{X}$ seconds or $-\mathrm{X}$ seconds) until alignment is achieved. 


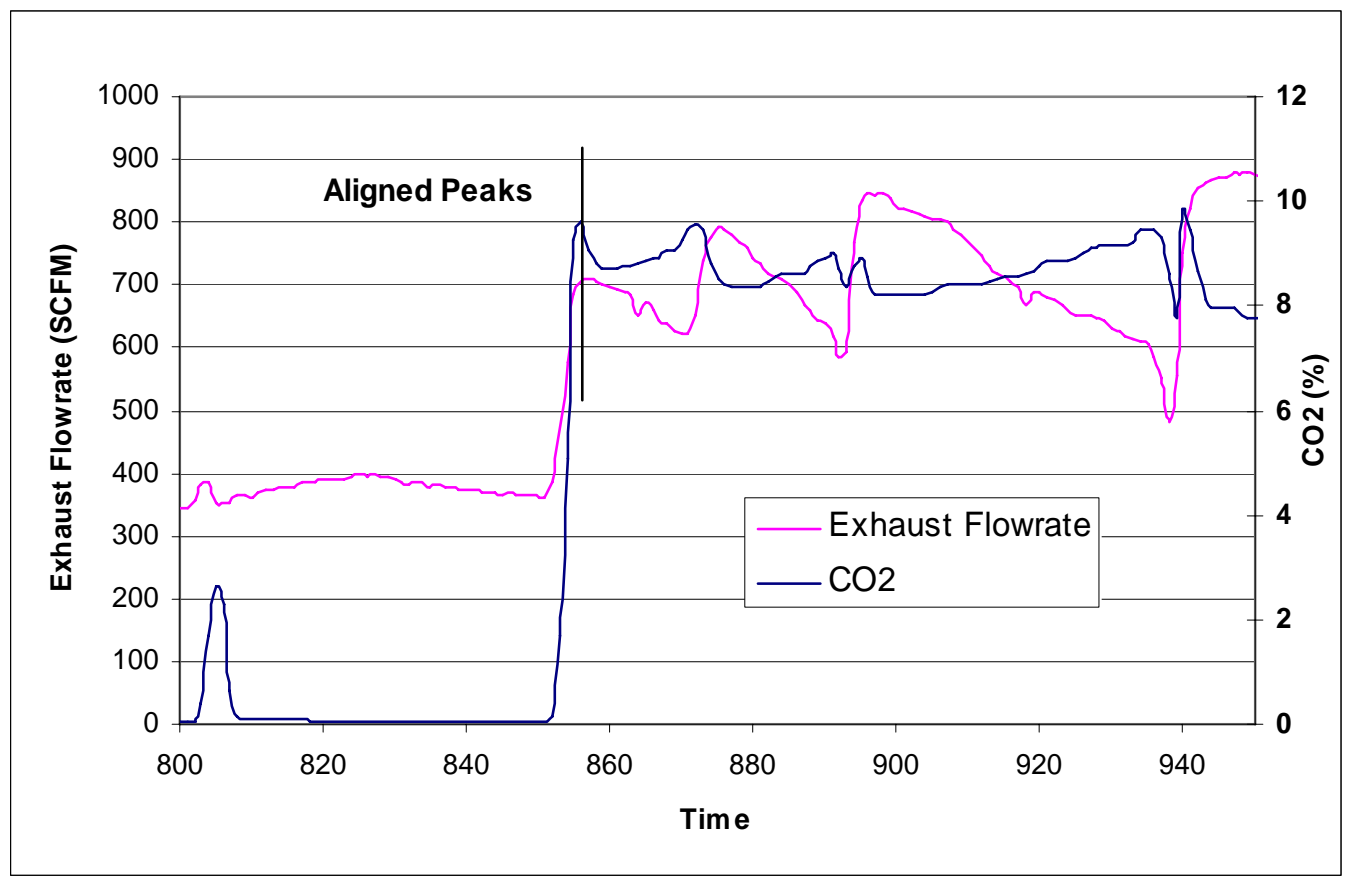

Figure 2.3 Properly Aligned Data

\subsubsection{SEMTECH-D EFM Purging}

The SEMTECH-D EFM combats condensation and soot in the pressure lines by using a 'purge' sequence. The EFM flow box has a port on the side that allows for a high pressure zero air line to be connected. In between tests, the purge button can be pushed and a small shot of zero air is blown through the lines and back into the flow tube, removing any debris or moisture. 


\section{Calculations}

\subsection{Discussion of Calculations}

Analyzers measure the instantaneous concentration of a certain exhaust gas constituent in either parts per million (ppm) or percent of total volume, depending on the gas. With the exception of the emissions standards in 30CFR Part 7 (mining applications), a concentration alone is not enough to certify that an engine is meeting the emissions standards.

There are several ways in which emissions are calculated and expressed. The method primarily used in this thesis is the time-specific mass flowrate of the pollutant or the mass-emissions rate. The industry standard for reporting emissions and certification is a work specific value. Two other widely used methods are fuel-specific and distance specific (used for chassis dynamometer tests, and on-road tests). With the time-specific method, the flowrate of the exhaust from the engine must be known to provide the rate at which the gases are being emitted. Mass emissions rate is computed from the measured instantaneous gaseous concentration, the exhaust flowrate, and the density of the gas at standard conditions.

\subsubsection{Mass Emissions Calculations}

Mass emissions are calculated using the molecular weight (MW) of the specific gaseous pollutant. 


\section{Equation 3.1 Molecular Weight/Density/Humidity Correction}

Molecular Weight $=\mathrm{MW}=\frac{1}{100}\left(\mathrm{CO}_{2} \times 44.01+\mathrm{O}_{2} \times 32+\mathrm{N}_{2} \times 28.013+\mathrm{H}_{2} \mathrm{O} \times 18.051\right)$

Standard Density $=\rho_{\text {std }}=\frac{P \times M W}{R \times T}, R=8314 \frac{\mathrm{KJ}}{\mathrm{K} \cdot \mathrm{mol}}, T=293 \mathrm{~K}, \mathrm{P}=101.325 \mathrm{KPa}$

Standard Exhaust Mass Flowrate $=V_{\text {std }}=\frac{\text { Corrected Mass Flow }}{\rho_{\text {std }}}$

Gas \% $($ wet $)=$ Gas Concentration $(\mathrm{ppm}) \times 10^{4}$

Gas \% $($ wet $)=$ Gas $\%($ dry $) \times K_{W}$

$K_{W}=1-\left[\mathrm{H}_{2} \mathrm{O}\right]_{\text {condensed }}$

$\left[\mathrm{H}_{2} \mathrm{O}\right]_{\text {condensed }}=\left[\mathrm{H}_{2} \mathrm{O}\right]_{\text {exhaust }}-\left[\mathrm{H}_{2} \mathrm{O}\right]_{\text {residual }}$

\section{Equation 3.2 Mass Emissions Exhaust Flowrate}

Mass Emissions $(\mathrm{g} / \mathrm{s})=\frac{\text { Gas \% }(\mathrm{wet})}{100} \times V_{\text {std }} \times \rho_{\text {std }}$

Final moisture content of the sample depends on the hydrogen/carbon ratio, ambient humidity, and measured gaseous concentrations [23]. Gas \% (wet) refers to the moisture corrected pollutant concentration. To protect optical sensors, exhaust streams are dried to remove moisture before measurement. By removing moisture, one is also removing some of the volume of the exhaust stream. Before emissions are reported the concentration needs to be 'corrected' for this loss.

\subsubsection{Brake Specific Emissions (using $\mathrm{NO}_{X}$ as an example)}

\section{Equation 3.3 Brake-Specific Mass Emissions}

$$
N O_{X}(g / b h p-h r)=\frac{\sum N O_{X} \text { mass }}{\sum w o r k}=\frac{\sum N O_{X} \text { mass }}{\sum b h p \times 1 s(h r / 3600 s)}
$$

The work specific emissions may be computed by dividing the total mass emissions rate by the work done over that same time segment.

\subsubsection{Fuel Specific Emissions (using NO as an example)}

\section{Equation 3.4 Fuel Flowrate Mass Emissions}

$$
N O_{f s}\left(\frac{g N O}{g \text { fuel }}\right)=\left(\frac{[N O]}{[C O]+[H C]+\left[\mathrm{CO}_{2}\right]-\left[\mathrm{CO}_{2}\right]_{\text {ambient }}}\right) \times\left(\frac{M W_{N O}}{M W_{\text {fuel }}}\right)
$$

**brackets indicate [mole fraction] 


\section{Equation 3.5 Fuel Flow Mass Emissions Flowrate}

$N O(g / s)=N O_{f s}\left(\frac{g N O}{g \text { fuel }}\right) \times$ Fuel flow $(g / s)$

Another method in use is the fuel specific mass emission, which requires the fuel flowrate to the engine for calculations instead of the mass flowrate of the exhaust. By knowing the mole fraction of the product (for example, NO) from a reaction, to the reactants (carbon and hydrogen containing constituents) and multiplying by the fuel flowrate, the fuel specific emissions are found. It is important to remember that the ambient air contains carbon dioxide that must be accounted for in this calculation. The fuel mass flowrate can come from the ECM or calculated from a carbon balance [See 3.1.6.2].

\subsubsection{Instantaneous Engine Power}

\section{Equation 3.6 Engine Horsepower}

$h p=\frac{\text { torque }(\mathrm{lb} \cdot \mathrm{ft}) \times R P M}{5,252}$

$1 \mathrm{hp}=33,000 \mathrm{ft} \cdot \mathrm{lb}($ force $) \cdot \mathrm{min}^{-1}$

1 rotation $=2 \pi$ (radians)

$\frac{33,000}{2 \pi}=5,252$

The power output from the engine is calculated from engine torque and speed and shown in Equation 3.6. These two parameters may be recorded from the ECM broadcast or from a load cell and a speed sensor if the engine is operating in a test cell.

\subsubsection{Dilution Ratio}

\section{Equation 3.7 Laboratory Dilution Ratio}

Dilution Ratio $=\frac{V_{\text {mix }}}{\text { Lab Fuel Flow }+ \text { Lab Intake Flow }}$ 
In a CVS-based emissions test cell engine intake air flowrate, fuel flowrate, and the dilute exhaust (raw exhaust and dilution air) flowrate are measured. The raw exhaust flowrate out of the engine is not measured. Therefore, to make comparisons between emissions measured with a CVS (dilute exhaust) and a PEMS (raw exhaust) the dilution ratio of the exhaust gas must be calculated. It is understood that, theoretically, mass emissions should remain unchanged whether they are measured with raw or dilute exhaust. Yet, the effect on measurements from water interference/displacement and moisture corrections is not completely understood. Also, discrepancies in exhaust flowrate measurements inject errors that are unaccounted for.

\subsubsection{Calculating Exhaust Flowrate}

To make comparisons between systems, air flow rates and fuel flow rates must have the same conditions (such as pressure and temperature). This is done by standardizing temperature and pressure to certain conditions, as seen below. The intake air flow to the engine along with the fuel flowrate is used to calculate an inferred exhaust flowrate.

\subsubsection{Calculating Exhaust Flowrate from Laboratory}

\section{Equation 3.8 Standardizing Laboratory Exhaust Flowrate}

$$
\begin{aligned}
& \text { temperature }_{\text {STANDARD }}=68^{\circ} \mathrm{F}=20^{\circ} \mathrm{C} \\
& \text { pressure }_{\text {STANDARD }}=29.92 \mathrm{inHg}=101.3207 \mathrm{kPa} \\
& \text { Volumetric Flowrate }_{\text {STANDARD }}=\frac{\text { Volume }(\text { fuel }+ \text { intake air })_{\text {MEASURED }} \times P_{\text {MEASURED }} \times T_{\text {STANDARD }}}{P_{\text {STANDARD }} \times T_{\text {MEASURED }}}=\frac{\text { standard } \mathrm{m}^{3}}{\text { second }} \\
& \text { SCFM }=\frac{\text { standard } \mathrm{m}^{3}}{\text { second }} \times \frac{60 \text { second }}{\text { minute }} \times \frac{35.315 \mathrm{ft}^{3}}{\mathrm{~m}^{3}} \\
& \text { Inferred Exhaust Flowrate }=S C F M_{\text {Intake Air }}+\text { SCFM }_{\text {Fuel }} ; \text { measurements from WVU EERL }
\end{aligned}
$$

\subsubsection{Fuel Recovered (Carbon Balance)}

For each test a carbon balance was performed. Carbon balance is a check for analyzer accuracy and quality assurance. All measured carbon-containing exhaust gas constituents are summed together to get the fuel flowrate, which can be compared to a measured fuel flowrate. The WVU EERL laboratory utilizes a positive displacement fuel flow meter for 
comparisons. The fuel flowrate is calculated by the carbon balance as expressed below $[25]$.

\section{Equation 3.9 Carbon Balance}

$G_{s}=\left[\frac{12.011}{12.011+\alpha(1.008)}\right] \times H C_{(\text {mass })}+(0.429) C O_{(\text {mass })}+(0.273) C O_{2(\text { mass })}$

$R_{2}=\frac{12.011}{12.011+\alpha(1.008)}$

Mass Fuel (pounds) $=\left(\frac{G_{s}}{R_{2}}\right)\left(\frac{1}{453.6}\right)$

$\alpha=$ atomic hydrogen to carbon ratio

- $\mathrm{G}_{\mathrm{s}}=$ grams of carbon measured during the hot or cold start test

- $\mathrm{R}_{2}=$ grams of carbon in the fuel per gram of fuel.

\subsubsection{Calculation for Exhaust Flowrate for SEMTECH-D EFM}

The SEMTECH-D calculates flowrate using the Bernoulli principle and the continuity equation [23].

\section{Equation 3.10 SEMTECH-D Exhaust Flowrate}

$\dot{m}=K(\mathrm{Re}) \times A \sqrt{\rho \times \Delta P}$

$A=$ cross section area

$K(\mathrm{Re})=$ discharge coefficient as $f(\mathrm{Re})$

$\mathrm{Re}=$ Reynolds Number $=$ ratio of Inertial forces $/$ Viscous forces of exhaust

$\rho=$ density of exhaust gas

$\Delta P=$ difference between $P_{\text {High }}$ and $P_{\text {Low }}$

\subsection{Data Reduction Procedure:}

Fuel rate from the ECM, which is recorded by the SEMTECH-D, is reported in gallons per second. The following density of diesel fuel was used far conversion to a mass flowrate.

$$
\rho=3.208366 \frac{\mathrm{kg}}{\mathrm{gal}}
$$


All comparisons to the laboratory measurement made in this thesis refer to integrated totals. The fact that the majority of the data was collected at $1 \mathrm{~Hz}$ frequency reduces Equation 9 to merely a sum. Percent differences are calculated using Equation 10, where the WVU EERL is the reference.

\subsubsection{Integrated Data and Percent Difference Equations}

The following equations were used for integrating data and calculating errors. The reference system is the laboratory.

\section{Equation 3.11 Integrated Data and Error}

$$
\begin{aligned}
& I=\sum_{i=1}^{N} x_{i}\left(t_{i}-t_{i-1}\right) \\
& \% \text { Difference }=\frac{\text { Sum }_{\text {measured }}-\text { Sum }_{\text {reference }}}{\text { Sum }_{\text {reference }}} \times 100 \% \\
& \text { - } t_{i}-t_{i-1} \text { is the time frame between consecutive data points (for } 1 \mathrm{~Hz} \text {. Data } \\
& \text { this value is } 1 \text { ), (seconds) } \\
& -x_{i} \text { is the measured value for that time frame (grams/second) }
\end{aligned}
$$

\subsection{Measurements Compared in this Study:}

The following parameters, collected from the SEMTECH-D were used for comparisons against the West Virginia University Engine Laboratory and, in many cases, WVU's MEMS:

- Fuel Flowrate via a carbon balance

- Exhaust Flowrate

- Time-specific gaseous emissions on a mass basis $(\mathrm{g} / \mathrm{s})$ 


\section{$4 \quad$ Experimental Procedure and Instrumentation}

A brief description of analyzer technology and PEMS used in this study is given below.

\subsection{Component Description}

The following section describes the various analyzers' theory of operation, advantages, and disadvantages.

\subsubsection{HFID}

The HFID is capable of measuring total hydrocarbons over the range of 0 to 10,000ppmC. After the sample enters the system via the heated sample line, a small portion of the sample is sent to the stainless steel heated FID chamber. The control temperature of the chamber is set to 191 degrees Celsius. The HFID works by passing the sample through a flame fueled by a $40 / 60$ ratio of hydrogen/helium. As the sample goes through the flame, the hydrocarbons undergo an ionization process in which electrons and positive ions are produced. Then polarized electrodes inside the instrument collect the electrons and ions, causing a small ionization current to pass between the electrodes. The current is proportional to the carbon atoms concentration in the sample, and can be measured to give the HC concentration in the sample [32].

\subsubsection{NDIR Analyzer}

The non-dispersive infrared detector is a spectrophotometer that is used to detect oxides of carbon and hydrocarbons. The term 'non-dispersive' refers to the fact that the light is not reflected or scattered, it is absorbed by the gas. The gas sample passes through a cell where it is bombarded with infrared light/energy. The energized gaseous compounds pass through a filter that only allows certain wavelengths of light to pass, since every gas absorbs infrared energy at different wavelengths. At the same time a separate cell has the same light passing through a static inert gas, such as nitrogen. The light source is pulsated with a chopper wheel, to allow for a 'continuous' measurement. After the light travels through the cells, it reaches a solid-state photoconductive detector, where the concentration is determined $[1,32]$. 


\subsubsection{Chemiluminescent Analyzer}

Chemiluminescent detection (CLD) analyzers provide the concentration of NO or total $\mathrm{NO}_{\mathrm{X}}$ if there is a $\mathrm{NO}_{\mathrm{X}}$ converter (converting $\mathrm{NO}_{2}$ to $\mathrm{NO}$ ) installed in the sampling stream. The detector relies on the following chemical reaction:

$\mathrm{NO}+\mathrm{O}_{3} \rightarrow \mathrm{NO}_{2}^{*}+\mathrm{O}_{2} \rightarrow \mathrm{NO}_{2}+\mathrm{O}_{2}+$ proton

The term chemiluminescence refers to the emission of light from an atom or molecule in an excited state from a chemical reaction. The exhaust sample is passed through a chamber filled with excess ozone, which reacts with the $\mathrm{NO}$. The $\mathrm{NO}_{2}$ is in an excited state and returns to a normal state and emits red light with photon emissions [33]. Chemiluminescent detection responds fast and has a wide dynamic measurement range [34]. The disadvantages of this instrument are the extra expenses required for a vacuum pump, ozonizer, additional operating gases, and converter efficiencies (90\%-100\%) [34]. Water and $\mathrm{CO}_{2}$ existing in the exhaust stream can also adversely affect the CLD due to quenching. Quenching occurs when the above reaction does not produce light emission; rather the energy is transferred, via collisions, to other masses in the exhaust stream (i.e. $\mathrm{H}_{2} \mathrm{O}$ and $\mathrm{CO}_{2}$ molecules) [35].

\subsubsection{NDUV Analyzer}

The non-dispersive ultraviolet photometer is used to detect oxides of nitrogen. The technology is very similar to the NDIR. Ultraviolet light has a shorter wavelength, but has a higher energy than infrared light. The NDUV analyzer has a single sample cell that has two filters and two detectors at the exit, one to measure absorbed energy and the other to measure non-absorbed energy. The ratio of these two measurements is the concentration of the nitrogen oxides [1].

\subsubsection{Zirconium Oxide $\mathrm{NO}_{X}$ Analyzer}

The unit, which is made of a ceramic-like material zirconium oxide, consists of two chambers that are in series. The sample passes into the first chamber where oxygen is able to travel through the zirconium oxide, leaving a more concentrated NO sample. Then the sample travels into the second chamber, where it is disassociated into nitrogen 
and oxygen. Now, as the oxygen is removed, a voltage is created corresponding to the concentration of previously bonded nitric oxide molecules [32].

\subsection{MEMS Discussion}

The Mobile Emissions Measurement System (MEMS) was built by West Virginia University. MEMS was built in response to the Consent Decrees which were entered into by the six settling heavy duty engine manufacturers and the Department of Justice. MEMS provides brake specific measurements of $\mathrm{NO}_{\mathrm{X}}$ and $\mathrm{CO}_{2}$. MEMS consists of a flow tube, flow box, emissions box, data acquisition box, and an ambient box. The flow box contains a differential pressure device for measuring the exhaust flowrate, and an absolute pressure transducer. The emissions box contains all the emissions measuring equipment including a heated filter, analyzers, chillers, and pumps.

The MEMS flow measurement device uses an Annubar pitot tube sensor [32]. The device is mounted perpendicular to the exhaust stream. The device has an upstream and a downstream side both with a series of holes spanning the width of the tube to provide an average pressure. The difference in the two average pressures is proportional to the velocity of the exhaust stream.

MEMS measures $\mathrm{NO}_{\mathrm{X}}$ with a Horiba MEXA-720 zirconium oxide sensor. After the sample enters the emission box via a heated line, the particulates are removed with a heated filter. The sample then passes through a heated $\mathrm{NO}_{\mathrm{X}}$ converter, which converts the $\mathrm{NO}_{2}$ to NO. Housed in the same apparatus is the heated $\mathrm{NO}_{\mathrm{X}}$ probe. The sample is then dried with a chiller before it passes through the Horiba BE-140 NDIR analyzer.

\subsection{SEMTECH-D Discussion}

\subsubsection{SEMTECH Introduction}

The Sensors SEMTECH-D is a commercially available PEMS. The SEMTECHD consists of the following: HFID for THC, NDUV for $\mathrm{NO}$ and $\mathrm{NO}_{2}, \mathrm{NDIR}$ for $\mathrm{HC}, \mathrm{CO}$, and $\mathrm{CO}_{2}$, and an electrochemical (EC) sensor for $\mathrm{O}_{2}$. For testing purposes the SEMTECH-D also requires a data logger, vehicle interface for engine communication, 
and a weather probe for ambient condition monitoring. A drawing of the front panel is seen in Figure 4.1 [23].

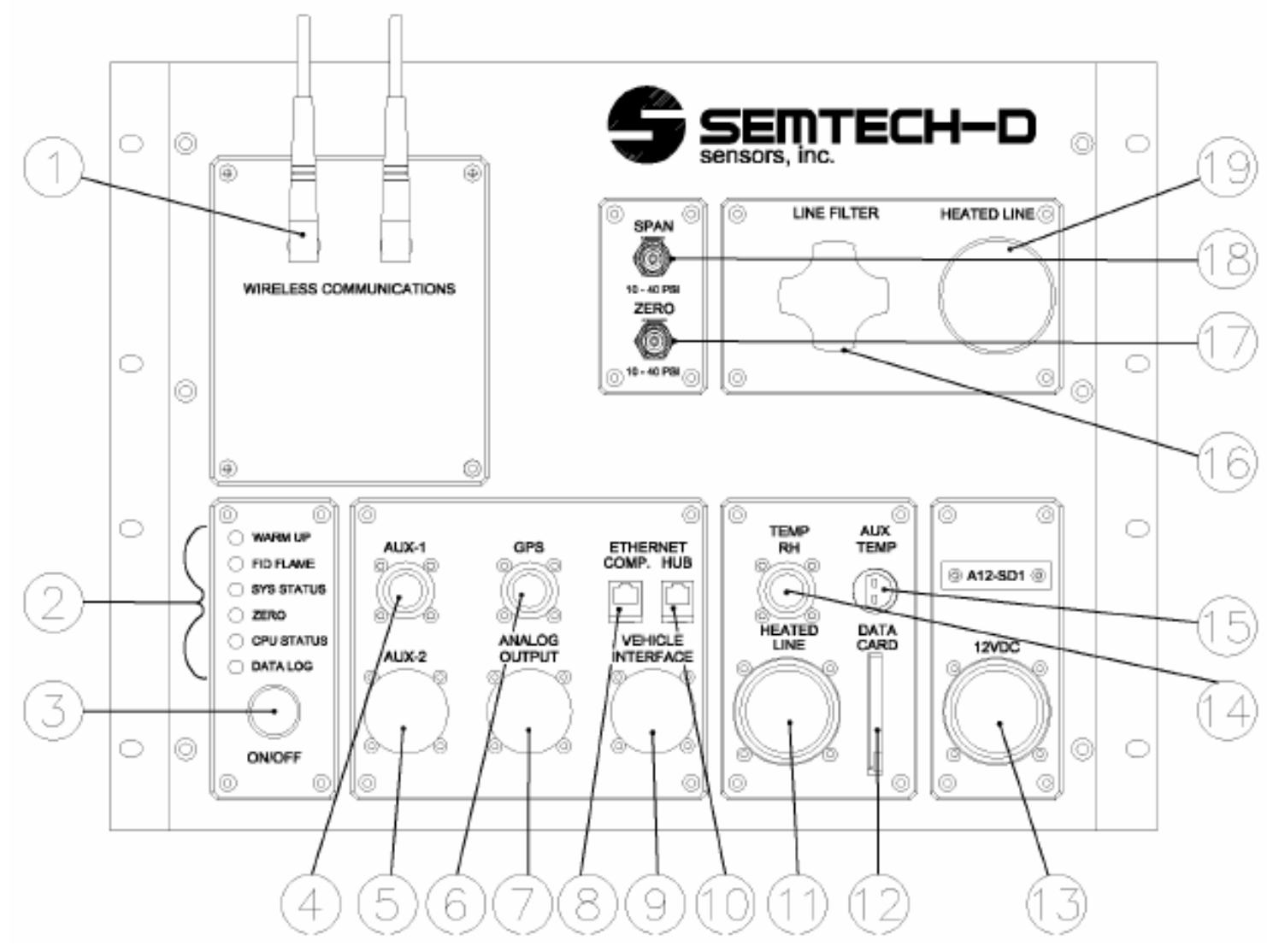

Figure 4.1 SEMTECH-D Front Panel [23]

1) Wireless Antennas

2) System Status LEDs

3) ON/OFF Button

4) AUX-1 Connection

5) AUX-2 Connection

6) GPS Connection

7) Analog Connection

8) Computer Ethernet Connection

9) Vehicle Network Interface Connector

10) Hub/Switch Ethernet Connector
11) Heated Line Power Connector

12) Data Card

13) System Power Connection

14) Temperature/Humidity Connection

15) Auxiliary Temperature Connection

16) Heated Filter

17) Zero Gas Port

18) Span Gas Port

19) Heated Line Hookup

\subsubsection{System Power}

SEMTECH-D is powered in-use by the vehicle's 12-volt direct current (DC) electric system. Sensors, Inc. sells an alternating current (AC) power supply that will provide 80 amperes at 12 volts DC. During initial warm up, the system draws $\sim 60$ amperes and once warm, the system draws $\sim 30$ amperes [23]. Typical voltage drops 
from SEMTECH-D experienced by heavy-duty vehicles is $0.2-0.3$ volts at idle [23]. From experience, to capture a cold start in-use, a battery charger must be attached to the vehicle's batteries to keep from completely draining them during the sixty minute SEMTECH-D warm up process.

\subsubsection{Gaseous Measurement}

The gaseous measurement through the SEMTECH-D starts with a heated sample line. The sample line is connected to a port on the side of the flow tube and extracts exhaust from the edge of the pipe at a flowrate of 8 liters per minute [23]. After the sample passes through the heated line and filter (to remove PM) it is split and sent to the HFID, and the other portion is sent to the NDIR and NDUV. The internal temperature of the sampling system (i.e. heated line, FID) is held constant to a temperature of 191 degrees Celsius (C), while the heated filter is set to 200 degrees C. Before the sample is sent to the optical analyzers it is dried first with a coalescing filter, then a thermoelectric chiller is used to remove moisture. Condensation in the sample stream causes interference and damage to the optics of the analyzers. The chiller temperature set point is 8 degrees C. After the sample is analyzed, it is discharged out the back of the unit, where tubing is connected to release at a desirable location.

The HFID fuel for the SEMTECH-D is available in small ( one liter) bottles that are mounted inside the unit. The bottle contains 105 liters of compressed fuel that will last roughly eight hours [23]. A drawing of the rear of the SEMTECH-D, along with the FID fuel bottle, is seen in Figure 4.2. 


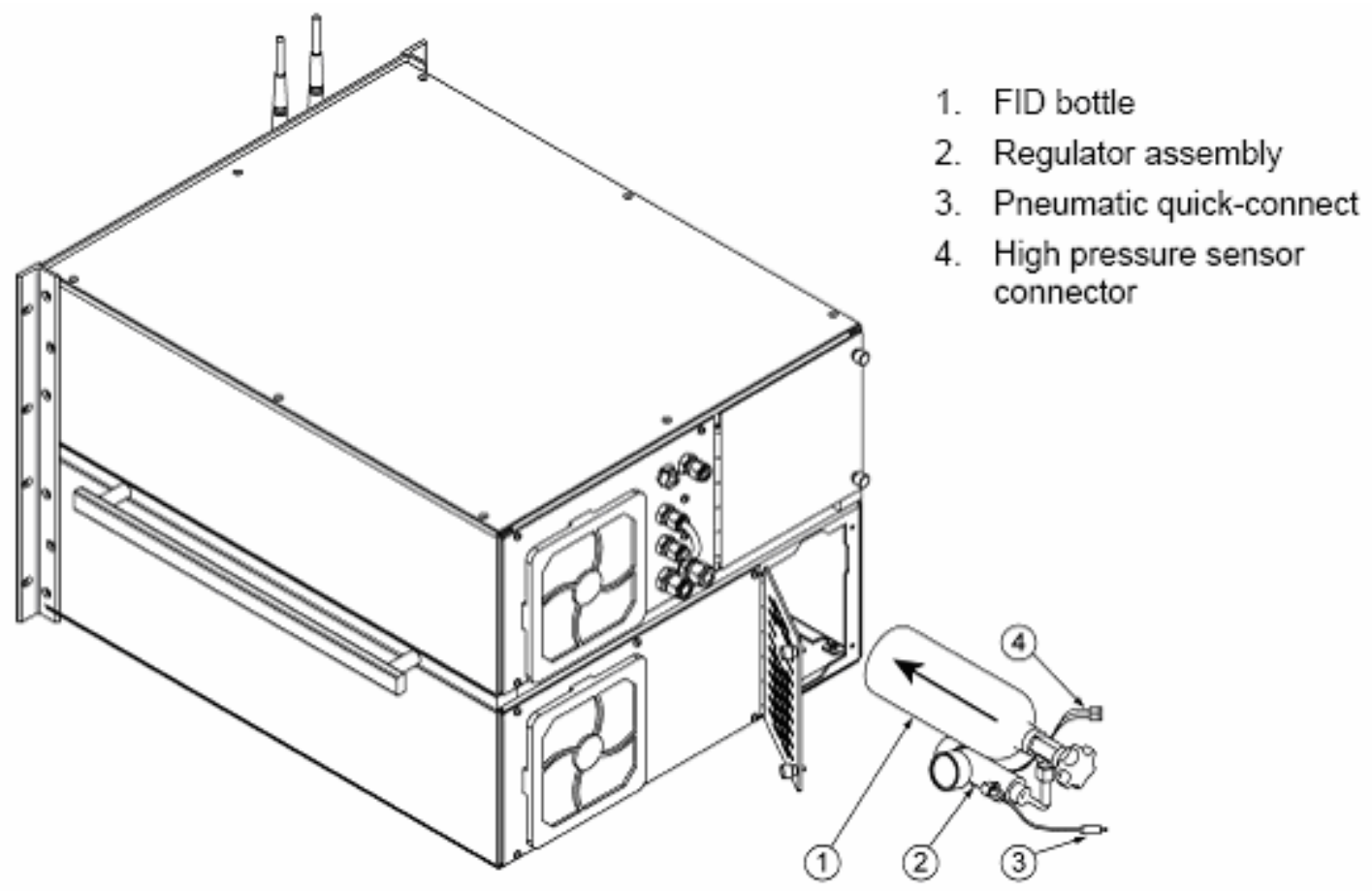

Figure 4.2 SEMTECH-D Rear View [23]

\subsubsection{Sampling Frequency/Engine Communication}

Due to the different technologies involved for the various gas analyzers, different sampling frequencies occur. The NDUV reports a signal every one half seconds, while the NDIR reports a reading every 1.2 seconds. Yet, a post processed SEMTECH-D data file has $1 \mathrm{~Hz}$ data. This means that the SEMTECH is averaging and interpolating data points in order to report at the desired $1 \mathrm{~Hz}$ frequency [23].

The SEMTECH-D communicates with the engine control unit (ECU) via a Dearborn Group Technology adapter. The Dearborn Adapter allows for collection of engine parameters such as engine speed, torque, fueling, and various other parameters.

\subsubsection{SEMTECH EFM}

The SEMTECH-D EFM exhaust flow measurement tube is seen in Figure 4.3. The tube is made of five inch stainless steel exhaust pipe and is three feet long. 


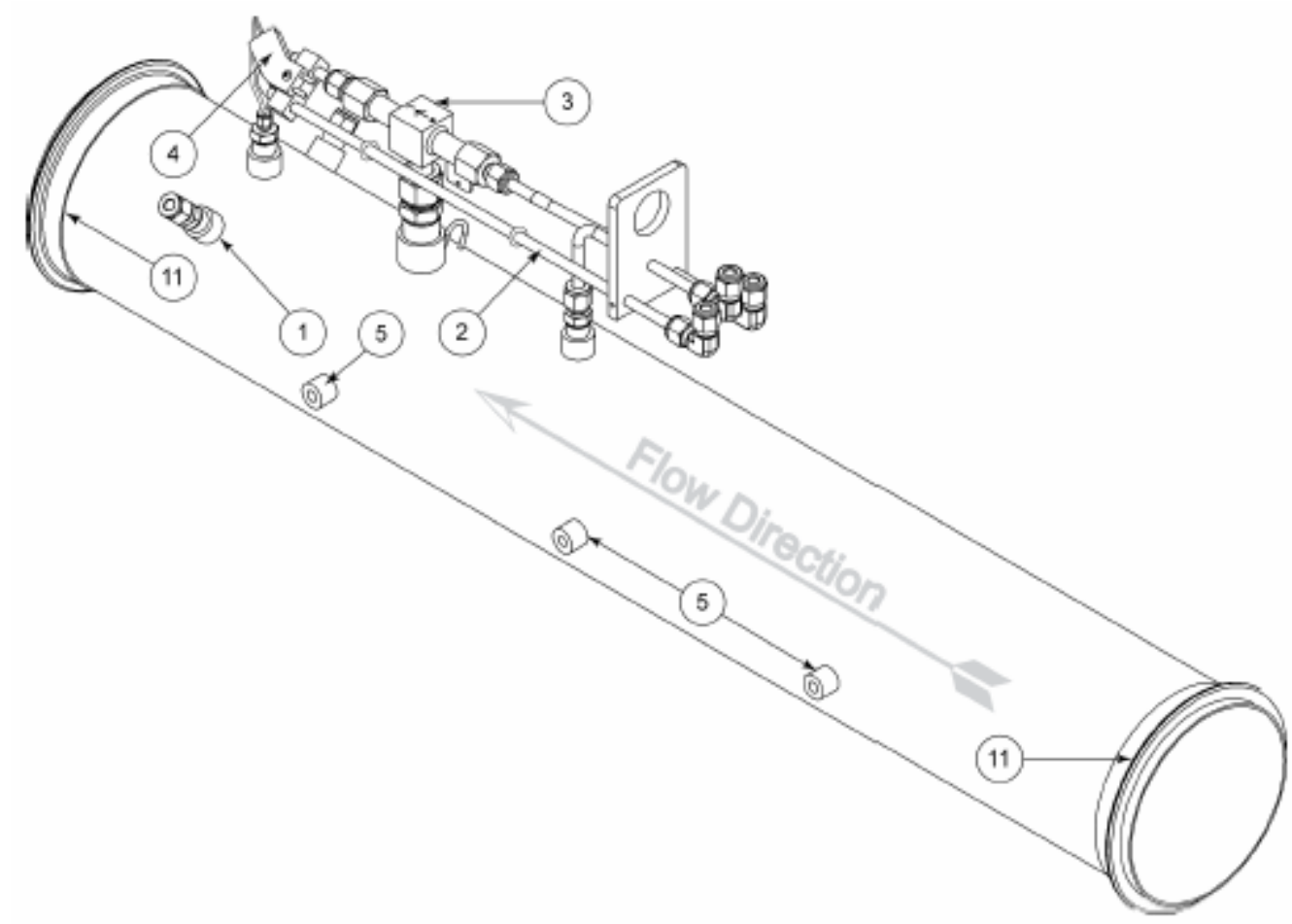

Figure 4.3 EFM Flow Tube [36]
1) Sample Port
4) Thermocouple
2) Low Pressure Tube
5) Mounting Bung
3) Flow Pressure Sensor

The SEMTECH-D measures the exhaust flowrate with a differential pressure device that operates on Bernoulli's Principle. SEMTECH's electronic flow meter (EFM) is comprised of four differential pressure transducers that are calibrated to measure a different portion of the total flow [36] (see Equation 7). The design is similar to the Annubar of MEMS, having a diamond shape that is oriented with a point upstream and downstream as seen in Figure 4.4. The pressure difference between the leading (upstream) and trailing (downstream) edges corresponds to the velocity of the exhaust. 


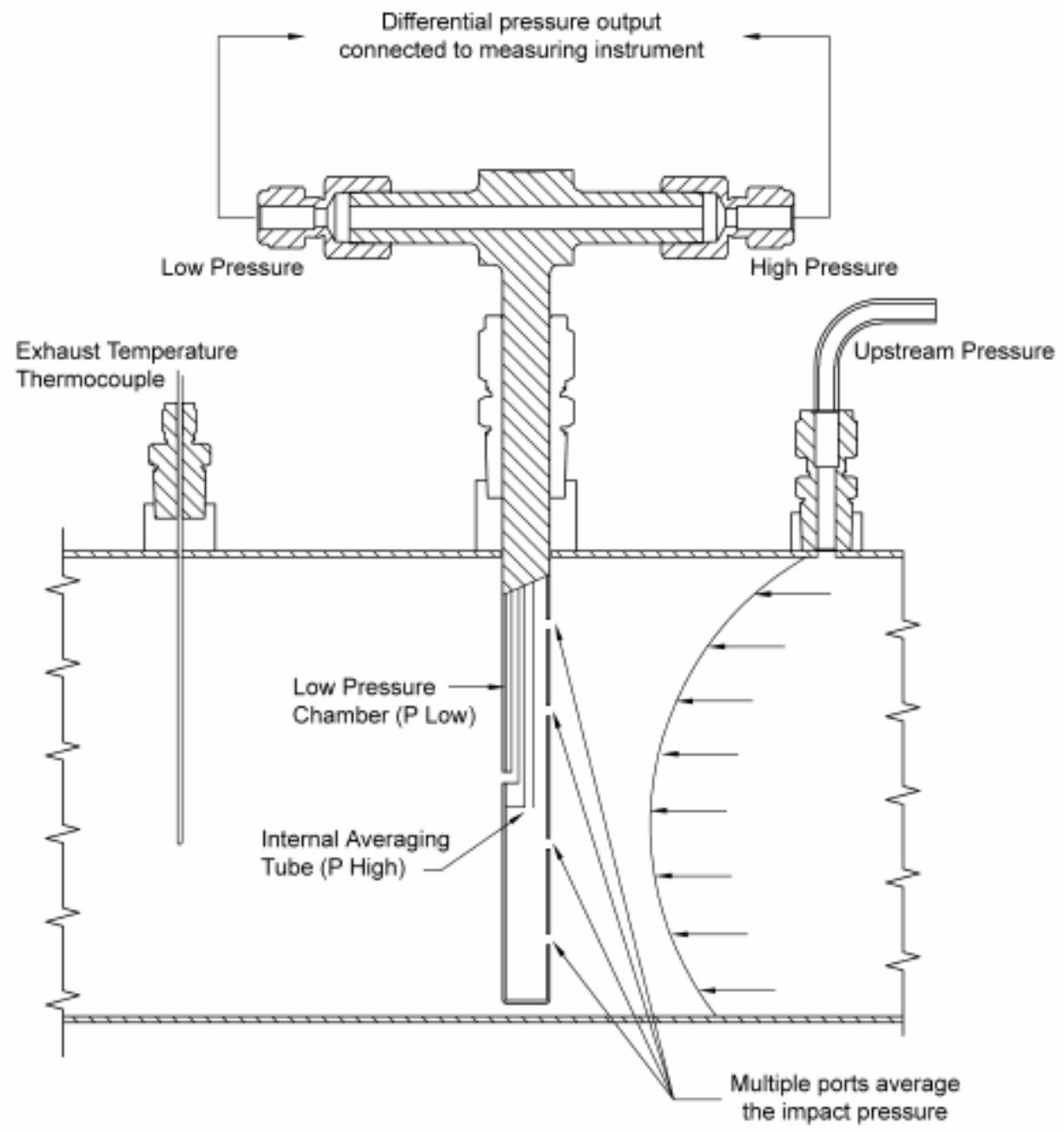

Figure 4.4 SEMTECH-D EFM Flow Tube Cross Section [36]

The EFM electronics are housed in the box seen in Figure 4.5. This box contains the diaphragm that the high and low pressure lines report to. The system automatically zeros the transducers every two minutes without losing data [36], by zeroing two transducers every minute. 


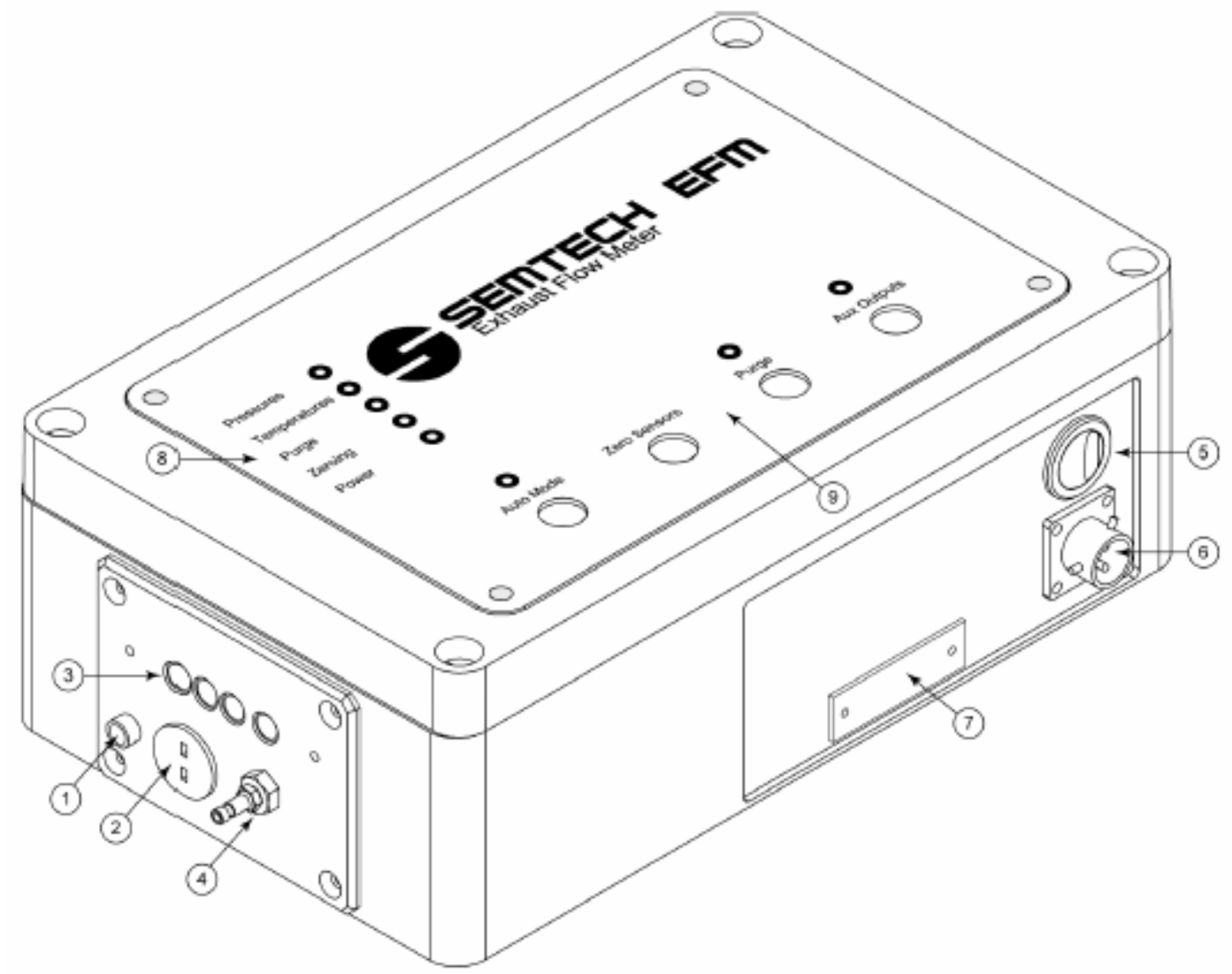

Figure 4.5 SEMTECH EFM Electronics Box [36]

1) Thermocouple Shield Ground

2) Thermocouple Connection

3) Differential Pressure Line Conneciton

4) High Pressure Purge Gas
5) ON/OFF Switch

6) Power and Serial Connection

7) Unit Number

8) Status LEDs

9) Function Buttons

\subsubsection{Data Processing}

SEMTECH-D records data files on a compact flash card located on the front panel of the unit. Raw data files are recorded using a .XML file type, after data processing the files are saved as Excel comma separated files. The SEMTECH-D software has a post processor program that is launched from the main screen as seen in Figure 4.6 SEMTECH-D Post Processor. The settings tab on the post processor allows the user to set the exhaust transport delays, manually input weather data, specify fuel properties, and vary calculation methods. The transport delay times are critical for properly aligning data. For each individual exhaust configuration, the delay times must be determined by aligning $\mathrm{CO}_{2}$ with either the fuel flowrate or the exhaust flowrate, depending on which calculation method was chosen. 


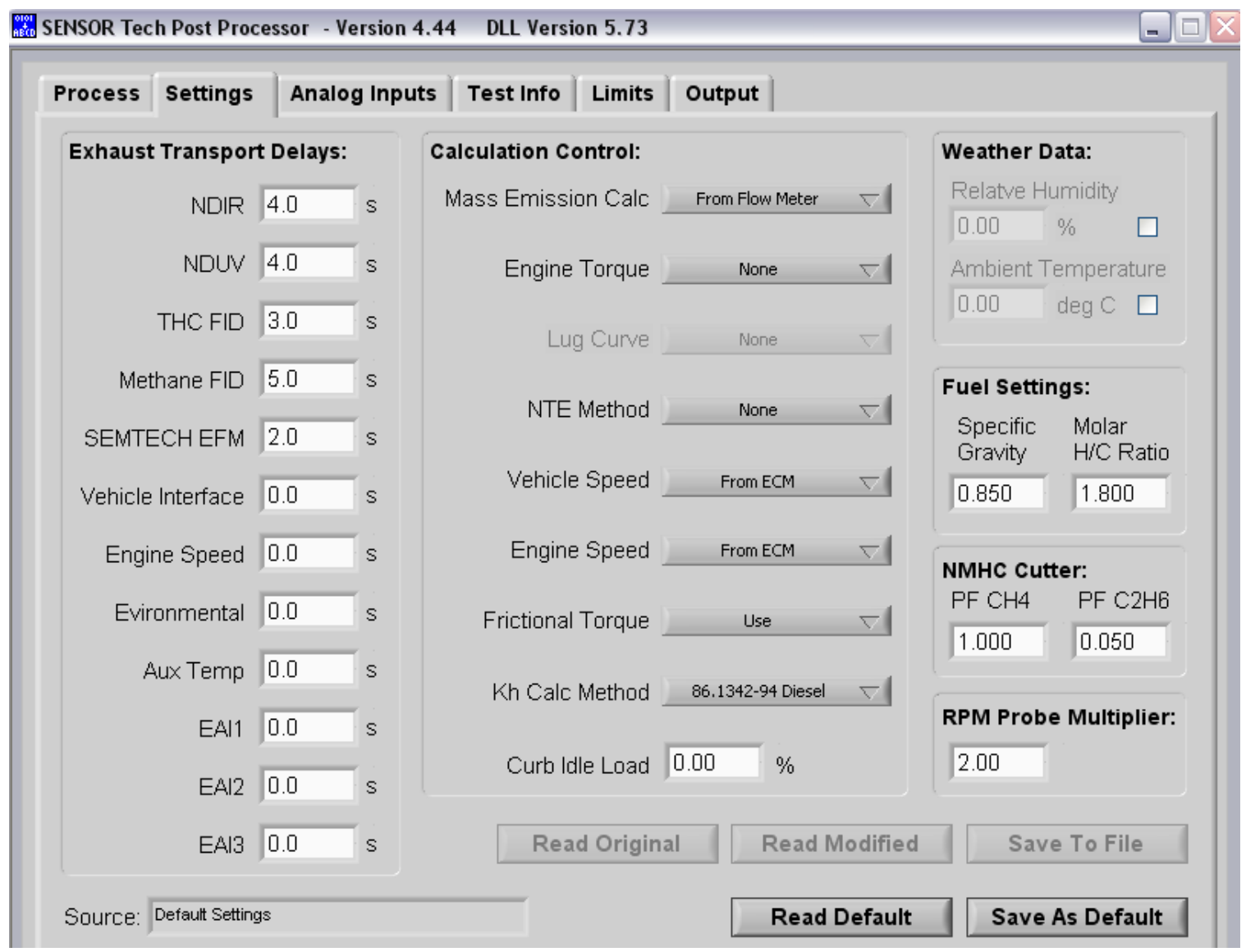

Figure 4.6 SEMTECH-D Post Processor

\subsection{SEMTECH-DS}

In 2005, Sensors Inc. released the latest version of their PEMS, the SEMTECH-

DS. The latest system improvements as listed by the manufacturer are [37]:

— CFR 1065 Subpart J compliant

- CE Compliant

- MIL-STD 810F shock and vibration

- Auto-ranging FID

- Real-time mass emission NTE calculations

- Temperature Stabilized emissions analyzers

— Flow-weighted fuel-specific emissions calculations 


\subsection{WVU EERL Discussion}

A brief discussion of the WVU EERL is given below. This section has been previously reported elsewhere [38].

The testing setup consisted of the engine mounted on an engine skid directly coupled to a GE direct current engine dynamometer. The engine exhaust is routed to a full-scale dilution tunnel (18 inches in diameter and 20 feet long) based on the critical flow venturi constant volume sampler concept [38]. Three feet from the tunnel entrance is a 10-inch diameter orifice. This ensures that the dilute exhaust is thoroughly mixed by the time it reaches the sampling zone, ten diameters downstream of the orifice. The exhaust is mixed with air and the quantity of diluted exhaust is measured precisely using critical flow venturis. These venturis are placed upstream of a blower that pulls the diluted exhaust sample at a constant mass flowrate once the venturis were under sonic or choked flow conditions at a nominal $2400 \mathrm{scfm}$. Temperature in the venturi is measured with an exposed fast-respond thermocouple and pressure is measured by an absolute pressure transducer. Heated sampling probes and lines transports diluted exhaust to a number of different gas analysis instruments. The engine test cell is equipped with a preconditioning system for intake air and dilution air. Microprocessor controlled heated probes and sampling lines are used to draw gaseous samples into the gas analysis bench. Continuous sampling and analysis of the exhaust stream is done by NDIR analyzers for $\mathrm{CO}$ and $\mathrm{CO}_{2}$; a wet chemiluminescent analyzer for NOx; and a heated FID for THC. Data from the exhaust analyzers, sampling trains, double dilution tunnel, and the engine are acquired and archived at a rate of $5 \mathrm{~Hz}$.

All dilution air is HEPA filtered to minimize the background particulate contribution entering the tunnel. Two HEPA filters, each at a $2400 \mathrm{cfm}$ capacity, are placed in parallel to provide up to $4800 \mathrm{cfm}$ dilution air capacity to the primary tunnel.

Additionally, the engine is instrumented for speed, torque, manifold air pressure, air intake restriction, total exhaust backpressure, manifold intake temperature, coolant temperature, oil temperature, and exhaust temperature according to CFR 40 Part 86 requirements [38]. 


\section{Test Matrix/Procedure}

Multiple test days were utilized to ensure that data presented encompassed a variety of ambient conditions and fuels.

\subsection{Sequence I 2005}

Two SEMTECH-D systems were coupled with a MEMS flow tube and installed in the EERL. Five FTP cycles and one steady state test were run and compared with the stationary laboratory analyzers.

\subsection{Sequence II 2006}

The SEMTECH-D and MEMS were placed back into EERL and two days of tests were conducted. Day one provided three valid FTP cycles for both systems, and on the second day two thirteen mode steady state tests were run. Then, the MEMS flow tube was removed and over the next two days a total of fourteen valid FTP tests were collected. All data collected were compared to the laboratory analyzers.

\subsection{Sequence III 2006}

Beginning on May 23 and ending on the May 26, a variety of FTP, steady state, and transient tests were conducted. The steady state tests were designed to provide insight into the behavior of the SEMTECH-D EFM. The transient test was a laboratory version of a road test developed by WVU.

\subsection{Sequence IV 2006}

Starting on August 18, the WVU EERL conducted fuel certification testing. The testing consisted of a series of FTP cycles, switching between a reference fuel and a candidate fuel. SEMTECH-D data were collected and compared to the laboratory. The emissions compared in this document are from the reference fuel tests. Twelve FTPs were collected total (nine hot, three warm) over two days of testing. 


\subsection{Test Procedure}

The following procedure was used for all tests that are being reported in this document. After the installation of the SEMTECH-D flow tube, and before any data was collected the following quality assurance steps were taken:

- SEMTECH-D leak check was performed after initial installation

- Exhaust filter was changed every other test

- Emission analyzers were zeroed and spanned before every test

- EFM pressure lines were purged multiple times before every test

- Sling psychrometer data collected at beginning of each test to compare to SEMTECH-D weather probe

- MEMS system calibrated

- MEMS heated filter replaced every other test

- MEMS analyzers zeroed and spanned before each test

- WVU EERL prepared accordingly before initial test and in between tests

\subsection{Test Cell Setup}

Pictured in Figure 5.1 is the SEMTECH-D setup inside the WVU EERL. The EFM flowtube is situated above the unit and installed directly into the exhaust pipe routed to the dilution tunnel. The exhaust setup was identical for all testing sequences, except for the location of the tube with respect to the turbo of the engine. Sequence I placed the tube closer to the turbo outlet. The SEMTECH-D received power from an alternating current to a direct current power supply capable of providing 80 amperes at 110 volts. A backup battery was included to provide power if there was an interruption from the power supply. 


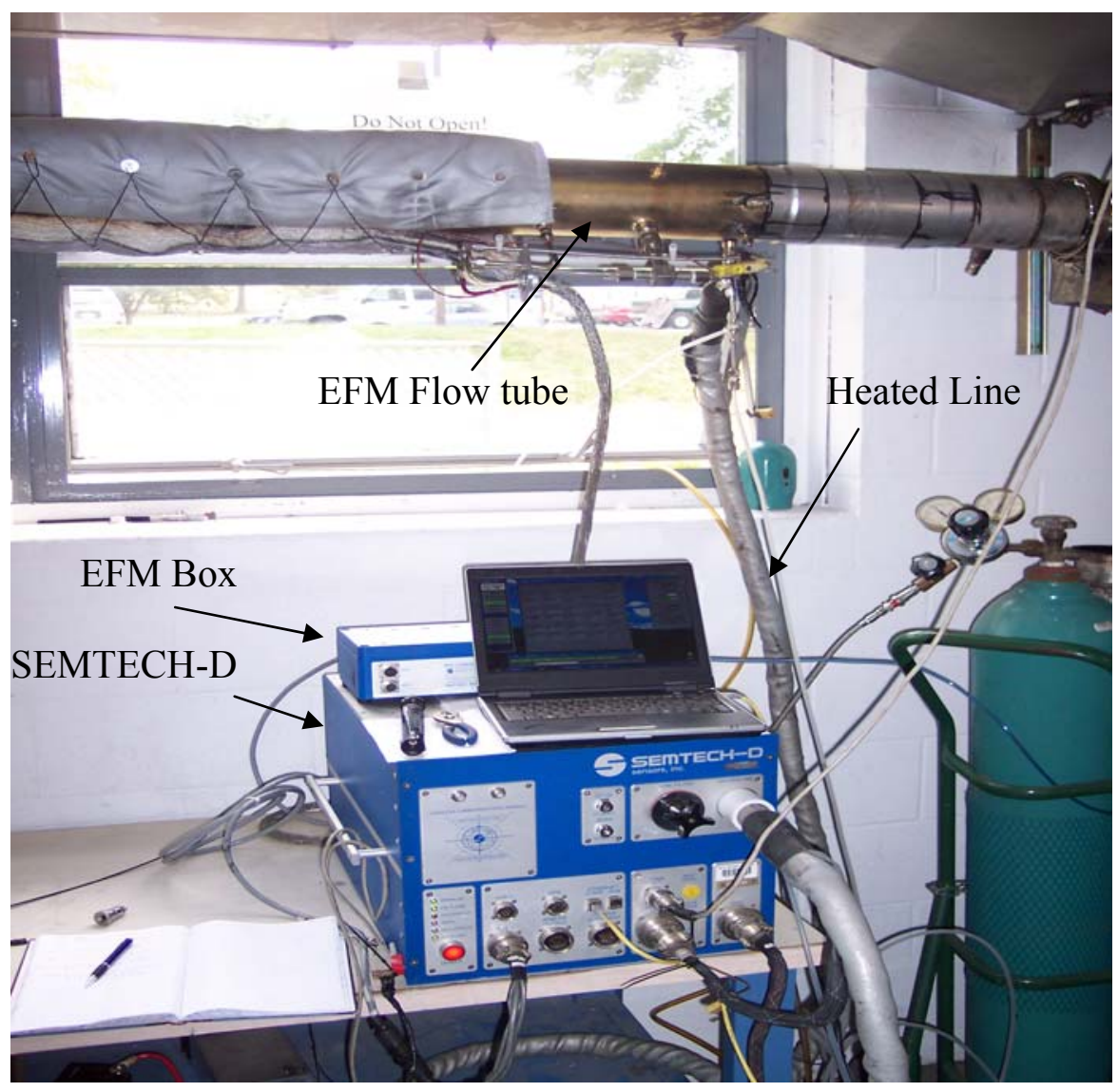

Figure 5.1 SEMTECH-D test setup inside EERL.

\subsection{Test Engine}

Table 5.1 Test Engine Specifications

\begin{tabular}{|l|l|}
\hline Engine Manufacturer & Detroit Diesel Corp. \\
\hline Engine Model & Series 60 \\
\hline Unit Number & O6R0105610 \\
\hline Model Year & 1992 \\
\hline Displacement (liters) & 12.7 \\
\hline Power Rating (hp) & $360 @ 1819$ rpm \\
\hline Configuration & Inline 6 \\
\hline Bore (in.) x Stroke (in.) & 5.12 x 6.30 \\
\hline Induction & Turbocharger with Aftercooler \\
\hline Fuel Type & Diesel \\
\hline Engine Strokes per Cycle & Four \\
\hline Injection & Direct, Electronic \\
\hline
\end{tabular}




\subsection{PEMS Span gases}

5.8.1 The SEMTECH-D was spanned with the following concentrations:

Table 5.2 SEMTECH-D Span Gases

\begin{tabular}{|l|l|}
\hline Gaseous Species & Concentration \\
\hline Propane & $257 \mathrm{ppm}$ \\
\hline $\mathrm{CO}$ & $1289 \mathrm{ppm}$ \\
\hline $\mathrm{CO}$ & $13.01 \%$ \\
\hline $\mathrm{NO}$ & $1728 \mathrm{ppm}$ \\
\hline $\mathrm{NO}_{2}$ & $256 \mathrm{ppm}$ \\
\hline
\end{tabular}

5.8.2 The MEMS span bottle used had the following concentrations:

Table 5.3 MEMS Span Gases

\begin{tabular}{|l|l|}
\hline Gaseous Species & Concentration \\
\hline $\mathrm{NO}_{\mathrm{X}}$ & $2190 \mathrm{ppm}$ \\
\hline $\mathrm{CO}_{2}$ & $11.92 \%$ \\
\hline
\end{tabular}




\section{Experimental Results and Discussion:}

\subsection{Introduction}

The purpose of this study was to validate the SEMTECH-D as an accurate and reliable option for in-use testing.

\subsection{Laboratory Performance/Consistency}

Before the PEMS could be evaluated for performance, efforts were made to document that the WVU EERL was performing as it should, in compliance with requirements of 40CFR Part 86 Subpart N. It should be noted that the laboratory has been performing fuel certification tests on heavy-duty engines for CARB and the Texas Commision on Envirironmental Quality (TCEQ) [38].

\subsubsection{Repeatability}

In December 2005, fuel certification testing was conducted at the WVU EERL using the DDC Series 60 engine described above. The schedule consisted of four days of testing, including three days of reference fuel preliminary testing. During this time, 27 hot start FTP tests were conducted using the reference fuel. Day one consisted of nine valid hot starts. On days two and three, twelve and six hot starts were conducted, respectively. Figure 6.1 represents the average $\mathrm{NO}_{\mathrm{X}}$ values for each of the three days of testing using the reference fuel. Note that there is a $0.08 \%$ difference between the average for day one and for day four [38]. 


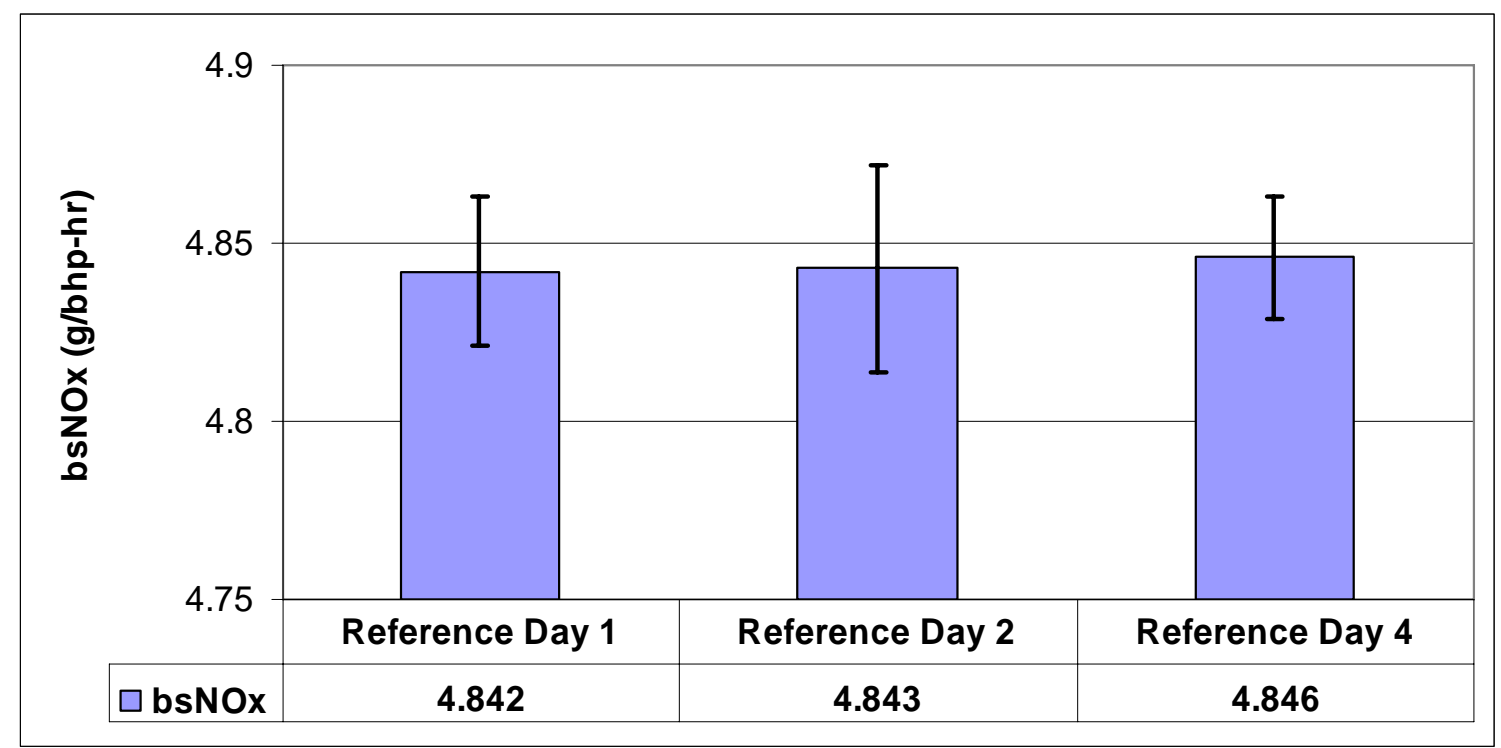

Figure 6.1 Average laboratory $\mathrm{NO}_{\mathrm{X}}$ values from hot-start FTP tests using reference fuel. Error bars represent one standard deviation for each data set. Note the expanded axis.

Figure 6.2 illustrates the brake-specific emissions of $\mathrm{CO}_{2}$ over the three days of testing. Notice that there is only a $0.4 \%$ difference between day two and day four.

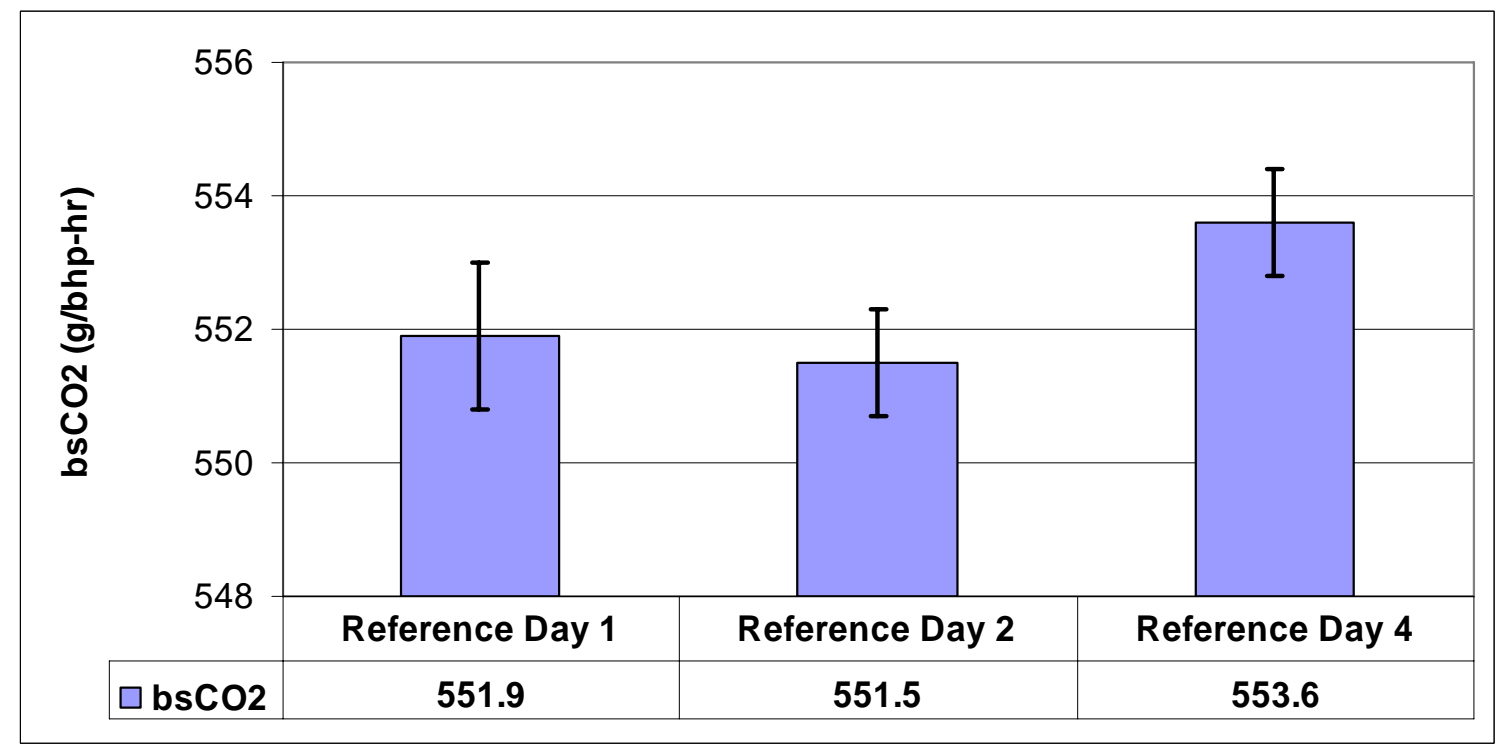

Figure 6.2 Average laboratory $\mathrm{CO}_{2}$ values from hot-start FTP tests using reference fuel. Error bars represent one standard deviation for each data set. Note the expanded axis. 
Brake-specific emissions of $\mathrm{CO}$ are shown in Figure 6.3 with the error bars representing one standard deviation for each test day. Note that there is a $2.3 \%$ difference between the average for day two and the average for day one.

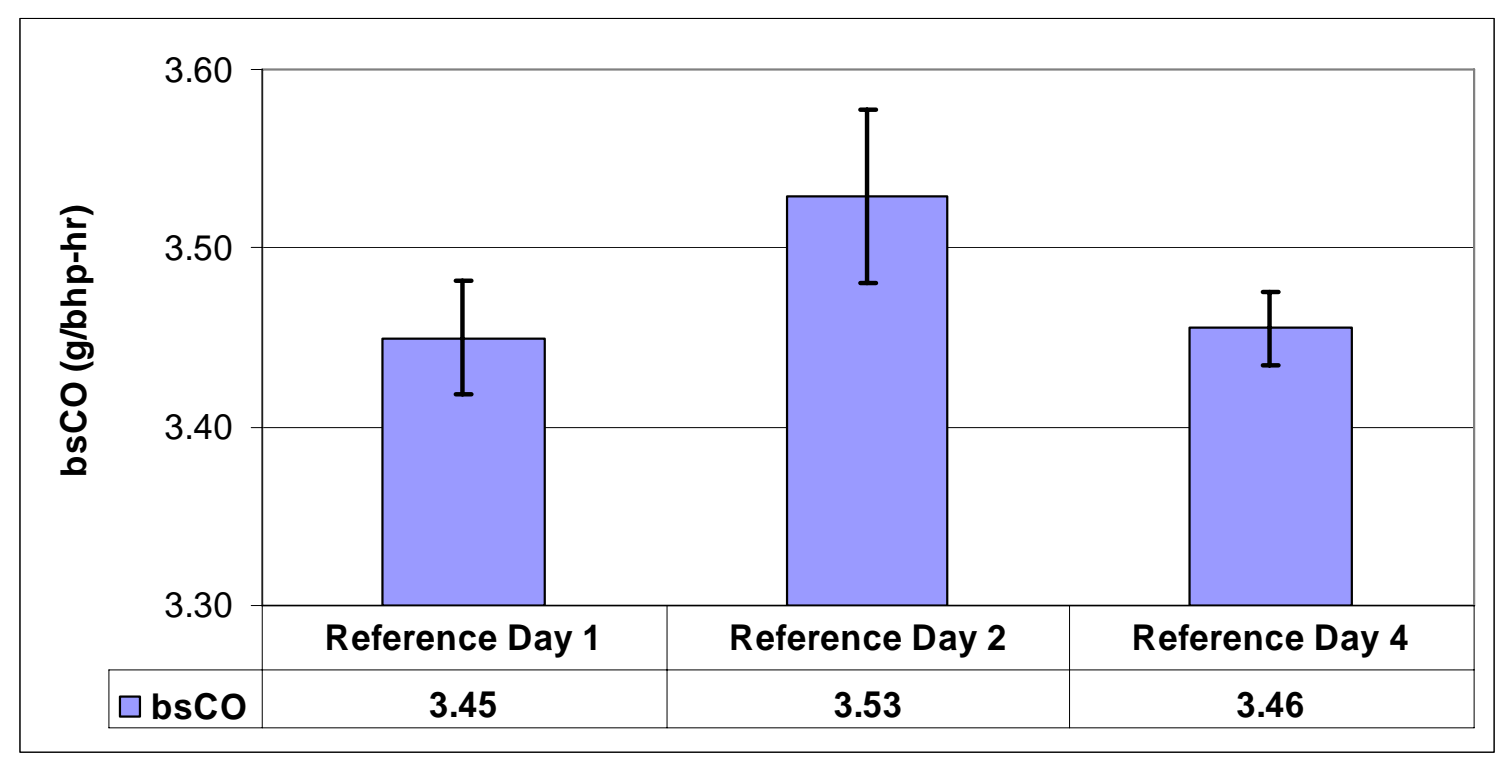

Figure 6.3 Average laboratory $\mathrm{CO}$ values from hot-start FTP tests using reference fuel. Error bars represent one standard deviation for each data set. Note the expanded axis.

The repeatability of the brake-specific total hydrocarbons (THC) and non-methane hydrocarbons (NMHC) is shown in Figure 6.4. Again, the error bars represent one standard deviation for each day of testing and the day-to-day variations are below three percent. 


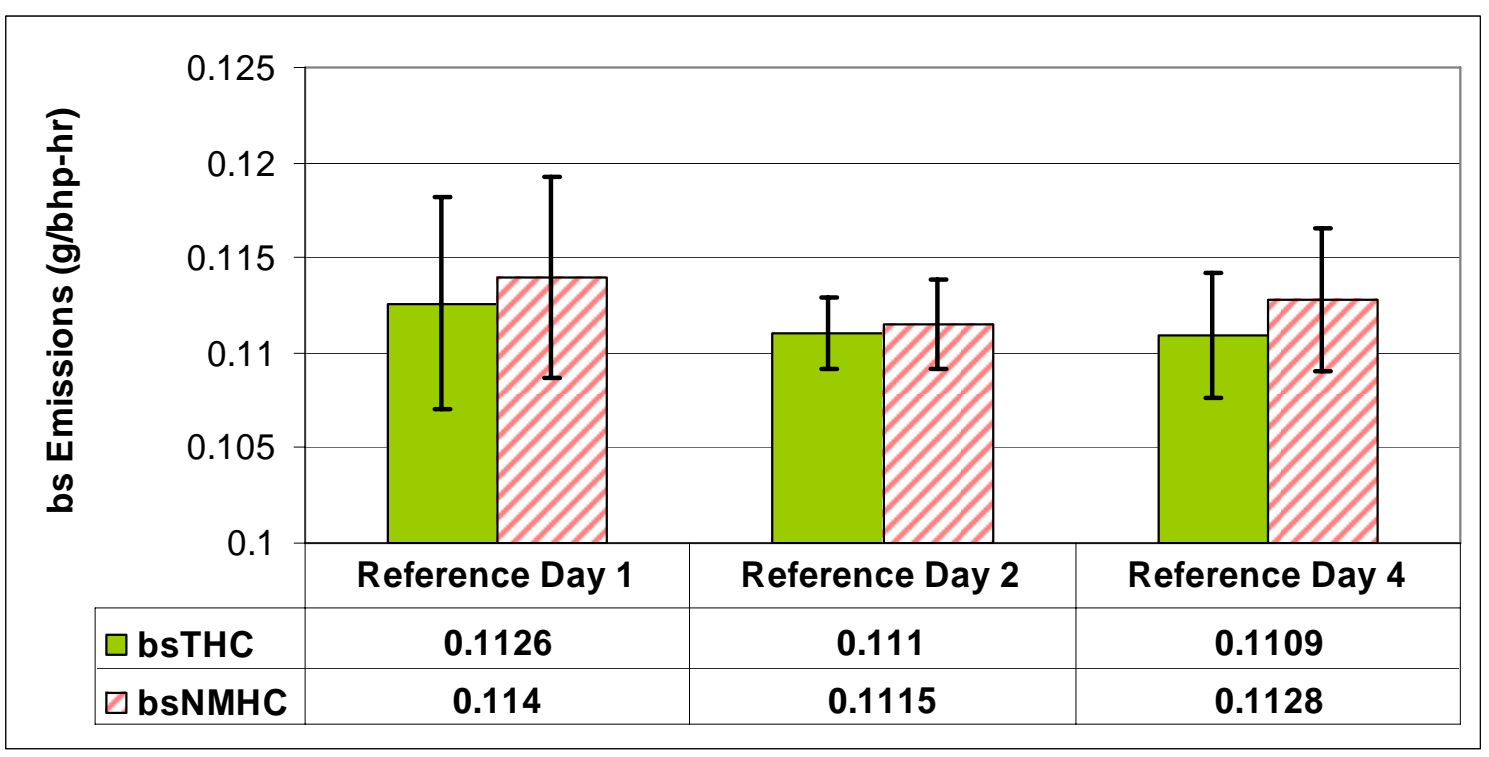

Figure 6.4 Average laboratory emission values from hot-start FTP tests using reference fuel.

As seen from the previous figures, the laboratory is very repeatable and can be confidently used for comparison testing.

\subsubsection{Carbon Balance}

Fuel consumption of the FTP cycles was determined by carbon-balance, and also measured with the positive displacement fuel flow meter. A comparison of these values offeres a basic quality assurance check on gaseous analyzer performance and exhaust flowrate measurements. Figure 6.5 displays the integrated percent difference between these two values. The engine used was a 1992 DDC Series 60 engine. As one can observe from Figure 6.5 , the carbon balance yields values that range from- $3 \%$ to $+2 \%$ in comparison to fuel flow meter. 


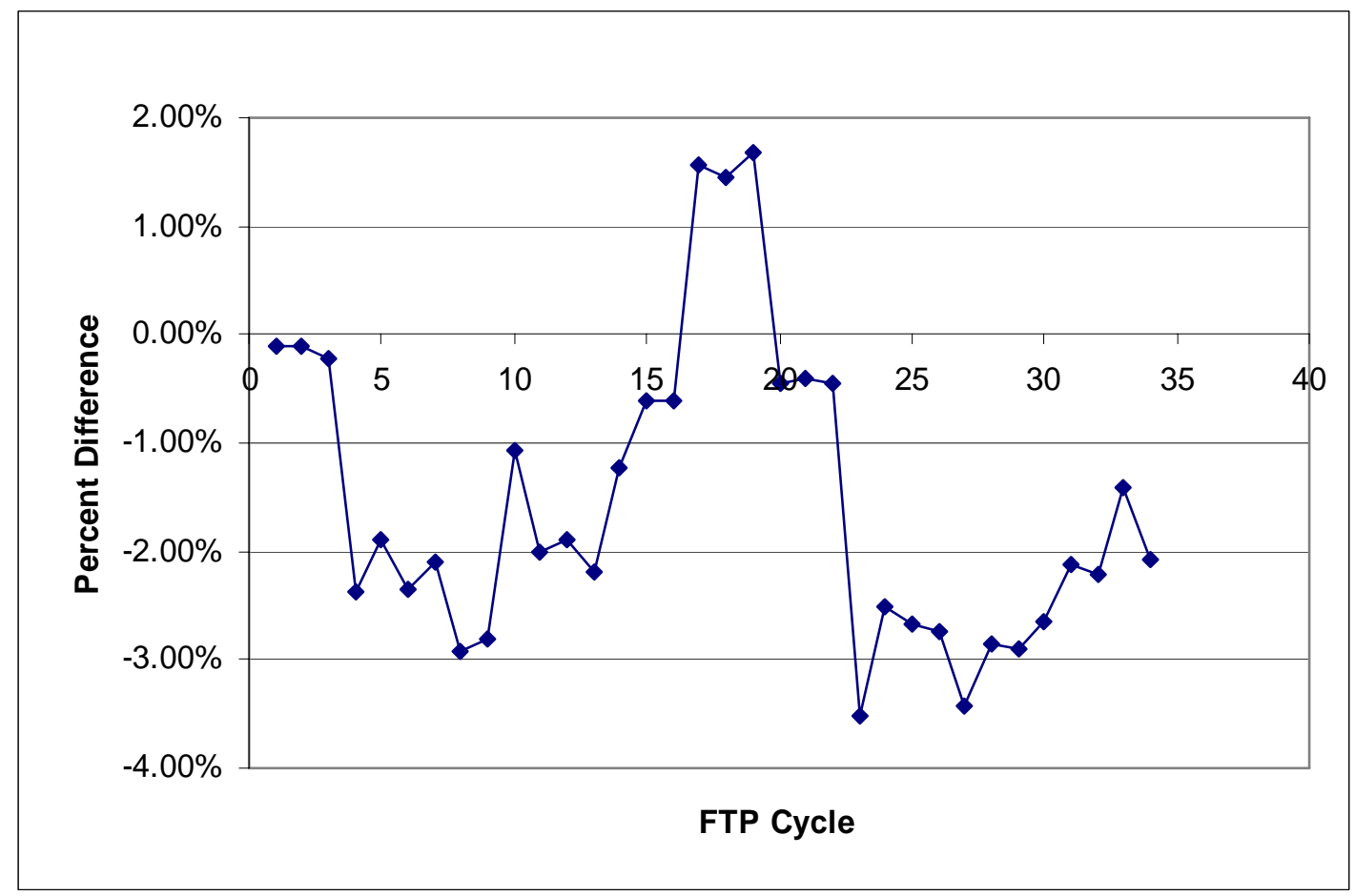

Figure 6.5 EERL Fuel Consumption Percent Difference (consumed vs. recovered)

The Sequence I 2005 testing had slightly higher fuel recovery numbers. On average, for the five FTPs collected during Sequence I 2005, the laboratory recovered $6.5 \%$ more fuel then the flow meter reported. On the contrary, during the August testing, the laboratory under recovered almost three percent less fuel than the flow meter measured, on average.

\subsection{Sequence I 2005}

The engine tested was a 1992 Detroit Diesel series 60 engine. The fuel used was federal D2 that was procured locally. Five FTP cycles were compared (laboratory sequence \#E00840), and the time aligned averaged data from two independent SEMTECH-D systems and MEMS was plotted versus the averaged WVU EERL values.

\subsubsection{NOx Mass Emission Flowrate}

$\mathrm{NO}_{\mathrm{X}}$ mass emissions data were compared against two Rosemount 955 CLD laboratory grade analyzers. Figure 6.6 provides a view of the transient behavior of the PEMS and the two laboratory analyzers (labeled LAB and LAB2). 


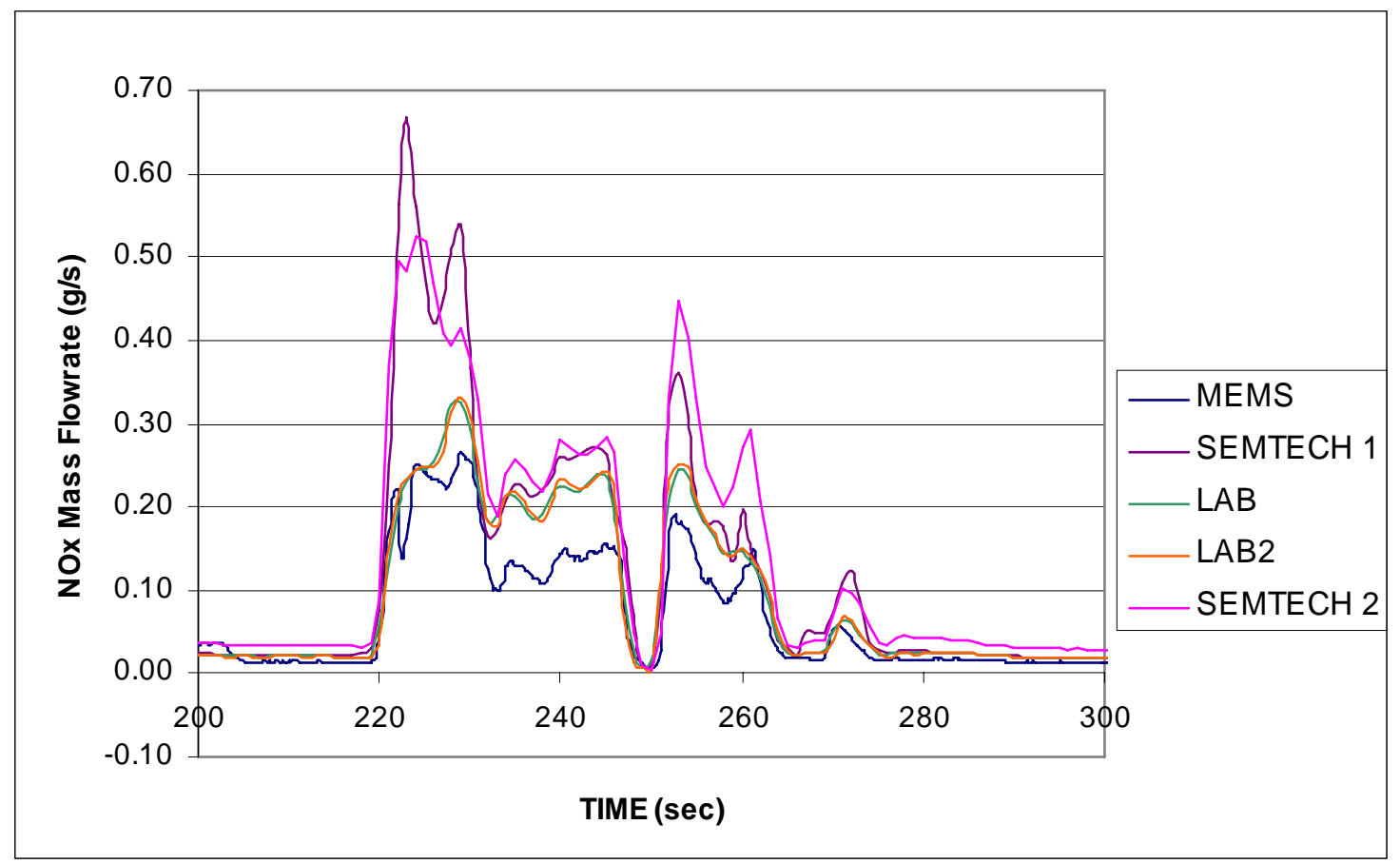

Figure 6.6 PEMS and laboratory NOx mass emission flowrate traces for FTP E00840_01.

The integrated total mass percent error for SEMTECH\#1 reported anywhere from 17$23 \%$ high, while SEMTECH\#2 reported $24-29 \%$ higher than the laboratory analyzers. MEMS error compared to the laboratory ranged from $4.1 \%$ to $6.8 \%$ higher. $\mathrm{NO}_{\mathrm{X}}$ mass emission totals for SEMTECH-Ds and laboratory are seen in Figure 6.7.

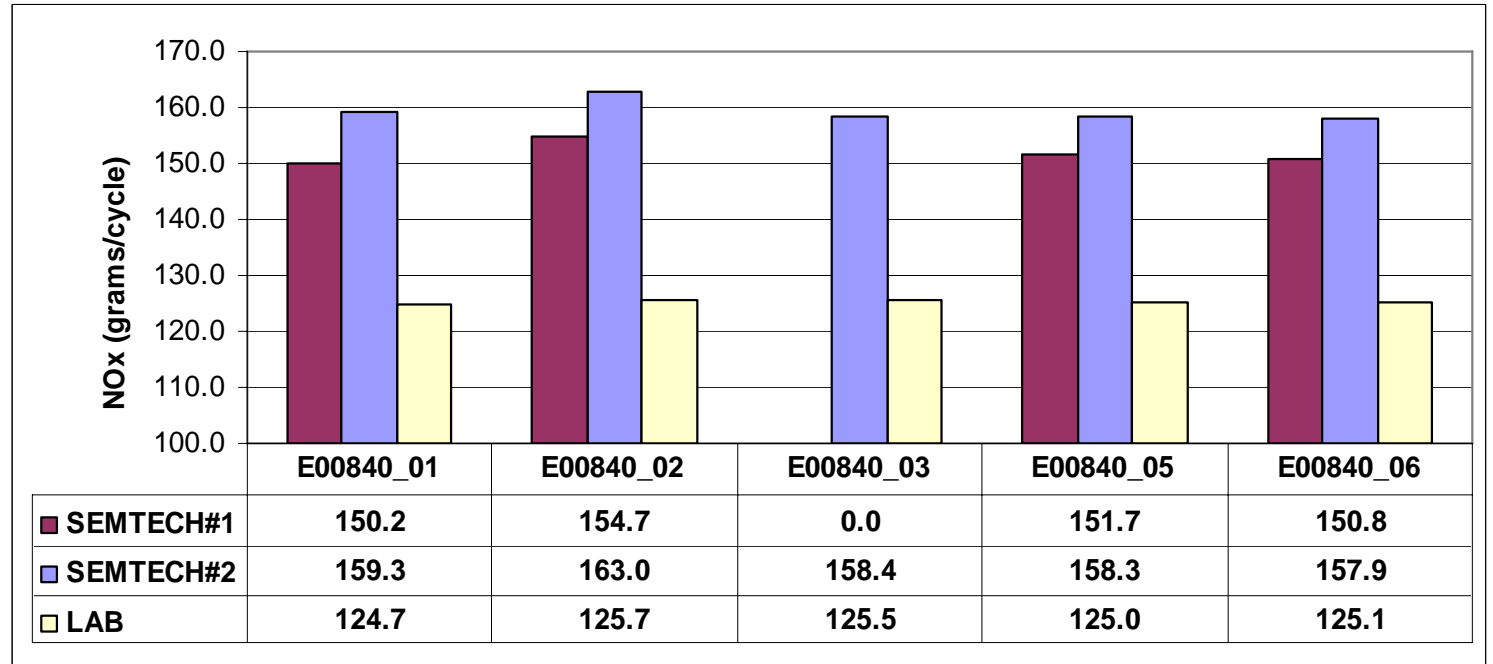

Figure 6.7 Total $\mathrm{NO}_{\mathrm{X}}$ Mass for Sequence I 2005 testing. SEMTECH\#1 did not capture E00840_03. 
Instantaneous time aligned values for all five FTP's were averaged for all three portable systems, and were plotted against the laboratory data. A linear regression was calculated for each plot and the intercept was forced through zero. The $\mathrm{R}^{2}$ value was 0.92 . The linear regression shows poor correlation. To produce the comparison plots seen below, all five FTP tests were time aligned and each individual data point was averaged and plotted against the corresponding reference system value. Figure 6.8 and Figure 6.9 show the time aligned averaged data compared to the laboratory for SEMTECH\#1 and SEMTECH\#2, respectively. The correlation equation listed $(\mathrm{y}=1.2)$ again shows the $\sim 20 \%$ error as calculated.

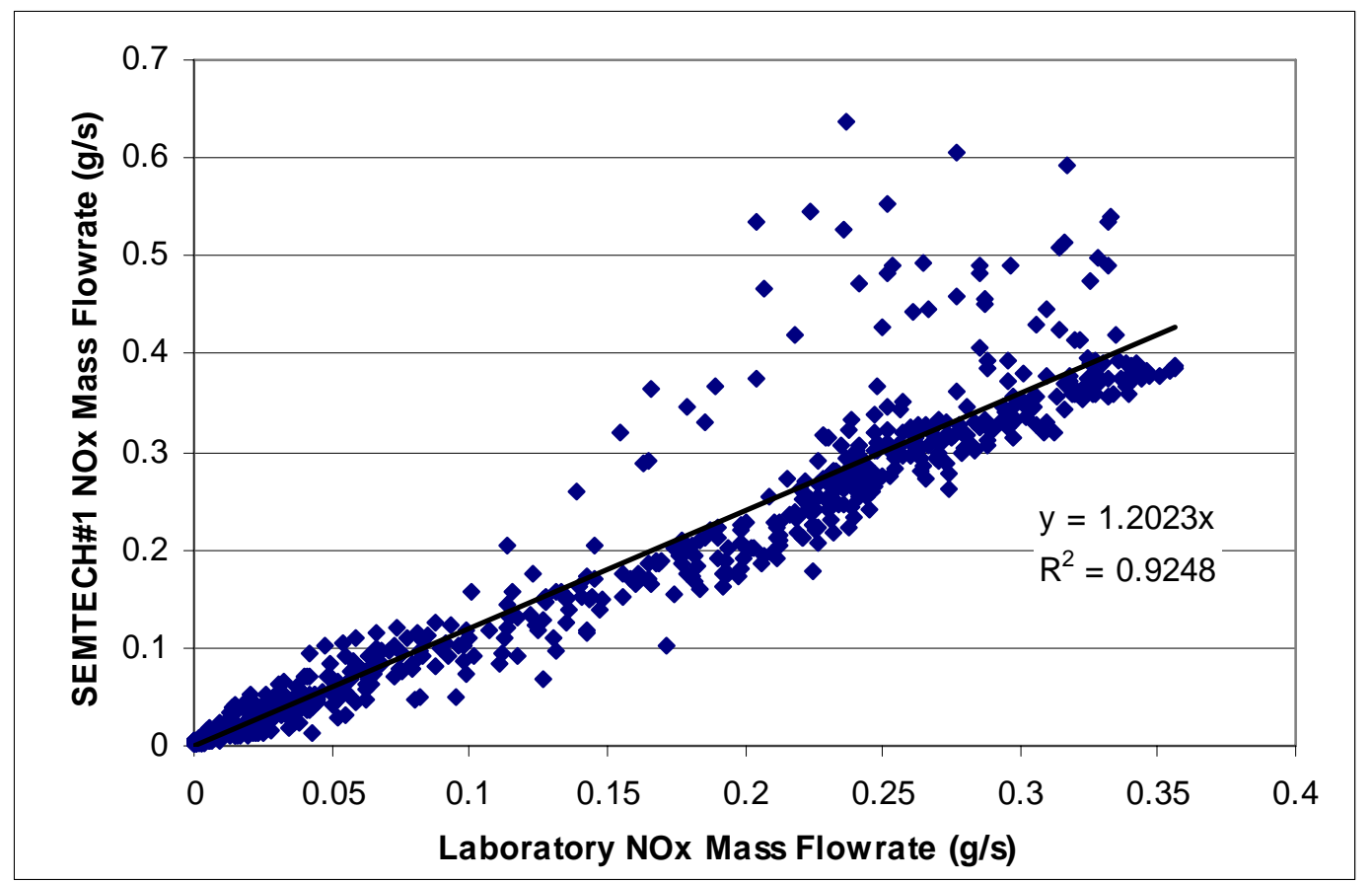

Figure 6.8 Laboratory versus SEMTECH\#1 averaged FTP $\mathrm{NO}_{\mathrm{X}}$ mass emissions rate. 


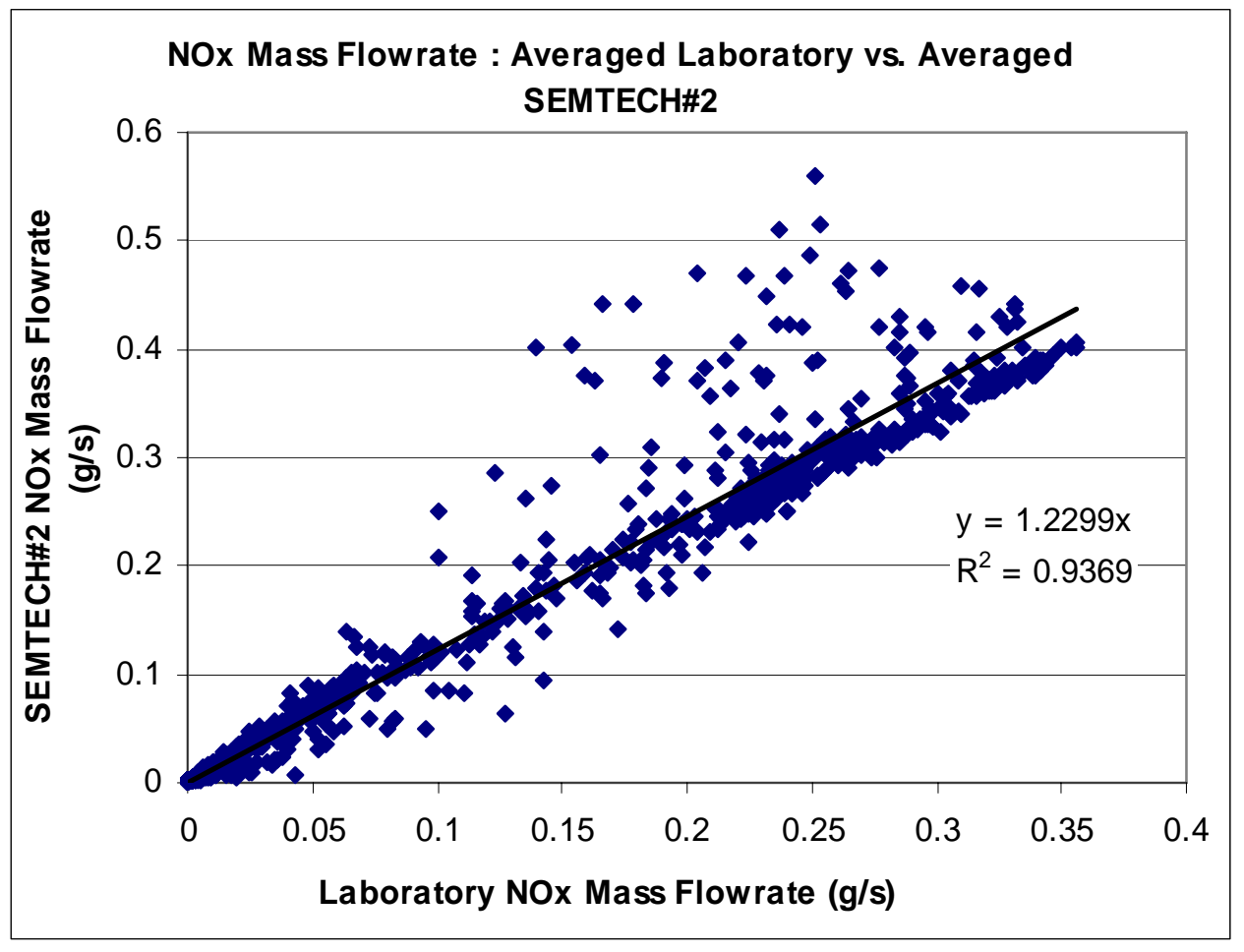

Figure 6.9 Laboratory versus SEMTECH\#2 averaged FTP $\mathrm{NO}_{\mathrm{X}}$ mass emissions rate.

Due to a system error, MEMS only captured four of the five FTP cycles. The test cycles recorded were E00840_01, 02, 05, and 06, and the averaged $\mathrm{NO}_{\mathrm{X}}$ mass emission error for these tests was $5.55 \%$ compared to the laboratory, with a range of $4.13 \%$ to $6.81 \%$.

Both SEMTECH-D systems were consistent from test to test. In order to demonstrate this, individual time aligned FTP tests were plotted against each other. Figure 6.10 plots the first and second FTP tests against one another to provide a glimpse of SEMTECH-D's repeatability. The $\mathrm{R}^{2}$ value equals 0.993. A second test to test repeatability plot is included in APPENDIX A Sequence I 2005. The $\mathrm{NO}_{\mathrm{X}}$ total mass emitted coefficient of variation for SEMTECH\#1 was $1.32 \%$. 


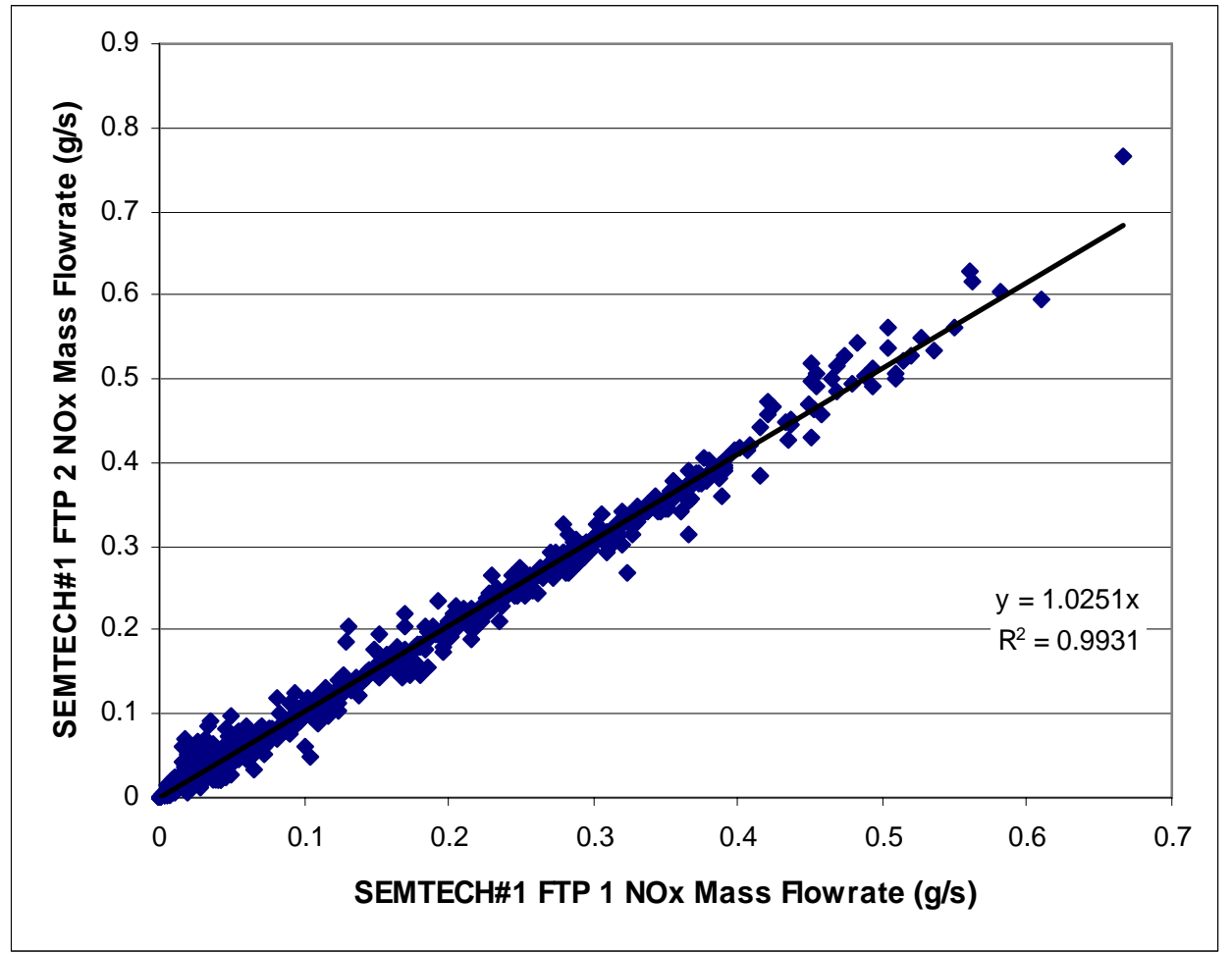

Figure 6.10 SEMTECH-D\#1 repeatability, FTP 1 versus FTP $2 \mathrm{NO}_{\mathrm{X}}$ mass emissions rate.

Figure 6.11 shows the repeatability of SEMTECH\#2, by plotting the first two FTP tests against one another. The comparison shows good correlation $\left(\mathrm{R}^{2}=0.988\right)$ and demonstrates a tight pattern. A second set of tests were plotted and included in APPENDIX A Sequence I 2005. The $\mathrm{NO}_{\mathrm{X}}$ total mass emitted coefficient of variation for SEMTECH\#2 was $1.27 \%$. 


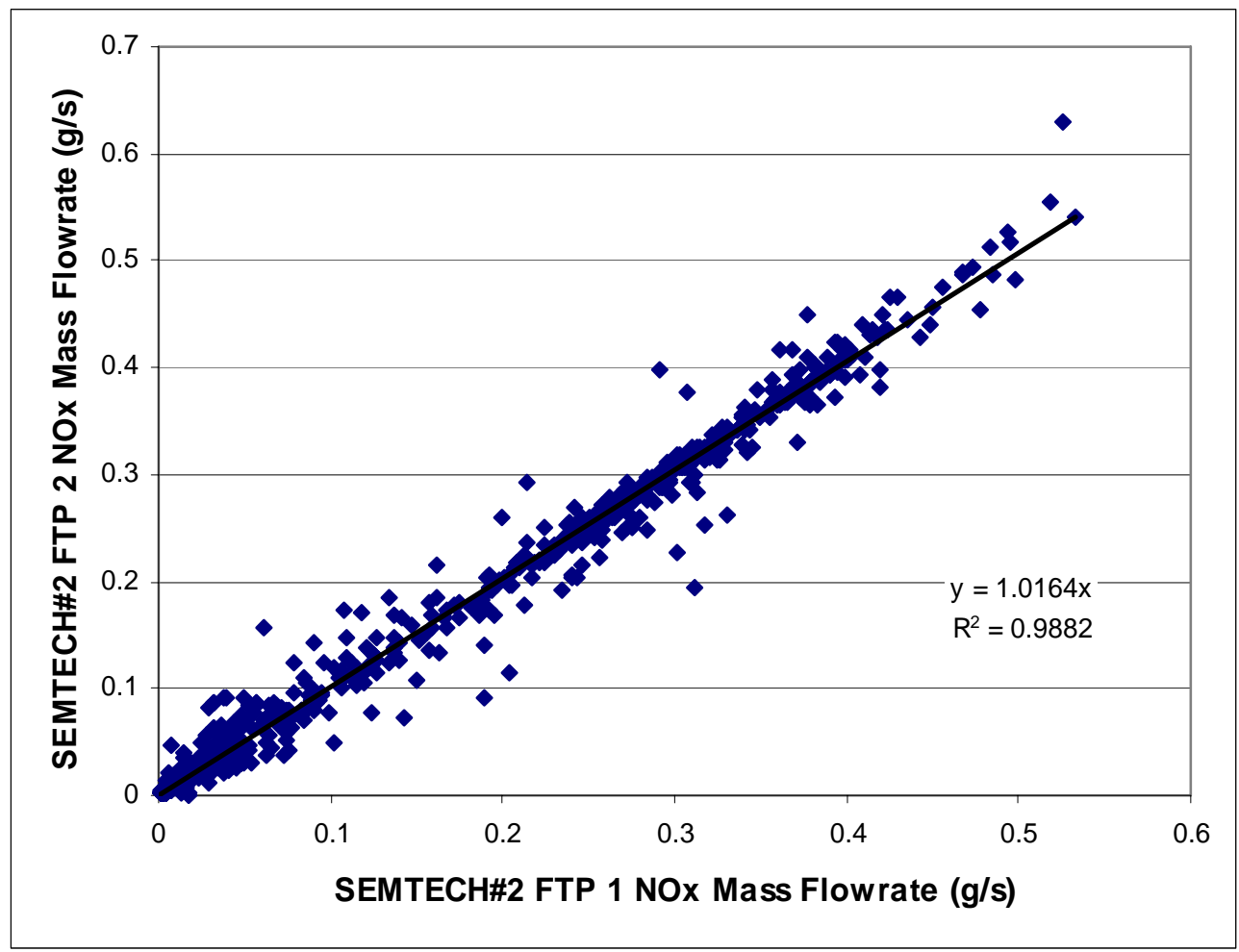

Figure 6.11 SEMTECH-D\#2 repeatability, FTP 1 versus FTP $2 \mathrm{NO}_{\mathrm{X}}$ mass emissions rate.

MEMS' $\mathrm{NO}_{\mathrm{X}}$ total mass emitted coefficient of variation is $0.99 \%$, and its repeatability is seen in Figure 6.12. 


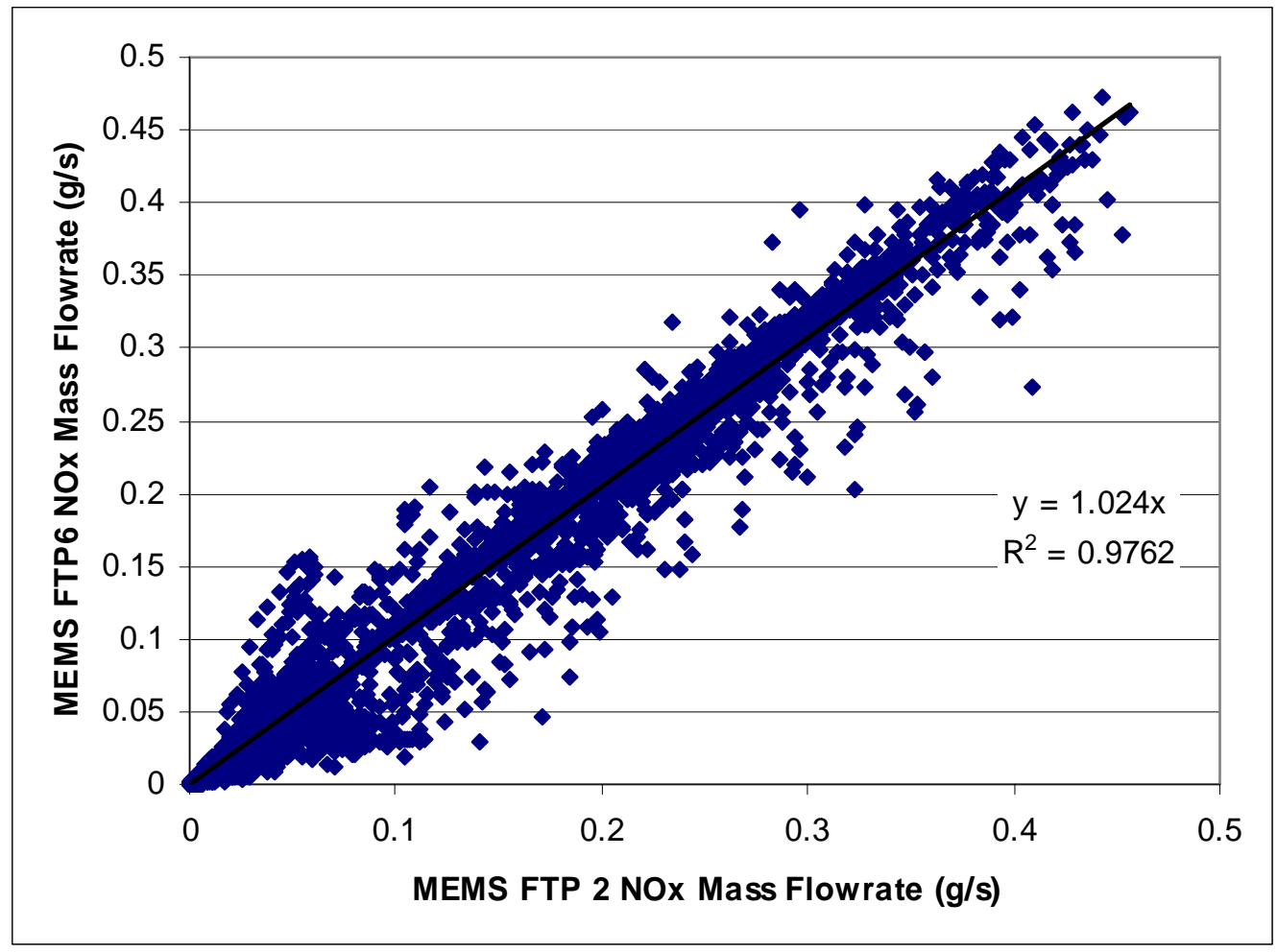

Figure 6.12 MEMS repeatability, FTP 2 versus FTP 6 NO$_{X}$ mass emissions rate.

Table 6.1 compiles the integrated percent differences for all three systems when compared to the laboratory. MEMS performed well averaging over 5\% error, while both SEMTECH systems were over $20 \%$ different.

Table 6.1 PEMS Integrated $\mathrm{NO}_{\mathrm{X}}$ Mass Percent Differences Compared to Laboratory

\begin{tabular}{|l|l|l|l|l|l|}
\hline Test Number & E00840_01 & E00840_02 & E00840_03 & E00840_05 & E00840_06 \\
\hline System & NOX Percent Difference (grams) \\
\hline SEMTECH\#1 & $20.4 \%$ & $23.1 \%$ & $18.0 \%$ & $21.5 \%$ & $20.6 \%$ \\
\hline SEMTECH\#2 & $27.7 \%$ & $29.6 \%$ & $25.0 \%$ & $26.8 \%$ & $26.2 \%$ \\
\hline MEMS & $6.7 \%$ & $4.4 \%$ & N/A & $4.1 \%$ & $6.8 \%$ \\
\hline
\end{tabular}

\subsection{2 $\mathrm{CO}_{2}$ Mass Emission Flowrate}

A sample of a trace from an individual FTP cycle is seen in Figure 6.13. Both SEMTECH-Ds can be seen spiking nearly $40 \%$ higher than the laboratory. 


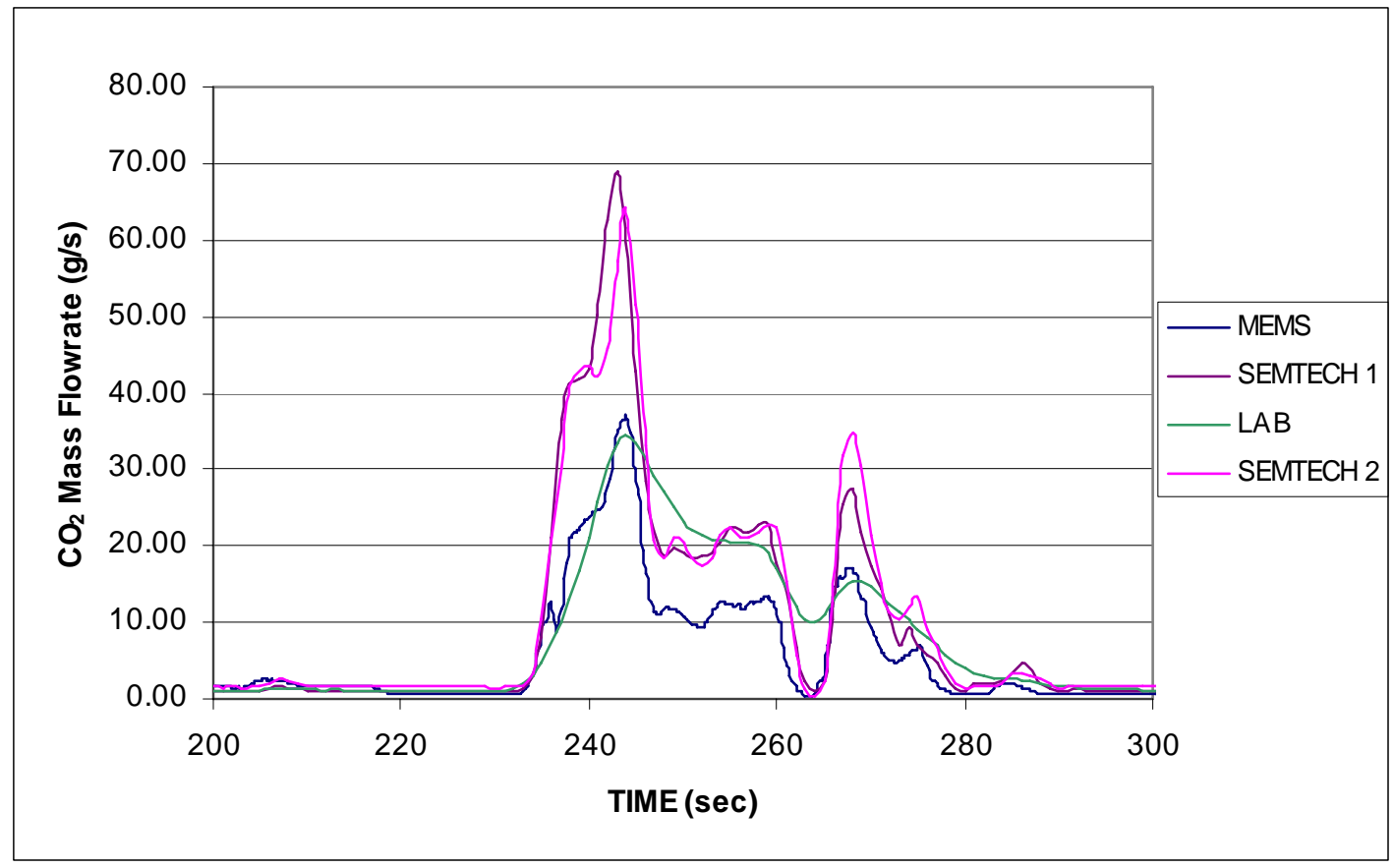

Figure 6.13 PEMS and laboratory $\mathrm{CO}_{2}$ mass emission flowrate traces for FTP E00840_01.

The $\mathrm{CO}_{2}$ mass emission totals, as seen in Figure 6.14, were better than those for $\mathrm{NO}_{\mathrm{X}}$. Cycle specific mass emissions (grams/cycle) of $\mathrm{CO}_{2}$ for both SEMTECH-D units were within $13 \%$ of the EERL for an integrated FTP cycle. The error associated with SEMTECH\#1 ranged from 8-13\% higher compared to the laboratory, while SEMTECH\#2 was anywhere from 6-11\% higher. The same test to test repeatability is again evident for both the laboratory analyzer and both SEMTECH-Ds. 


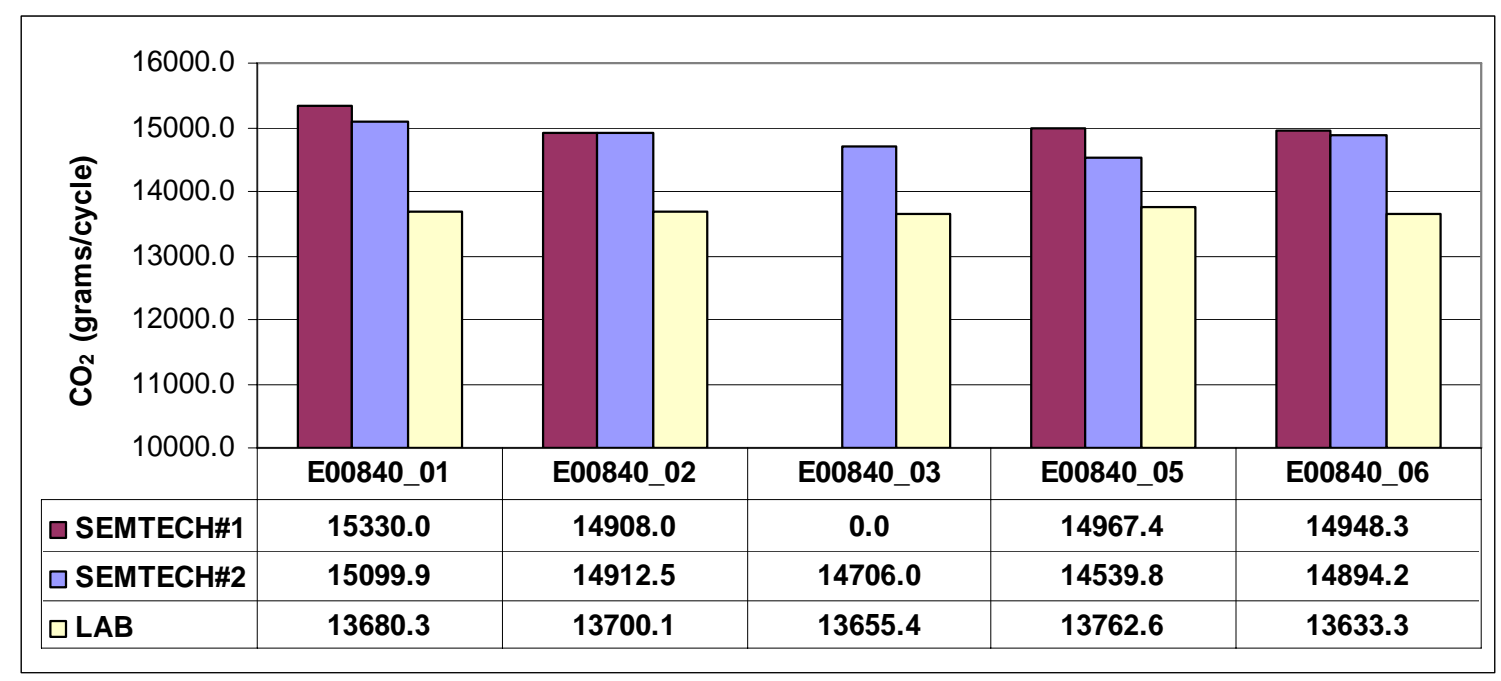

Figure 6.14 $\mathrm{CO}_{2}$ mass emission totals for Sequence I 2005 testing. E00840_03 was not captured by SEMTECH\#1.

Figure 6.15 shows the averaged $\mathrm{CO}_{2}$ mass emission flowrate values for the laboratory versus the average $\mathrm{CO}_{2}$ mass emission flowrate values for SEMTECH\#1. $\mathrm{R}^{2}$ is equal to 0.88 .

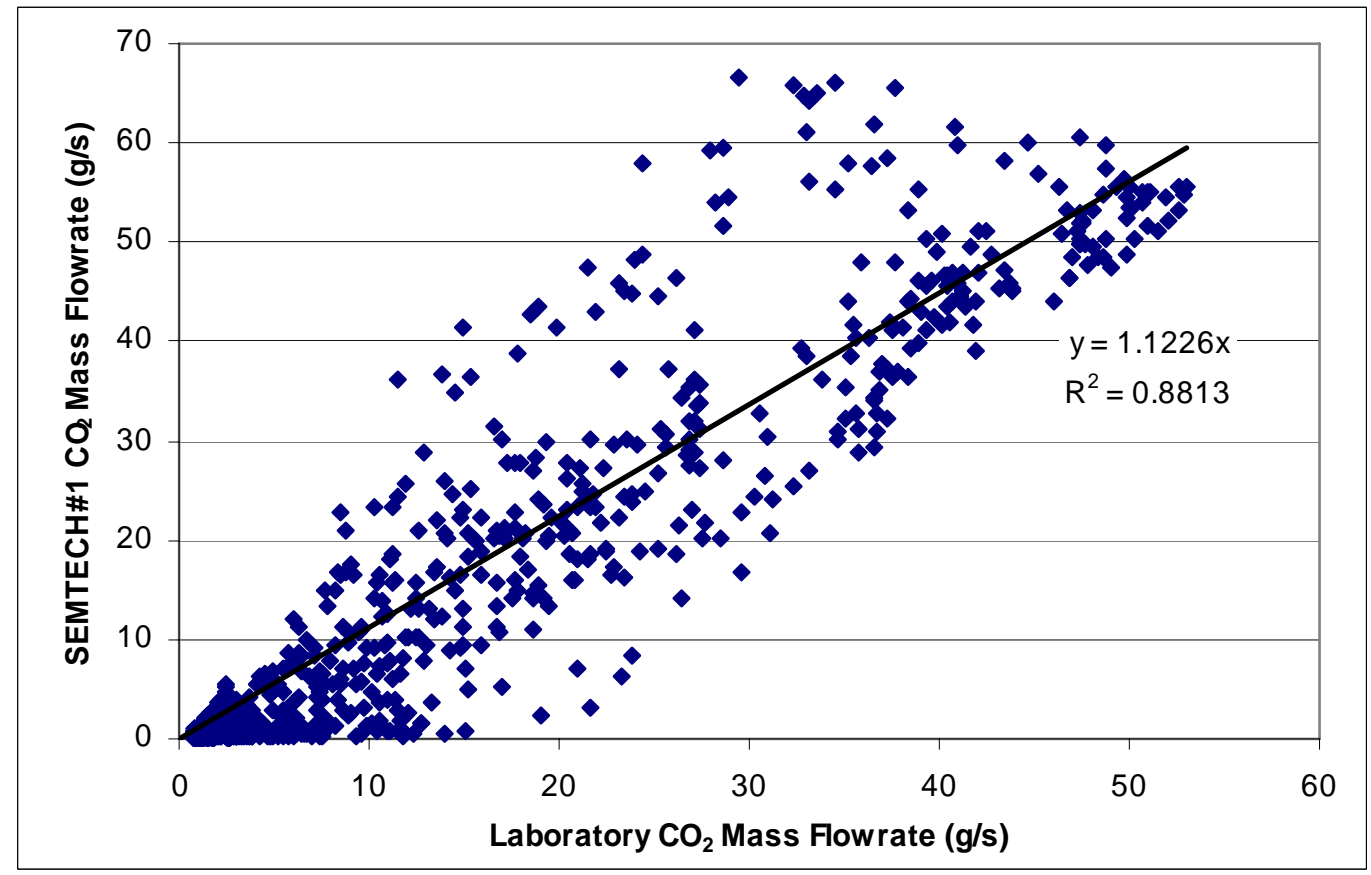

Figure 6.15 Laboratory versus SEMTECH\#1 averaged FTP $\mathrm{CO}_{2}$ mass emissions rate. 
Figure 6.16 provides a view of the averaged laboratory $\mathrm{CO}_{2}$ mass emission flowrate values versus the corresponding averaged SEMTECH\#2 values. Correlation is poor, with the $\mathrm{R}^{2}$ value equal to 0.88 for the trend line.

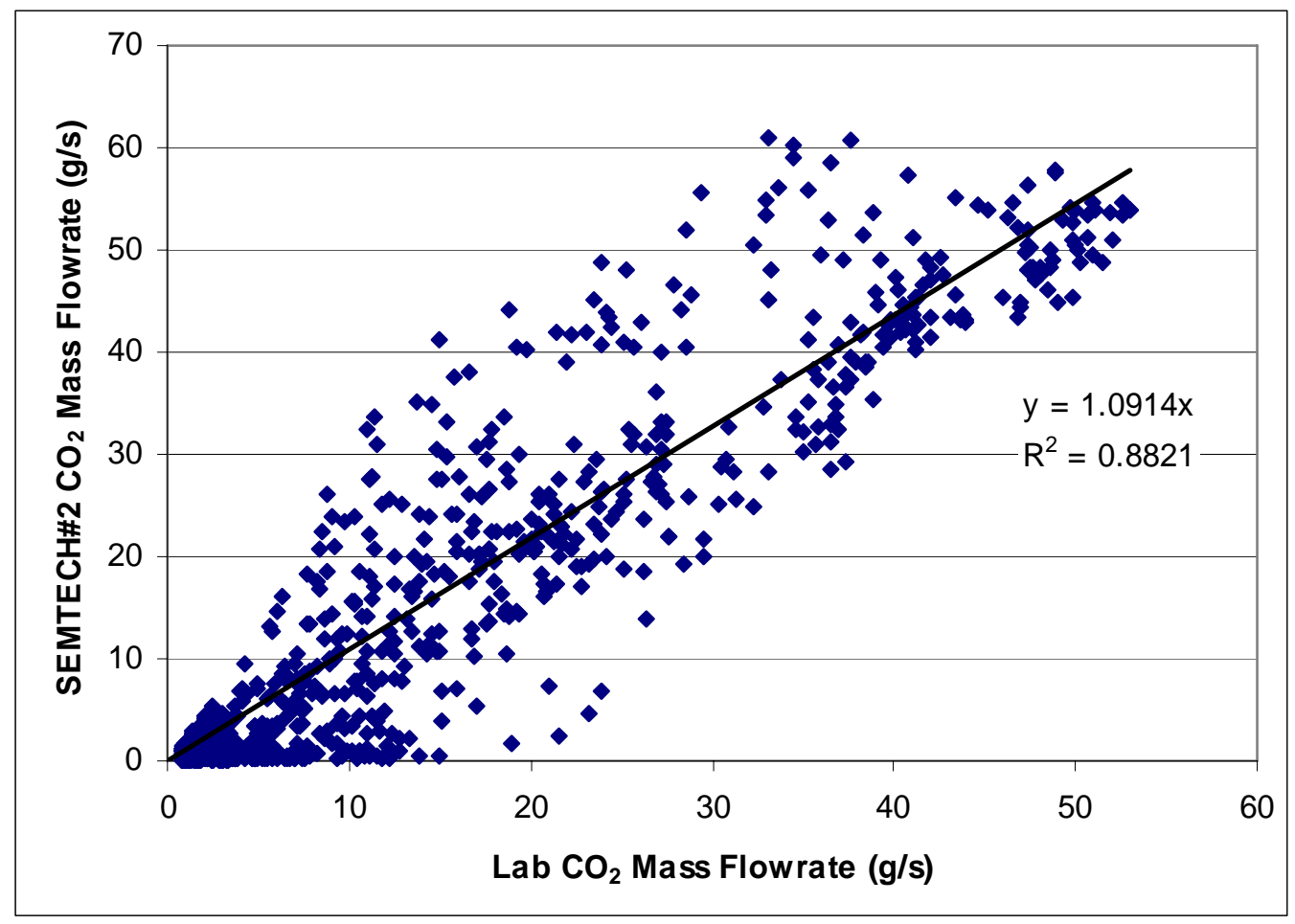

Figure 6.16 Laboratory versus SEMTECH\#2 averaged $\mathrm{FTP} \mathrm{CO}_{2}$ mass emissions rate.

To show the consistency of the PEMS, the following system specific test versus test plots were included: Figure 6.17 and APPENDIX A Figure 9.5 that are repeatability plots for SEMTECH\#1, while Figure 6.18 and APPENDIX A Figure 9.6 are for SEMTECH\#2. 


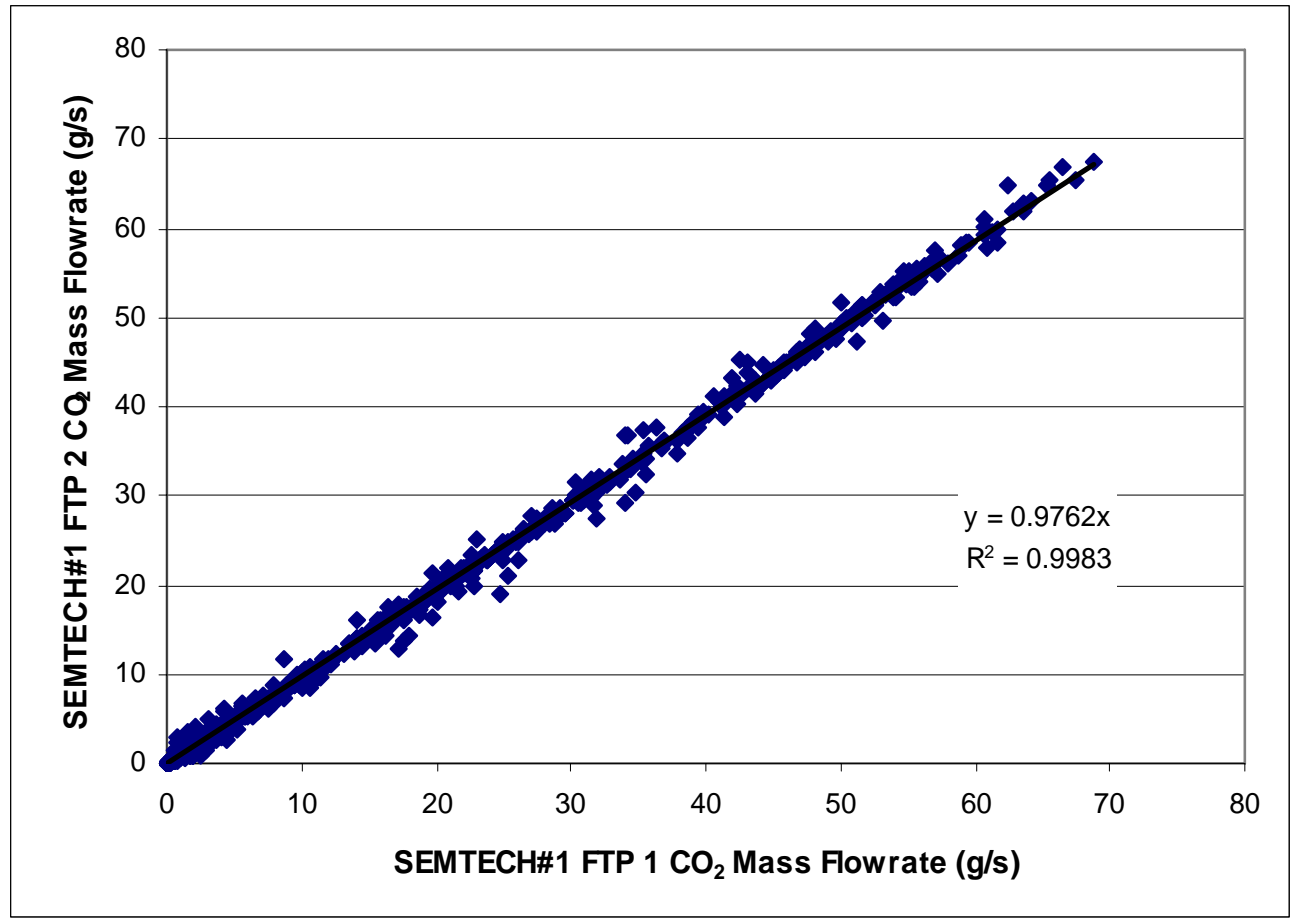

Figure 6.17 SEMTECH-D\#1 repeatability, FTP 1 versus FTP $2 \mathrm{CO}_{2}$ mass emissions rate.

SEMTECH-D\#1 had a coefficient of variation of $3.74 \%$ for total $\mathrm{CO}_{2}$ mass emissions. 


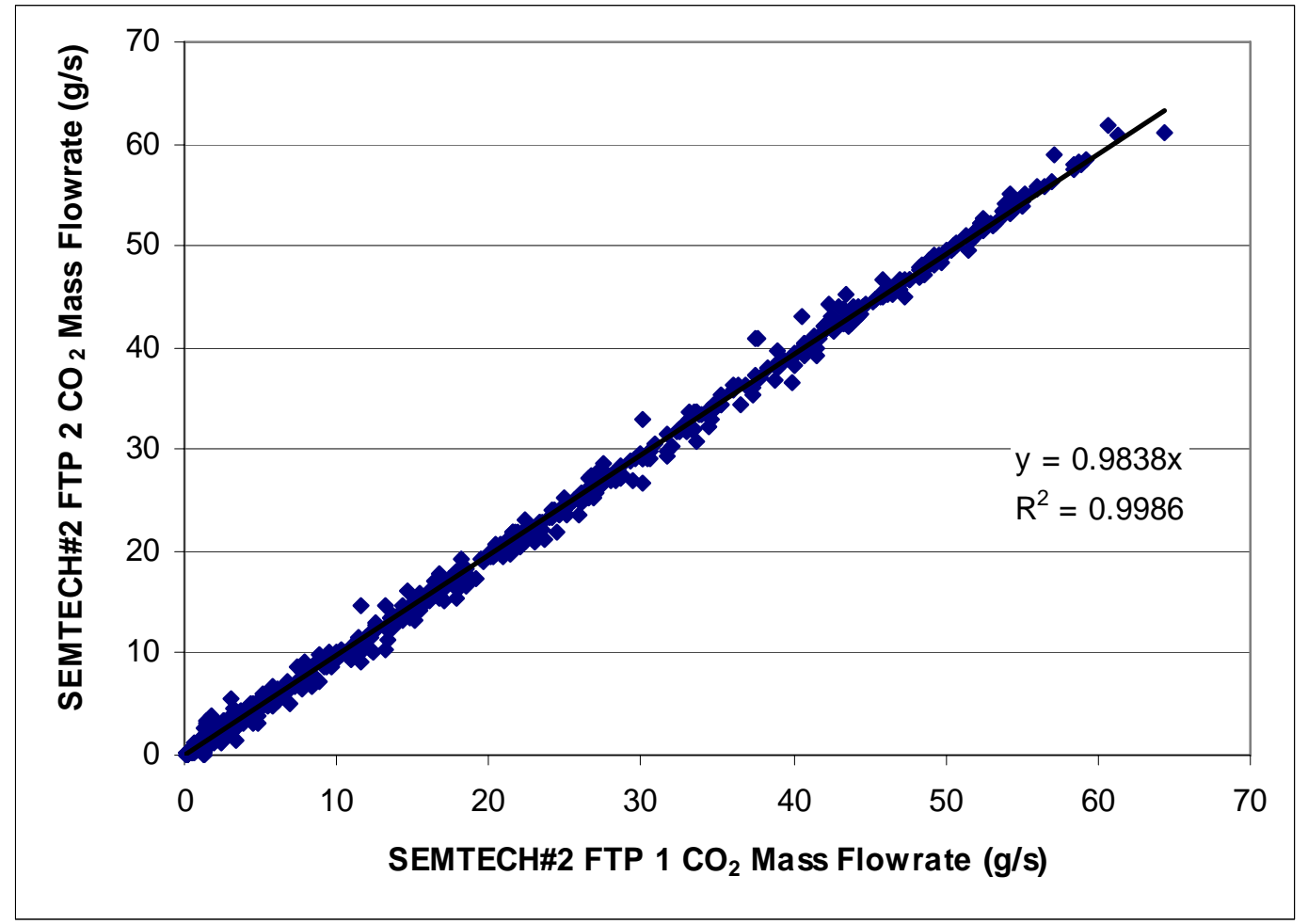

Figure 6.18 SEMTECH-D\#2 repeatability, FTP 1 versus FTP $2 \mathrm{CO}_{2}$ mass emissions rate.

Both systems prove to be repeatable with $\mathrm{R}^{2}$ values equal to 0.99 . The $\mathrm{CO}_{2}$ total mass emission coefficient of variation was $1.63 \%$ for SEMTECH-D\#2. Figure 6.19 shows the repeatability of MEMS. The first two FTP tests collected were plotted against each other and a regression line is included that shows poor conformity to a 45 degree line. 


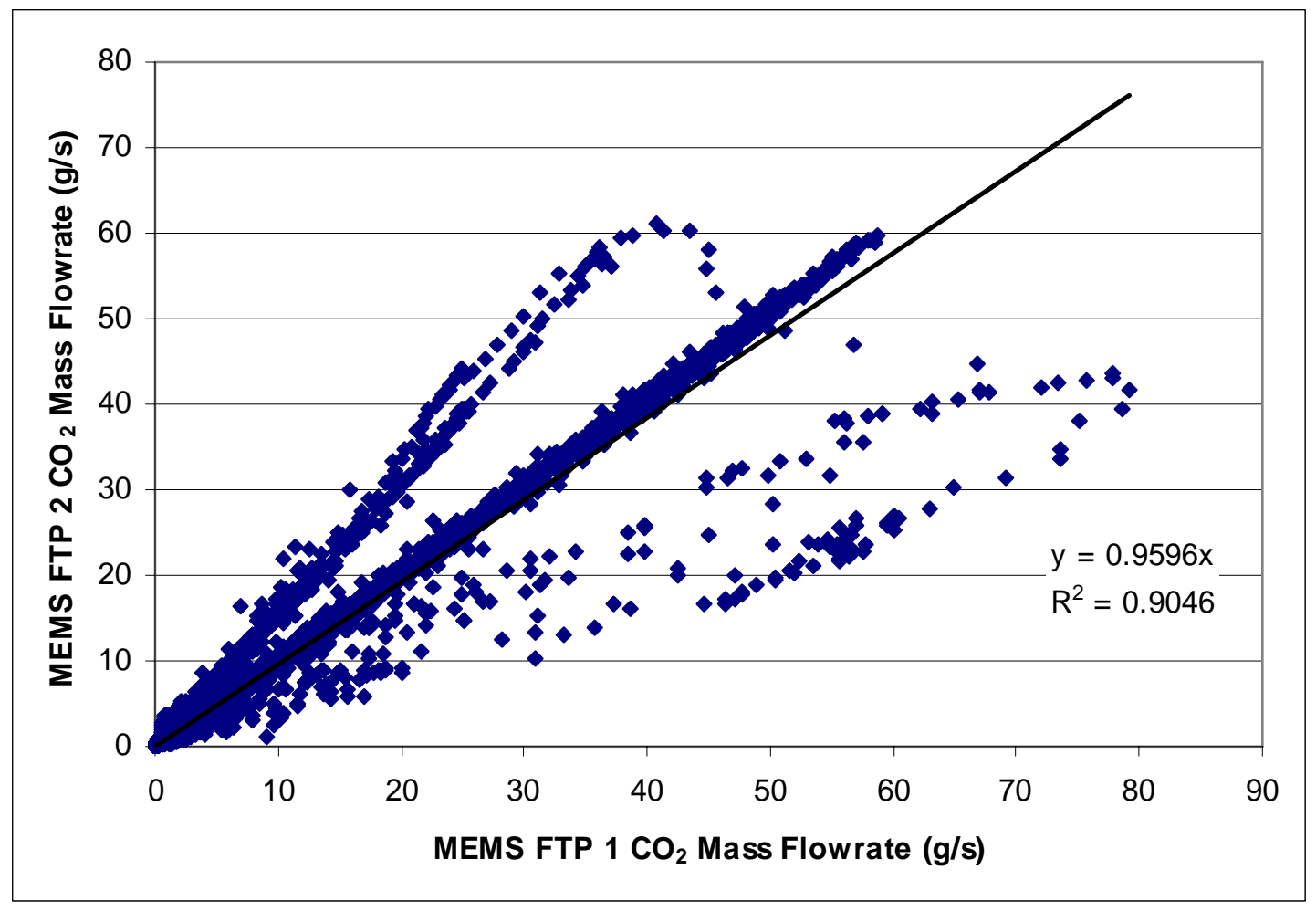

Figure 6.19 MEMS repeatability, FTP 1 versus FTP $2 \mathrm{CO}_{2}$ mass emissions rate.

The $\mathrm{CO}_{2}$ total mass coefficient of variation was $0.71 \%$ for MEMS. Table 6.2 shows the individual percent differences of total $\mathrm{CO}_{2}$ mass for each system. Each individual PEMS calculated $\mathrm{CO}_{2}$ mass emission value was time aligned with the laboratory and integrated. Then the percent difference (compared to the laboratory) in total $\mathrm{CO}_{2}$ mass emitted was calculated. As noted before, MEMS failed to record valid data for E00840_03.

Table 6.2 $\mathrm{CO}_{2}$ Integrated Percent Differences Compared to Laboratory

\begin{tabular}{|l|l|l|l|l|l|}
\hline Test Number & E00840_01 & E00840_02 & E00840_03 & E00840_05 & E00840_06 \\
\hline System & CO 2 Percent Difference (grams) \\
\hline SEMTECH\#1 & $12.4 \%$ & $9.1 \%$ & $8.6 \%$ & $9.2 \%$ & $10.0 \%$ \\
\hline SEMTECH\#2 & $11.3 \%$ & $8.8 \%$ & $6.9 \%$ & $5.9 \%$ & $9.5 \%$ \\
\hline MEMS & $-0.3 \%$ & $2.4 \%$ & N/A & $-1.1 \%$ & $-0.9 \%$ \\
\hline
\end{tabular}

\subsubsection{Exhaust Flowrate}

The inferred standard exhaust flowrate, calculated from the laboratory data, was compared to the measurements from both SEMTECH-Ds. Since the $\mathrm{NO}_{\mathrm{X}}$ mass emission 
flowrate numbers for both SEMTECH-Ds were at least $20 \%$ in error, one would expect the exhaust flowrate values may account for the error. This was not exactly the scenario. SEMTECH\#1 had an integrated difference ranging from 5-8.7\% high compared to the laboratory's inferred flowrate, while SEMTECH\#2 varied from $11 \%$ to $14 \%$ higher when compared to the laboratory. Figure 6.20 illustrates the total volume of exhaust measured for each system. Both SEMTECH-D systems report higher totals for every transient FTP cycle collected.

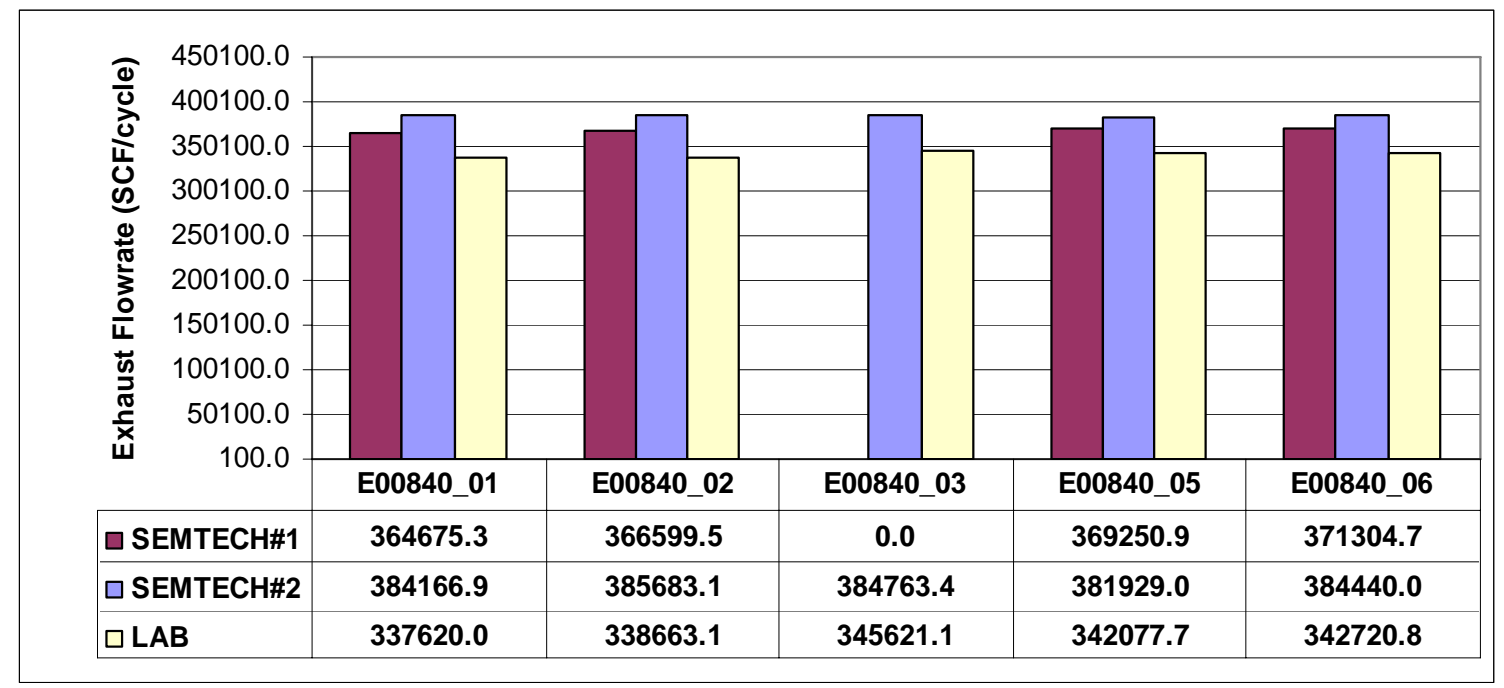

\section{Figure 6.20 Exhaust volumetric totals from Sequence I 2005 testing. SEMTECH\#1 did not capture FTP E00840_03.}

Flowrate comparisons to the laboratory for both SEMTECH-D systems shows slightly scattered behavior for both EFMs. Figure 6.21 and Figure 6.22 show plots of inferred flowrate (laboratory) against the flowrate measured by the SEMTECH-D units. 


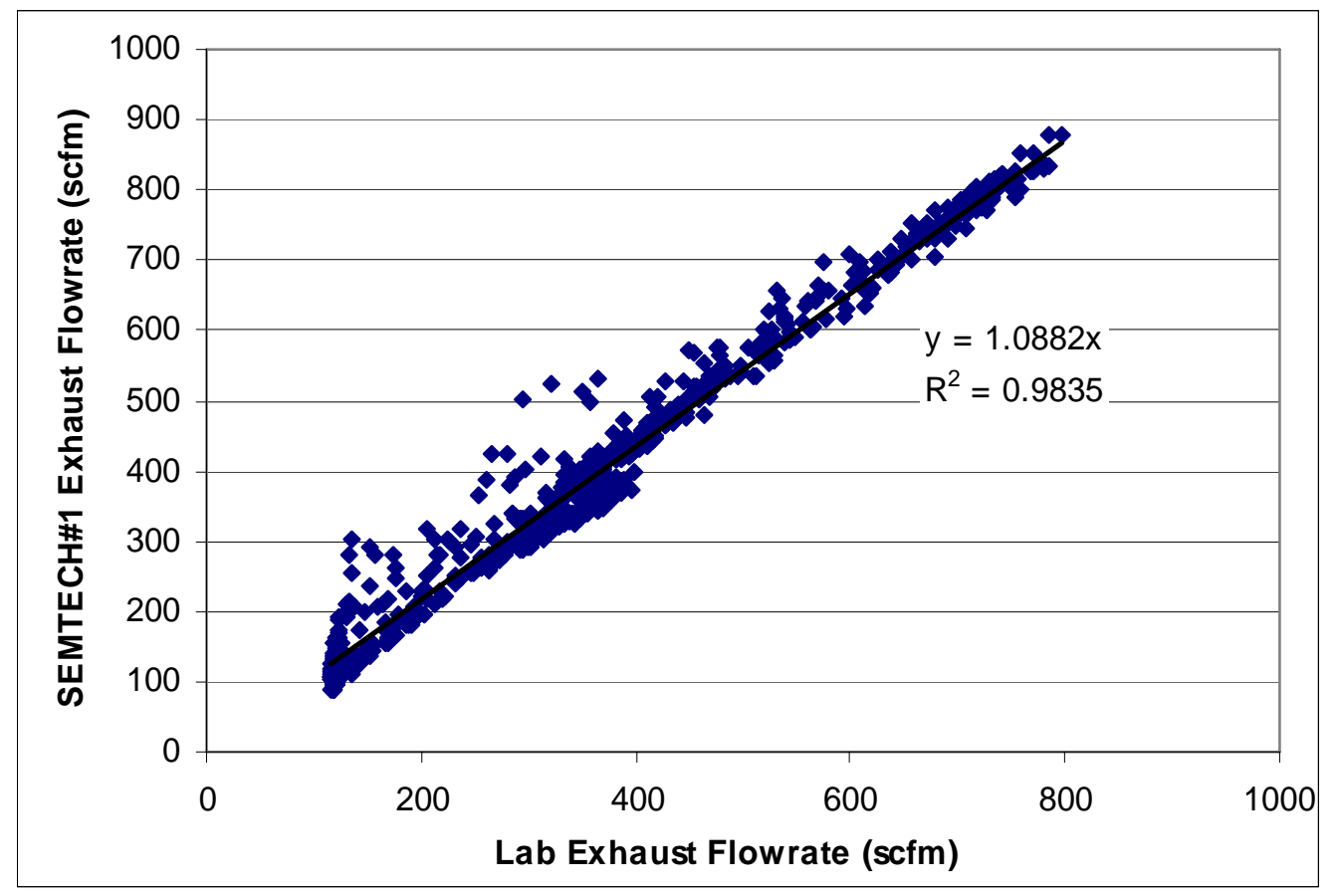

Figure 6.21 Laboratory versus SEMTECH\#1 averaged FTP exhaust flowrate.

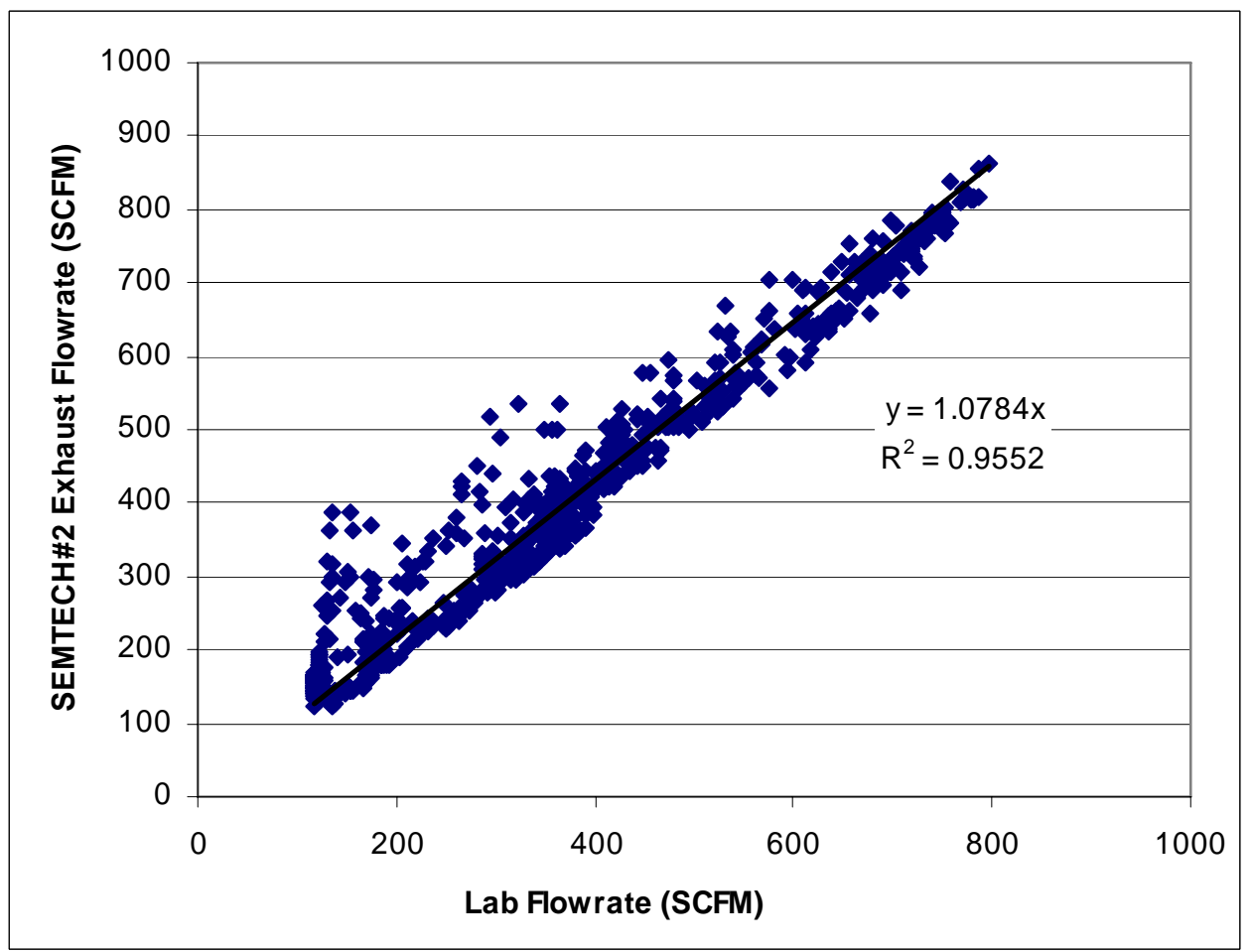

Figure 6.22 Laboratory versus SEMTECH\#2 averaged FTP exhaust flowrate. 
While comparing the SEMTECH-D flowrates to one another, one can see that SEMTECH\#2 is consistently 50 SCFM higher than SEMTECH\#1 when the flowrate is below 200 SCFM. Yet, when the flowrate is above 200 SCFM the two systems correlate very well. This discrepancy is not as clear when viewing the emission flowrate traces seen earlier (Figure 6.6\&Figure 6.13). This can be observed in Figure 6.23, which contains a portion of the plot of multiple SEMTECH\#1, SEMTECH\#2, and WVU EERL exhaust flowrate traces. The first two tests collected for all three systems are included in this plot, and SEMTECH\#2 behaves the same in both traces. This shows that the EFM for SEMTECH\#2 is improperly zeroing its low end transducers. This could explain the larger $\mathrm{NO}_{\mathrm{X}}$ mass emission errors reported by SEMTECH\#2.

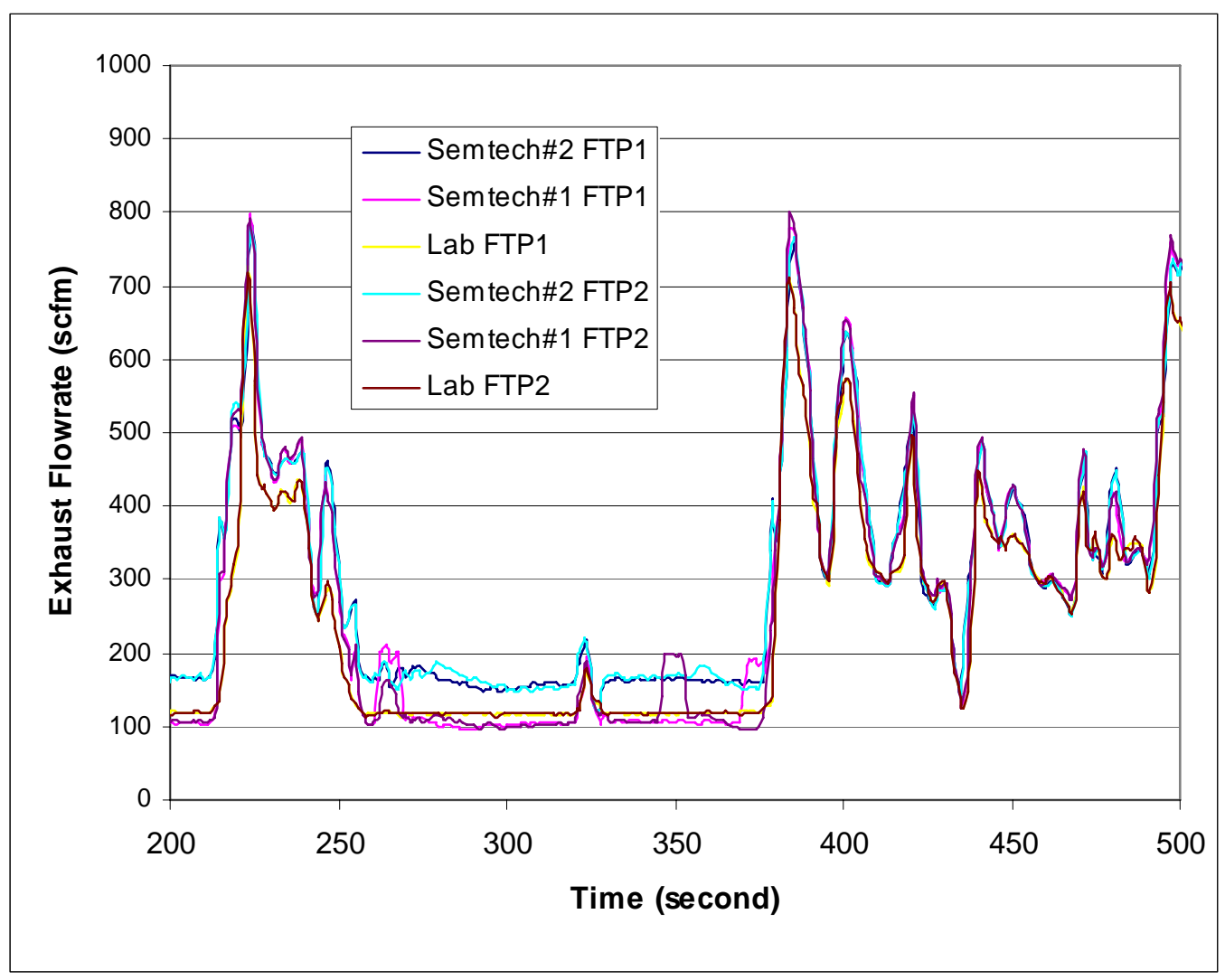

Figure 6.23 Multiple system exhaust flowrate trace.

Table 6.3 shows the error associated with exhaust flowrate measurement compared to the laboratory intake air plus fuel flow. As expected, SEMTECH\#2 totaled larger errors than SEMTECH\#1, due to the poor behavior at lower flow rates. 
Table 6.3 Exhaust Flowrate Integrated Percent Differences.

\begin{tabular}{|l|l|l|l|l|l|}
\hline Test Number & E00840_01 & E00840_02 & E00840_03 & E00840_05 & E00840_06 \\
\hline System & \multicolumn{6}{|l|}{ Exhaust Flowrate Percent Difference (SCF) } \\
\hline SEMTECH\#1 & $7.8 \%$ & $7.8 \%$ & $5.3 \%$ & $7.7 \%$ & $8.1 \%$ \\
\hline SEMTECH\#2 & $13.2 \%$ & $13.2 \%$ & $10.9 \%$ & $11.1 \%$ & $11.6 \%$ \\
\hline MEMS & $-0.3 \%$ & $2.4 \%$ & N/A & $-1.1 \%$ & $-0.9 \%$ \\
\hline
\end{tabular}

\subsubsection{Steady State Test}

One steady state test was conducted when both SEMTECH-D systems were available.

The test was a seven-mode test consisting of engine speeds ranging from 600-1650 rpm.

Table 6.4 provides percent errors for $\mathrm{NO}_{\mathrm{X}}$ and $\mathrm{CO}_{2}$ mass emissions rates and exhaust flowrate errors compared to the laboratory for all three PEMS.

Table 6.4 Sequence I 2005 steady-state test errors compared to the laboratory.

\begin{tabular}{|l|c|c|c|c|c|c|c|c|}
\hline NOx & Mode 1 & Mode 2 & Mode 3 & Mode 4 & Mode 5 & Mode 6 & Mode 7 & Average \\
\hline SEMTECH\#1 & $51.27 \%$ & $16.74 \%$ & $27.98 \%$ & $18.46 \%$ & $13.04 \%$ & $14.99 \%$ & $15.10 \%$ & $\mathbf{2 2 . 5 1 \%}$ \\
\hline SEMTECH\#2 & $54.09 \%$ & $8.47 \%$ & $31.26 \%$ & $21.53 \%$ & $7.65 \%$ & $22.59 \%$ & $13.34 \%$ & $\mathbf{2 2 . 7 1 \%}$ \\
\hline MEMS & $-5.44 \%$ & $-1.54 \%$ & $4.02 \%$ & $-1.26 \%$ & $0.97 \%$ & $-2.82 \%$ & $-2.92 \%$ & $\mathbf{- 1 . 2 8 \%}$ \\
\hline CO $_{2}$ & Mode 1 & Mode 2 & Mode 3 & Mode 4 & Mode 5 & Mode 6 & Mode 7 & Average \\
\hline SEMTECH\#1 & $37.42 \%$ & $6.56 \%$ & $19.71 \%$ & $9.10 \%$ & $5.54 \%$ & $7.72 \%$ & $7.23 \%$ & $\mathbf{1 3 . 3 3 \%}$ \\
\hline SEMTECH\#2 & $41.05 \%$ & $-0.02 \%$ & $23.47 \%$ & $11.45 \%$ & $-1.10 \%$ & $13.03 \%$ & $5.32 \%$ & $\mathbf{1 3 . 3 2 \%}$ \\
\hline MEMS & $-15.52 \%$ & $-7.39 \%$ & $-0.08 \%$ & $-5.74 \%$ & $-7.20 \%$ & $-10.50 \%$ & $-8.98 \%$ & $\mathbf{- 7 . 9 1 \%}$ \\
\hline Ex. Flowrate & Mode 1 & Mode 2 & Mode 3 & Mode 4 & Mode 5 & Mode 6 & Mode 7 & Average \\
\hline SEMTECH\#1 & $33.92 \%$ & $12.91 \%$ & $24.93 \%$ & $15.66 \%$ & $28.33 \%$ & $12.62 \%$ & $12.19 \%$ & $\mathbf{2 0 . 0 8 \%}$ \\
\hline SEMTECH\#2 & $40.00 \%$ & $5.79 \%$ & $28.59 \%$ & $18.36 \%$ & $20.55 \%$ & $18.16 \%$ & $9.91 \%$ & $\mathbf{2 0 . 2 0 \%}$ \\
\hline MEMS & $-13.18 \%$ & $0.04 \%$ & $5.96 \%$ & $0.89 \%$ & $13.47 \%$ & $-4.80 \%$ & $15.05 \%$ & $\mathbf{2 . 4 9 \%}$ \\
\hline
\end{tabular}

\subsubsection{1 $\mathrm{NO}_{X}$ Mass Emission Flowrate}

Figure 6.24 shows the three PEMS time aligned with the laboratory. Both SEMTECH-D systems are consistently higher than the laboratory, with an average error for all modes being $22.5 \%$ and $22.7 \%$ for SEMTECH\#1 and SEMTECH\#2, respectively. The MEMS average percent difference is $-1.3 \%$ for all modes. Both SEMTECH-D systems are in agreement with one another, yet reporting drastically different values against the laboratory. This leads the author to believe that the SEMTECH-D units may have a problem that was not unique to the WVU-owned unit. 


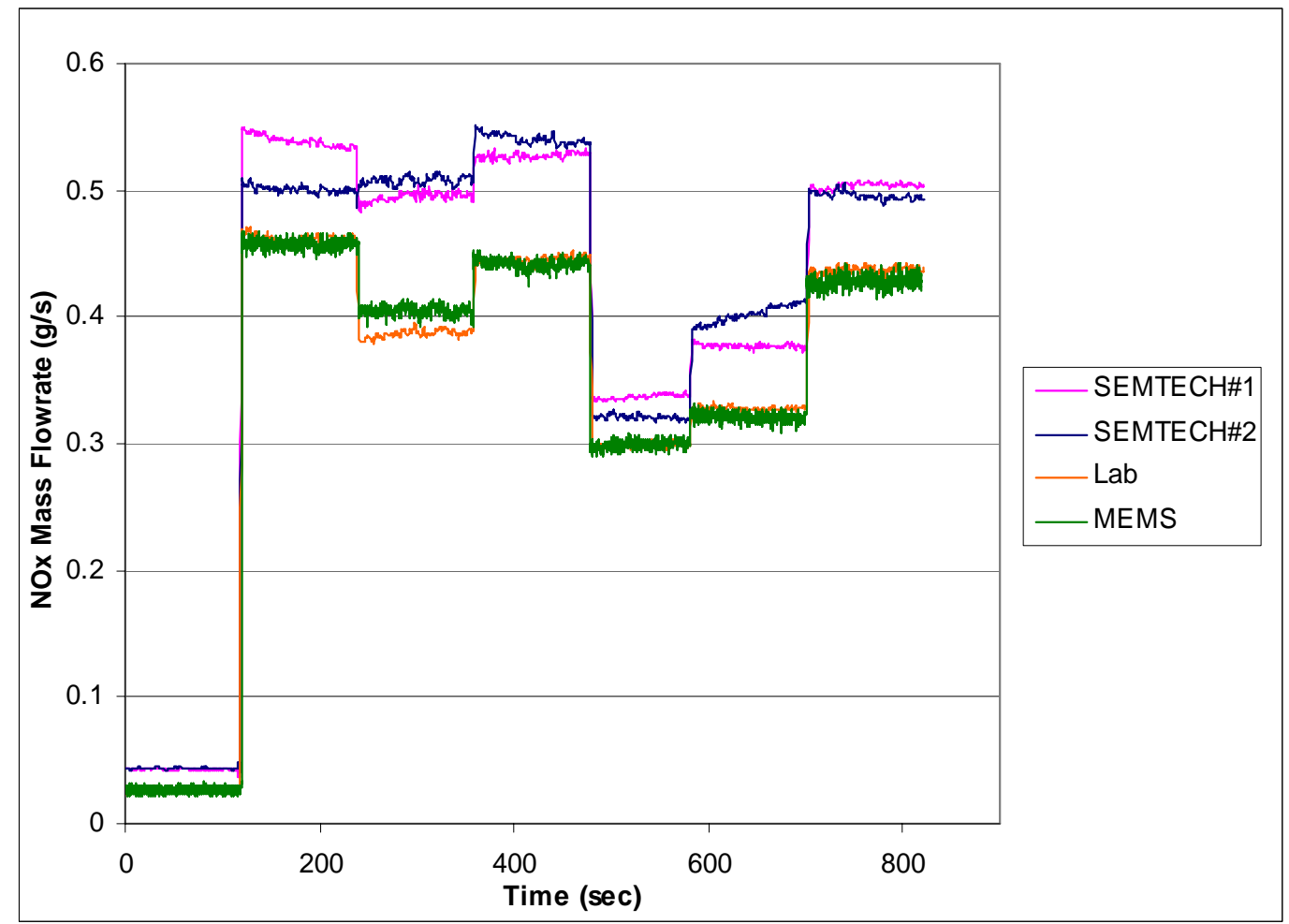

Figure 6.24 Steady state $\mathrm{NO}_{\mathrm{X}}$ mass emission flowrate.

\subsubsection{2 $\mathrm{CO}_{2}$ Mass Emission Flowrate}

In Figure 6.25 the $\mathrm{CO}_{2}$ mass emission flowrate is time aligned with respect to the laboratory. Both SEMTECH-D systems average about $13.3 \%$ higher readings than reported by the laboratory, while MEMS is $7.9 \%$ under the laboratory. Again, both SEMTECH-Ds are in agreement, yet nearly $14 \%$ different than the laboratory. 


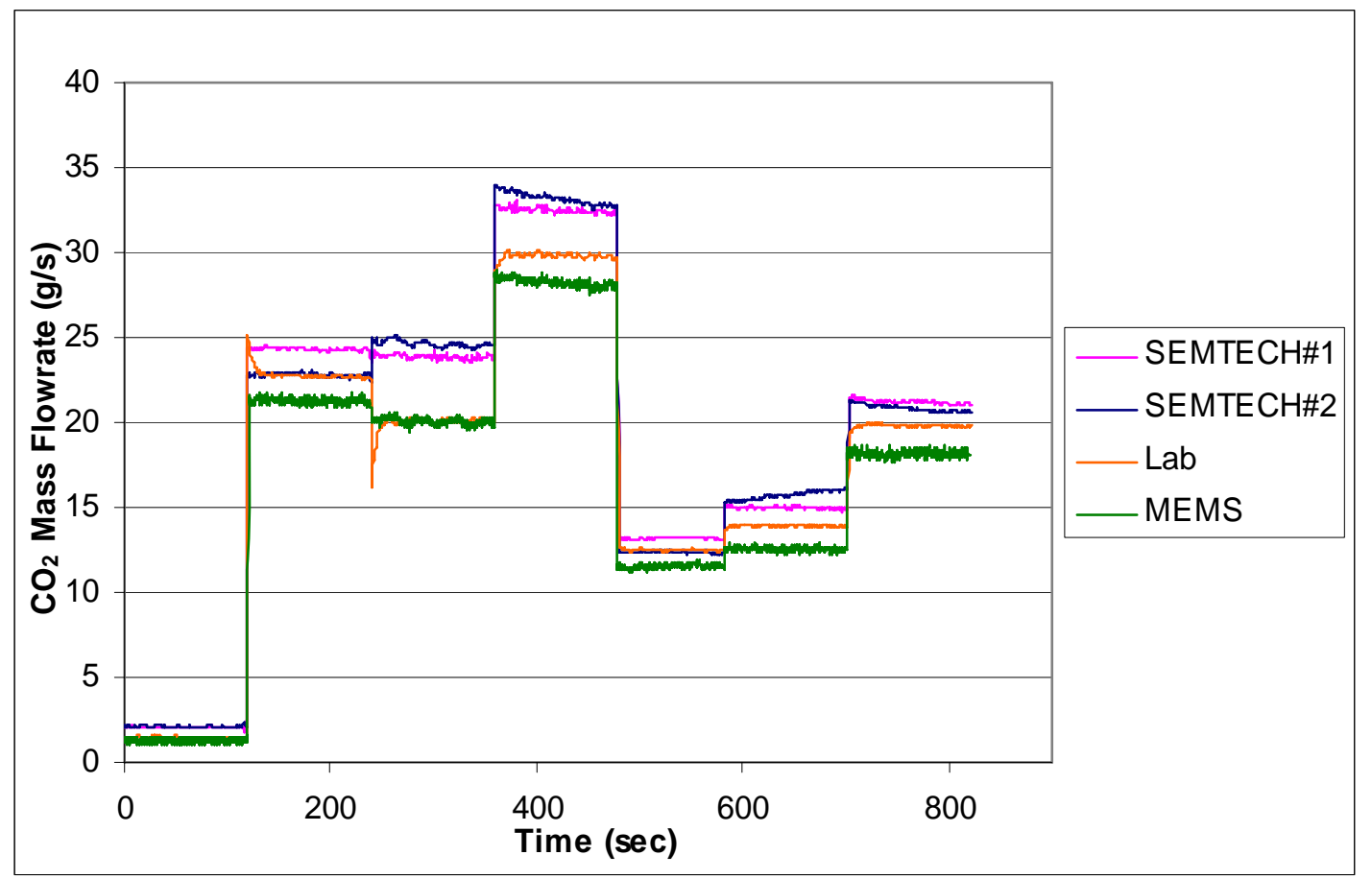

Figure 6.25 Steady state $\mathrm{CO}_{2}$ mass emission flowrate.

\subsubsection{Exhaust Flowrates}

Figure 6.26 is a plot of the integrated exhaust flowrate from each system. SEMTECH\#1 and SEMTECH\#2 average $20.6 \%$ and $21.2 \%$ error compared to the laboratory, respectively, and MEMS averages 5.3\% higher than the laboratory.

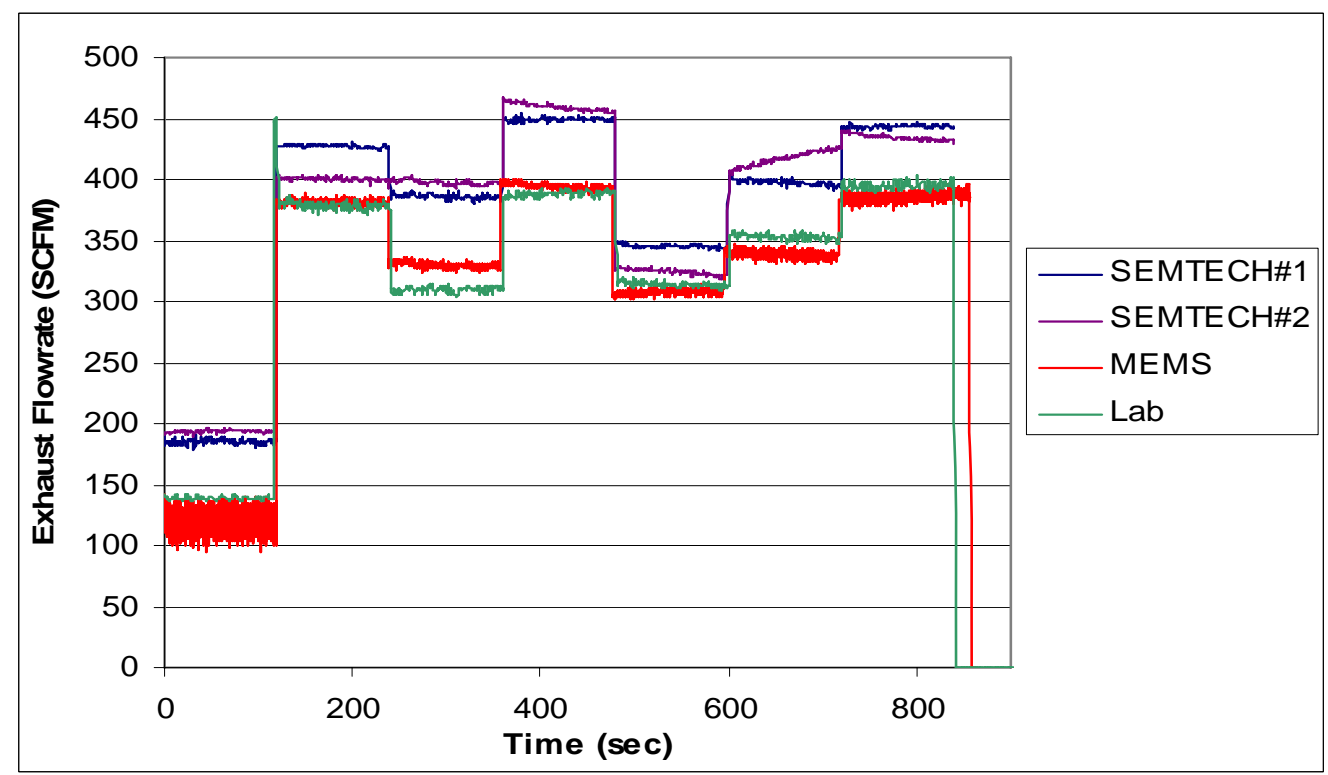

Figure 6.26 Exhaust volumetric flowrate. 
Between modes two and three, SEMTECH\#2 does not change exhaust flow rates. A glimpse of the raw file shows the flowrate dip at the end of mode two, then return to the same flowrate for mode three. SEMTECH\#2 error during mode two was $\sim 6 \%$ and the error during mode three was $\sim 29 \%$. Figure 6.27 shows this behavior. This phenomenon explains the poor correlation $\mathrm{CO}_{2}$ mass emissions rate for SEMTECH\#2 between modes two and three, when the laboratory drops in flowrate and SEMTECH\#2 actually rises. The same occurrence is visible in the $\mathrm{NO}_{\mathrm{X}}$ plot (Figure 6.24) where the laboratory drops and SEMTECH\#2 gradually increases (SEMTECH\#2: $8 \%$ error mode 2 to $31 \%$ error mode three) and in the $\mathrm{CO}_{2}$ mass emissions rate (SEMTECH\#2: $-0.2 \%$ error mode 2 to $23 \%$ error mode 3 ).

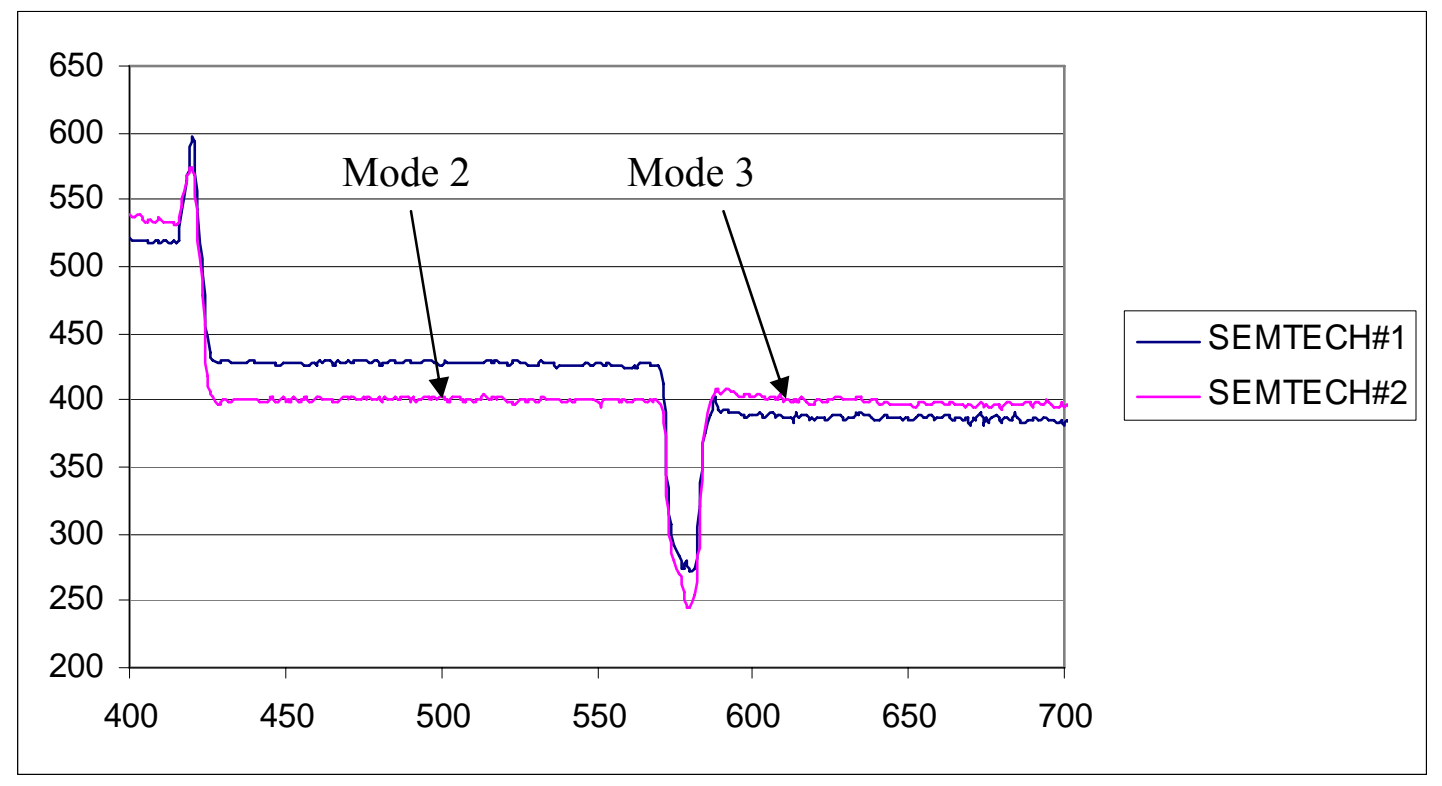

Figure 6.27 SEMTECH-D raw steady-state exhaust flow rate traces.

\subsection{Sequence II 2006}

Multiple FTP cycles were captured over four test days. Day one, five tests were performed. Days two and three both consisted of six hot-start FTP tests, while day four captured four tests. The third day was broken into two parts, Day 3 and Day3X2, with both parts consisting of three hot start FTP tests. Data were kept separate because Day 3 was in the morning and Day $3 X 2$ was in the evening. 


\subsection{1 $\mathrm{NO}_{X}$ Mass Emission Flowrate}

Figure 6.28 shows mass emissions (grams/cycle) averaged totals for each system and each individual day's tests. Error bars on the plot represent the standard deviation for each system and each day of testing. Percent differences are calculated using the laboratory as the reference [Equation 3.11]. The largest standard deviation occurred on Day 2 and was equal to 4.4 grams. Day3X2 error was largest for testing period and equal to $16.9 \%$.

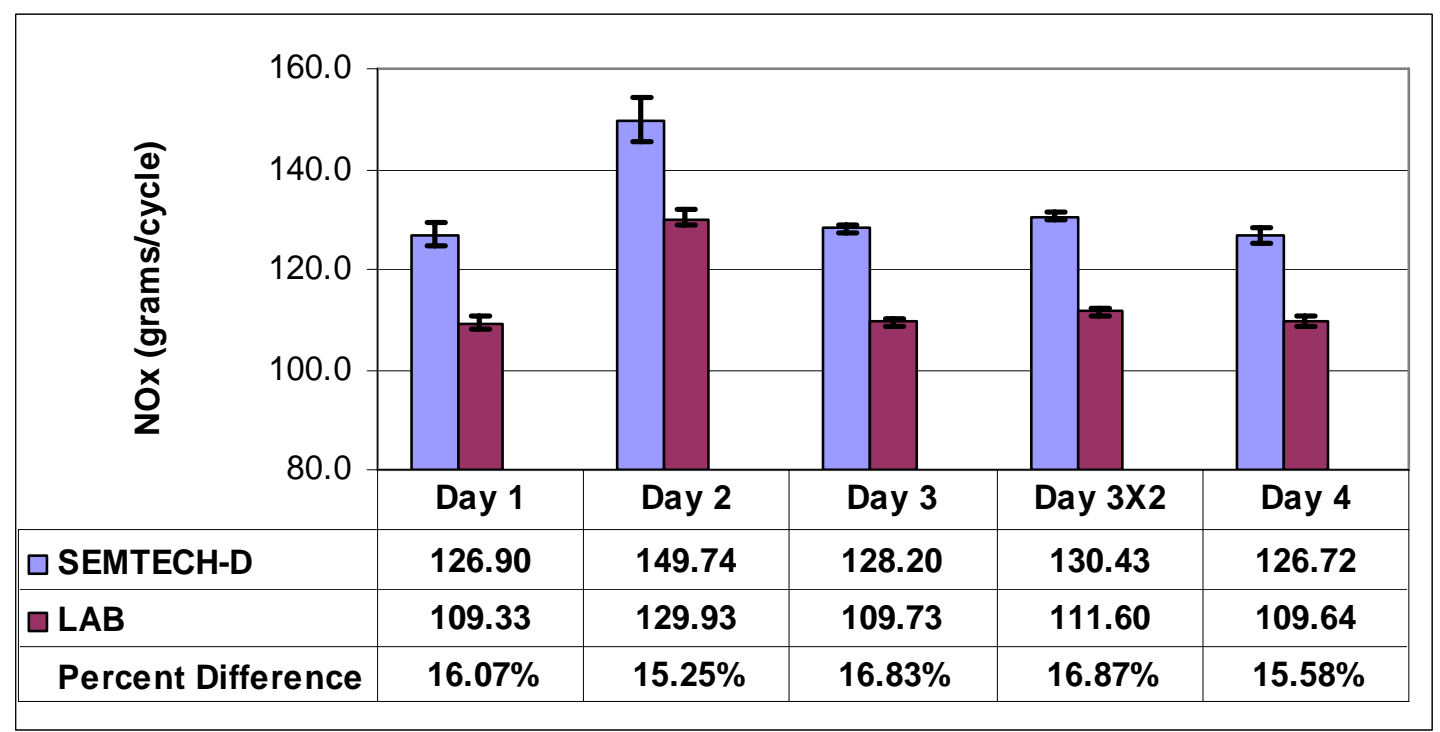

Figure 6.28 Average $\mathrm{NO}_{\mathrm{X}}$ mass emission totals. Error bars represent one standard deviation for each day of testing. Percent difference calculation made using Laboratory as standard.

\subsection{2 $\mathrm{CO}_{2}$ Mass Emission Flowrate}

Figure 6.29 contains averaged $\mathrm{CO}_{2}$ mass emitted totals for each day during Sequence II 2006. Again, Day 1and 2 are both comprised of six hot start FTP tests, while Day 3 and Day3X2 have three tests and Day 4 has four tests. SEMTECH-D totals are clearly higher for each test day. 


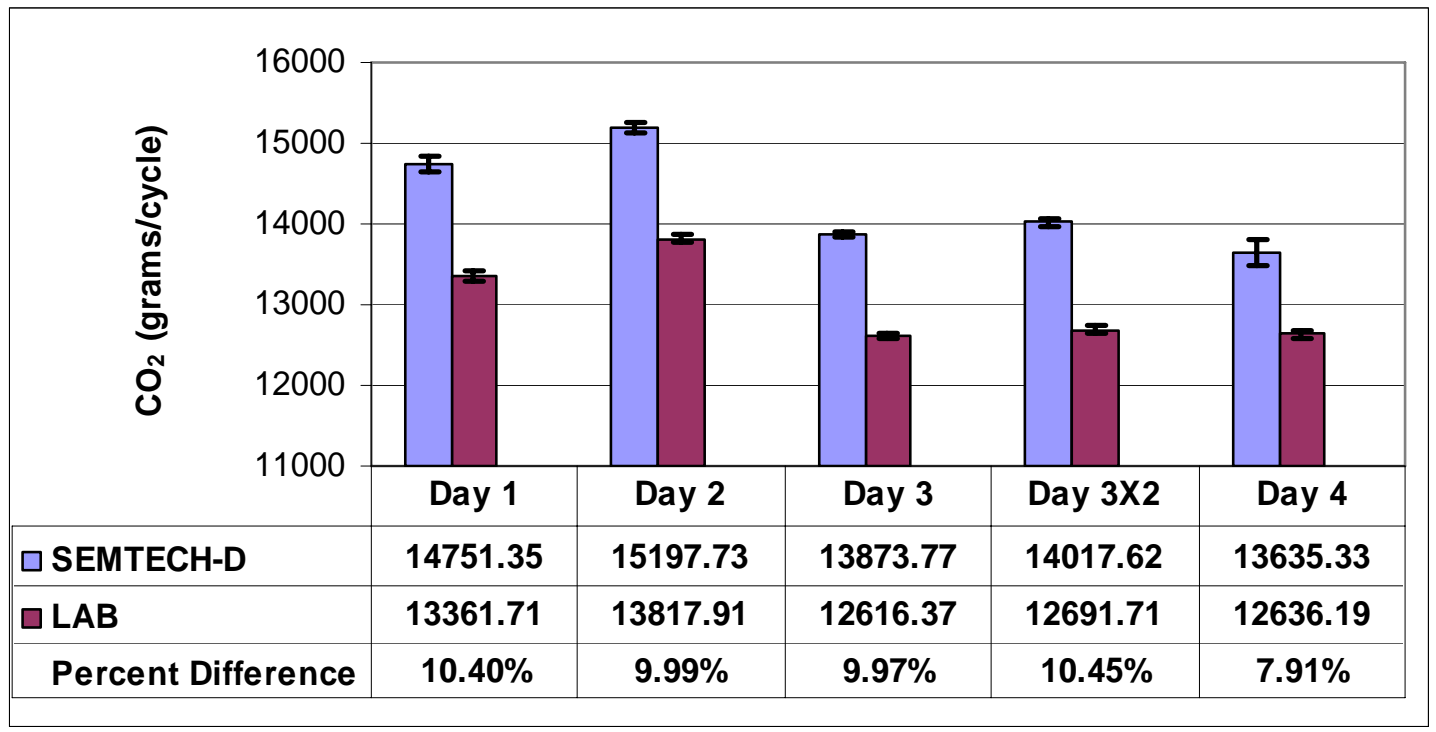

Figure 6.29 Average $\mathrm{CO}_{2}$ mass emission totals. Error bars represent one standard deviation for each day of testing. Percent difference calculations made using Laboratory as reference.

\subsubsection{CO Mass Emission Flowrate}

Figure 6.30 contains average CO totals for each day during Sequence II 2006 testing. Due to calibration errors, Day 1 values are invalid for the laboratory. As one can see from the plot, the SEMTECH is consistently $20 \%$ higher than the laboratory.

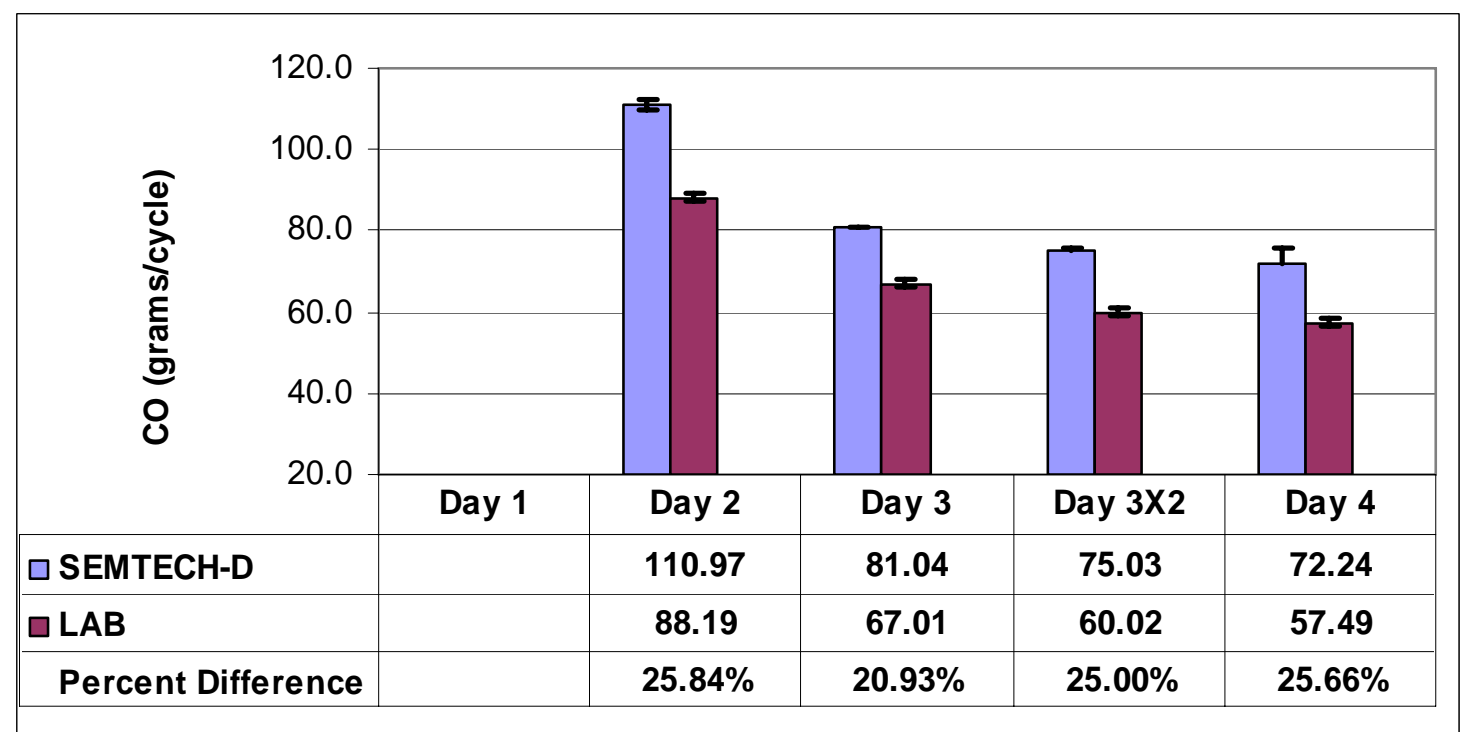

Figure 6.30 Average CO mass emission totals. Error bars represent one standard deviation for each day of testing. Percent difference calculations made using Laboratory as reference. 


\subsubsection{HC Mass Emission Flowrate}

Figure 6.31 includes the average $\mathrm{HC}$ totals for the various days of testing along with error bars. Fuels used for individual days were not documented to explain the variations dayto-day of the laboratory.

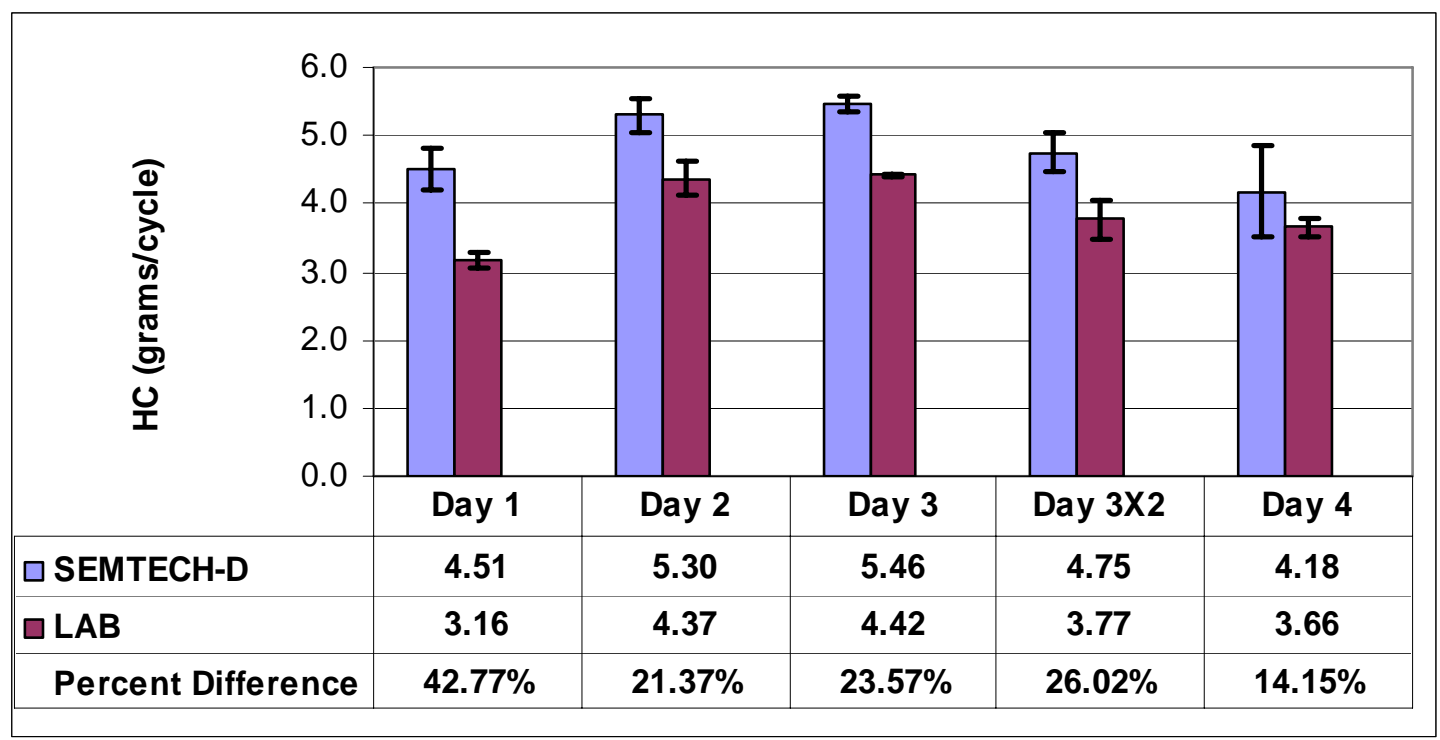

Figure 6.31 Average HC mass emission totals. Error bars represent one standard deviation for each day of testing. Percent difference calculations made using laboratory as reference.

\subsubsection{Exhaust Volumetric Flowrate}

Figure 6.32 represents the exhaust flowrate data for Sequence I 2006 testing. As mentioned before, the laboratory flowrate is a calculated value from intake air and fueling. 


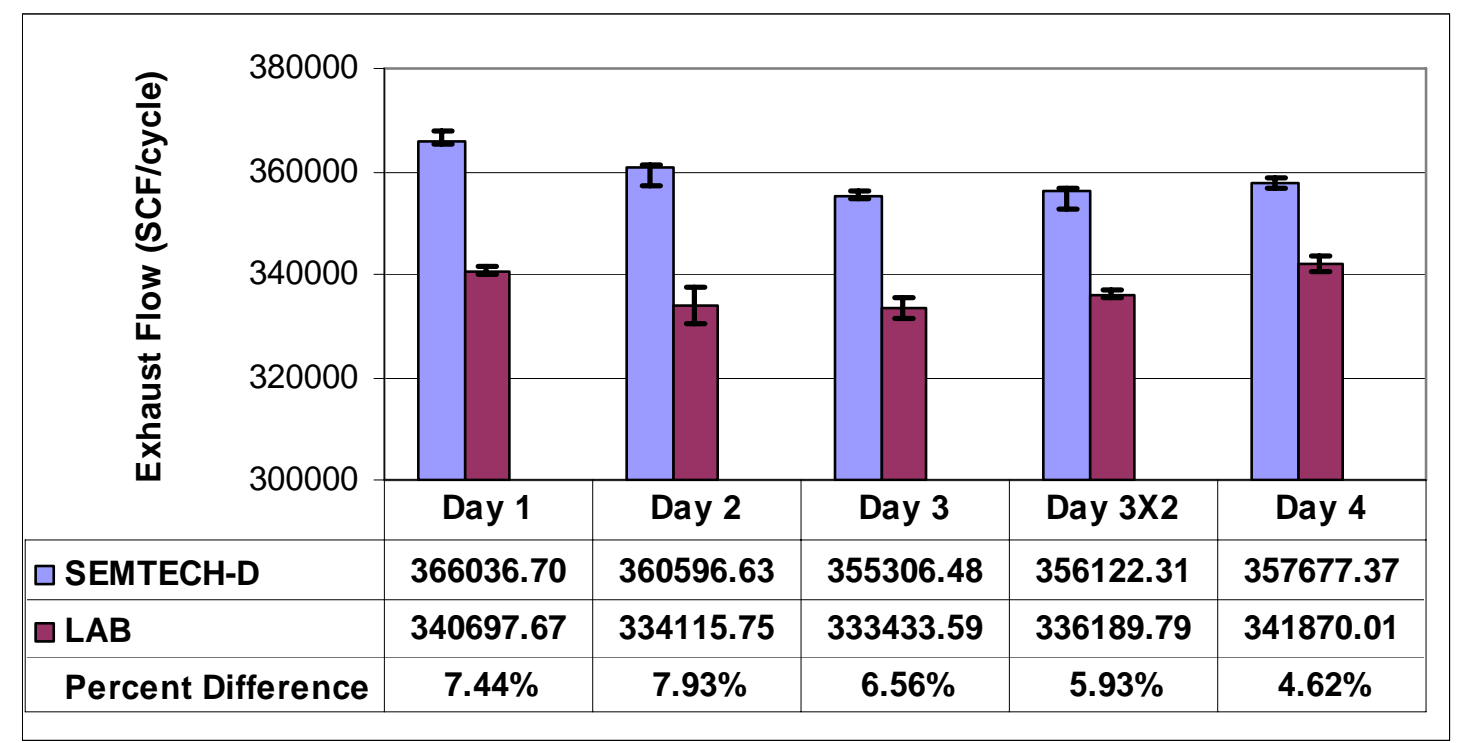

Figure 6.32 Average exhaust volumetric flowrate totals. Error bars represent one standard deviation for each day of testing. Percent difference calculations made using Laboratory as reference.

\subsection{Sequence III 2006}

The testing conducted during May 2006 provides WVU EERL and SEMTECH-D data. Mass emission comparisons match what has previously been reported, and the following provides a good overview of what was observed. Table 9.3 in APPENDIX A compiles all measured gas constituents and exhaust flowrate measurement percent differences for SEMTECH-D.

\subsubsection{NOx Mass Emission Flowrate}

This test showed typical erroneous results that came from FTP test E01118_01. One can observe that SEMTECH-D matches well at lower flowrates $(<0.12 \mathrm{~g} / \mathrm{s})$, and strays at higher flowrates $(>0.12 \mathrm{~g} / \mathrm{s})$, see Figure 6.33. This fact is quite apparent when examining the integrated error. At mass emission flowrates below $0.12 \mathrm{~g} / \mathrm{s}$ the average difference of the SEMTECH-D to the laboratory analyzers is $\sim 4 \%$. On the other hand, at mass emission rates greater than $0.12 \mathrm{~g} / \mathrm{s}$ the average difference is $\sim 21 \%$. These differences can be explained once the exhaust flowrate plot is viewed, see Figure 6.34. In this plot the exact opposite occurs, the SEMTECH-D under estimates the flowrate at steady state operation, and correlates well during transient events. 


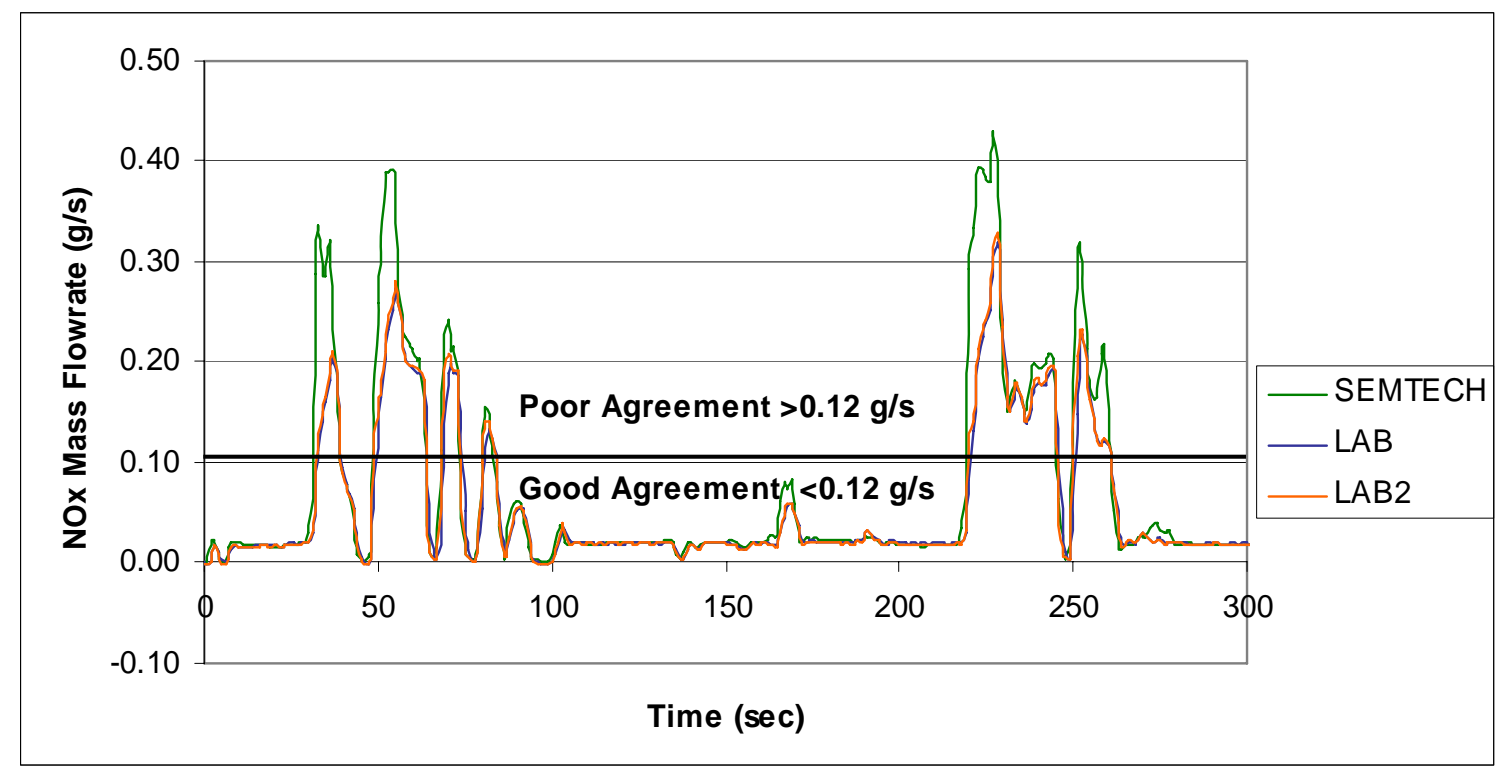

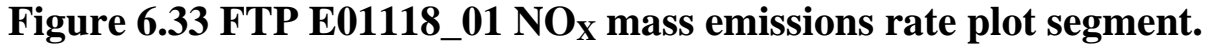

Further, Figure 6.33 shows the phenomenon of the SEMTECH $\mathrm{NO}_{\mathrm{X}}$ mass emission flowrate straying by nearly $25 \%$ higher than the laboratory analyzers during highly transient events. In Figure 6.34 the SEMTECH-D is nearly 50\% under measuring the exhaust flowrate, compared to the laboratory, during idle conditions and correlates well during transient events. For the complete test, the SEMTECH-D total exhaust volume is $1 \%$ higher than the laboratory. 


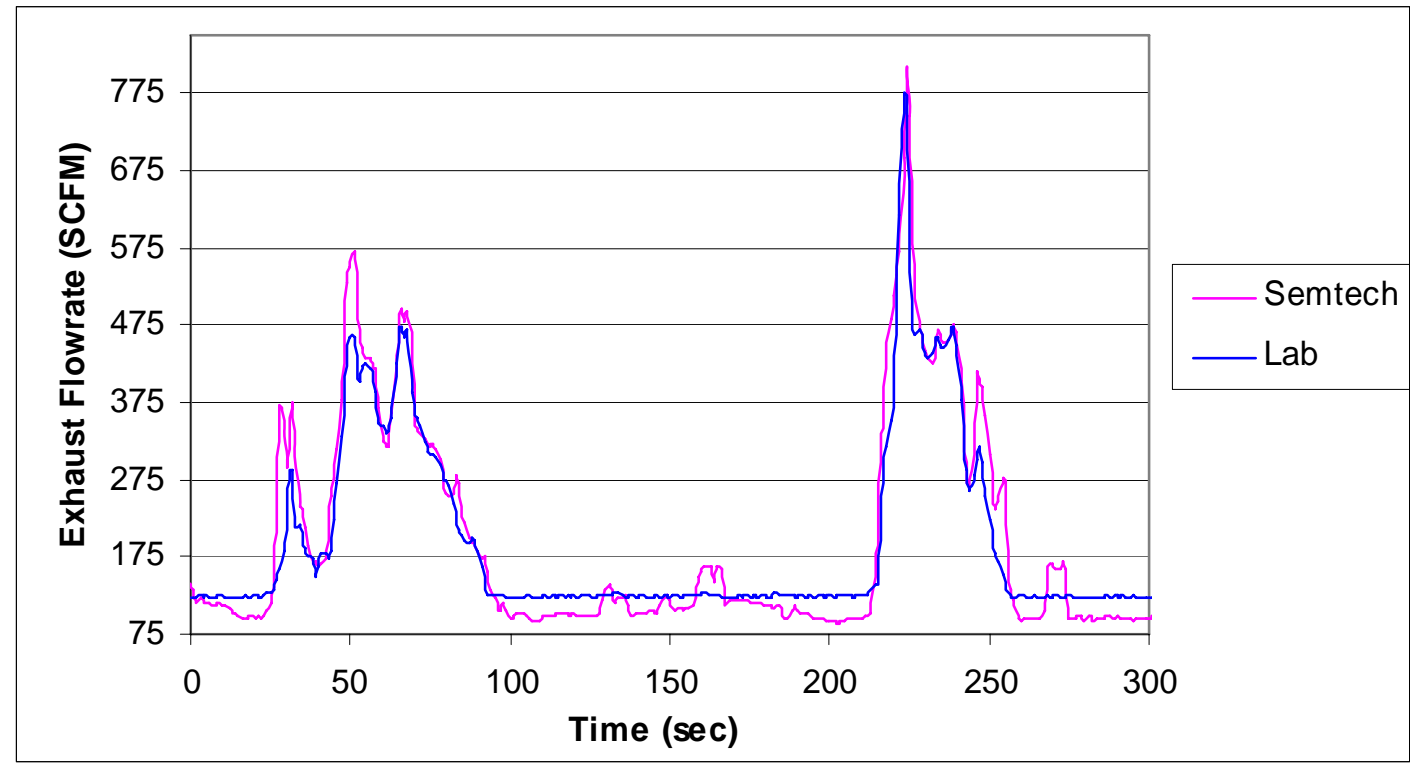

Figure 6.34 Segment of Exhaust Flowrate for FTP E01118_01.

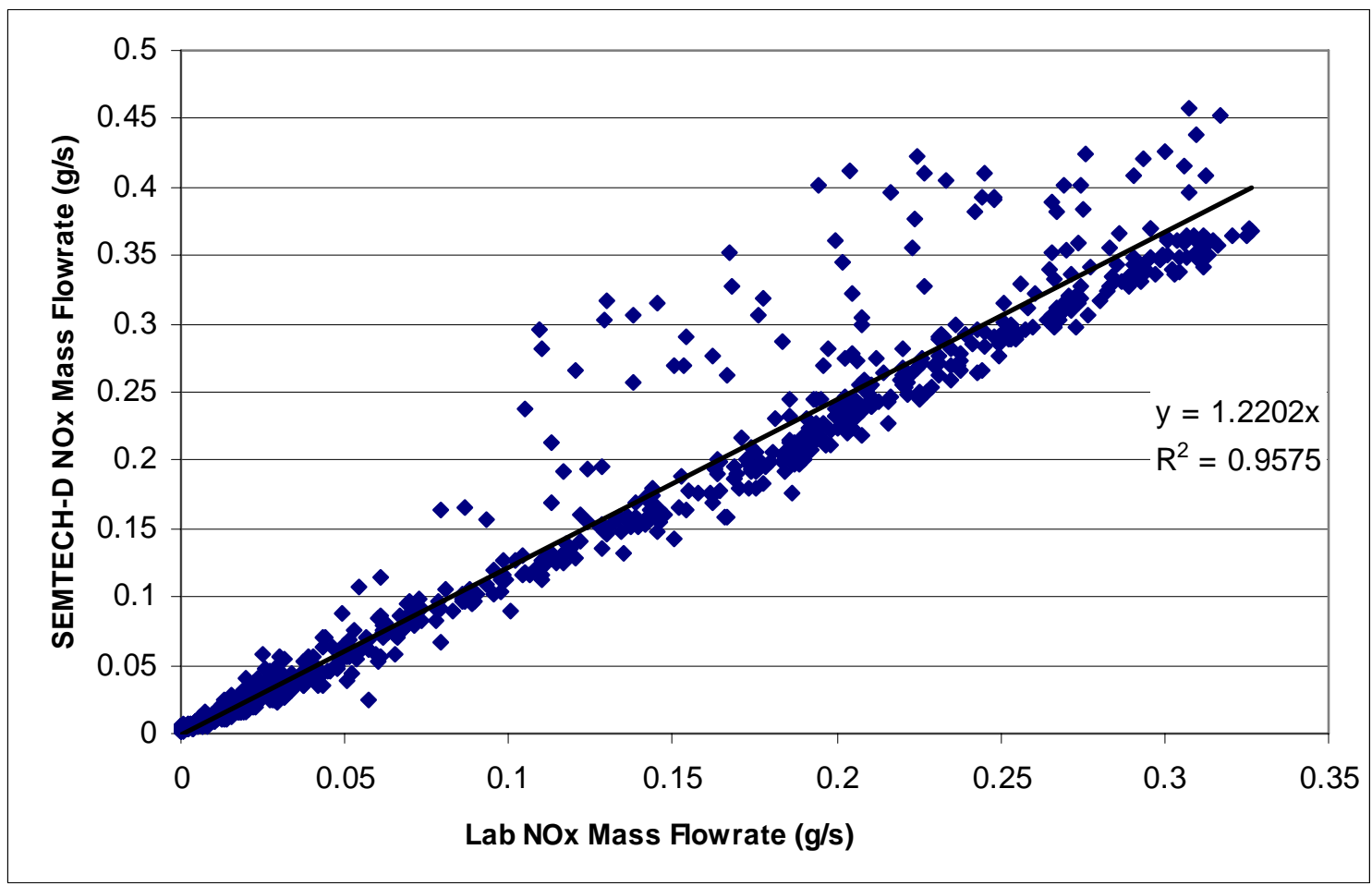

Figure 6.35 System agreement for FTP Sequence $\mathrm{E} 01118 \mathrm{NO}_{\mathrm{X}}$ mass emissions rate.

Two complete sets (three consecutive hot starts) of FTP tests were averaged and the statistics are included in Figure 6.36. The differences seen for the two test sequences collected were $22.4 \%$ higher and $19.2 \%$ higher than the laboratory. 


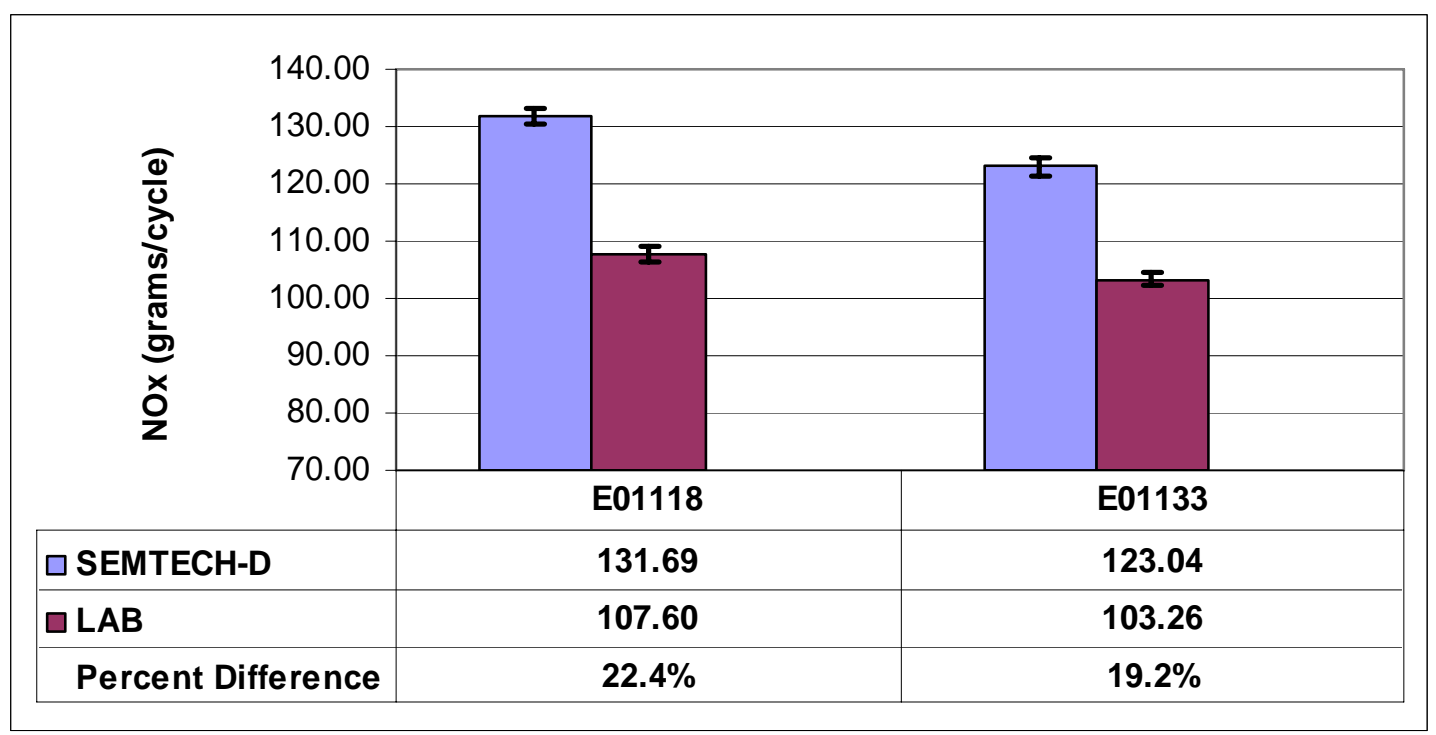

Figure 6.36 Average NOx mass emission totals. Error bars represent one standard deviation for each day of testing. Percent difference calculations made using Laboratory as reference.

As mentioned in the Section 5, there are several ways to calculate the mass emission rates. The SEMTECH-D allows the user to choose either the exhaust flowrate or the fuel flowrate method. For FTP E01118_01, both methods were used and compared to the laboratory, as seen in Figure 6.37. The difference compared to the laboratory for the fuel flowrate method was $21.3 \%$ and $19.3 \%$ different from each $\mathrm{NO}_{\mathrm{X}}$ laboratory analyzers (LAB and LAB2). In comparison, the exhaust flowrate method yielded differences of $19.6 \%$ and $17.6 \%$, respectively. 


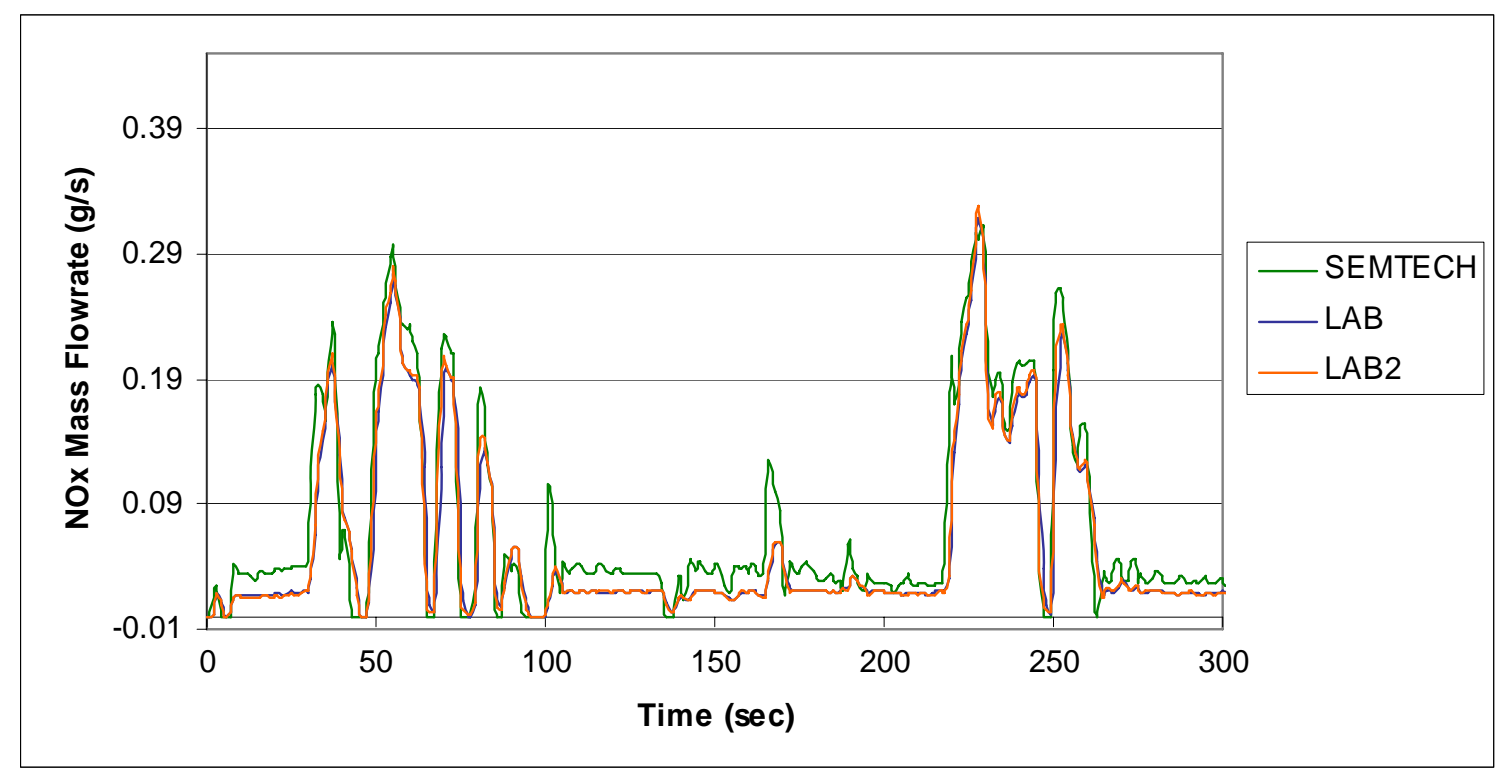

Figure 6.37 Segment of E01118_01 NOx plot with SEMTECH mass emissions calculated using ECU fuel flowrate. Complete test shown in Appendix A Figure 9.8. The same 300 seconds of the FTP cycle that was examined in Figure 6.33 is seen in Figure 6.37. In Figure 6.37 SEMTECH behaves well during the transient events (that is, between $0-100$ seconds), yet settles nearly 50\% higher than the laboratory during steadier portions of the cycle (that is, 100-200 seconds). This behavior could possibly be explained by the difference in characteristics of the test fuel and the fuel used by the manufacturer to generate the engine maps for the ECU.

\subsection{2 $\mathrm{CO}_{2}$ Mass Emission Flowrate}

Figure 6.38 shows carbon dioxide traces from a typical test. For the FTP presented, the SEMTECH-D over predicted by $14 \%$, when compared to the laboratory. It appears that the majority of the error is contributed by the higher mass emission rate portions of the cycles $(>30 \mathrm{~g} / \mathrm{s})$. It should be noted that this is also the region where SEMTECH-D NOX readings deviated by nearly 50\% from laboratory readings (Section 6.5.1). 


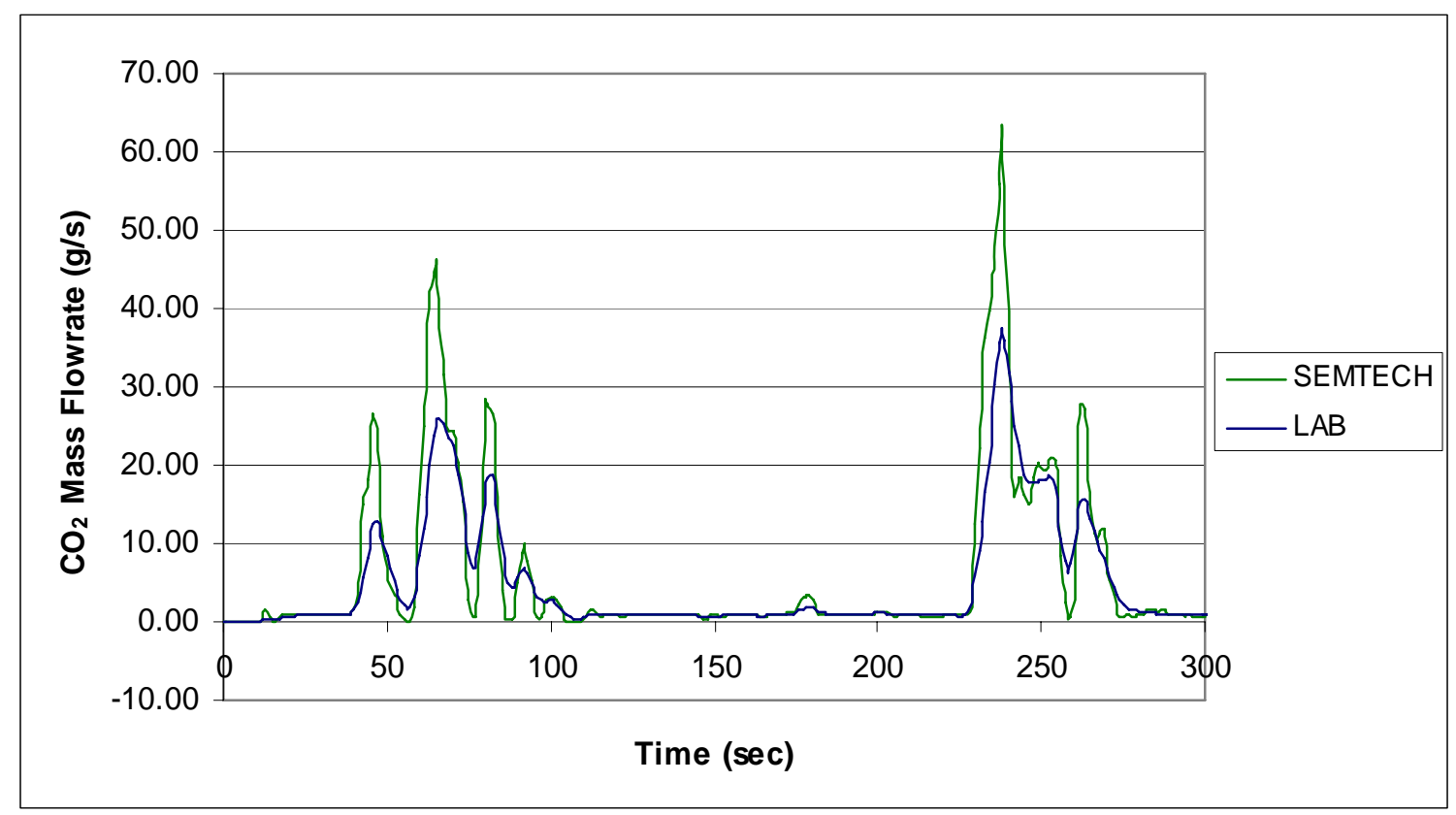

Figure 6.38 Segment of FTP E01118_01 $\mathrm{CO}_{2}$ mass emission plot. Complete plot shown in APPENDIX A Figure 9.9.

Data (grams/cycle) for $\mathrm{CO}_{2}$ are shown in Figure 6.39. For both sets of three hot starts, SEMTECH-D reported $15 \%$ higher $\mathrm{CO}_{2}$ mass emitted than the laboratory.

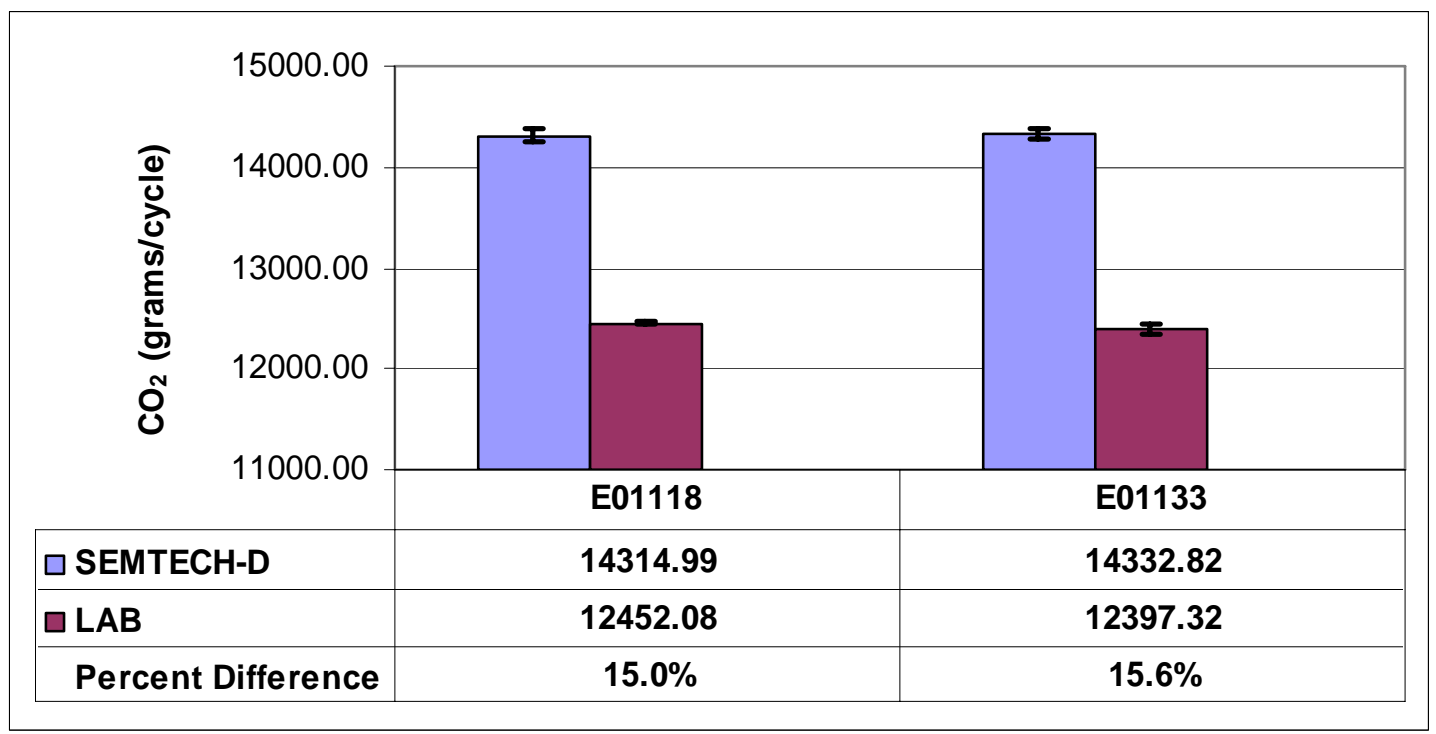

Figure 6.39 Average $\mathrm{CO}_{2}$ mass emission totals. Error bars represent one standard deviation for each day of testing. Percent difference calculations made using Laboratory as reference. 
The averaged values from the three E01118 hot starts are plotted against the corresponding averaged laboratory values in Figure 6.40 to show system agreement. The plot shows a high bias associated with the SEMTECH-D results.

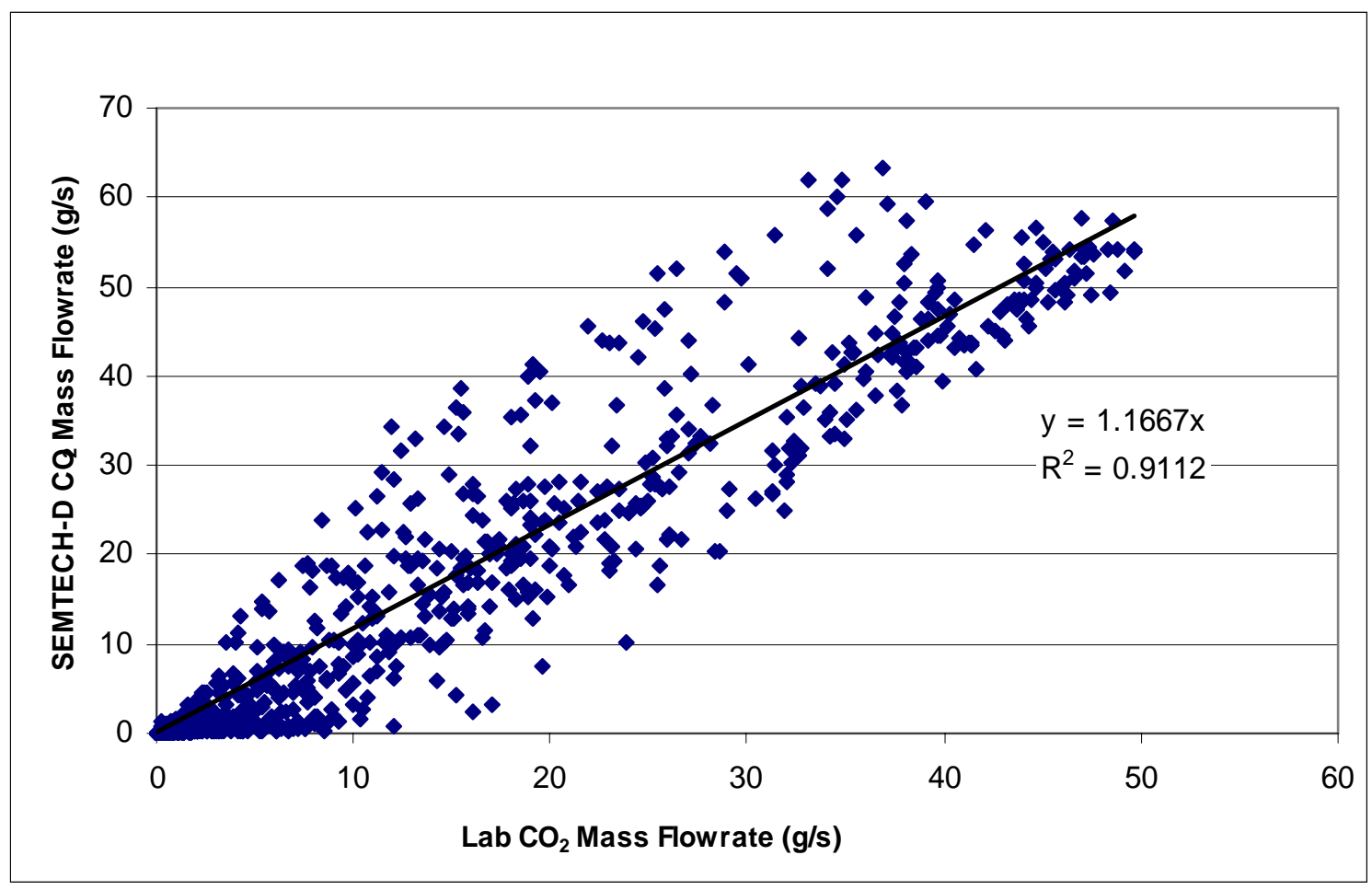

Figure 6.40 System agreement for FTP Sequence E01118 $\mathrm{CO}_{2}$ mass emissions rate.

\subsubsection{CO Mass Emission Flowrate}

A segment of FTP E01118_01 CO comparison plot is seen in Figure 6.41. Once again, SEMTECH-D reported twice the flowrate as measured by the laboratory at the peaks. 


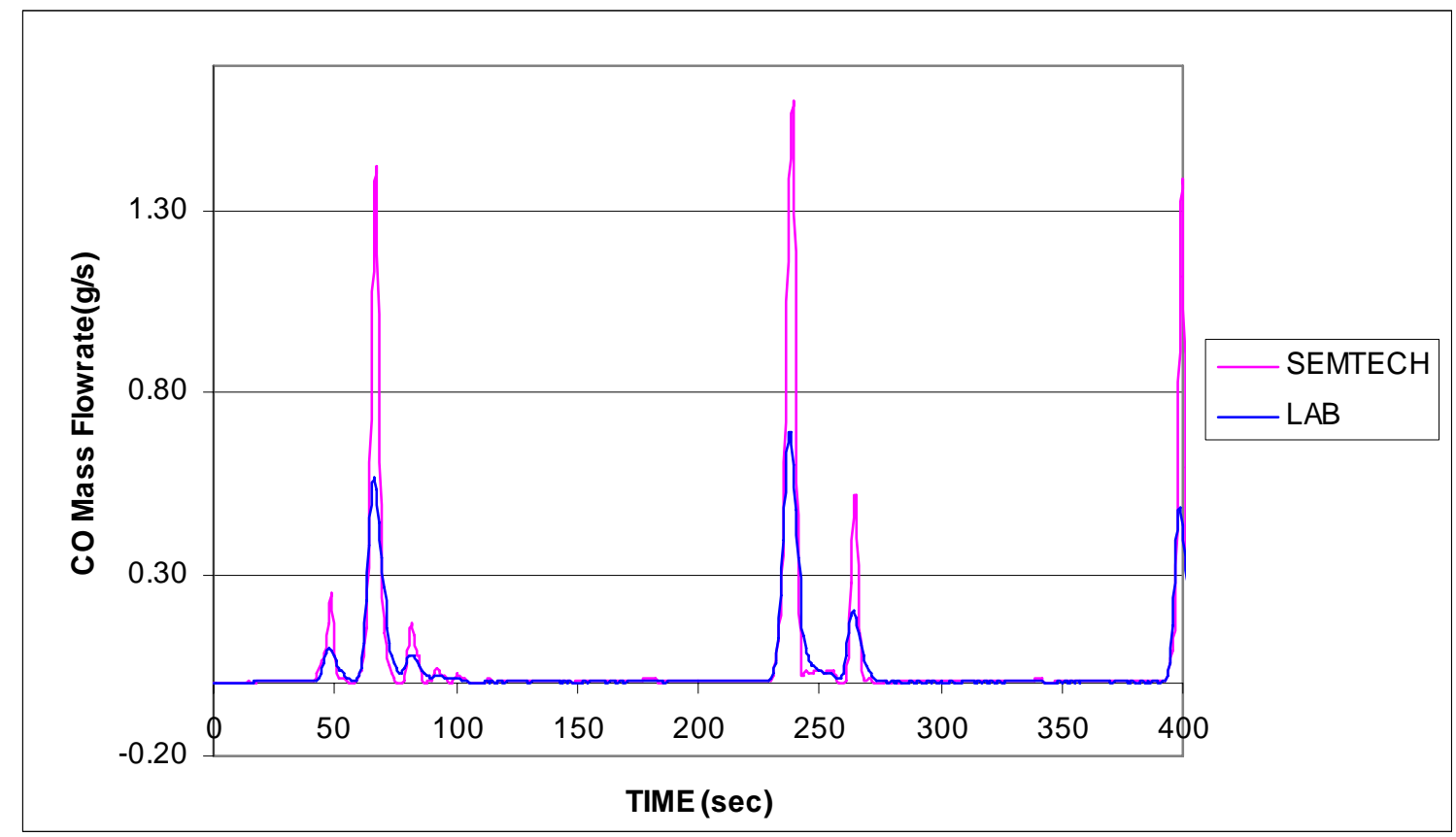

Figure 6.41 Segment of CO mass emission comparison for FTP E01118_01. Complete plot shown in Appendix A Figure 9.9.

Figure 6.42 contains sequence E01118 averaged laboratory CO mass emissions rate versus the SEMTECH-D output.

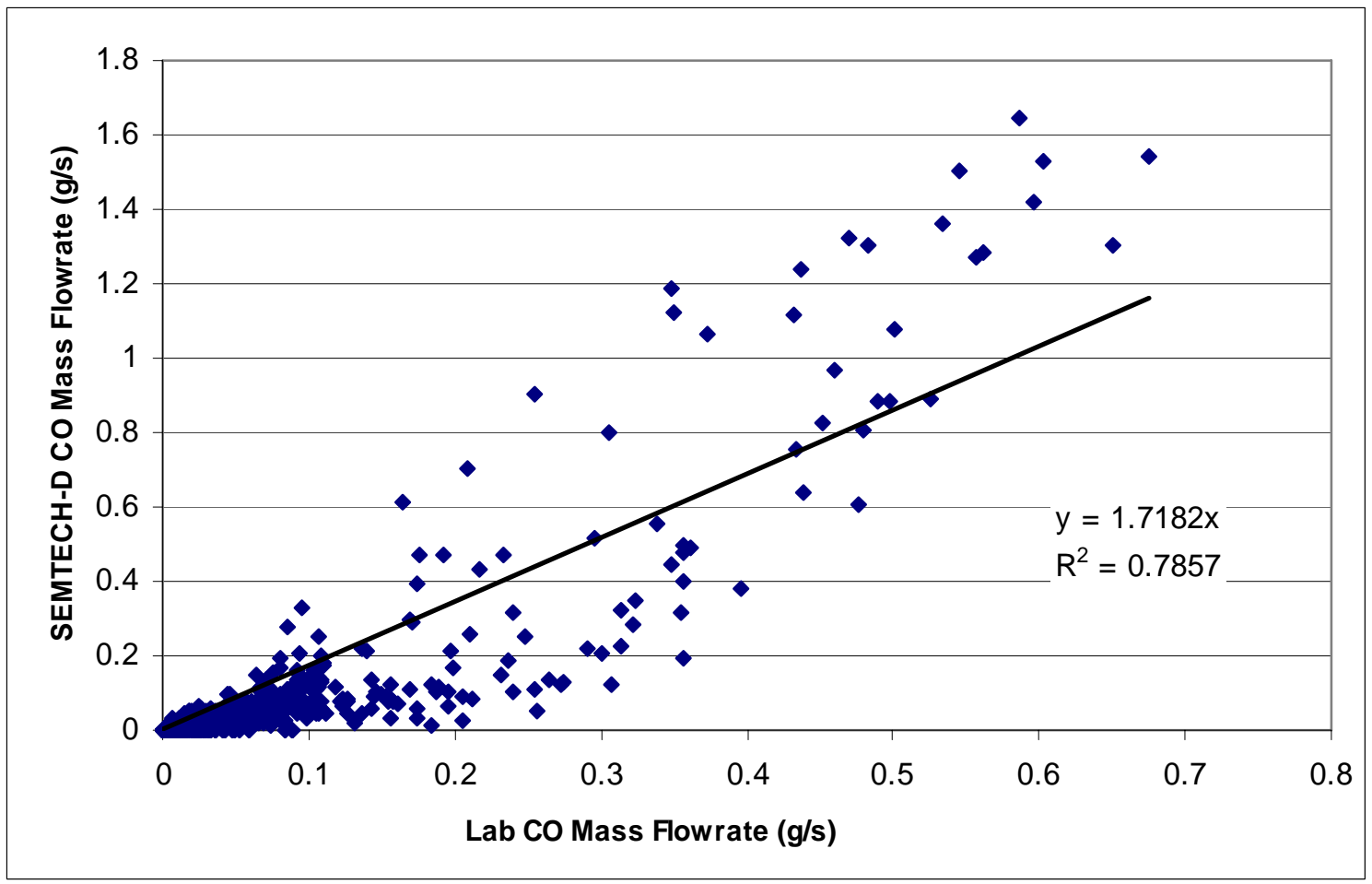

Figure 6.42 System agreement for FTP Sequence E01118 CO mass emissions rate. 
Figure 6.43 contains the statistics for both test sequences captured during Sequence II 2006. CO measurements were poor for both sequences and resulted in differences over $30 \%$.

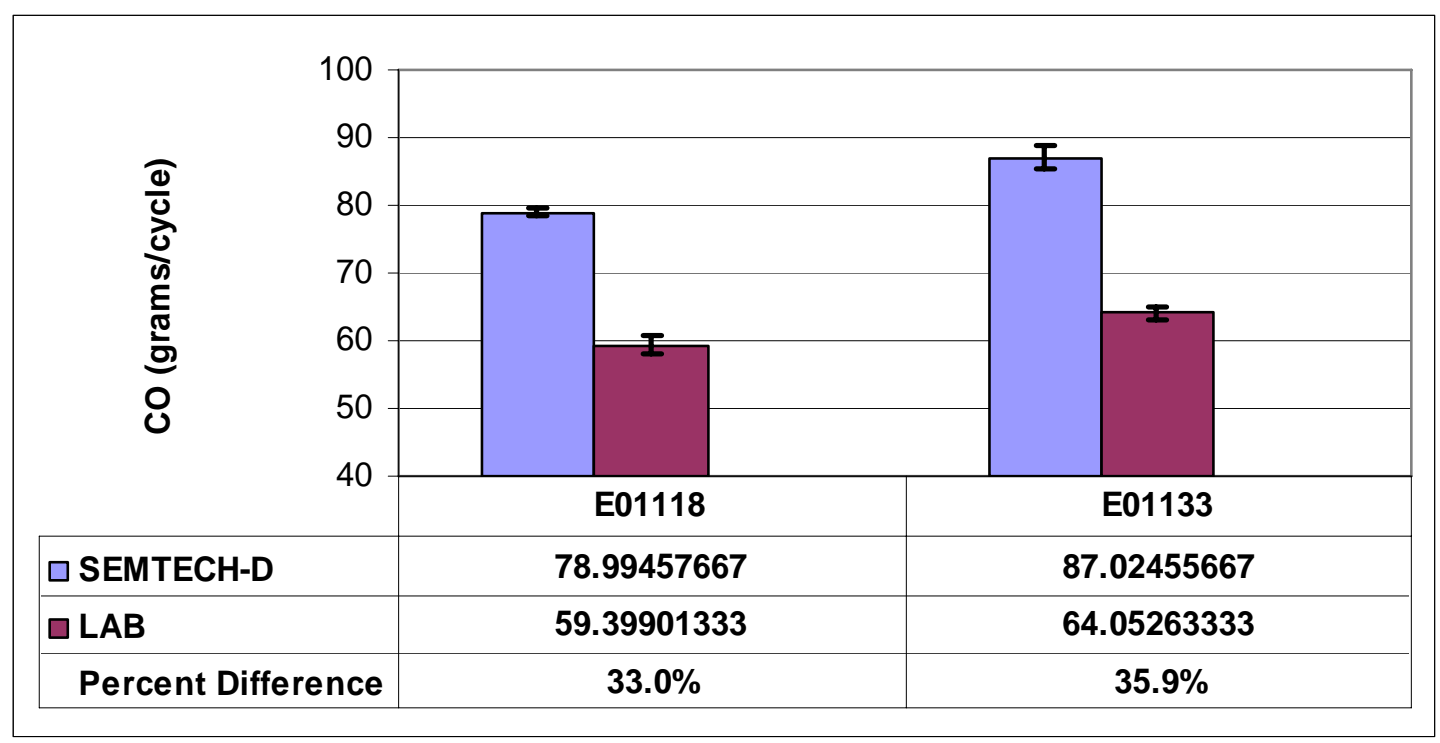

Figure 6.43 Average CO mass emission totals. Error bars represent one standard deviation for each day of testing. Percent difference calculations made using Laboratory as reference.

\subsubsection{HC Mass Emission Flowrate}

SEMTECH-D HC measurement was highly erroneous compared to the laboratory during this testing period and can be seen in Figure 6.44. 


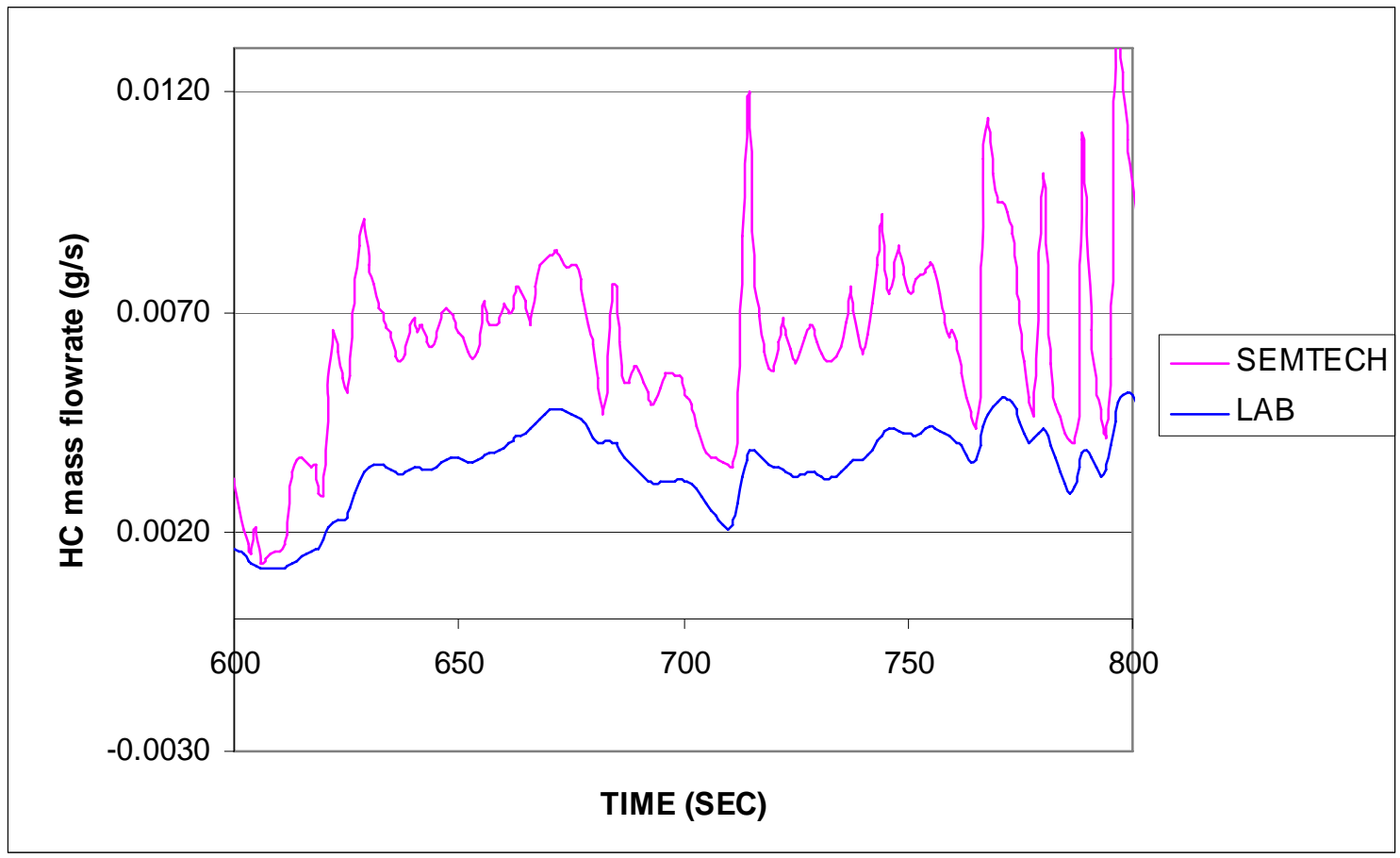

Figure 6.44 Segment of HC mass emission comparison for FTP E01118_01.

The laboratory HC mass flowrate versus SEMTECH-D HC mass flowrate plot produces a scattered plot seen in Figure 6.45. The $\mathrm{R}^{2}$ coefficient was 0.77 .

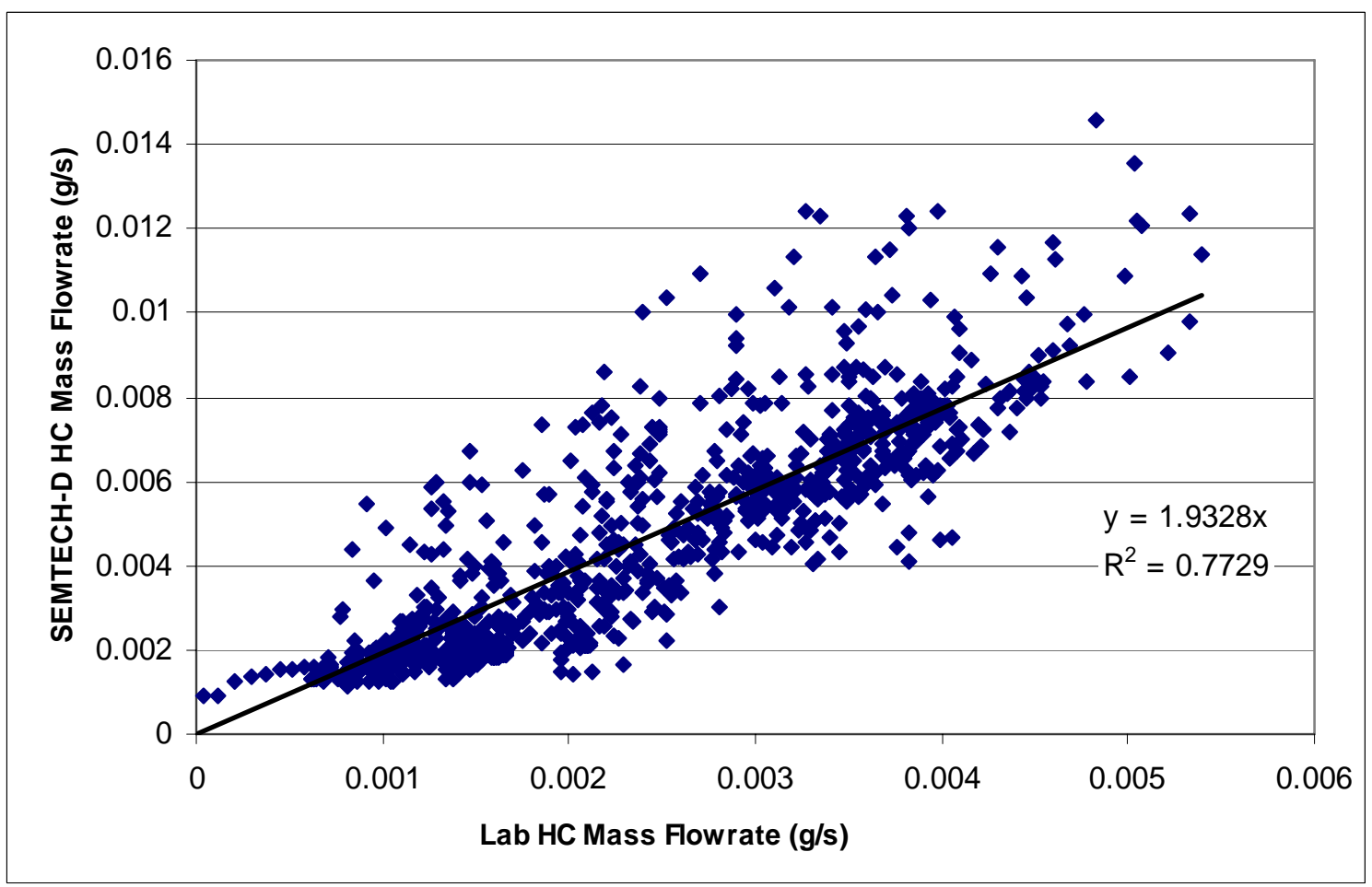

Figure 6.45 System agreement for FTP Sequence E01118 HC mass emissions rate. 
Sequence E01118 and E01133 both experienced very high errors.

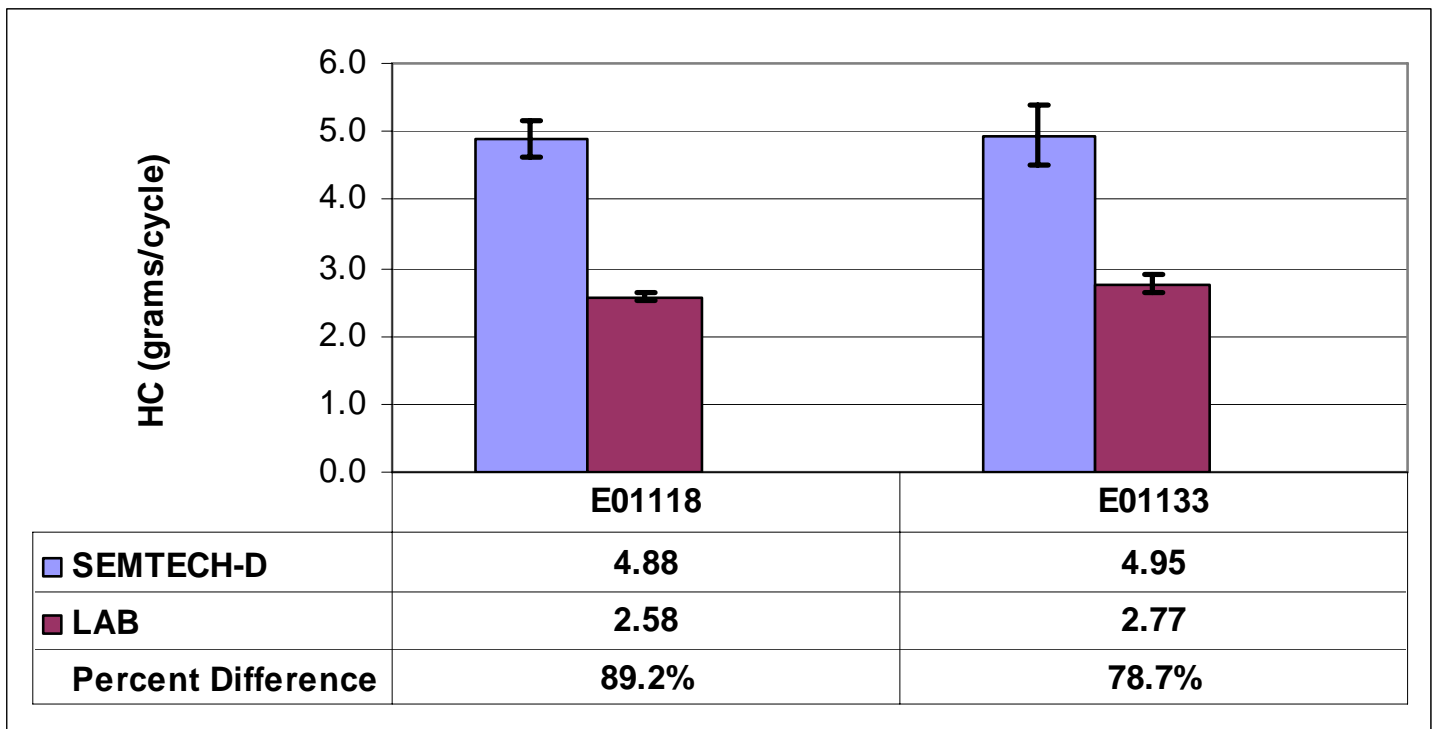

Figure 6.46 Average HC mass emission totals. Error bars represent one standard deviation for each day of testing. Percent difference calculations made using Laboratory as reference.

\subsubsection{Exhaust Flowrate}

The exhaust flowrate plot corresponding to the above mentioned test is shown below. SEMTECH-D aligns very well with the calculated flowrate from the laboratory. As a reminder, the laboratory exhaust flowrate was calculated using intake air and fuel consumed as reported by the laboratory flowmeter. 


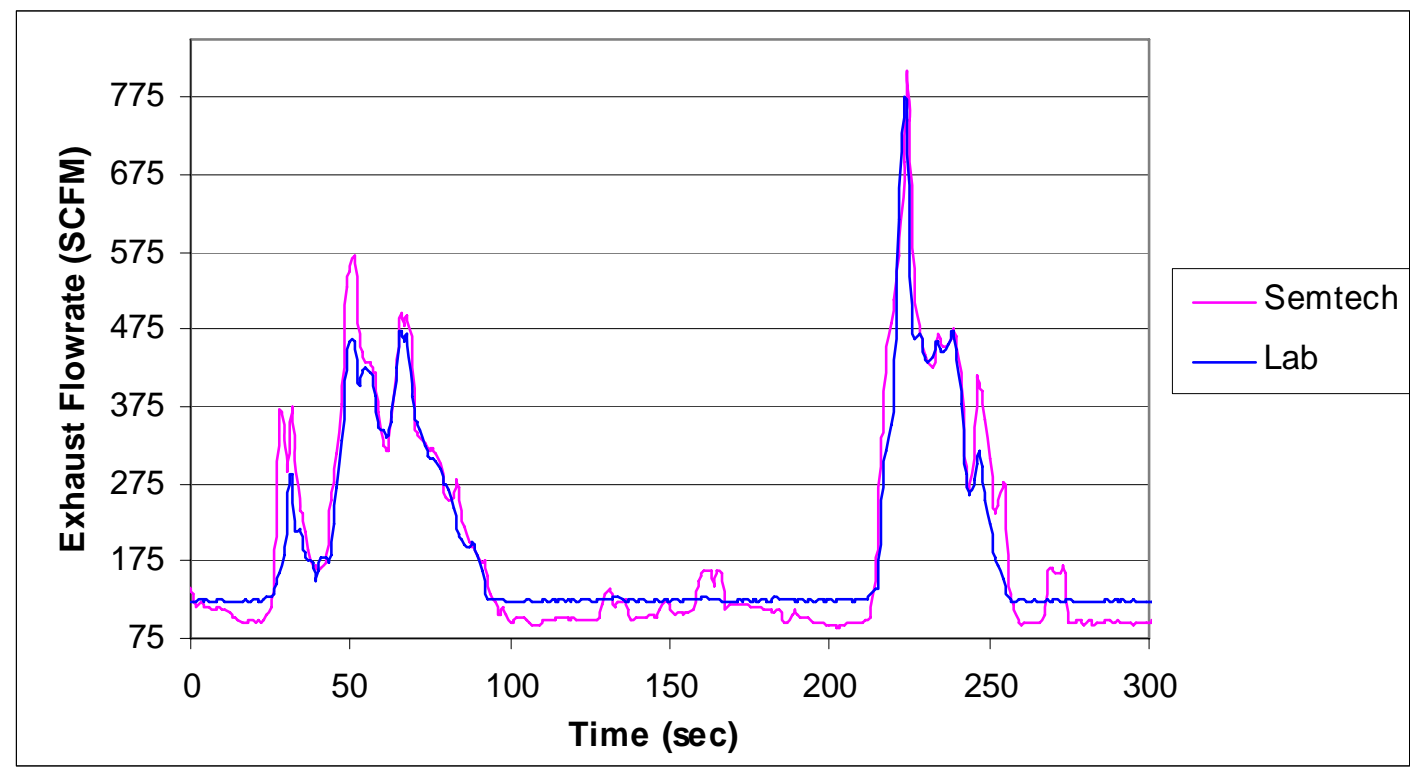

Figure 6.47 Segment of FTP E01118_01 exhaust flowrate plot. Complete trace shown in APPENDIX A Figure 9.13

Shown in Figure 6.48 is the average laboratory exhaust volumetric flowrate versus the SEMTECH-D EFM exhaust flowrate. The agreement between the two systems is quite good, having an $\mathrm{R}^{2}$ value equal to 0.98 .

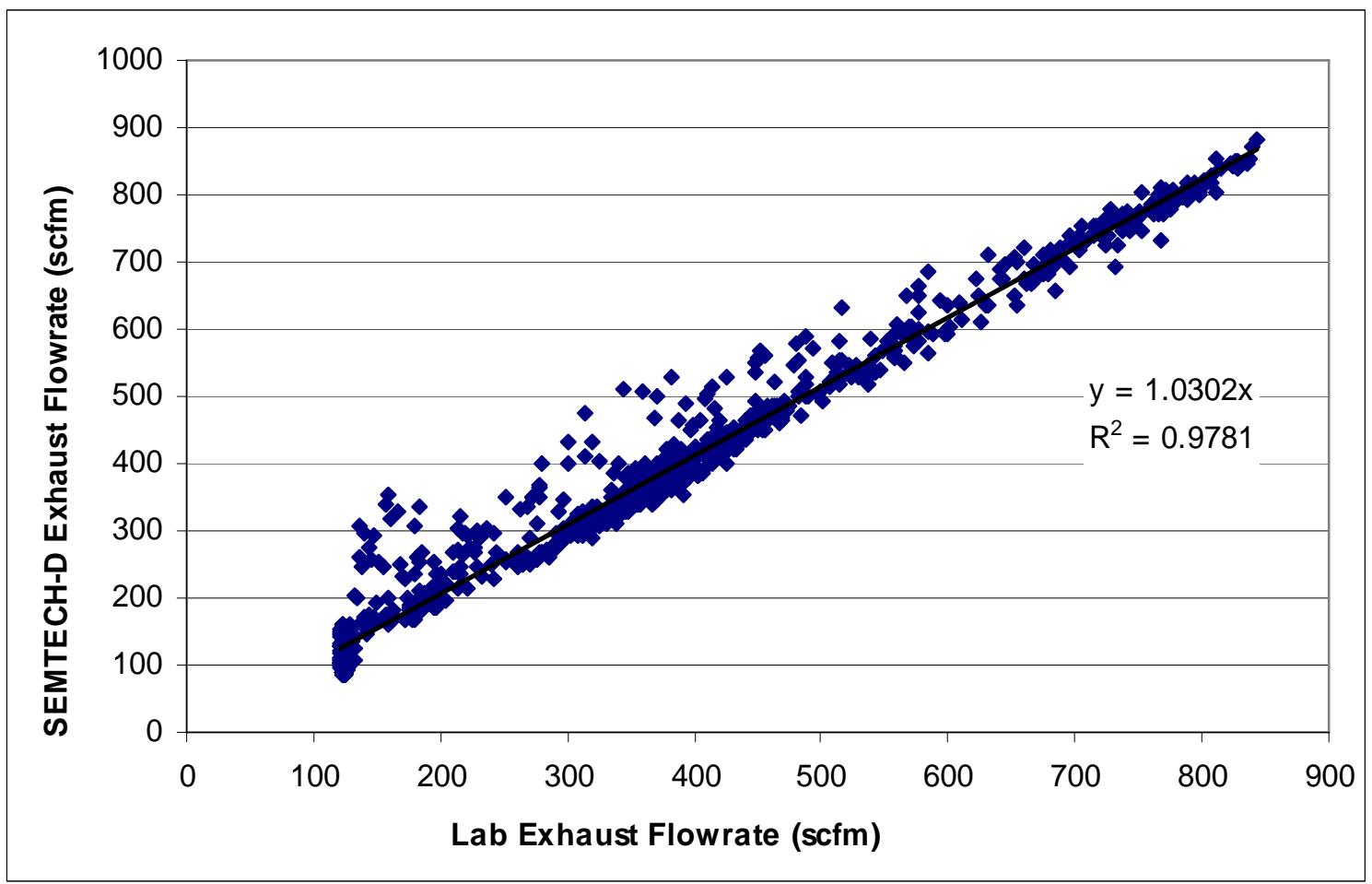

Figure 6.48 System agreement for FTP Sequence E01118 exhaust flowrate. 
Due to the nature of the calculation, the laboratory trace does not show the pulsating behavior of the exhaust as observed by the SEMTECH-D. This stems from the laboratory flowrate being determined with a laminar flow element at the engine intake, which is steadier than the actual exhaust. In this particular test, the SEMTECH-D is $1.0 \%$ higher then the laboratory in an integrated comparison. Over the course of the three above mentioned FTP cycles, the SEMTECH-D averaged $2.1 \%$ difference from integrated laboratory values. This is significantly better than results of previous testing periods (Section 6.4.5), where errors when compared to the laboratory averaged 6-8\%. Figure 6.49 provides total volumes of exhaust reported by both systems.

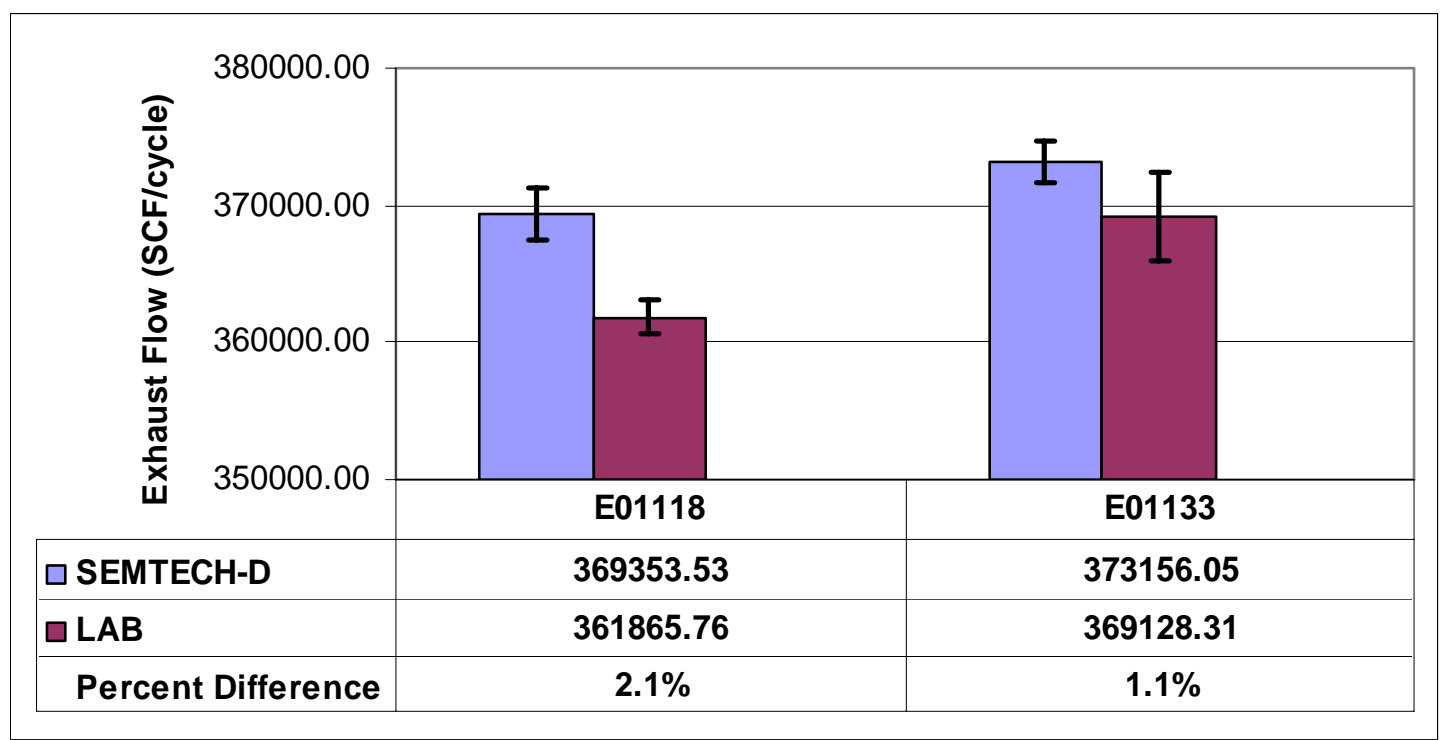

Figure 6.49 Average exhaust volumetric totals. Error bars represent one standard deviation for each day of testing. Percent difference calculations made using laboratory as reference. 


\subsection{Sequence IV 2006}

In early August, 2006 the SEMTECH-D and EFM were sent back to Sensors, Inc for a complete system check. The following note was received from the manufacturer upon receipt of the unit:

The coalescing filter (inside the clear bowl) was wet with raw diesel fuel. It was also found in the FID bypass line, and some of the in-line particulate filters. It is unusual to get raw fuel in the system during vehicle testing, but can occur during test cell work where the engine can be forced to operate outside normal conditions. It can also happen if there is post-injection that fails to ignite a particulate trap. Any idea how or when this may have occurred? Once raw fuel is in the sample system, it can damage the optical gas analyzers (it cannot be separated out of the sample like water). This may have caused damage to the NDUV optics in particular.

Also, some of the pressure ports in the averaging pitot tube were completely plugged with soot when the unit arrived, and this caused the initial audit to fail by $4 \%$ overall (high). We were able to blow the lines back out, and readings were then within spec. The lines should be backpurged after every test using the automated function on the control box. You just need to apply dry compressed air or N2 and press the button. Do you know how often the operators did this? Also on the EFM tube, some of the stainless pressure tubing was bent considerably, and about 6" of the the flexible pressure lines had been pulled through the bulkhead where they attach. We trimmed back the extra exposed line to prevent damage and installed new compression fittings.

Prior to the SEMTECH being shipped back to WVU in mid-August the following update was provided the manufacturer: 
The NDUV repairs were completed, and the SEMTECH has been fully tested and will ship back to you on Monday. The new EFM firmware with pulsation compensation is also complete and programmed into your EFM control box

On August 17, 2006, the SEMTECH-D was reinstalled into the EERL. Fuel certification testing was scheduled to begin the next day. A total of twelve FTP tests ( 3 warm and 9 hot) were conducted over the next two days.

\subsubsection{Test Setup/Procedure}

The test setup was the same as previously used in the engine laboratory. The flow tube was mounted in the exhaust tube before the sample reaches the dilution tunnel. The Sensors, Inc. specified SEMTECH setup procedure was followed including a leak check before the initial test, filters were changed, analyzers zeroed/spanned, and EFM purged. Two separate methods were used for calibrating the analyzers. For the E01357 test sequence, zero and span gases were fed into the front of the unit through the zero and span ports. For the following two test sequences, the calibration was performed using a flooded probe. The calibration gases were fed into a tee joint that was connected to a two-way valve. The pressurized gas escaped the tee to ambient conditions, while the heated line drew in a necessary sample.

Following the testing, a check was performed to verify the concentration of the calibration gases. After the system was calibrated, an 'audit' was performed on the NDUV analyzer. Two different gas bottles of different concentrations were independently fed through the heated line. The span gases used for this testing were $1728 \mathrm{ppm} \mathrm{NO}$, and 256ppm $\mathrm{NO}_{2}$, while the audit gases were 503.9ppm $\mathrm{NO}_{\mathrm{X}}$ and 994.9ppm $\mathrm{NO}_{\mathrm{X}}$. The following test was performed: 
Table 6.5 Audit Test

\begin{tabular}{|l|l|}
\hline Time $(\mathrm{sec})$ & Test Gas $(\mathrm{ppm})$ \\
\hline 60 & Ambient \\
\hline 60 & $994.9 \mathrm{NO}_{\mathrm{X}}$ \\
\hline 60 & Ambient \\
\hline 60 & $503.9 \mathrm{NO}_{\mathrm{X}}$ \\
\hline 30 & Ambient \\
\hline 30 & $994.9 \mathrm{NO}_{\mathrm{X}}$ \\
\hline 30 & Ambient \\
\hline 30 & $503.9 \mathrm{NO}_{\mathrm{X}}$ \\
\hline 30 & Ambient \\
\hline 30 & $1728 \mathrm{NO}$ \\
\hline 30 & Ambient \\
\hline 30 & $256 \mathrm{NO}_{2}$ \\
\hline$\sim 8$ & Ambient \\
\hline
\end{tabular}

Results from the audit test are shown in Figure 6.50. It is evident that the SEMTECH-D performed very well.

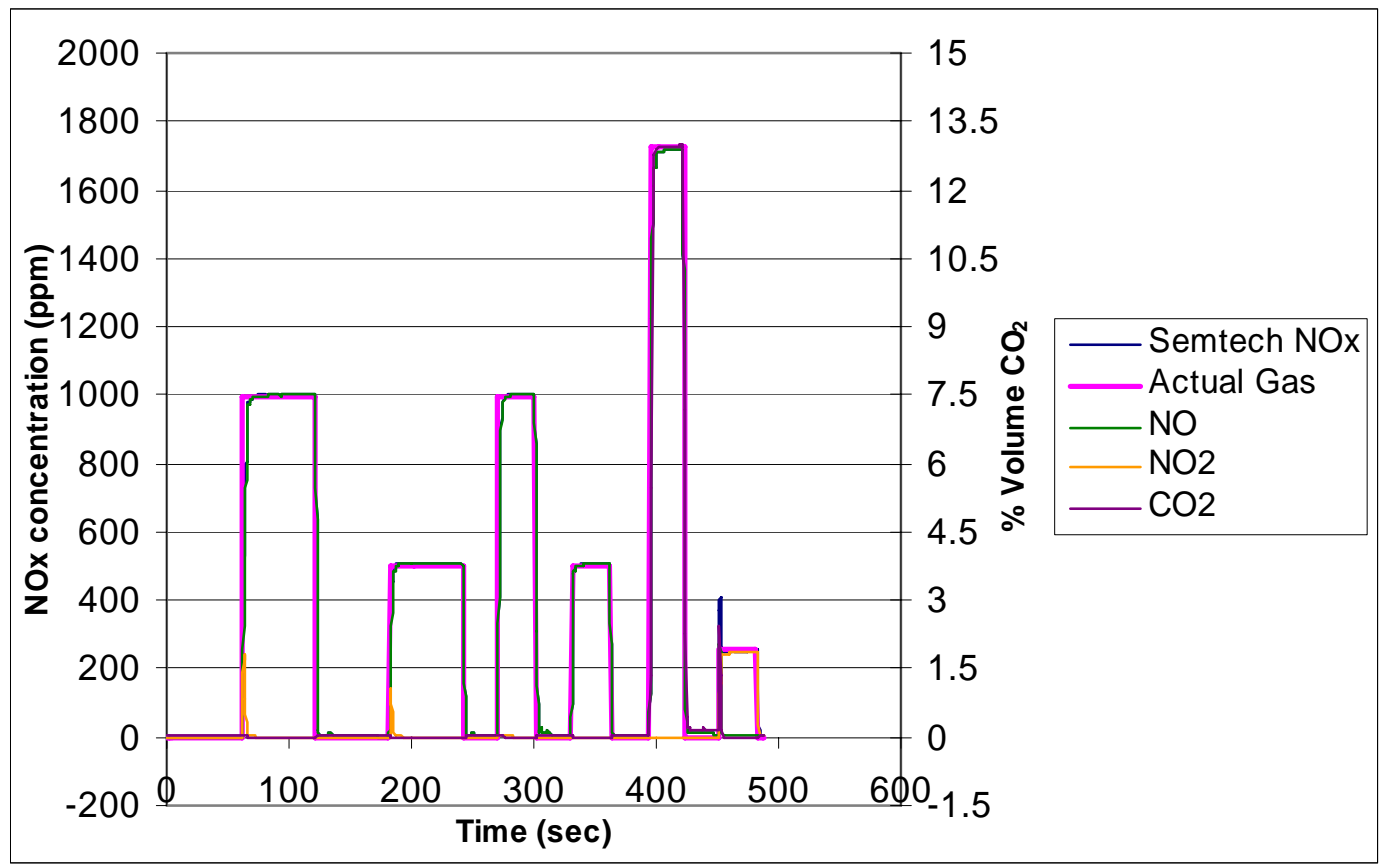

Figure 6.50 Calibration Verification Test 


\subsubsection{Results}

Table 6.6 provides percent differences for all gas constituents, and the exhaust flowrate for all FTP tests which were conducted in Sequence IV 2006. Results from this series of tests are very similar to data generated in Sequences II and III. Complete plots are available in APPENDIX A. Table 6.6 combines all gaseous and exhaust flowrate data from Sequence IV.

Table 6.6 Sequence IV 2006 Percent Differences Compared to Laboratory.

\begin{tabular}{|c|c|c|c|c|c|c|}
\hline & NOx1 & NOx2 & $\mathrm{CO}_{2}$ & CO & HC & Ex. Flowrate \\
\hline Test Number & (grams) & (grams) & (grams) & (grams) & (grams) & (SCF) \\
\hline 8/18/06 E01357_02 & $17.2 \%$ & $18.7 \%$ & $11.6 \%$ & $29.9 \%$ & $58.6 \%$ & $4.2 \%$ \\
\hline E01357 03 & $17.3 \%$ & $17.4 \%$ & $11.6 \%$ & $30.1 \%$ & $78.3 \%$ & $4.9 \%$ \\
\hline E01357_04 & $18.2 \%$ & $19.3 \%$ & $12.2 \%$ & $31.2 \%$ & $61.5 \%$ & $4.6 \%$ \\
\hline Average & $17.6 \%$ & $18.5 \%$ & $11.8 \%$ & $30.4 \%$ & $66.1 \%$ & $5.2 \%$ \\
\hline E01361_02 & $16.1 \%$ & $17.4 \%$ & $12.7 \%$ & $29.2 \%$ & $42.2 \%$ & $5.5 \%$ \\
\hline E01361_03 & $17.2 \%$ & $18.2 \%$ & $13.0 \%$ & $28.4 \%$ & $73.1 \%$ & $5.6 \%$ \\
\hline E01361_04 & $18.9 \%$ & $19.9 \%$ & $12.7 \%$ & $29.7 \%$ & $45.3 \%$ & $5.6 \%$ \\
\hline Average & $17.4 \%$ & $18.5 \%$ & $12.8 \%$ & $29.1 \%$ & $53.5 \%$ & $6.2 \%$ \\
\hline 8/19/06 E01368_02 & $17.6 \%$ & $19.3 \%$ & $12.8 \%$ & $25.2 \%$ & $44.2 \%$ & $5.6 \%$ \\
\hline E01368_03 & $18.7 \%$ & $20.2 \%$ & $12.8 \%$ & $27.0 \%$ & $19.4 \%$ & $5.7 \%$ \\
\hline E01368_04 & $17.1 \%$ & $18.4 \%$ & $12.1 \%$ & $26.1 \%$ & $40.0 \%$ & $3.7 \%$ \\
\hline Average & $17.8 \%$ & $19.3 \%$ & $12.6 \%$ & $26.1 \%$ & $34.5 \%$ & $5.6 \%$ \\
\hline
\end{tabular}

\subsubsection{NOx Mass Emission Flowrate}

As mentioned earlier, the NOx values were very similar to the results of sequences II and III. Results of hot start E01361_03 were representative of the majority of tests, so plots from only this test are presented here. This particular test had $\mathrm{NO}_{\mathrm{X}}$ errors of $17.18 \%$ and $18.17 \%$ from the two laboratory $\mathrm{NO}_{\mathrm{X}}$ analyzers.

A close up of the first three hundred seconds reveals that the SEMTECH-D was overshooting for every transient event, as seen in Figure 6.51. Previously, this fact was written off as engine pulsation resulting from being in a test cell, and having fewer pipe restrictions. The new firmware for the EFM was supposedly the fix for this problem. 


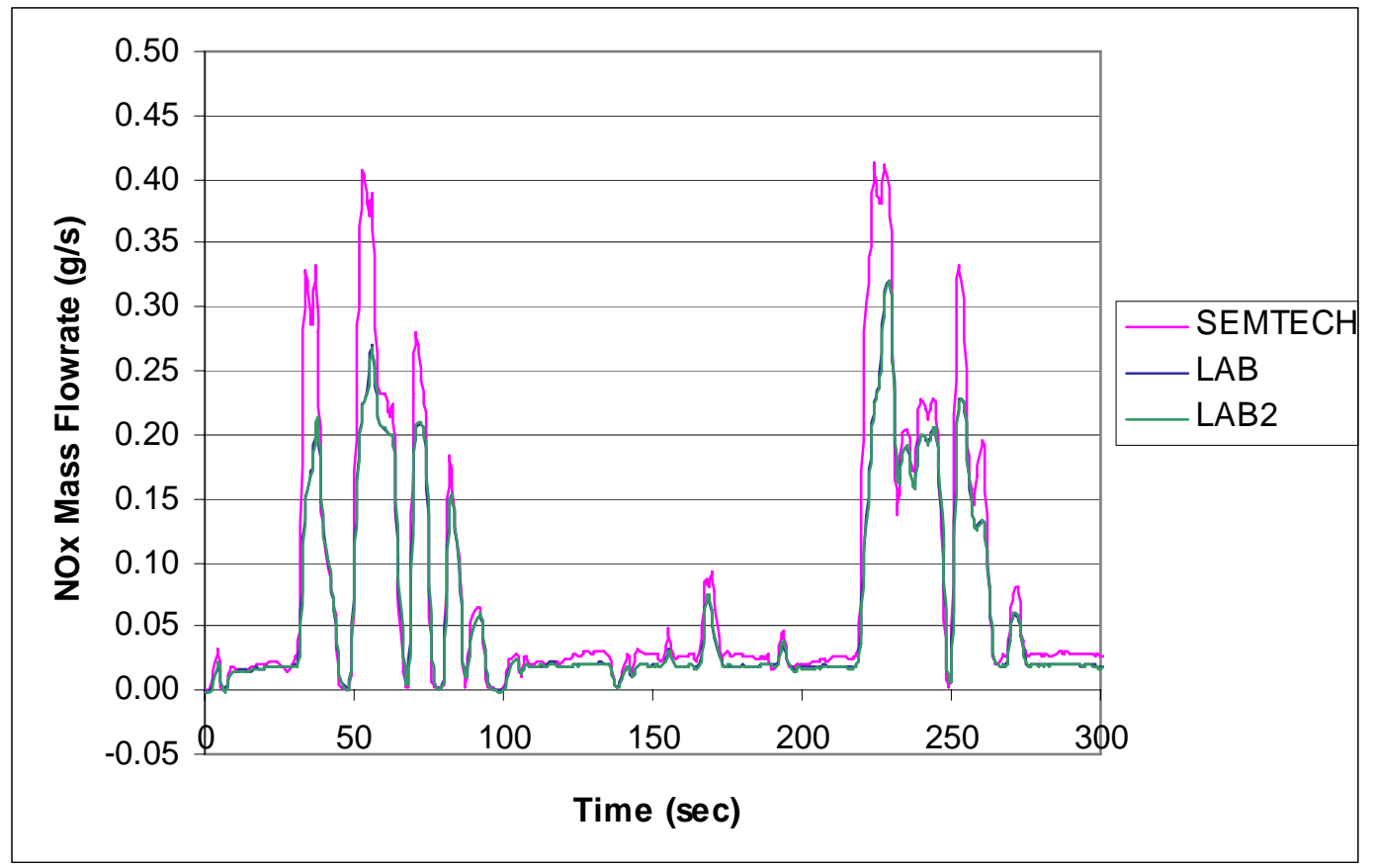

Figure 6.51 Segment of FTP E01361_03 $\mathrm{NO}_{\mathrm{X}}$ mass emission flowrate plot. Complete plot seen in APPENDIX A Figure 9.14.

Figure 6.52 provides statistics from all FTP tests conducted during Sequence IV (Note the expanded y-axis). The SEMTECH-D averaged $17.6 \%$ more $\mathrm{NO}_{\mathrm{X}}$ than the laboratory.

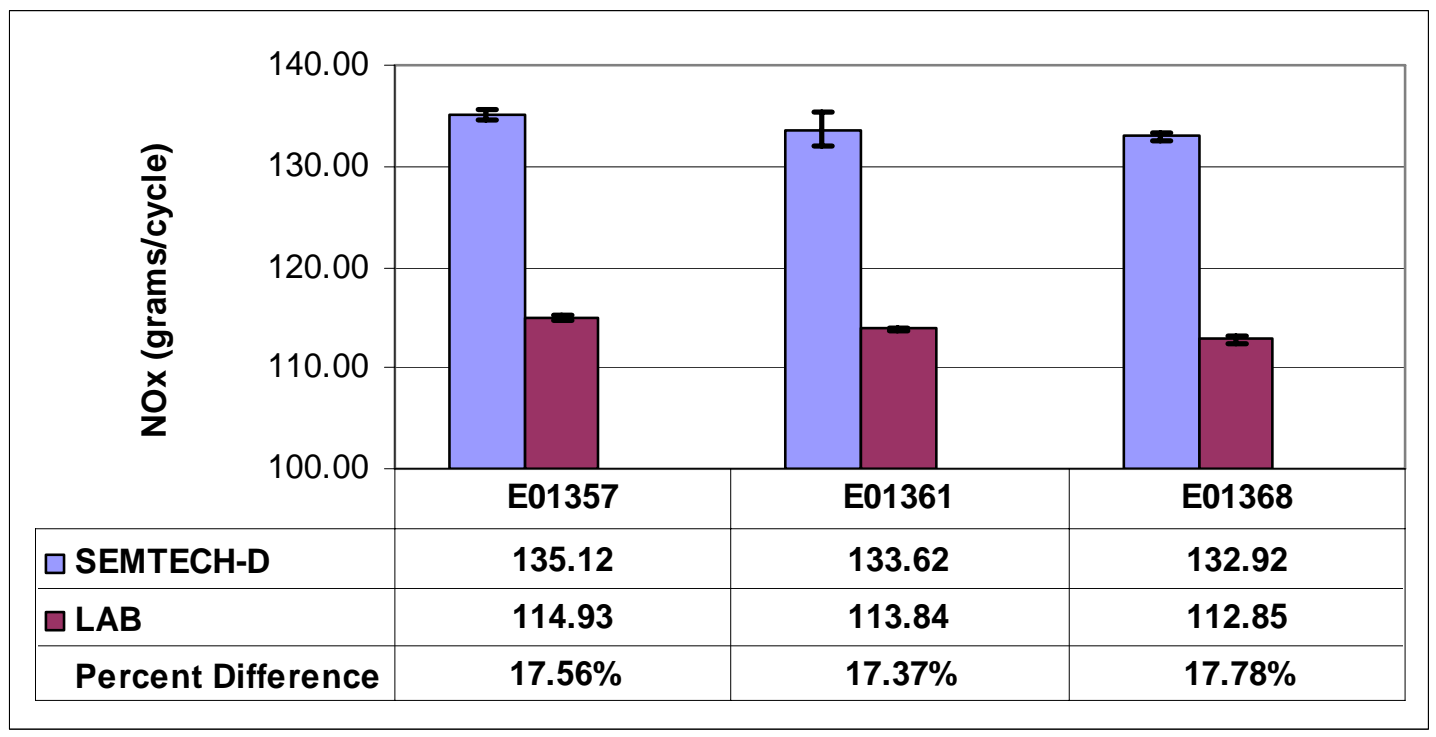

Figure 6.52 Average $\mathrm{NO}_{\mathrm{X}}$ mass emission totals. Error bars represent one standard deviation for each day of testing. Percent difference calculations made using laboratory as reference. 


\subsubsection{2 $\mathrm{CO}_{2}$ Mass Emission Flowrate}

The NDIR performance was slightly worse than previous test days. Test E01361_03 had an integrated percent error of $13.01 \%$ for a twenty minute FTP. However, the average for the three E01361 tests was $12.8 \%$ error.

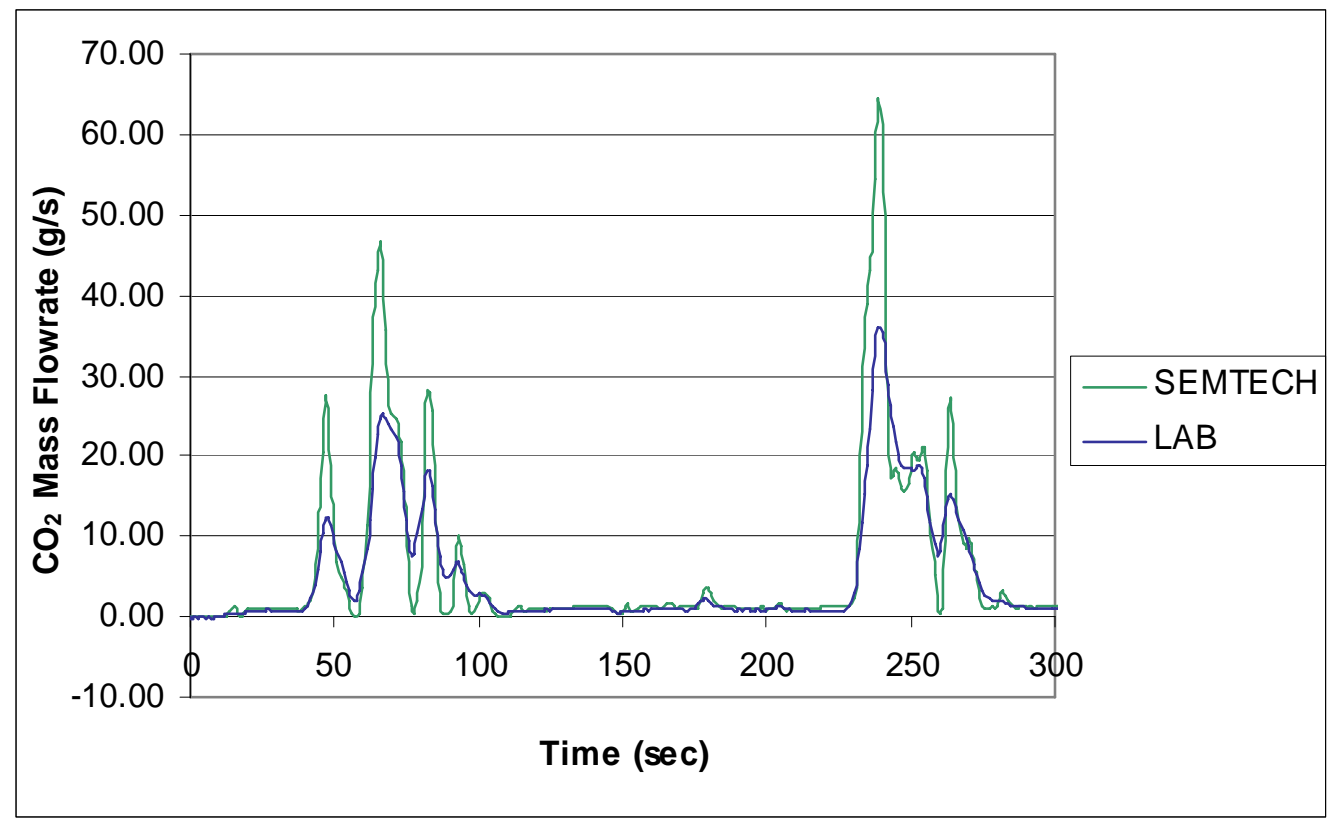

Figure 6.53 Segment of FTP E01361_03 $\mathrm{CO}_{2}$ mass emission plot. Complete plot seen in APPENDIX A Figure 9.16.

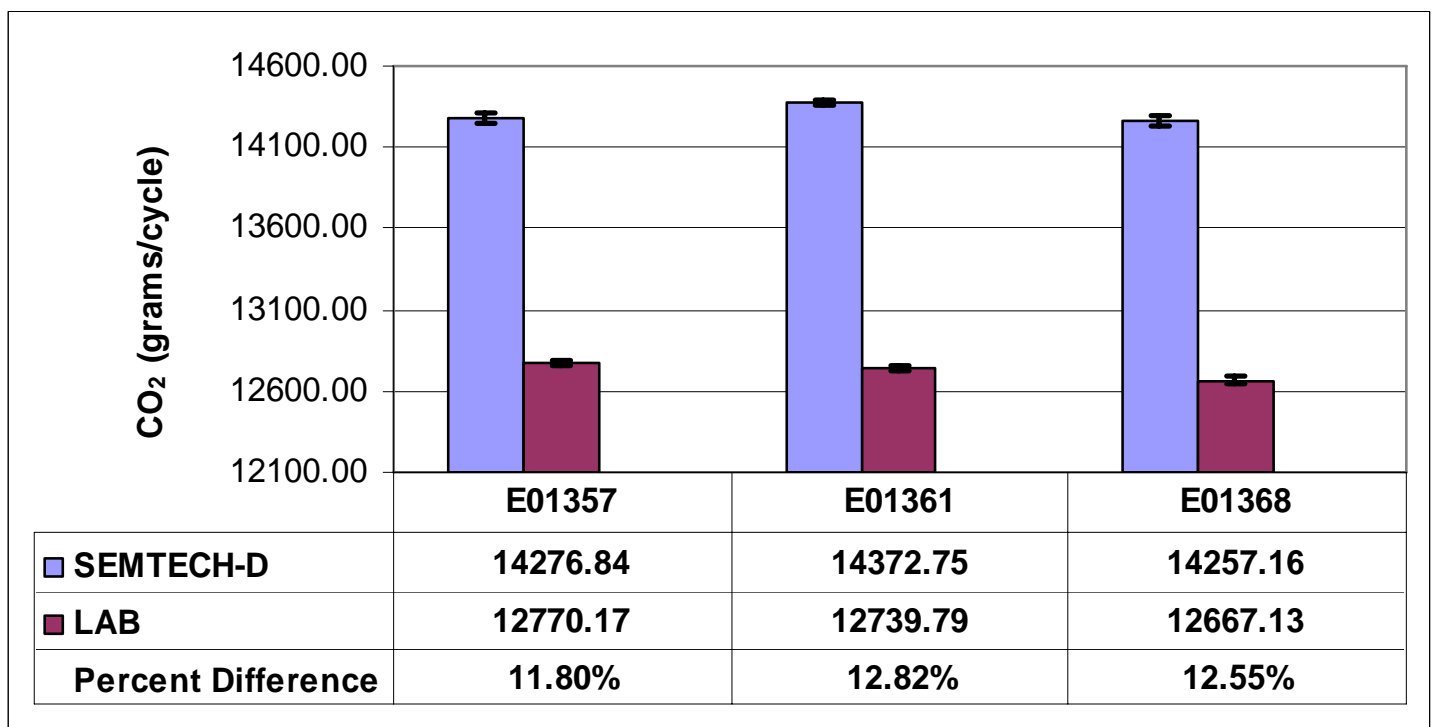

Figure 6.54 Average $\mathrm{CO}_{2}$ mass emission totals. Error bars represent one standard deviation for each day of testing. Percent difference calculations made using laboratory as reference. 


\subsubsection{CO Mass Emission Flowrate}

Carbon monoxide numbers were typical of what has already been seen in Sequence II and III. Figure 6.55 provides a glimpse of the overshooting experienced by the SEMTECHD.

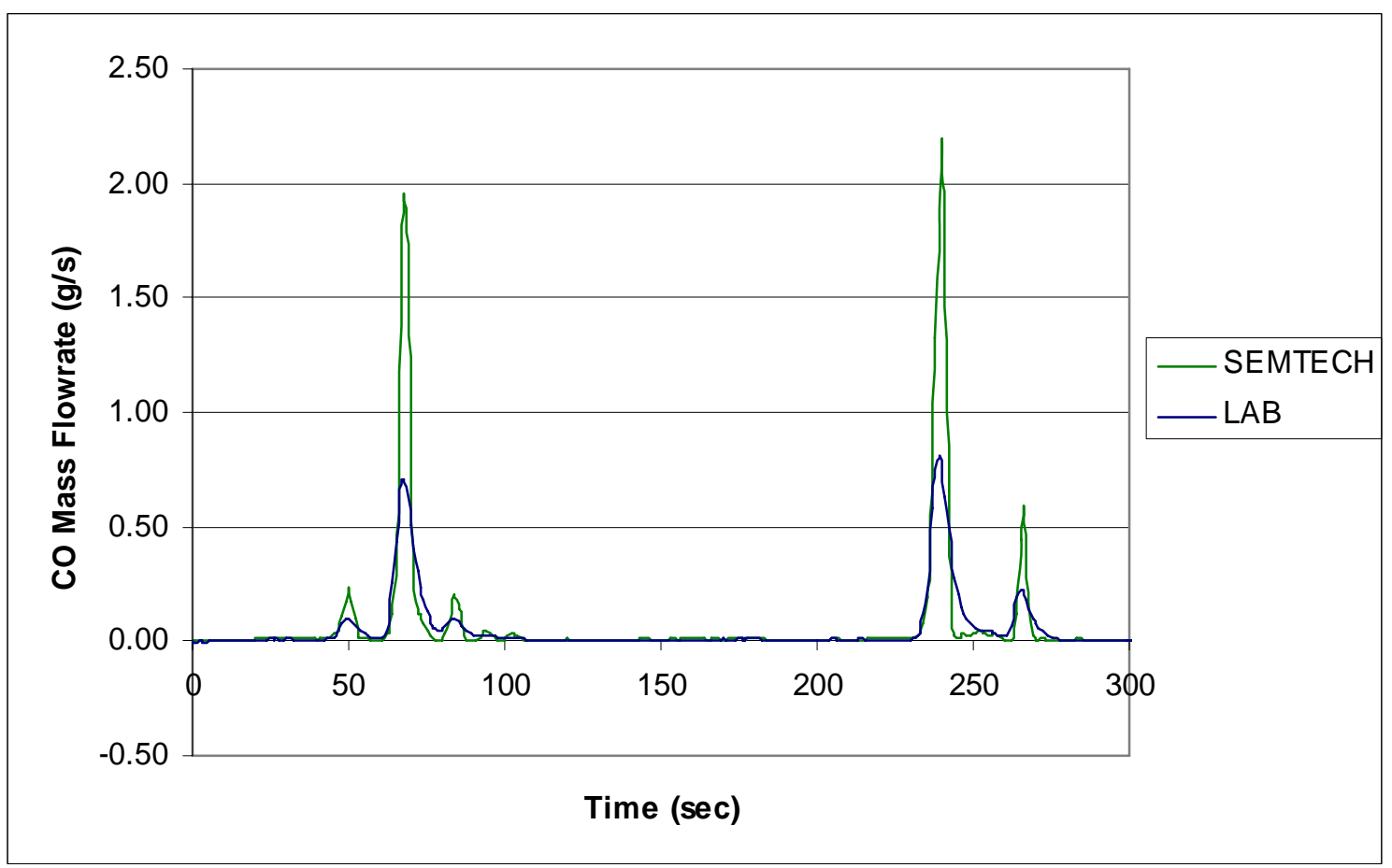

Figure 6.55 Segment of FTP E01361_03 CO mass emission plot. Complete plot seen in APPENDIX A Figure 9.18.

SEMTECH-D consistently averaged over $26 \%$ error for the nine FTP tests collected, as seen in Figure 2.1. 


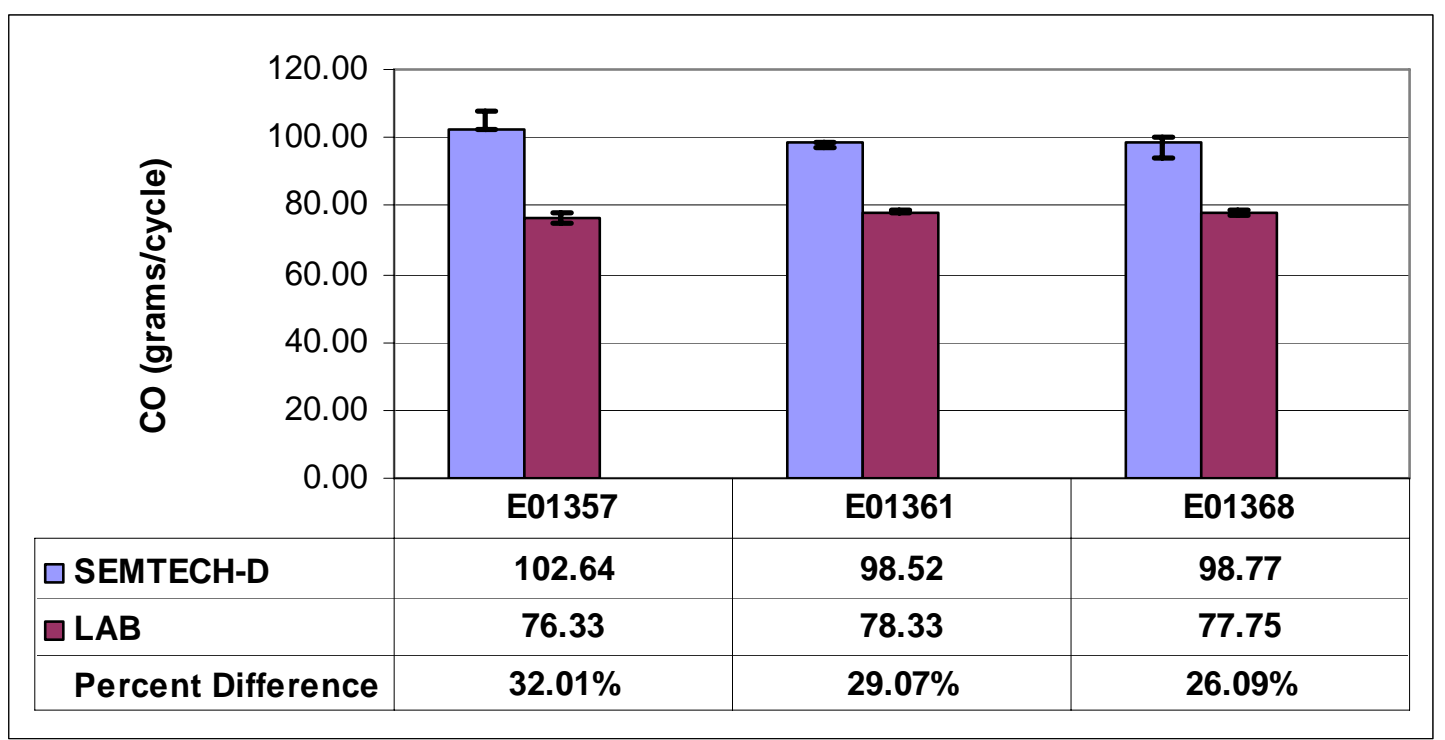

Figure 6.56 Average CO mass emission totals. Error bars represent one standard deviation for each day of testing. Percent difference calculations made using laboratory as reference.

\subsubsection{HC Mass Emission Flowrate}

Hydrocarbon measurements were very inconsistent during this period, having a range of differences of $34 \%$ to $67 \%$. Figure 6.57 shows a segment of the HC trace for FTP E01361_03. SEMTECH-D can be seen to exceed the laboratory for every data point.

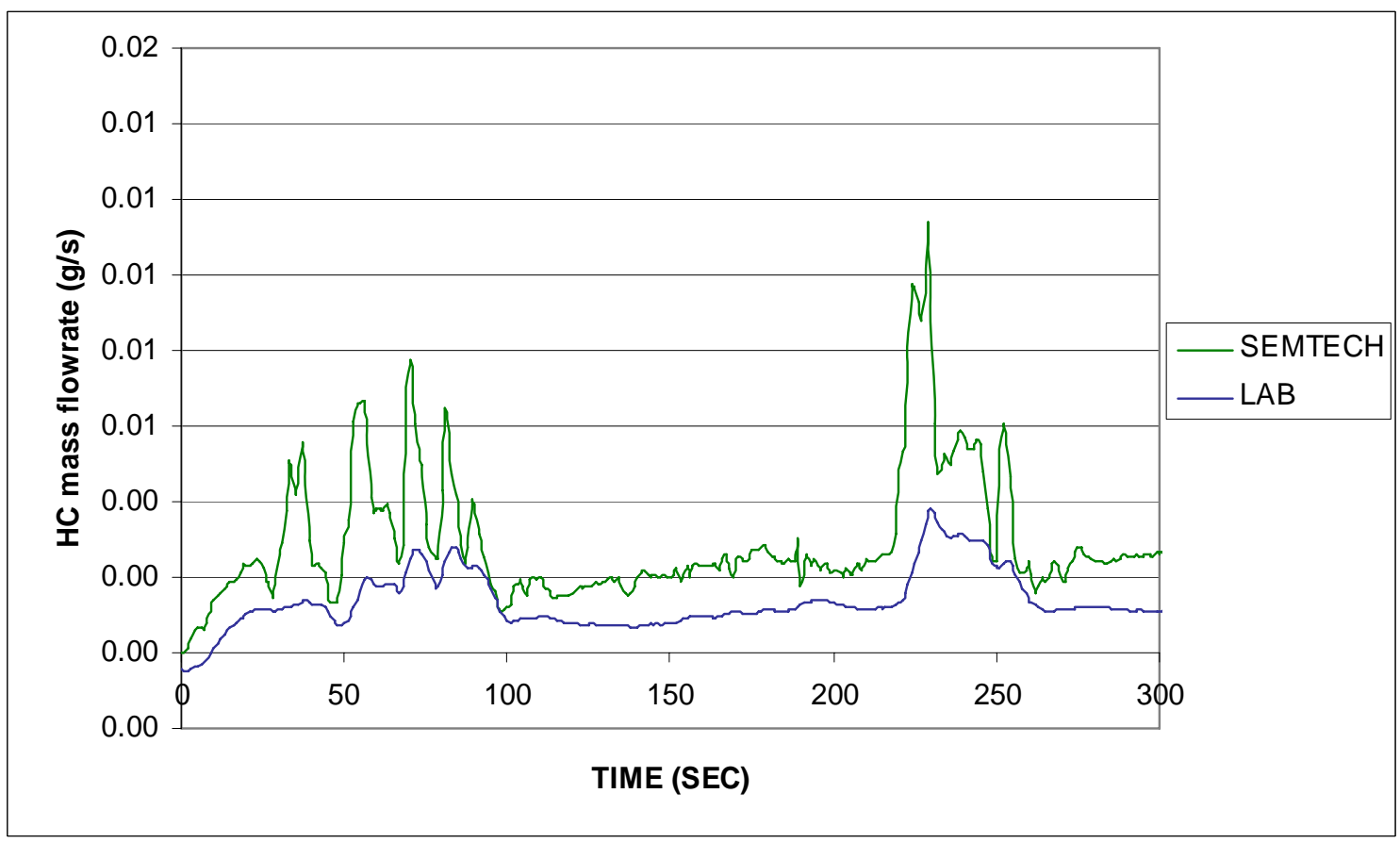

Figure 6.57 Segment of FTP E01361_03 HC Plot. Complete plot seen in 


\section{APPENDIX A Figure 9.19.}

Figure 6.58 provides the statistics for HC during Sequence IV.

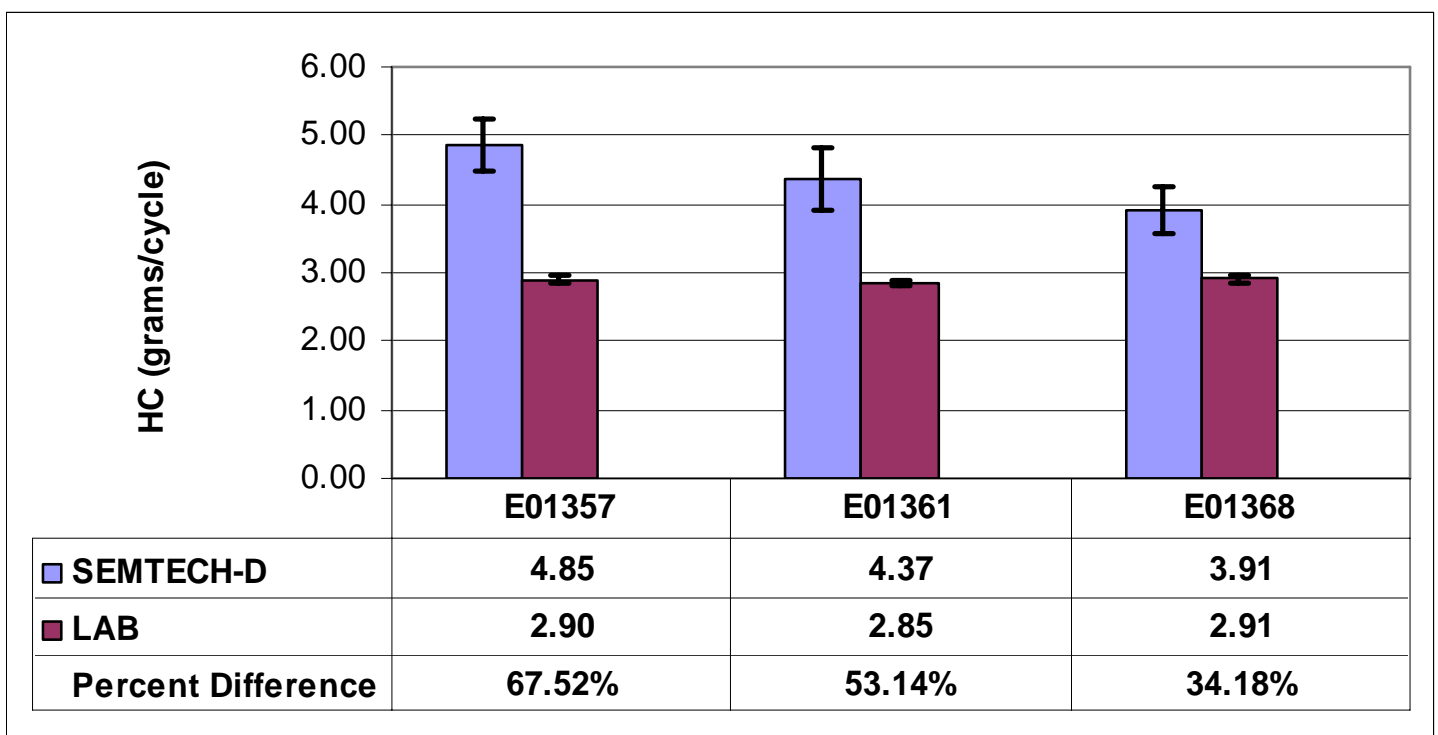

Figure 6.58 Average HC mass emission totals. Error bars represent one standard deviation for each day of testing. Percent difference calculations made using laboratory as reference.

\subsubsection{Exhaust Flowrate}

Figure 6.59 shows the SEMTECH-D EFM exhaust flowrate measurement behavior compared to the laboratory. Again, transient events are captured precisely, while steady state events are inaccurate. 


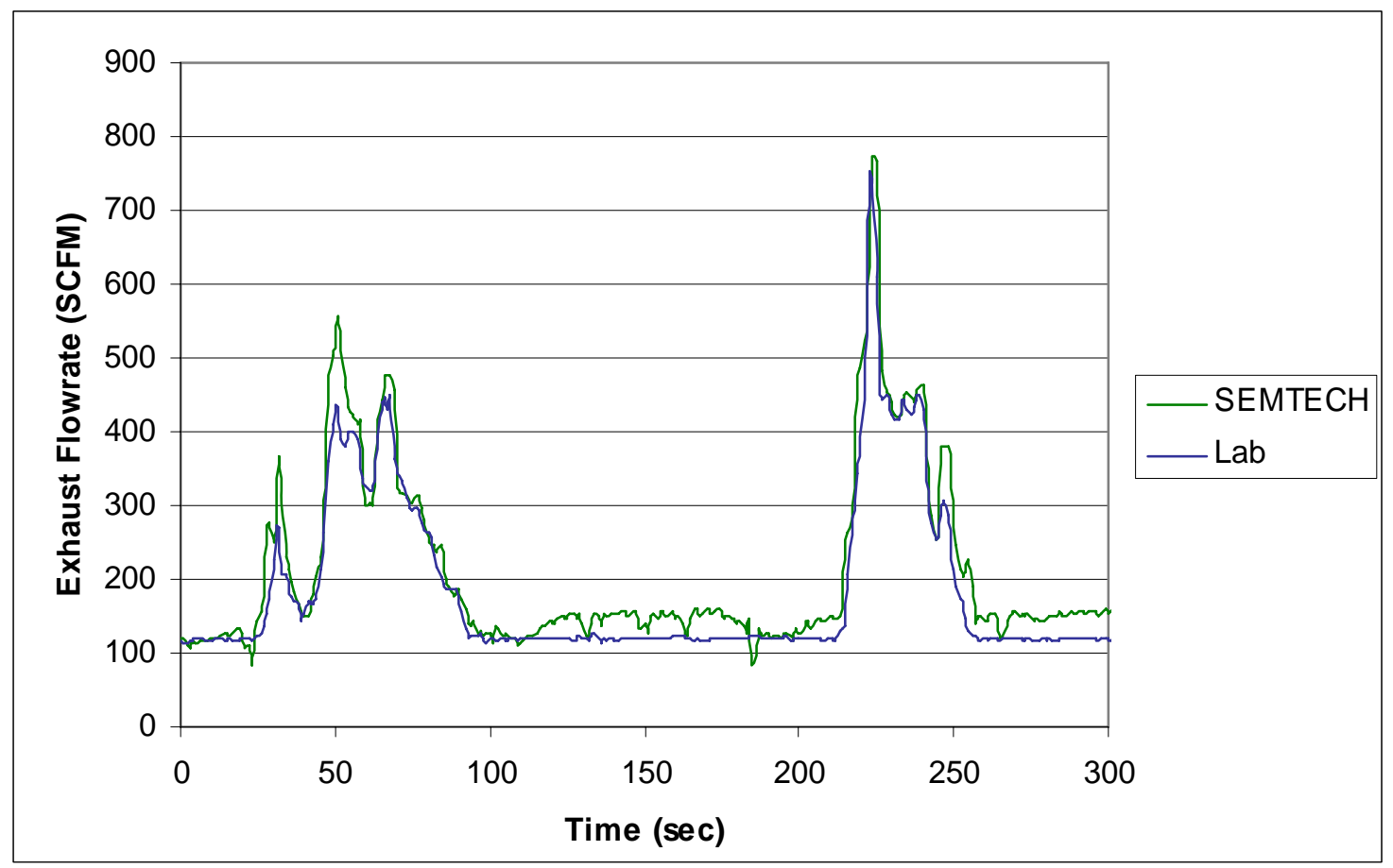

Figure 6.59 Segment of FTP E01361_03 exhaust flowrate plot. Complete plot seen in APPENDIX A Figure 9.20.

During Sequence IV exhaust flowrate was both consistent and accurate, as seen in Figure 6.60. SEMTECH-D on average is $5 \%$ higher than the laboratory flowrate, which is slightly worse than Sequence III. 


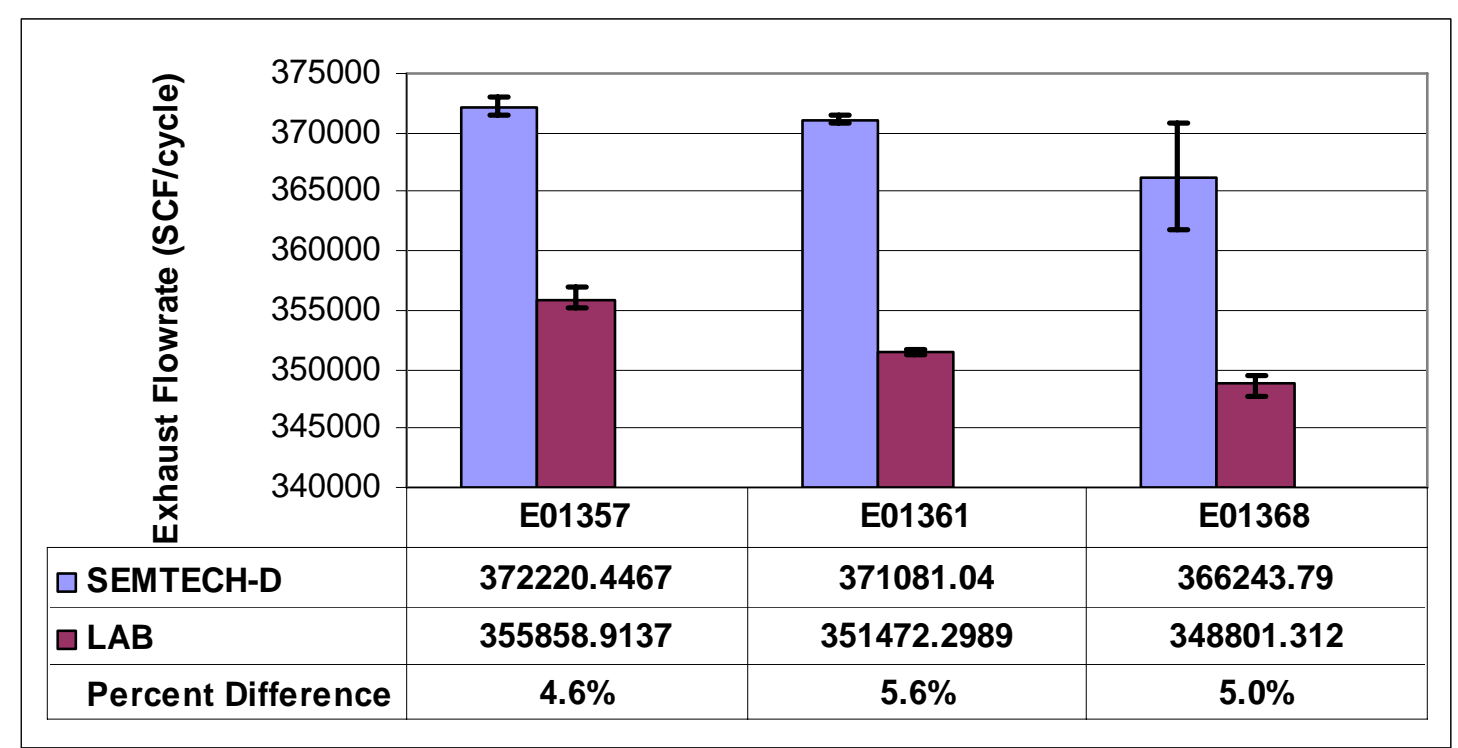

Figure 6.60 Average exhaust volumetric totals. Error bars represent one standard deviation for each day of testing. Percent difference calculations made using laboratory as reference.

\subsection{Additional Findings}

The second-by-second SEMTECH-D NO $\mathrm{X}$ mass emission flowrate percent error was examined for a few FTP cycles. In particular, the error occurring during the three NTE periods of the FTP was studied. It was discovered that the average SEMTECH-D NTE region error was $4-6 \%$ less than the error for the entire 20 minute test. This occurrence can be observed in Table 6.7. The three errors listed for each test are the $\mathrm{NO}_{\mathrm{X}}$ total mass error for each NTE operation sequence. Region 1 consists of 57 data points, while regions two and three contain 39 and 52 values, respectively.

Table 6.7 SEMTECH-D NTE Region NO $_{X}$ Error

\begin{tabular}{|c|c|c|c|c|}
\hline & \multicolumn{3}{|c|}{ NTE Region Percent Error } & FTP Total Error \\
\hline TEST & $\mathbf{1}$ & $\mathbf{2}$ & $\mathbf{3}$ & \\
\hline E01039_02 & $8.81 \%$ & $9.08 \%$ & $9.32 \%$ & $15.83 \%$ \\
\hline E01133_01 & $15.14 \%$ & $13.11 \%$ & $24.62 \%$ & $18.49 \%$ \\
\hline E01133_02 & $13.08 \%$ & $13.94 \%$ & $14.78 \%$ & $19.62 \%$ \\
\hline E01133_03 & $13.74 \%$ & $12.97 \%$ & $12.35 \%$ & $19.45 \%$ \\
\hline E01357_01 & $11.53 \%$ & $10.96 \%$ & $10.75 \%$ & $17.40 \%$ \\
\hline
\end{tabular}

The three NTE regions from cycle E01357_01 are plotted in Figure 6.61. While in the NTE zone, the changes in engine speed and torque are fairly low from point to point. 
The largest 'instantaneous' engine speed change is $70 \mathrm{rpm}$, which occurs in region three. One could argue that this is almost steady operation, and could explain the better performance of the unit accordingly.

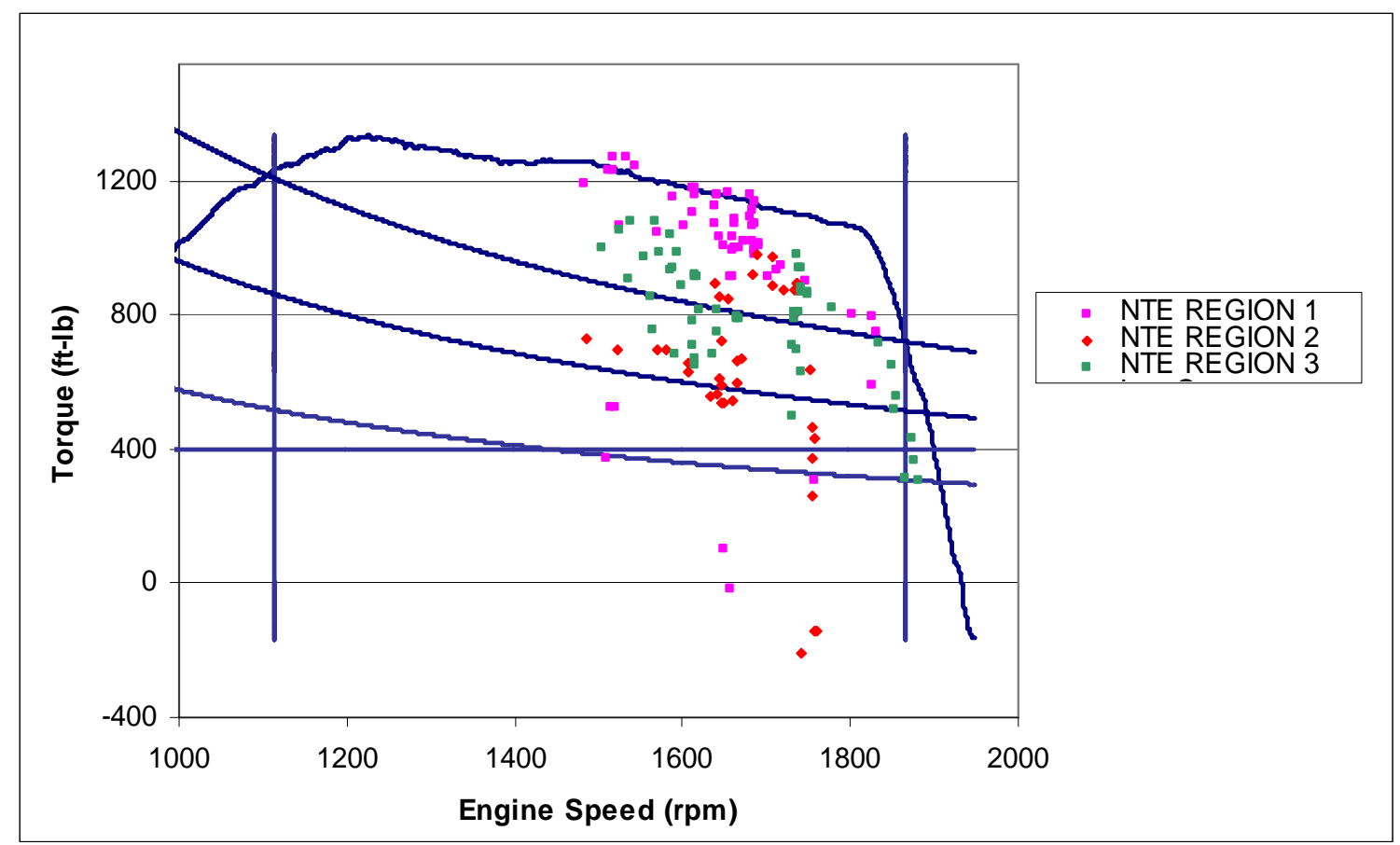

Figure 6.61 FTP NTE engine operating region and NTE segments from FTP E01357_01. 


\section{Conclusions and Recommendations}

\subsection{Overview}

The main objective of this study was to qualify SEMTECH-D as a viable system for the measurement of emissions from heavy-duty diesel engines while 'in-use'. Numerous test cell comparisons have been collected over the course of ten months to develop an understanding of the transient behavior of the SEMTECH-D. Over this time, four different testing periods were utilized, each providing multiple FTP comparisons.

\subsection{Conclusions}

When the performance of the SEMTECH-D was questioned, the logical method of gauging its performance was to capture numerous tests and compare it to a proven reliable and consistent system; the West Virginia University Engine and Emission Research Laboratory. From this ten month study, the WVU owned SEMTECH-D total NOx mass emission from a twenty minute FTP has averaged differences of $16 \%-23 \%$ for a series of three consecutive FTP cycles. The SEMTECH-D borrowed from Cummins, Inc. had total errors as high as $29 \%$ different from the laboratory for a single FTP. Carbon Dioxide has seen averaged percent differences of $8 \%-15 \%$ for a series of three consecutive FTP cycles. Carbon monoxide has a larger error range of 20\%-36\% average difference for a set of three consecutive FTP cycles, and HC repeatability is the poorest averaging as low as $20 \%$ difference to over $80 \%$ error. Exhaust flowrate measurements averaged ranges anywhere from $2 \%$ to $8 \%$ higher than the laboratory. (Noting that the laboratory flowrate is derived from intake air and fueling.) The borrowed SEMTECH averaged $12.0 \%$ different from the laboratory during the 2005 testing sequence.

The SEMTECH-D repeatability from day to day and month to month was good. During the first testing period, when two SEMTECH-D units were in line, gaseous emissions results were consistent from system to system. Over the six FTP cycles collected the two units were within $6 \%$ of one another for $\mathrm{NO}_{\mathrm{X}}$ and there was less than $0.1 \%$ variation for $\mathrm{CO}_{2}(\mathrm{HC}$ and $\mathrm{CO}$ both within $10 \%)$. Sequence $\mathrm{II} \mathrm{NO}_{\mathrm{X}}$ and $\mathrm{CO}_{2}$ variations were both under 3\% for different tests series with the same fuel (CO was 17\% and $\mathrm{HC}$ was $21 \%$ ). Variations during Sequence $\mathrm{III}$ for $\mathrm{NO}_{\mathrm{X}}$ and $\mathrm{CO}_{2}$ were $7 \%$ and less than $1 \%$, respectively. For Sequence $I V \mathrm{NO}_{\mathrm{X}}$ maximum variation from day-to-day was 
under $2 \%$ and $\mathrm{CO}_{2}$ variation for the same set of tests was less than $1 \%$ (HC was $25 \%$ and CO was $4 \%)$.

The testing and comparisons presented in the previous pages provide a glimpse of typical behavior of a SEMTECH-D. Yet, the root cause of these errors is unknown. The performance of the West Virginia University EERL need not be questioned; therefore, the erroneous system is the SEMTECH-D.

Given the aforementioned comparisons against laboratory analyzers, quality assurance protocols must be established to provide checks and balances for a PEMS. It is known that many organizations that purchase a PEMS do not have the capability to run quality assurance tests to verify data and system robustness. Thus, users could be measuring and reporting emissions and be unaware of error in the collected data. Since PEMS will be used for compliance purposes and possibly to compliment engine certification tests, it is imperative that procedures outlined in Part 1065 be strictly followed.

\subsection{Recommendations}

CFR Part 1065 should include a quality assurance schedule, so when PEMS users report measurements, uncertainty statistics can be included.

After completing this study, the one comparison that was not captured was a raw versus raw comparison. West Virginia University has recently completed the verification and checking of a laboratory grade raw system and a testing day was not possible due to a full laboratory schedule. This comparison will verify the performance of just the analyzers, rather than compounding the error of flow measurement and/or dilution air ratio to a possible analyzer error. 


\section{References}

1. "US EPA Signs Final Rule on In-Use Testing for Heavy-Duty Diesel Engines," $<$ www.dieselnet.com>, Ecopoint, Inc., Brampton, ON, 2005.

2. US EPA, CARB, EMA, "Memorandum of Agreement: Program to Develop Emission Measurement Accuracy Margins for Heavy Duty In-Use Testing," $<$ www.epa.gov>, 2005.

3. Englund, M. S., "Field Compatible $\mathrm{NO}_{\mathrm{X}}$ Emission Measurement Technique," SAE Technical Paper No. 820647, Warrendale, Pa, 1982.

4. Human, D. M., and Ullman, T. L., "Develoment of an I/M Short Emissions Test for Buses," SAE Technical Paper No. 920727, Warrendale, Pa, 1992.

5. Kelly, N. A., and Grolicki, P. J., "Real-World Emissions from a Modern Production Vehicle Driven in Los Angeles," Journal of the Air and Waste Management Association, Vol. 43, No. 10, 1993.

6. Butler, J. W., Gierczak, C. A., Jesion, G., Stedman, D. H., and Lesko, J. M., “OnRoad NOx Emissions Intercomparison of On-Board Measurements and Remote Sensing," Final Report, Coordinating Research Council, Inc., Atlanta, GA, CRC Report No. VE-11-6, 1994.

7. Bentz, A. P. and Weaver, E., "Marine Diesel Exhaust Emissions Measured by Portable Instruments," SAE Technical Paper No. 941784, Warrendale, PA, 1994.

8. Bentz, A. P., "Final Summary Report on Project 3310, Marine Diesel Exhaust Emissions (Alternative Fuels)," United States Department of Transportation United States Coast Guard Systems, Report No. CG-D-08-98, Washington, D.C., 1997.

9. Vojtisek-Lom, M. and Cobb, Jr., J. T., “On-Road Light-Duty Vehicle Mass Emission Measurements Using a Novel Inexpensive On-Board Portable System," Proceedings of the Eighth CRC On-Road Vehicle Workshop, San Diego, CA, 1998.

10. “Construction Equipment Retrofit Project," Northeast States for Coordinated Air Use Management, Boston, MA, 1998.

11. Gautam, M., Clark, N. N., Thompson, G. J., and Lyons, D. W., “Assessment of Mobile Monitoring Technologies for Heavy-Duty Vehicle Emissions," White paper Submitted to the Settling Heavy-Duty Diesel Engine Manufacturers, Department of Mechanical and Aerospace Engineering, West Virginia University, Morgantown, WV, 1999. 
12. Butler, J. W., Kornisk, T. J., Reading, A. R., and Kotenko, T. L., "Dynamometer Quality Data On-board Vehicles for Real-World Emission Measurements," Proceedings of the Ninth CRC On-Road Vehicle Workshop, San Diego, CA, 1999.

13. Kihara, N., Tsukamoto, T., Matsumoto, K., Ishida, K., Kon, M., and Murase, T., "Real-time On-board Measurement of Mass Emission of NOx, Fuel Consumption, Road Load, and Engine Output for Diesel Vehicles," SAE Technical Paper No. 2000-01-1141, Warrendale, PA, 2000.

14. Vojtisek-Lom, M., Allsop, J. E., "Development of Heavy-Duty Diesel Portable, On-Board Mass Exhaust Emissions Montoring System With $\mathrm{NO}_{\mathrm{X}}, \mathrm{CO}_{2}$ and Qualitative PM Capabilities," SAE Technical Paper No. 2001-01-3641, Warrendale, PA, 2001.

15. Weaver, C. S. and Balam-Almanza, M. V. "Development of the 'RAVEM' RideAlong Vehicle Emissions Measurement System for Gaseous and Particulate Emissions," SAE Technical Paper No. 2001-01-3644, Warrendale, PA, 2001.

16. "Horiba Announces On-Board Exhaust Gas Measuring System," $<$ www.dieselnet.com>, Ecopoint, Inc., Brampton, ON, 2005.

17. Akard, M., Oestergaard, K., Porter, S., Gautam, M., Carder, D., Love, D., Moye, T., Garabedian, H., "Further Investigation into the Performance of Two Different On-Board Emissions Measurement System Compared to Laboratory Measurements," SAE Technical Paper No. 2004-01-3480, Warrendale, Pa, 2005.

18. "New On-Board Emission Measuring System from Sensors Inc.," $<$ www.dieselnet.com>, Ecopoint, Inc., Brampton, ON, 2002.

19. "Sensors, Ford to Partner in Development of On-Board Emission Analyzers," $<$ www.dieselnet.com>, Ecopoint, Inc., Brampton, ON, 2005.

20. Akard, M., Nakamura, H., Aoki, S., Kihara, N., Adachi, M., "Performance Results and Design Considerations for a New In-Use Testing Instrument," SAE Technical Paper No. 2005-01-3606, Warrendale, Pa, 2005.

21. Sensors, Inc., On-Road Emissions Testing of 18 Tier 1 Passenger Cars and 17 Diesel Powered Public Transportation Buses, EPA420-R-02-030, October 22, 2002.

22. Dearth, M.A., Butler, J.W., Colvin, A., Gierczak, C., Kaberline, S., Korniski, T., "SemtechD: The Chassis Roll Evaluation of a Commercial Portable Emission Measurement System (PEMS)," SAE Technical Paper No. 2005-01-0673, Warrendale, $\mathrm{Pa}, 2005$. 
23. Sensors, Inc., “On-Vehicle Diesel Emissions Analyzer SEMTECH-D User's Manual,” Document 9510-064, Rev. 3.7.1, Saline, MI, 2005.

24. Ensfield, C., Bachman, J.L., Erb, A., Bynum, C., "Evaluating Real-World Fuel Economy on Heavy Duty Vehicles Using a Portable Emissions Measurement System," SAE Technical Paper No. 2006-01-3543, Warrendale, Pa, 2005.

25. "Code of Federal Regulations," CFR 40 Part 86, Office of the Federal Register National Archives and Records Administration, Washington, D.C., 1994.

26. US EPA, CARB, EMA, “Test Plan to Determine PEMS Measurement Allowances for the Gaseous Emissions Regulated under the Manufacturer-Run Heavy-Duty Diesel Engine In-Use Testing Program," <www.epa.gov>, 2005.

27. "Engine Manufacturers Reach Agreement on NTE Limits and In-Use Testing with U.S. EPA and California ARB," <www.dieselnet.com>, Ecopoint, Inc., Brampton, ON, 2005.

28. "Title 13: California Air Resources Board: Notice of Public Hearing to Consider Amendments to Adopt Not-to-Exceed and Euro III European Stationary Cycle Emission Test Procedures for the 2005 and Subsequent Model Year Heavy-Duty Diesel Engines,"<www.arb.ca.gov>, Sacramento, CA, 2005.

29. Krishnamurthy, M., Gautam, M., "Quality Assurance of Exhaust Emissions Test Data Measured Using Portable Emissions Measurement System," SAE Technical Paper No. 2005-01-3799, Warrendale, Pa, 2005.

30. Heywood, J. B., Internal Combustion Engine Fundamentals, McGraw-Hill, New York, NY, 1998.

31. Thompson, G. J., Gibble, J. C., Clark, N. N., Gautam, M., "Influences of RealWorld Conditions on In-Use Emission from Heavy-Duty Diesel Engines," SAE Technical Paper No. 2006-01-3393, Warrendale, Pa, 2005.

32. Shade, B.C., "A Performance Evaluation of MEMS-An On-Road Emissions Measurement System Study," M.S. Thesis, Department of Mechanical and Aerospace Engineering, West Virginia University, Morgantown, WV, 2000.

33. "Gas Phase Measurements," <www.dieselnet.com>, Ecopoint, Inc., Brampton, ON, 2005.

34. Heller, B., Lach, G., Baronick, J.D., Fabinski, W., Moede, M., "Evaluation of an $\mathrm{UV}$-Analyzer for the Simultaneous $\mathrm{NO}$ and $\mathrm{NO}_{2}$ Vehicle Emission Measurement," SAE Technical Paper No. 04SFL-112, Warrendale, Pa, 2005. 
35. Gluck, S., Glenn, C., Logan, T., Vu, B., Walsh, M., Williams, P., "Evaluation of $\mathrm{NO}_{\mathrm{X}}$ Flue Gas Analyzers for Accuracy and Their Applicability for LowConcentration Measurements," Journal of the Air \& Waste Management Association, Vol. 53:749-758, Pittsburgh, Pa, 2003

36. Sensors, Inc., "Vehicle Exhaust Flowmeter SEMTECH EFM User's Manual," Document 9510-085, Rev. 1.3, Saline, MI, 2005.

37. "SEMTECH-DS On-Board, In-Use Diesel Vehicle Emissions Analyzer," $<$ www.sensors-inc.com>, Sensors, Inc., Saline, MI, 2005.

38. Thompson, G., [Proprietary Testing Report], Department of Mechanical and Aerospace Engineering, Morgantown, WV, 2005

39. Riddle, W.C., "Design and Evaluation of the Emission Measurement Components for a Heavy-Duty Diesel Powered Vehicle Mobile Emissions Measurement System (MEMS)," M.S. Thesis, Department of Mechanical and Aerospace Engineering, West Virginia University, Morgantown, WV, 2001.

40. Bolyard, J.D., "Evaluation of an Air-to-Fuel Derived Exhaust Flow Rate for InUse Emissions Testing," M.S. Thesis, Department of Mechanical and Aerospace Engineering, West Virginia University, Morgantown, WV, 2005. 


\section{APPENDIX A}

\subsection{Sequence I 2005}

Table 9.1 Complete Statistics from Sequence I, 2005

\begin{tabular}{|c|c|c|c|c|c|c|c|c|c|}
\hline NOx & semtech1 & semtech2 & MEMS & Iab & $\mathrm{CO}_{2}$ & semtech1 & semtech2 & MEMS & lab \\
\hline E00840_01 & 138.6481 & 147.2368 & 132.8403 & 116.1992 & E00840_01 & 14419.52 & 14268.37 & 13547.49 & 12958.34 \\
\hline E00840_02 & 142.7034 & 150.374 & 131.327 & 117.0191 & E00840_02 & 14039.05 & 14001.87 & 13654.78 & 12974.88 \\
\hline E00840_03 & 138.0791 & 146.2173 & & 116.9492 & E00840_03 & 13044.14 & 13812.64 & & 12934.94 \\
\hline E00840_05 & 140.7253 & 146.0644 & 130.6772 & 116.3336 & E00840_05 & 14100.22 & 13663.71 & 13546.63 & 13029.53 \\
\hline E00840_06 & 139.3399 & 145.9218 & 133.5021 & 116.4472 & E00840_06 & 14080.29 & 13985.94 & 13419.65 & 12915.48 \\
\hline average & 139.8992 & 147.1629 & 132.0867 & 116.5897 & average & 13936.64 & 13946.51 & 13542.14 & 12962.63 \\
\hline stdev & 1.853179 & 1.867996 & 1.308319 & 0.371486 & stdev & 521.4449 & 226.9978 & 96.16291 & 43.68554 \\
\hline Cov & 1.324654 & 1.269339 & 0.990501 & 0.318627 & Cov & 3.741539 & 1.627632 & 0.710101 & 0.337011 \\
\hline error & $19.99 \%$ & $26.22 \%$ & $5.38 \%$ & & error & $7.51 \%$ & $7.59 \%$ & $-1.18 \%$ & \\
\hline $\begin{array}{l}\text { Ex. } \\
\text { Flowrate }\end{array}$ & semtech2 & semtech1 & & lab & CO & semtech1 & semtech2 & & lab \\
\hline E00840_01 & 384166.9 & 364675.3 & & 337620 & E00840_01 & 120.4712 & 95.86052 & & 74.00154 \\
\hline E00840_02 & 385683.1 & 366599.5 & & 338663.1 & E00840_02 & 94.89514 & 92.76072 & & 71.59715 \\
\hline E00840_03 & 384763.4 & & & 345621.1 & E00840_03 & 94.30919 & 87.08189 & & 70.82733 \\
\hline E00840_05 & 381929 & 369250.9 & & \begin{tabular}{|l|}
342077.7 \\
\end{tabular} & E00840_05 & 95.75463 & 92.07213 & & 71.42055 \\
\hline E00840_06 & 384440 & 371304.7 & & 342720.8 & E00840_06 & 92.59488 & 87.56553 & & 68.92035 \\
\hline Average & 384196.5 & 367957.6 & & 341340.6 & average & 99.605 & 91.06816 & & 71.35338 \\
\hline Stdev & 1390.391 & 2915.103 & & 3231.989 & stdev & 11.72169 & 3.708038 & & 1.82161 \\
\hline COV & $0.36 \%$ & $0.79 \%$ & & $0.95 \%$ & Cov & 11.76817 & 4.071718 & & 2.552941 \\
\hline Error & $12.56 \%$ & $7.80 \%$ & & & error & 0.395939 & 0.276298 & & \\
\hline $\mathrm{HC}$ & semtech1 & semtech2 & & lab & & & & & \\
\hline E00840_01 & 4.68997 & 4.91377 & & 2.61391 & & & & & \\
\hline E00840_02 & 4.63504 & 5.49071 & & 2.70996 & & & & & \\
\hline E00840_03 & 4.62498 & 4.45479 & & 2.72068 & & & & & \\
\hline E00840_05 & 3.9546 & 3.98821 & & 2.42005 & & & & & \\
\hline E00840_06 & 4.2341 & 4.50762 & & 2.45178 & & & & & \\
\hline average & 4.427738 & 4.67102 & & 2.583276 & & & & & \\
\hline stdev & 0.320936 & 0.563583 & & 0.141245 & & & & & \\
\hline COV & 7.248304 & 12.06553 & & 5.467686 & & & & & \\
\hline error & 0.714001 & 0.808177 & & & & & & & \\
\hline
\end{tabular}

\subsubsection{NOx}

The time aligned data traces from all systems are included in Figure 9.1. 


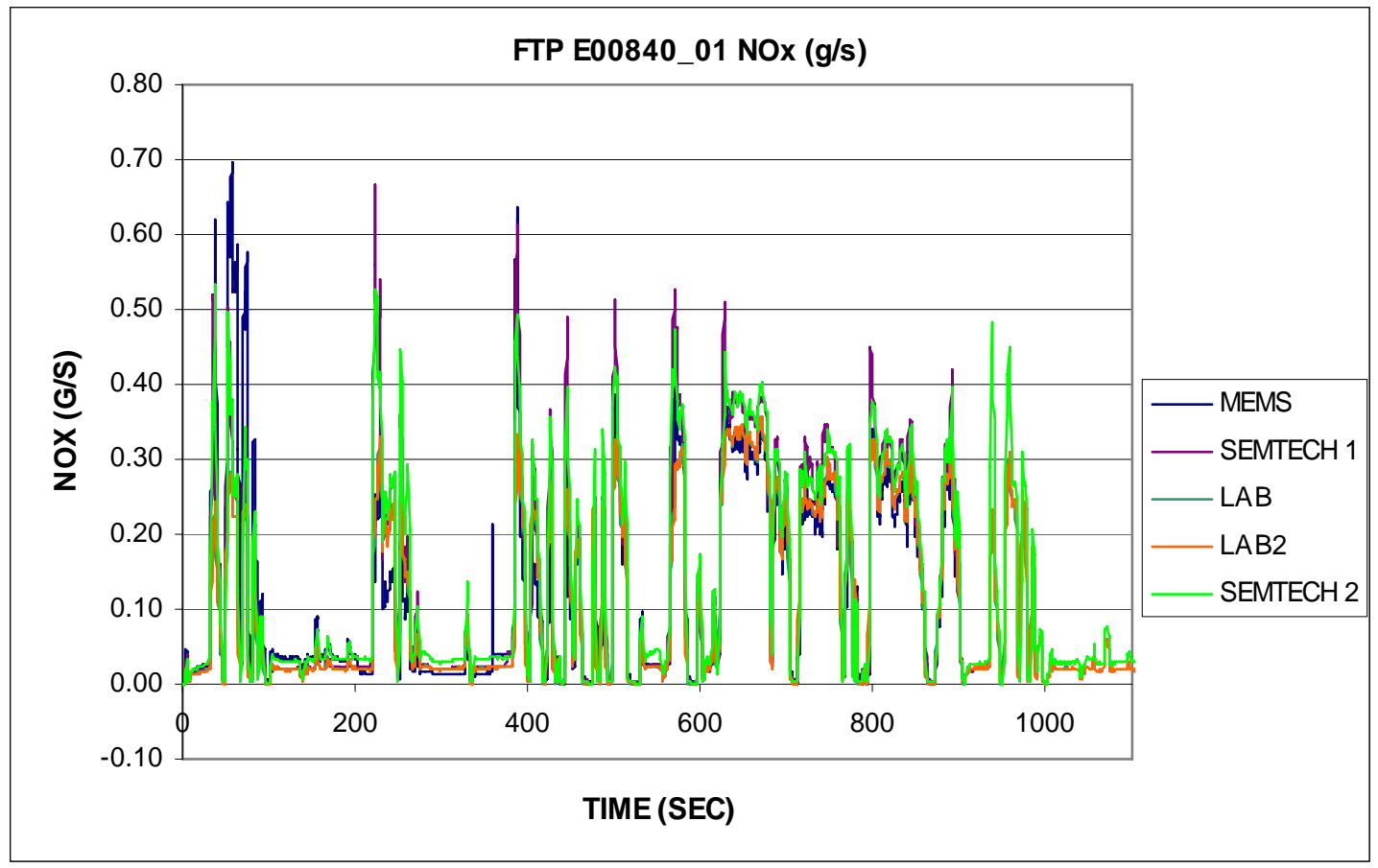

Figure 9.1 Time Aligned Data from Multiple PEMS

SEMTECH\#1 and SEMTECH\#2 repeatability is seen in the following figures. 


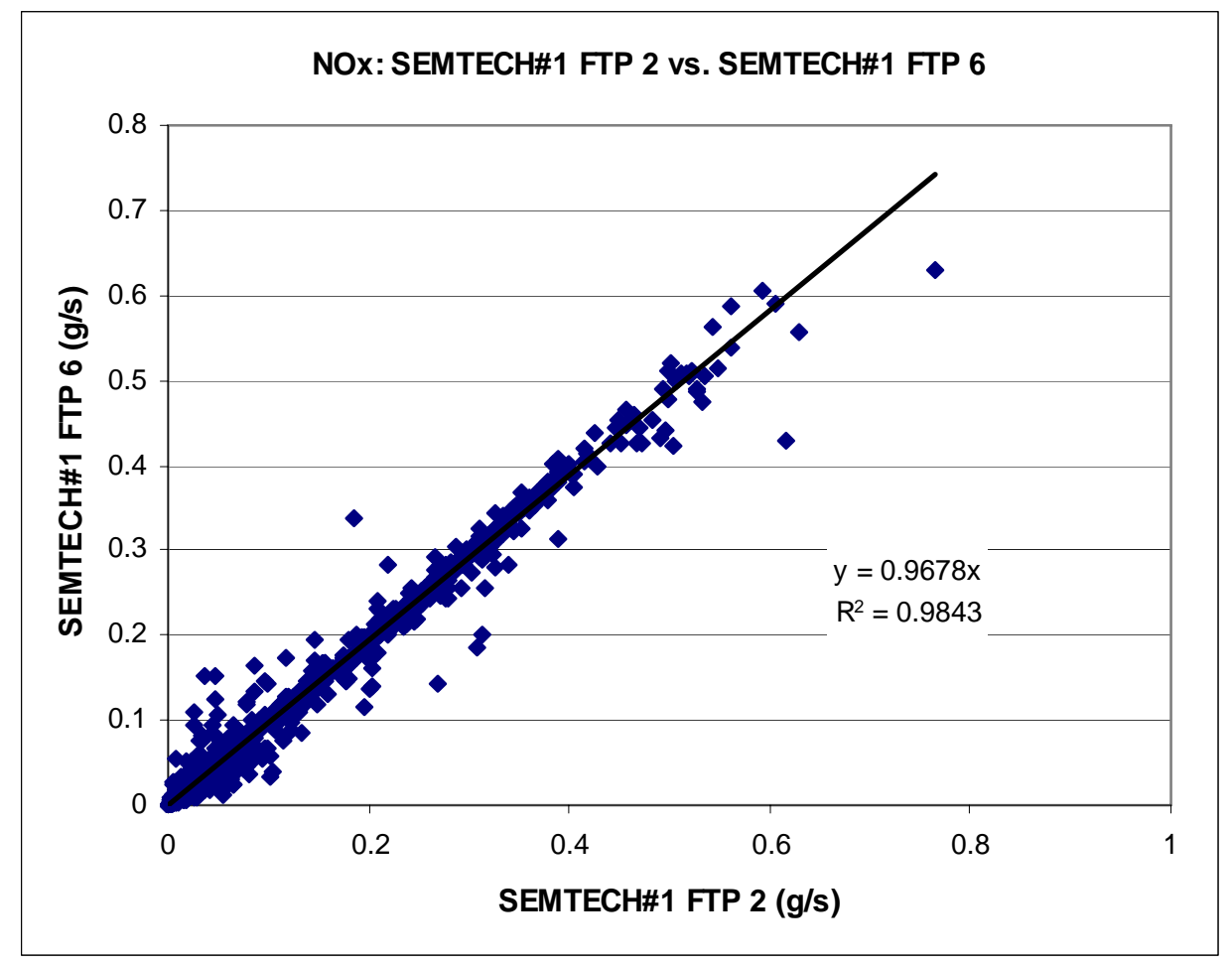

Figure 9.2 Test To Test Variability of SEMTECH-D\#1

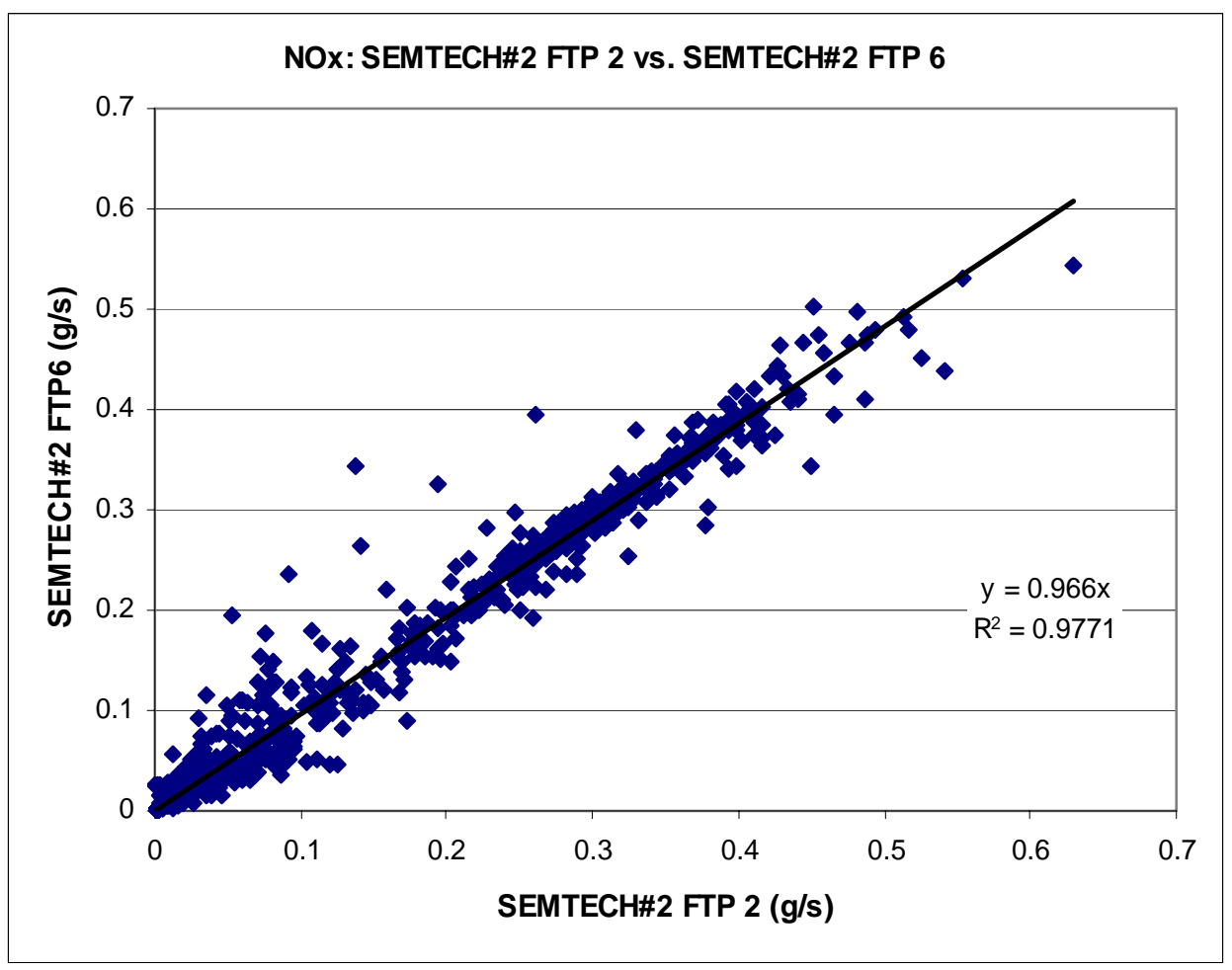

Figure 9.3 Test To Test Variability of SEMTECH-D \#2 
Test E00840_01 didn't match well with other tests, yet the integrated error wasn't the highest for MEMS. The following figure shows this behavior.

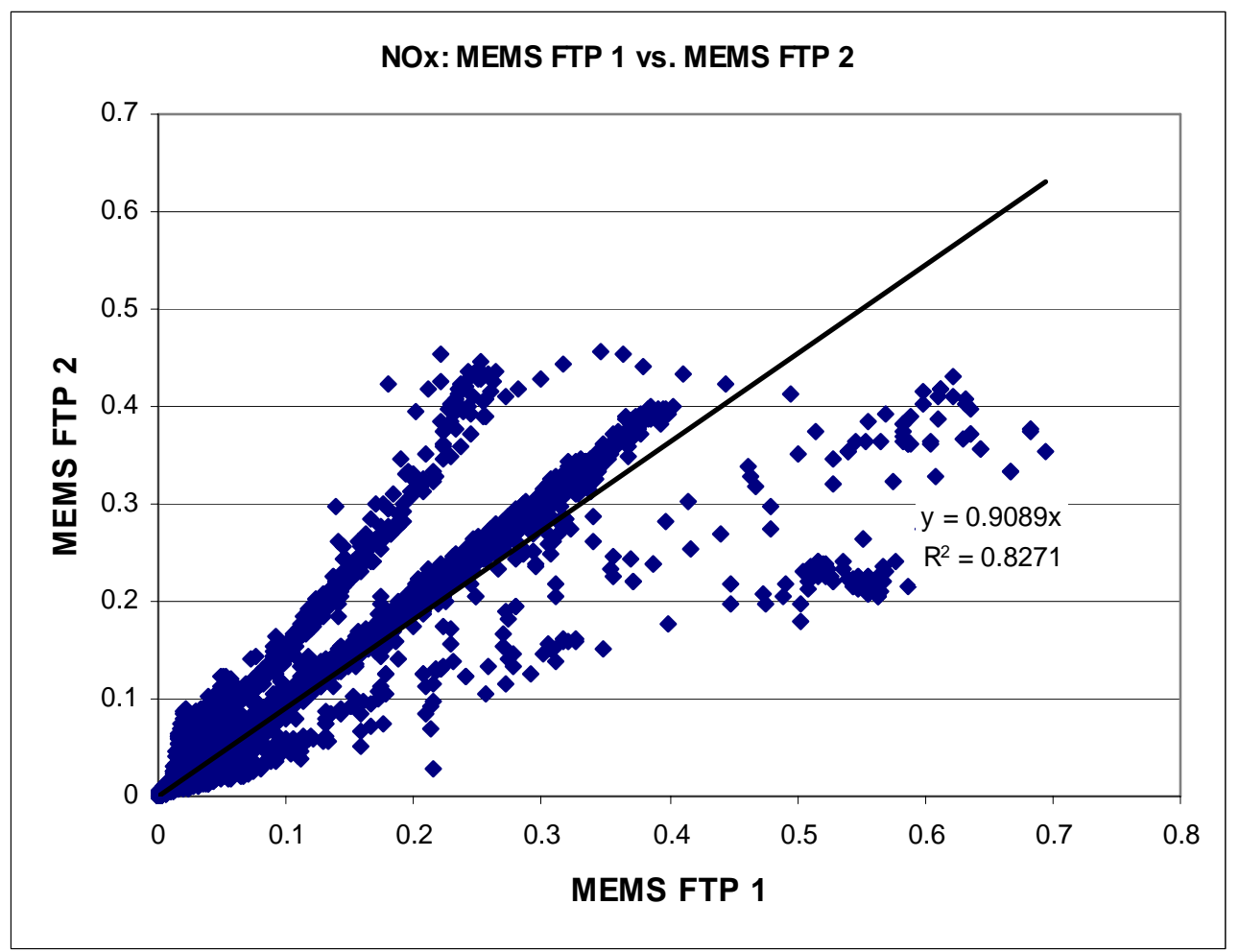

Figure 9.4 Test To Test Variability of MEMS

\subsection{1 $\mathrm{CO}_{2}$ Sequence I 2005}

$\mathrm{CO}_{2}$ repeatability of SEMTECH\#1 and SEMTECH\#2 


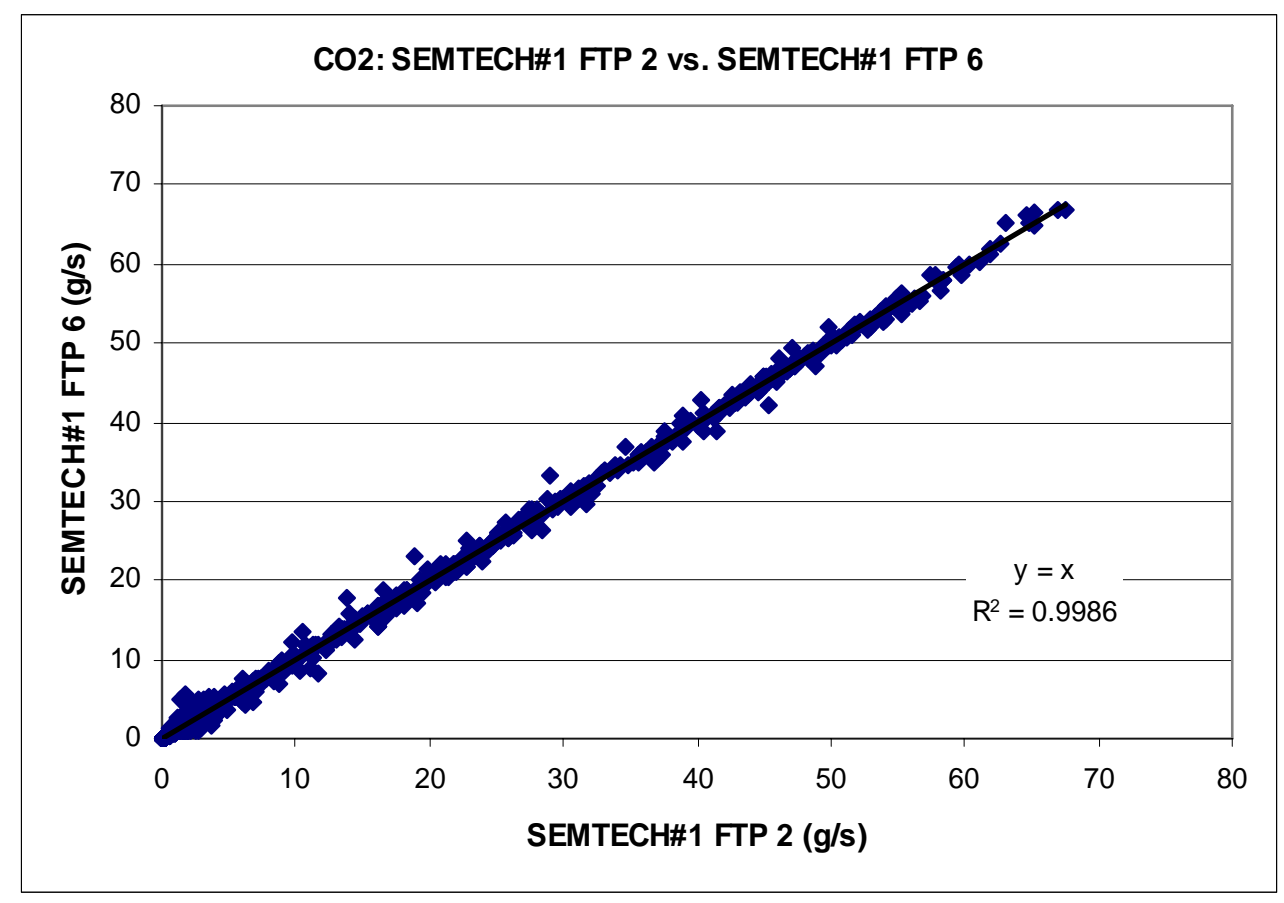

Figure 9.5 Test To Test Repeatability of SEMTECH-D\#1

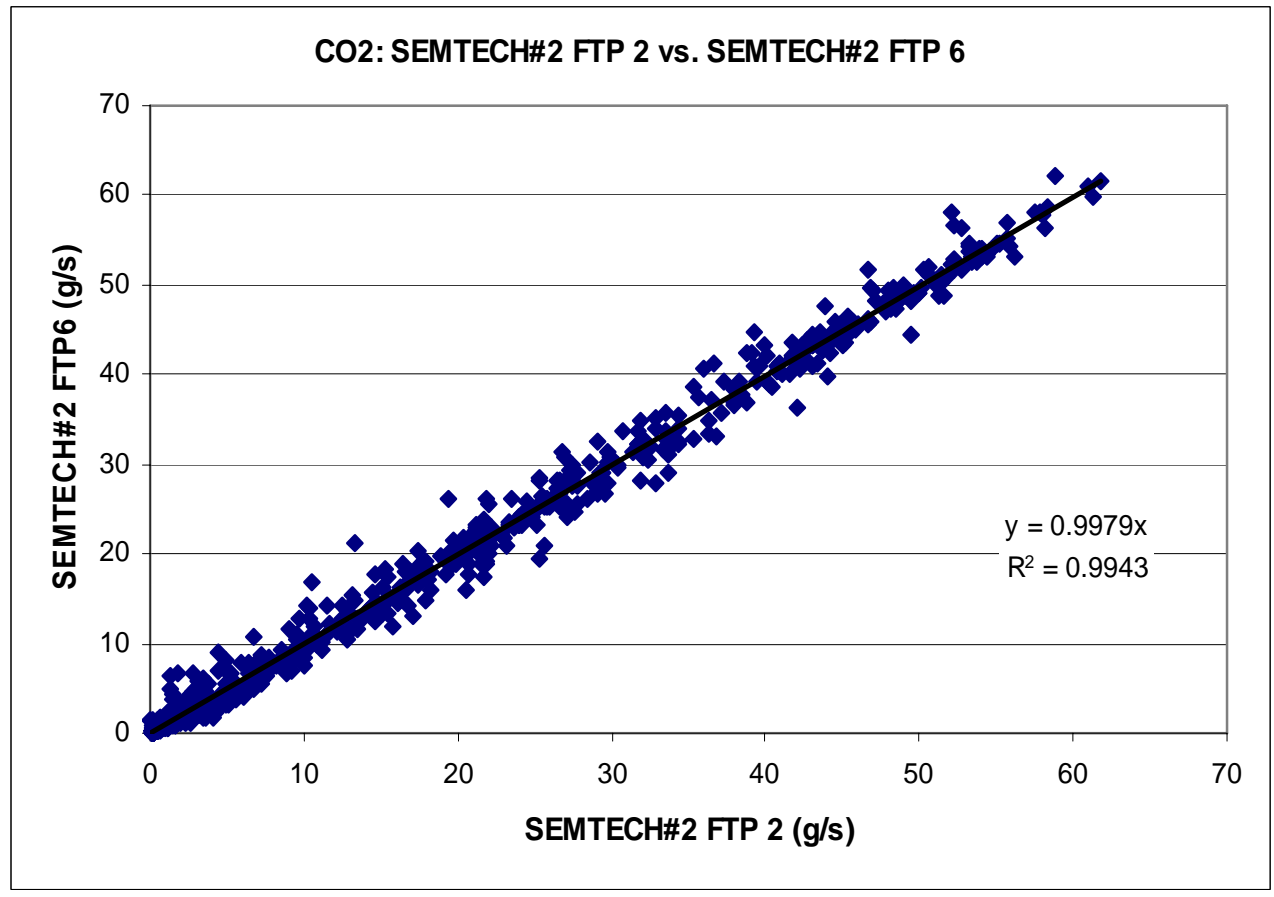

Figure 9.6 Test To Test Repeatability of SEMTECH-D\#2 


\section{Sequence II 2006}

Table 9.2 Complete results from Sequence I 2006

\begin{tabular}{|c|c|c|c|c|c|c|c|}
\hline & April 2006 Per & t Diffe & ce Con & ared to & boratory & & \\
\hline & Test Number & $\begin{array}{c}\text { NOx } \\
\text { (grams) }\end{array}$ & $\underset{\text { (grams) }}{\mathrm{CO}_{2}}$ & $\begin{array}{c}\text { CO } \\
\text { (grams) }\end{array}$ & $\begin{array}{c}\mathrm{HC} \\
\text { (grams) }\end{array}$ & $\begin{array}{l}\text { Ex. Flowrate } \\
\text { (SCF) }\end{array}$ & $\begin{array}{c}\text { Carbon Balance } \\
\text { (grams) }\end{array}$ \\
\hline $4 / 5 / 2006$ & E01021_01 & $17.1 \%$ & $10.5 \%$ & & $31.0 \%$ & $6.7 \%$ & $12.6 \%$ \\
\hline & E01022_01 & $14.4 \%$ & $14.9 \%$ & & $43.9 \%$ & $3.6 \%$ & $13.5 \%$ \\
\hline & E01022_02 & $16.3 \%$ & $10.4 \%$ & & $54.8 \%$ & $7.3 \%$ & $12.7 \%$ \\
\hline & E01022_03 & $16.2 \%$ & $11.0 \%$ & & $58.5 \%$ & $7.7 \%$ & $12.8 \%$ \\
\hline & E01022_04 & $16.8 \%$ & $9.6 \%$ & & $30.9 \%$ & $7.9 \%$ & $12.0 \%$ \\
\hline & E01022_05 & $14.1 \%$ & $10.8 \%$ & & $39.9 \%$ & $7.4 \%$ & $13.3 \%$ \\
\hline & Average & $15.6 \%$ & $11.3 \%$ & \#DIVIO! & $45.6 \%$ & $6.8 \%$ & $12.9 \%$ \\
\hline 4/7/2006 & & & & & & & \\
\hline & E01027_04 & $15.9 \%$ & $9.5 \%$ & $26.1 \%$ & $15.2 \%$ & $6.2 \%$ & $13.5 \%$ \\
\hline & E01027_05 & $16.3 \%$ & $10.1 \%$ & $24.6 \%$ & $22.3 \%$ & $6.9 \%$ & $14.0 \%$ \\
\hline & E01029_02 & $16.6 \%$ & $9.8 \%$ & $24.5 \%$ & $21.3 \%$ & $8.2 \%$ & $11.2 \%$ \\
\hline & E01029_03 & $10.9 \%$ & $10.9 \%$ & $28.2 \%$ & $18.2 \%$ & $8.5 \%$ & $12.2 \%$ \\
\hline & E01029_04 & $16.8 \%$ & $9.7 \%$ & $26.7 \%$ & $23.1 \%$ & $8.8 \%$ & $10.8 \%$ \\
\hline & E01029_05 & $15.0 \%$ & $10.0 \%$ & $25.0 \%$ & $28.2 \%$ & $8.8 \%$ & $11.5 \%$ \\
\hline & Average & $15.3 \%$ & $10.0 \%$ & $25.9 \%$ & $21.4 \%$ & $7.9 \%$ & 12.2 \\
\hline 2006 & & & & & & & \\
\hline & E01035_02 & $17.7 \%$ & $9.9 \%$ & $19.0 \%$ & $21.9 \%$ & $7.0 \%$ & $12.4 \%$ \\
\hline & E01035_03 & $16.4 \%$ & $9.9 \%$ & $21.1 \%$ & $22.2 \%$ & $6.5 \%$ & $12.5 \%$ \\
\hline & E01035_04 & $16.4 \%$ & $10.1 \%$ & $22.9 \%$ & $26.5 \%$ & $6.2 \%$ & $12.7 \%$ \\
\hline & E01037_02 & $16.6 \%$ & $9.8 \%$ & $24.8 \%$ & $25.2 \%$ & $5.9 \%$ & $10.4 \%$ \\
\hline & E01037_03 & $17.0 \%$ & $10.2 \%$ & $23.6 \%$ & $23.1 \%$ & $6.0 \%$ & $11.2 \%$ \\
\hline & E01037_04 & $17.1 \%$ & $11.3 \%$ & $26.7 \%$ & $30.2 \%$ & $5.6 \%$ & $12.1 \%$ \\
\hline & Average & $16.9 \%$ & $10.2 \%$ & $23.0 \%$ & $24.9 \%$ & $6.2 \%$ & $11.9 \%$ \\
\hline 4/9/2006 & & & & & & & \\
\hline & E01039_02 & $15.8 \%$ & $9.2 \%$ & $26.6 \%$ & $27.6 \%$ & $4.2 \%$ & $10.0 \%$ \\
\hline & E01039_03 & $15.3 \%$ & $7.4 \%$ & $16.3 \%$ & $-5.9 \%$ & $4.7 \%$ & $7.9 \%$ \\
\hline & E01039_04 & $15.9 \%$ & $7.6 \%$ & $29.9 \%$ & $37.1 \%$ & $4.9 \%$ & $8.0 \%$ \\
\hline & E01039_05 & $15.4 \%$ & $7.4 \%$ & $29.9 \%$ & $-0.8 \%$ & $4.7 \%$ & $7.7 \%$ \\
\hline & Average & $15.6 \%$ & $7.9 \%$ & $25.7 \%$ & $14.5 \%$ & $4.6 \%$ & 8.4\% \\
\hline
\end{tabular}


Table 9.3 Sequence III 2006 Complete Results

May 2006 Percent Difference Compared to Laboratory

$\begin{array}{lllllll}\mathrm{NO} 1 & \mathrm{NO} 2 & \mathrm{CO}_{2} & \mathrm{CO} & \mathrm{HC} & \mathrm{Ex} . \text { Flowrate } & \begin{array}{l}\text { Carbon } \\ \text { Balance }\end{array}\end{array}$

Test Number

E01118_01

E01118_02

E01118_03

Average

E01133_01

E01133_02

E01133_03

Average (grams) (grams) (grams) (grams) (grams)

$19.6 \% \quad 17.6 \% \quad 14.2 \% \quad 31.3 \% \quad 78.3 \%$

$23.4 \%$

$19.4 \%$

$15.2 \%$

$33.5 \%$

$84.3 \%$

$15.6 \%$

$34.4 \%$

$18.7 \%$

$15.0 \%$

$33.1 \%$

$18.5 \%$

$16.0 \%$

$15.8 \%$

$14.7 \%$

$16.3 \%$

$31.6 \%$

$39.1 \%$

$36.75 \%$

$19.45 \%$

$15.75 \%$

$15.90 \%$

$15.6 \%$

$35.8 \%$

$105.7 \%$
(SCF)

(grams of fuel)

$24.4 \%$

$9.8 \%$

$23.0 \%$

$2.0 \%$

$75.50 \% \quad 0.63 \%$

$71.70 \% \quad 1.03 \%$

$11.5 \%$

$12.8 \%$

$12.5 \%$

$1.1 \%$

$19.1 \%$

$12.3 \%$

NOx

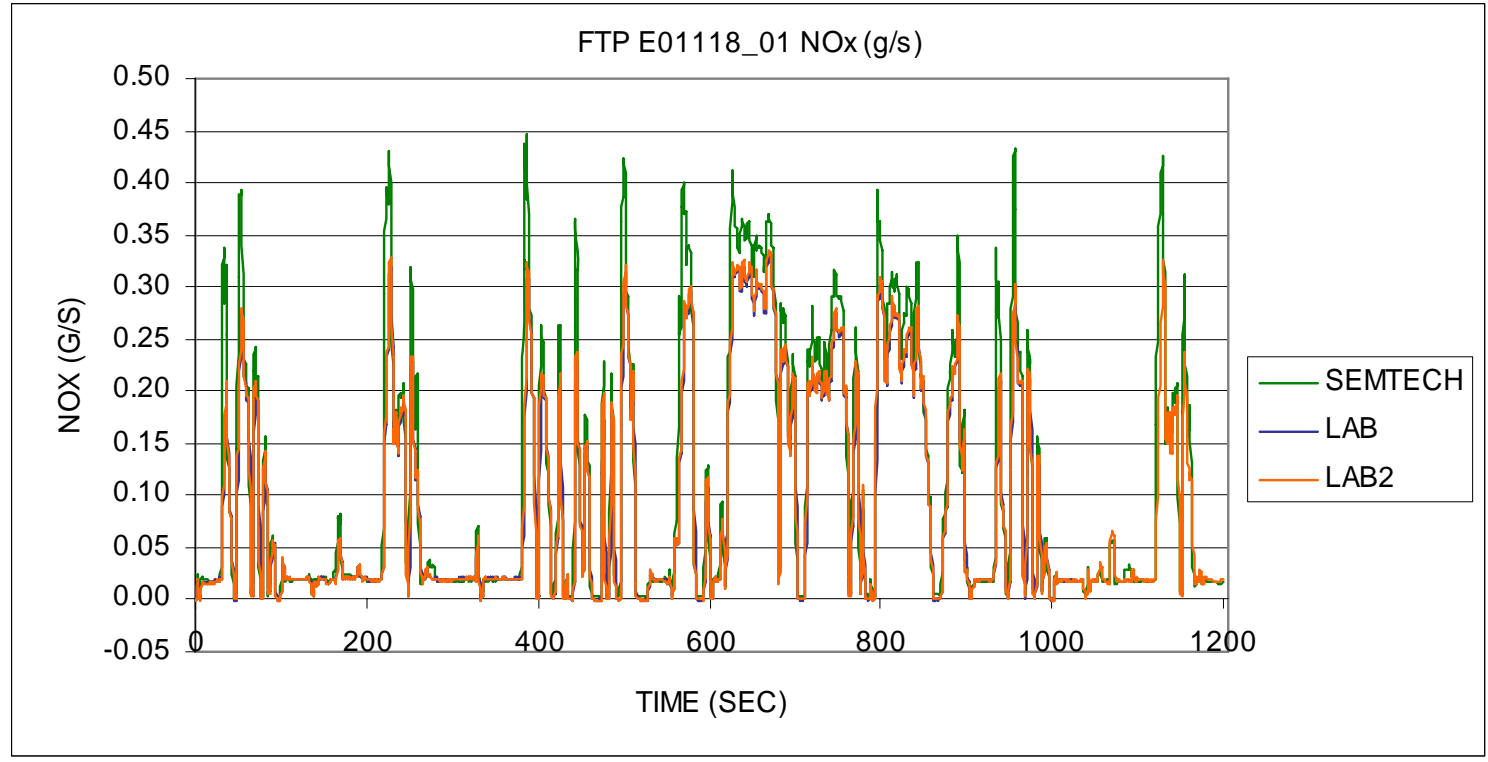

Figure 9.7 SEMTECH-D and Laboratory $\mathrm{NO}_{\mathrm{X}}$ 


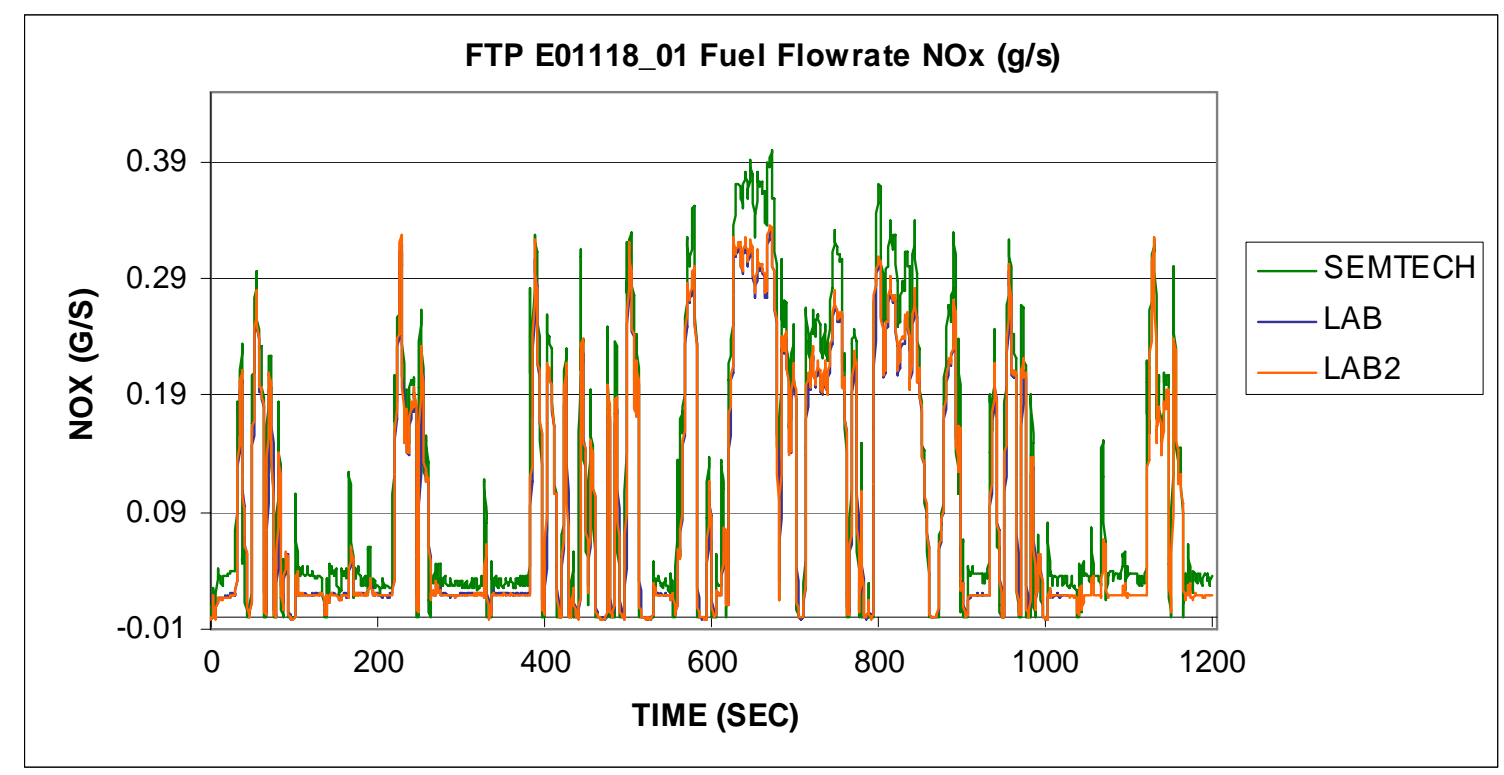

Figure 9.8 FTP E01118_01 Fuel Flowrate NOx

$\mathrm{CO}_{2}$

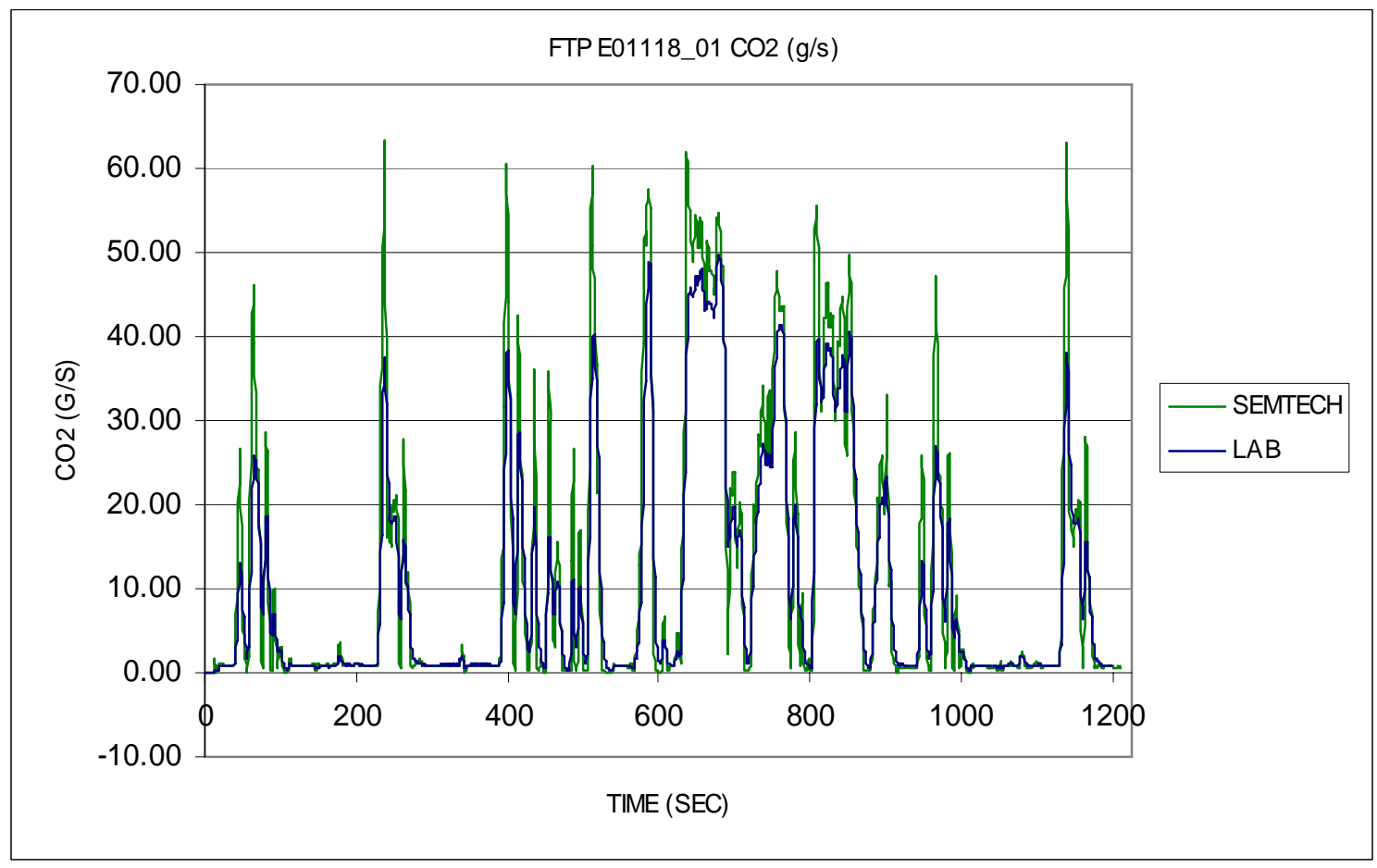

Figure 9.9 $\mathrm{CO}_{2}$ for FTP E01118_01

\section{A.1.1.1 $\mathrm{NO}_{X}$ Concentration}

The following figures represent the results from a typical FTP. Laboratory values are sampled diluted, therefore readings must be multiplied by a dilution ratio in order to 
compare to the SEMTECH-D. As mentioned earlier, the dilution ratio is calculated by dividing the entire dilution tunnel flowrate by the addition of intake air and fuel used. The presented test had an integrated error of $11.79 \%$ and $9.13 \%$ difference from Laboratory and Laboratory2, respectively.

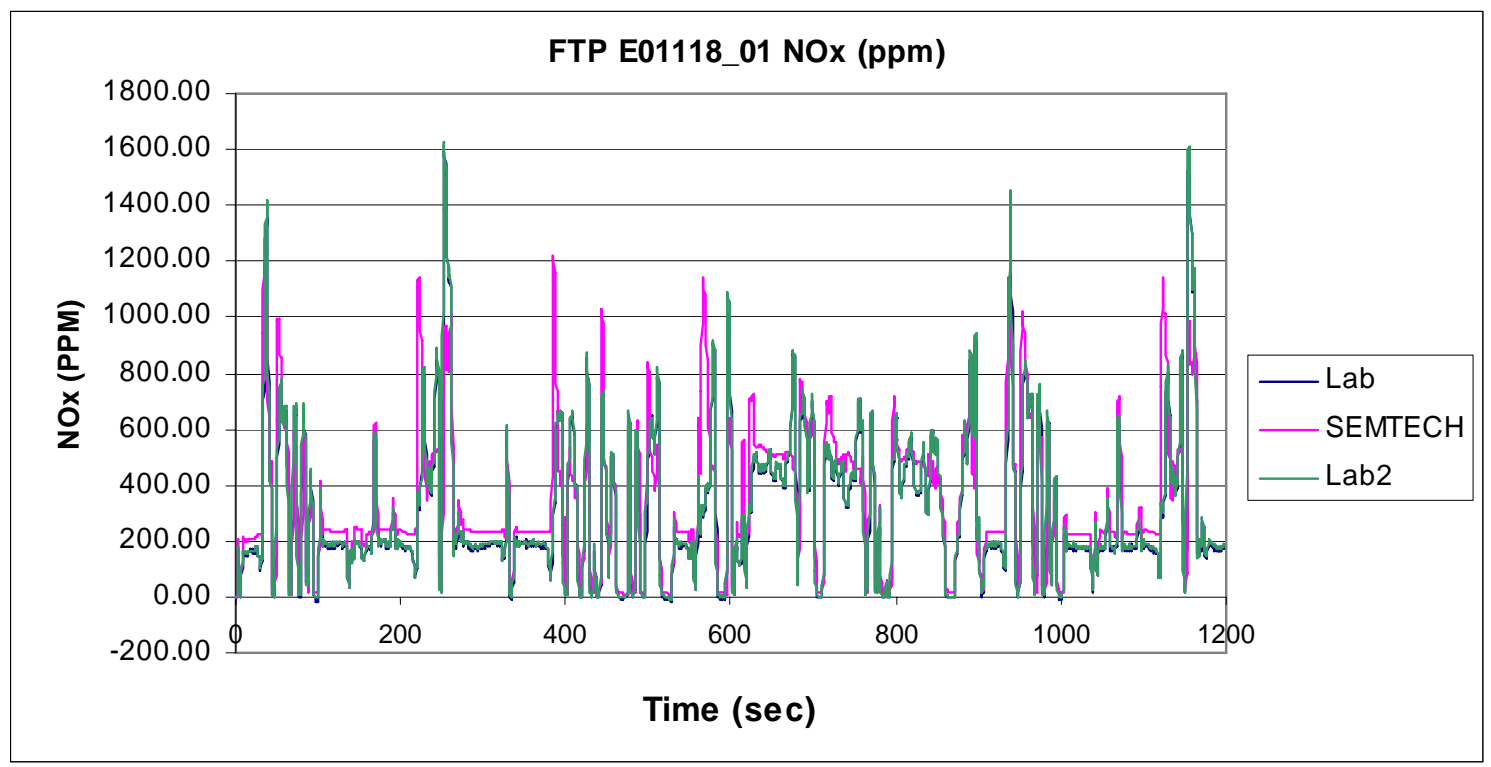

Figure 9.10 $\mathrm{NO}_{\mathrm{X}}$ Concentration from FTP E01118_01

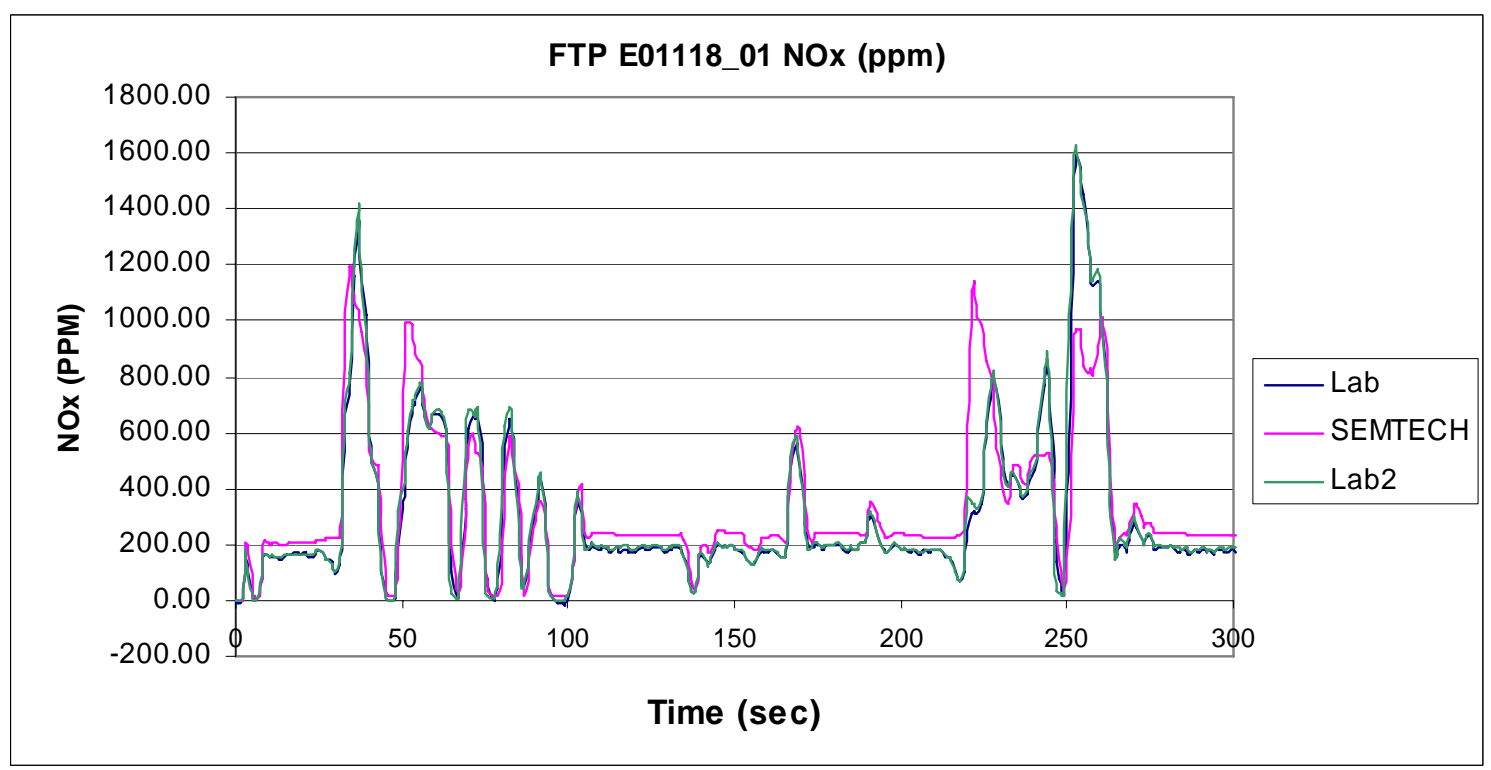

Figure 9.11 Segment of Figure 9.10 
For the E01118 test sequence, which consisted of three FTPs, the SEMTECH-D averaged 13.6\% higher readings than Laboratory, and 9.1\% for Laboratory 2.

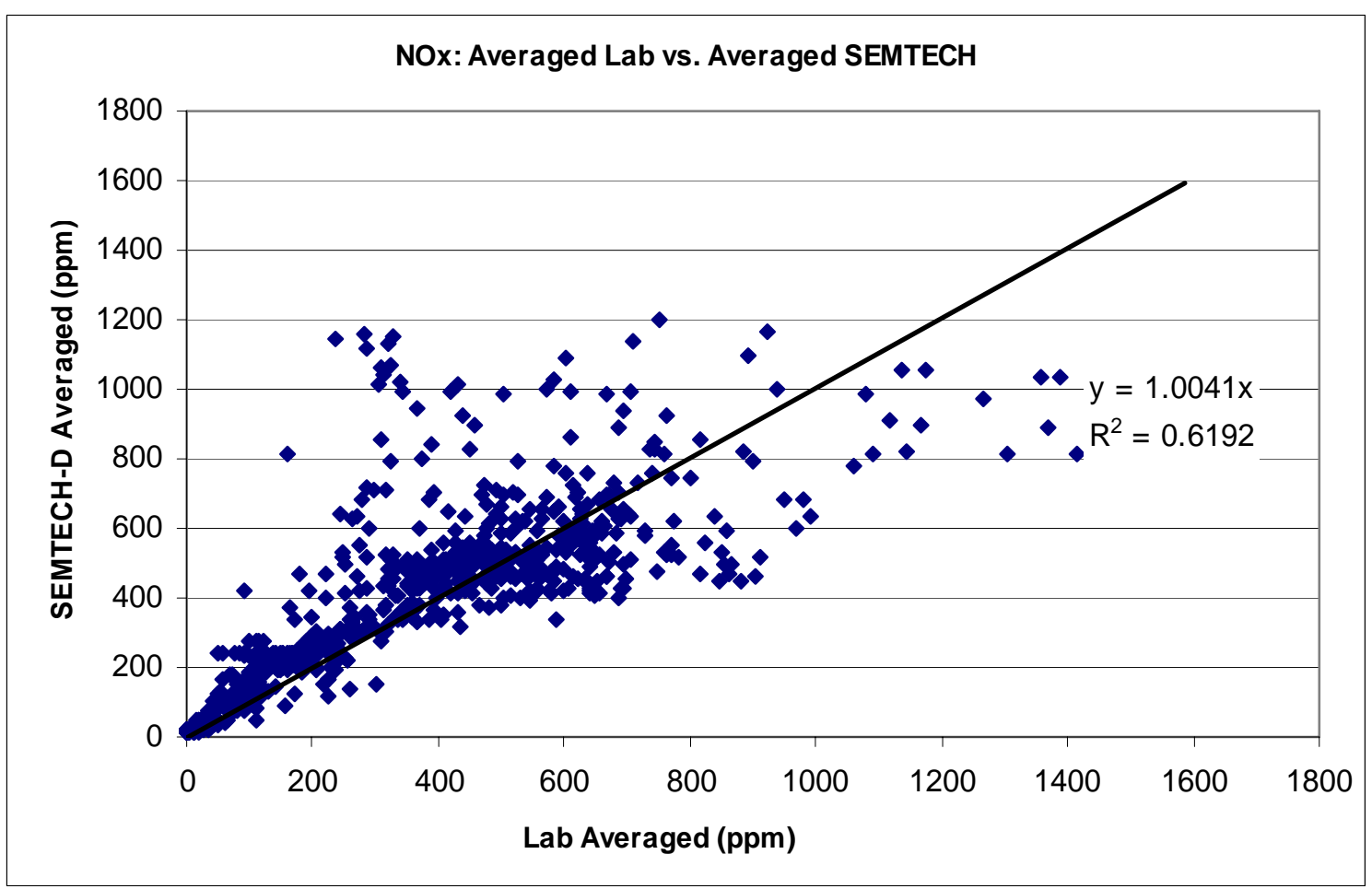

Figure 9.12 Time Aligned Averaged Laboratory vs. Averaged SEMTECH-D E01118

\section{Exhaust flowrate}

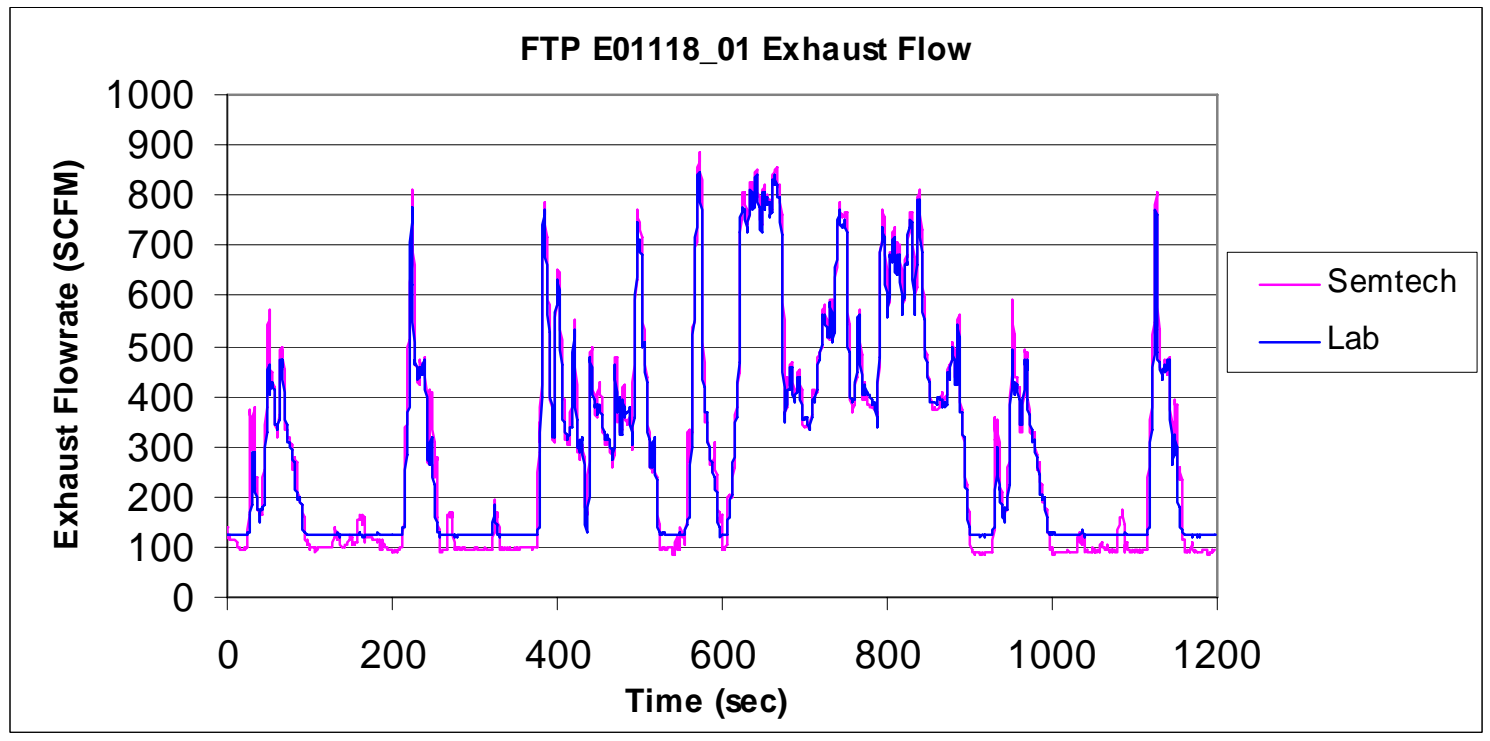

Figure 9.13 Exhaust Flowrate from a FTP 


\section{Sequence IV 2006}

Table 9.4 August 2006 Percent Differences Compared to Laboratory August 2006 Percent Difference Compared to Laboratory

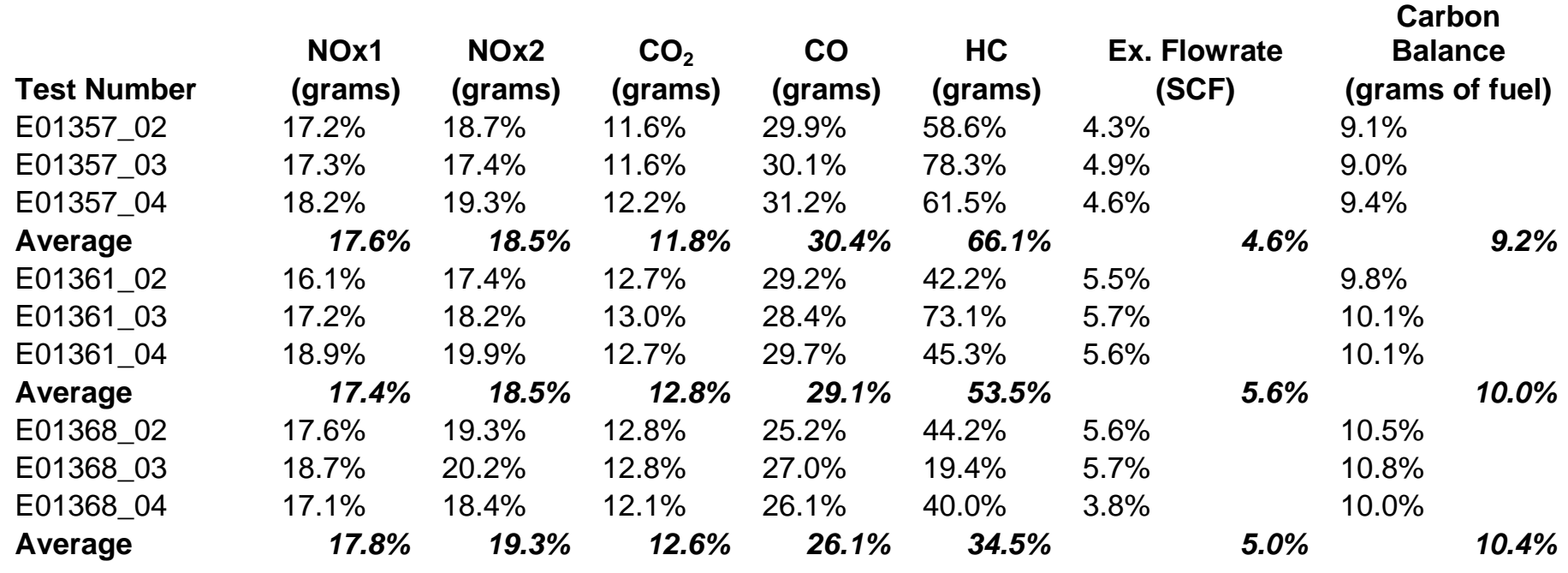

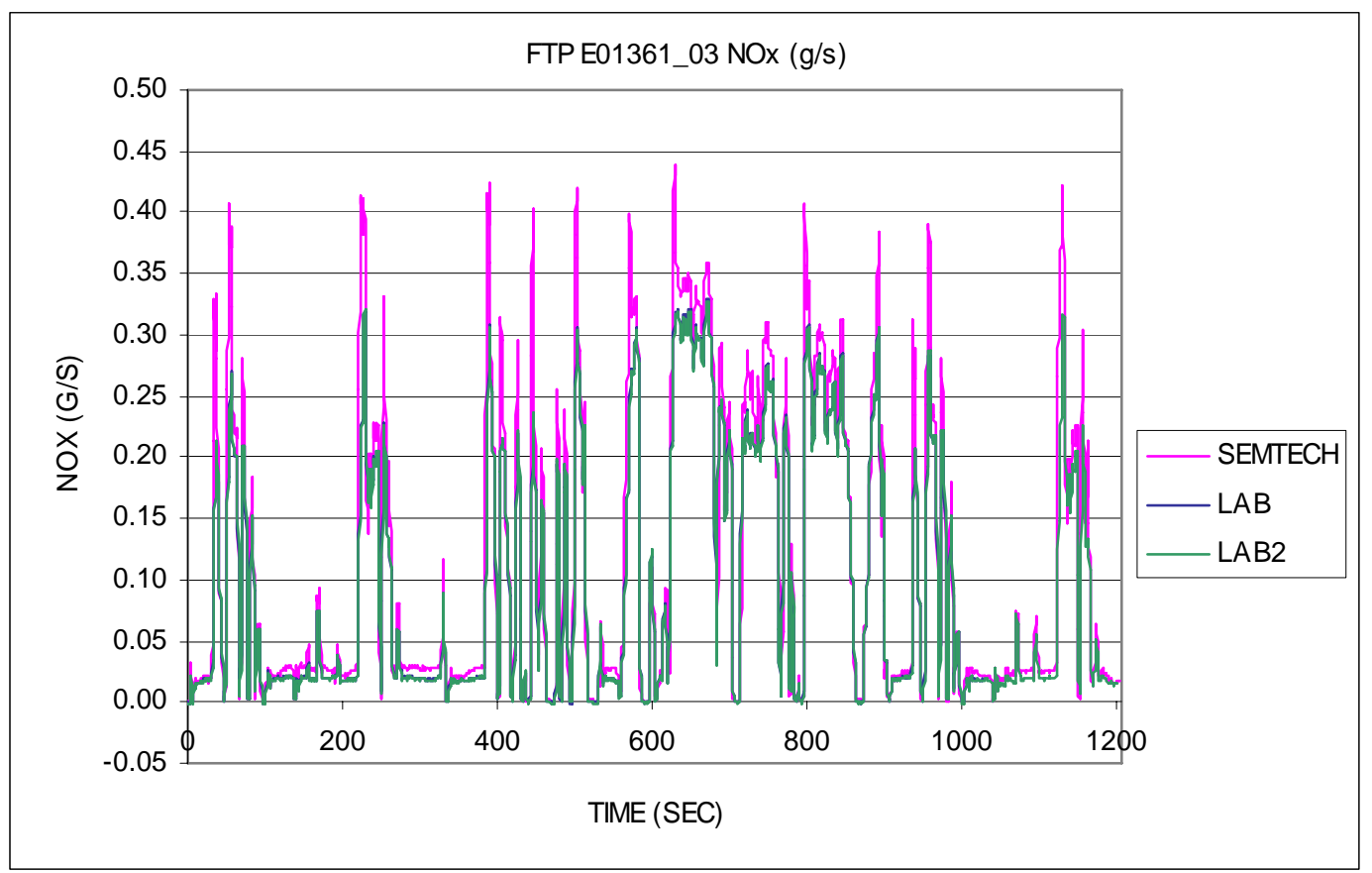

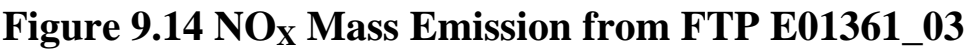




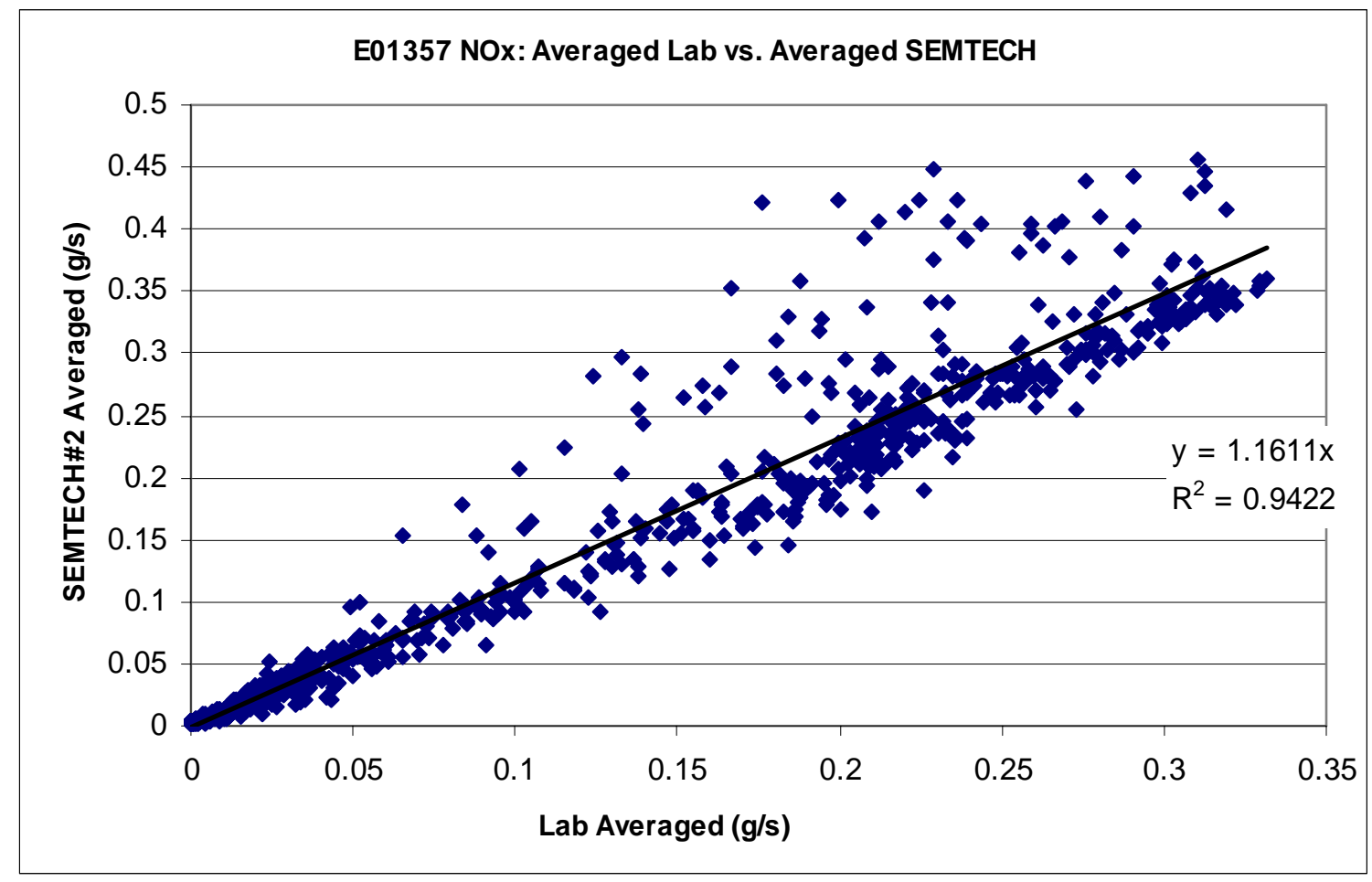

Figure 9.15 Time Aligned Averaged Laboratory vs. Averaged SEMTECH-D E01357

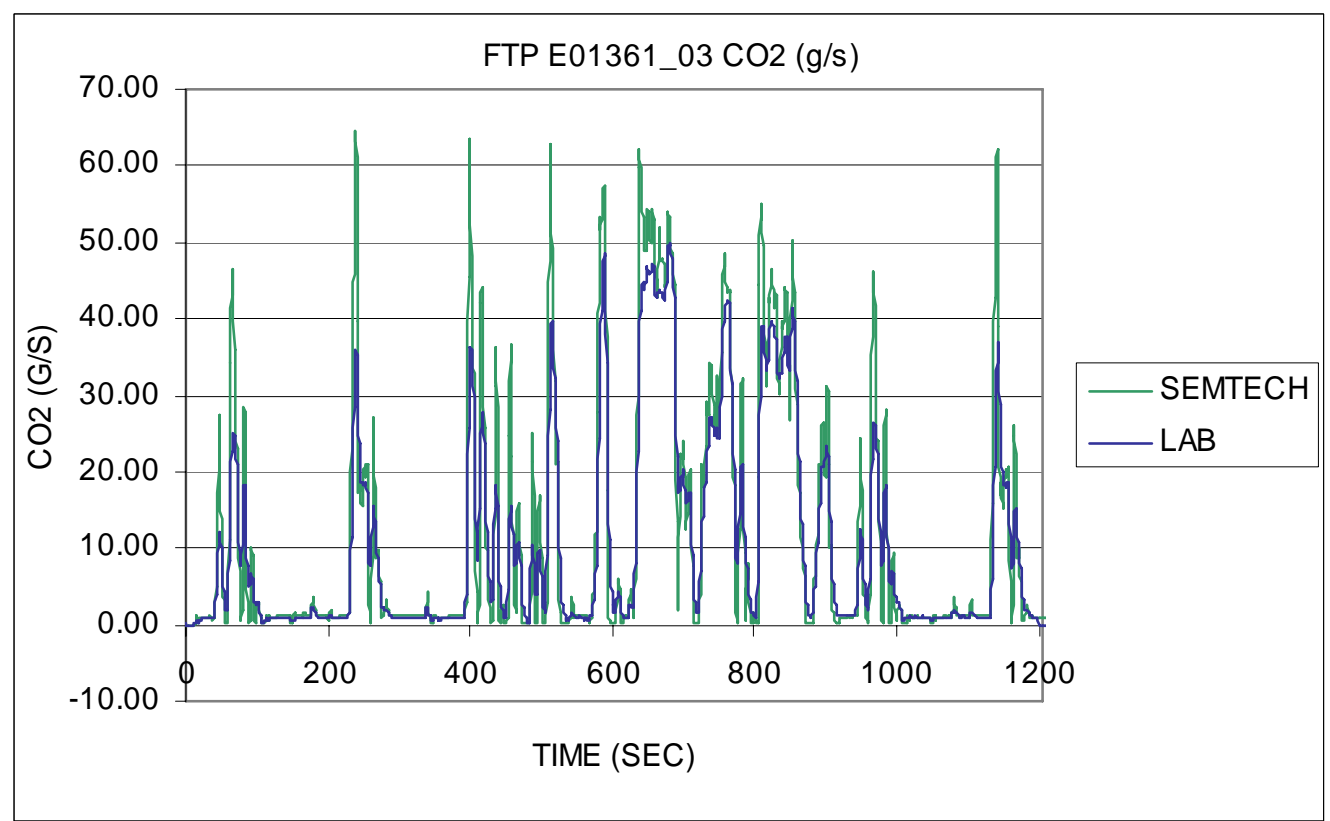

Figure 9.16 $\mathrm{CO}_{2}$ Mass Emission for FTP E01361_03 


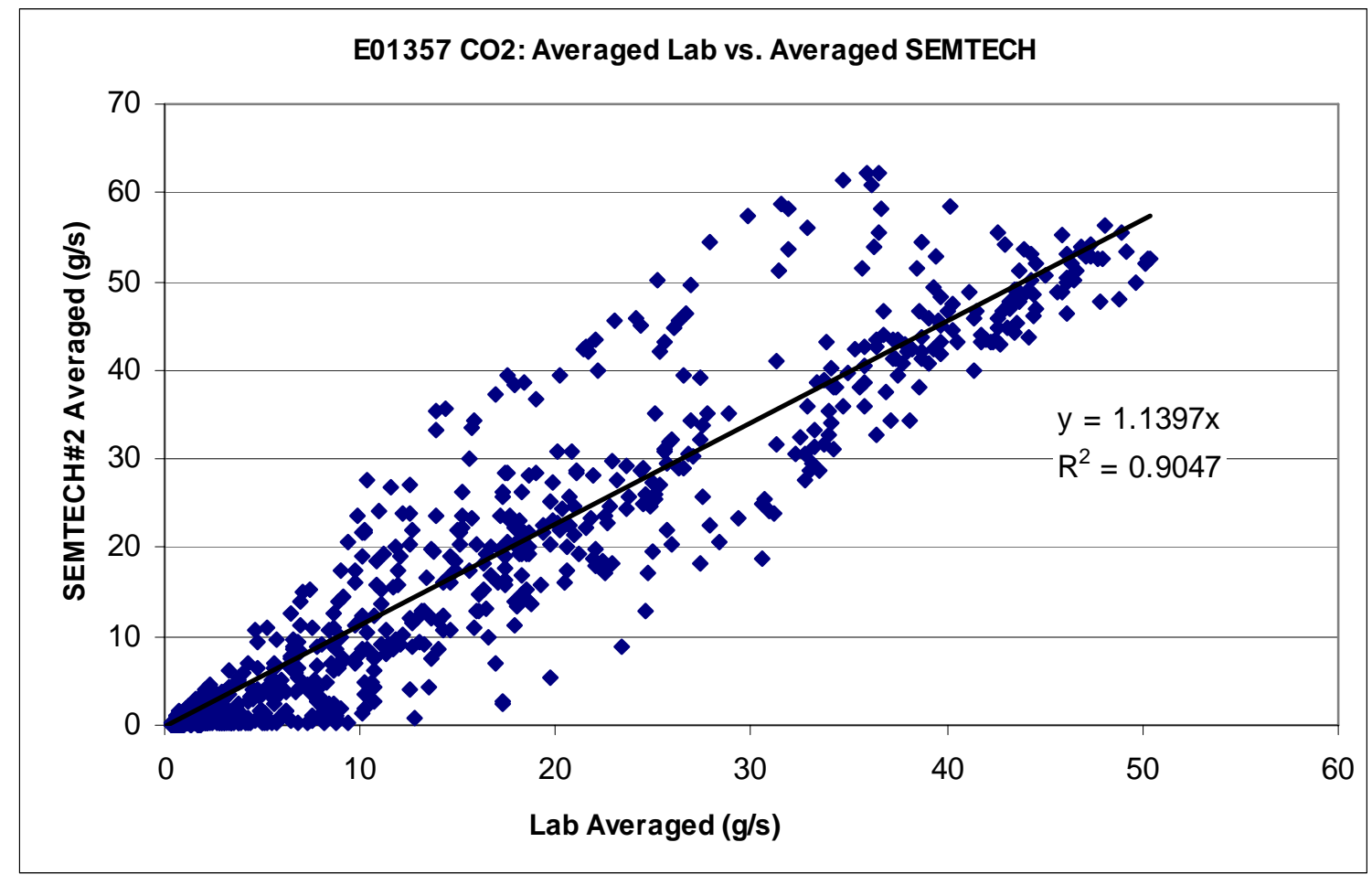

Figure 9.17 Time Aligned Averaged Laboratory vs. Averaged SEMTECH-D E01357

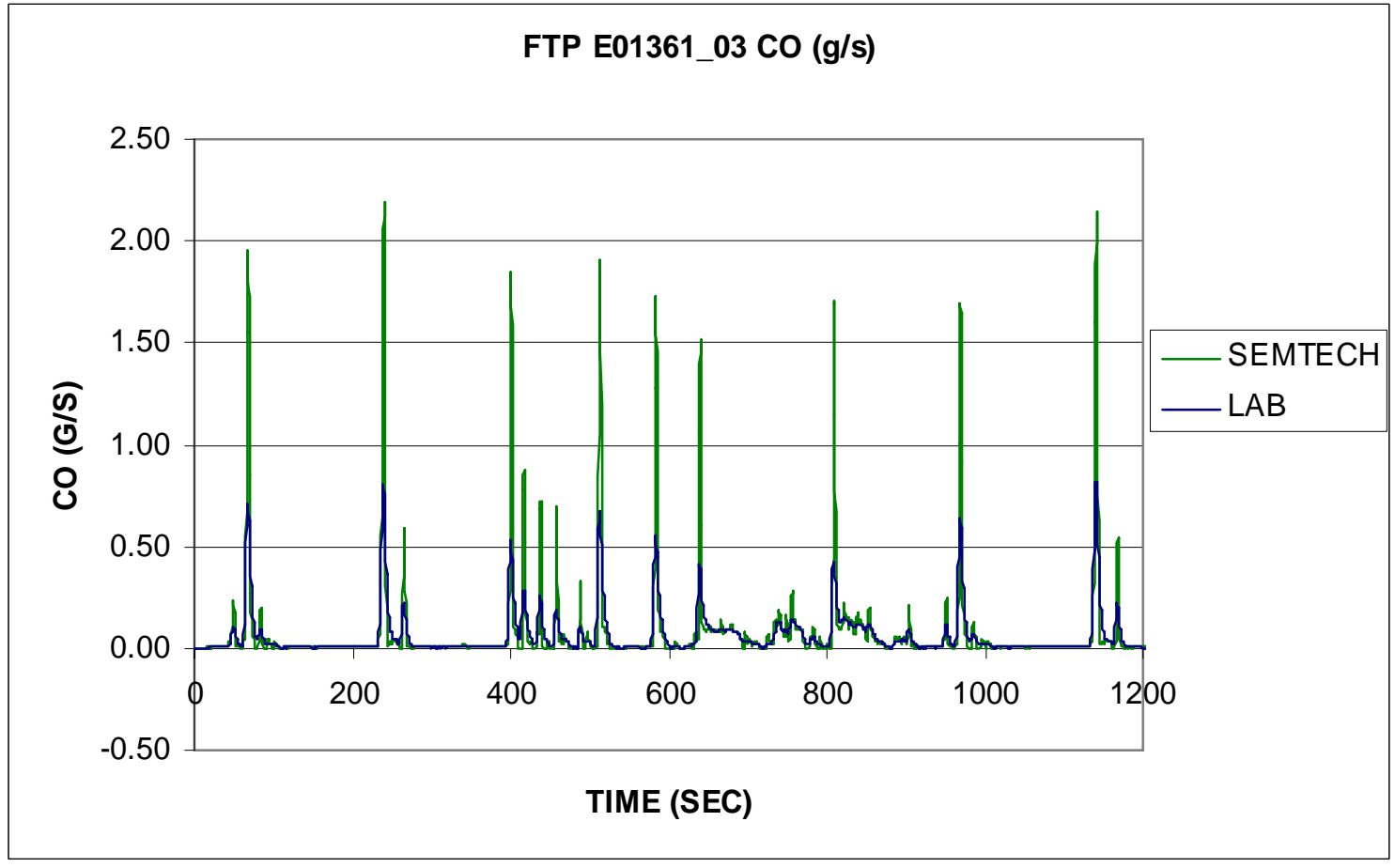

Figure 9.18 CO Mass Emission for FTP E01361_03 


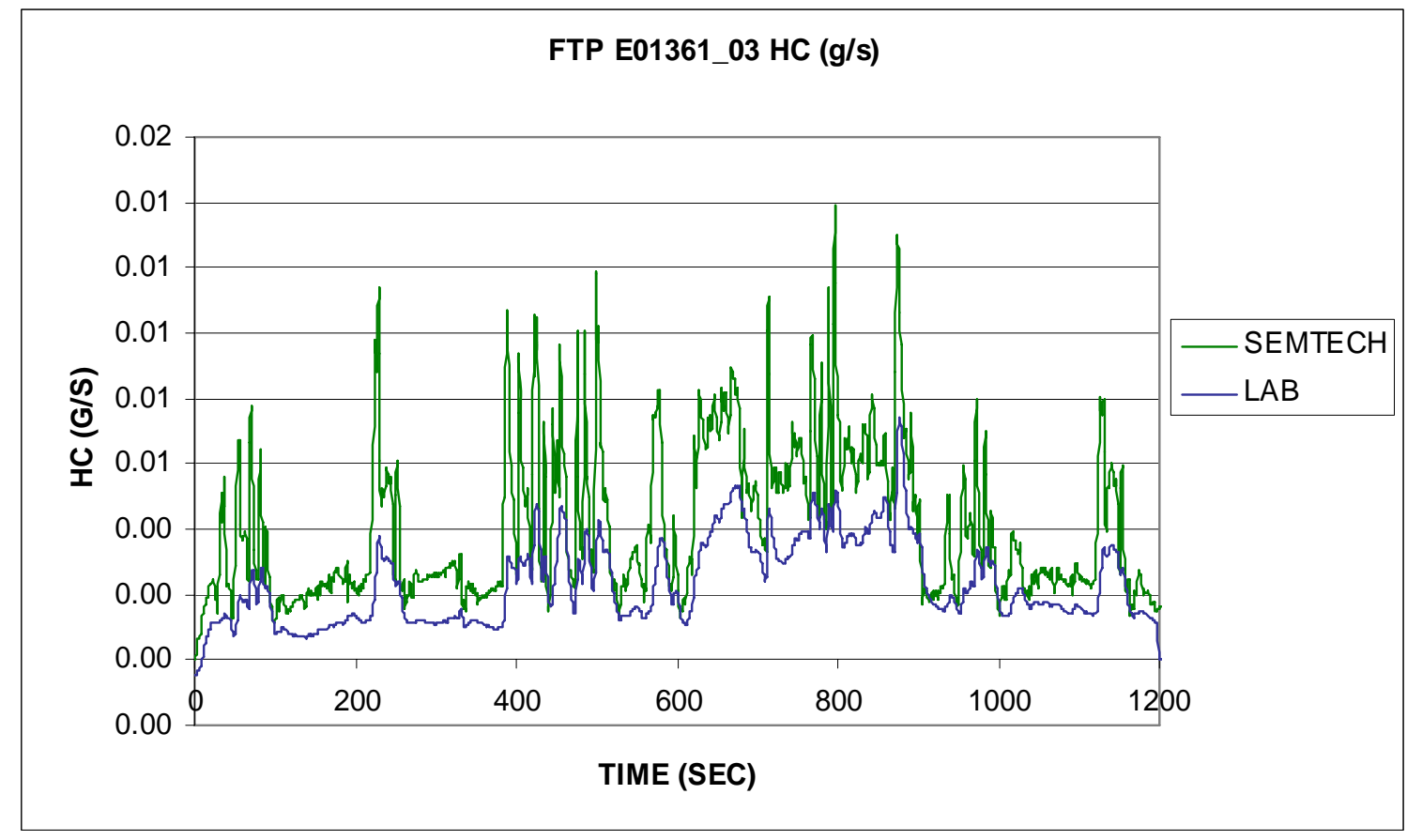

Figure 9.19 HC Mass Emission for FTP E01361_03

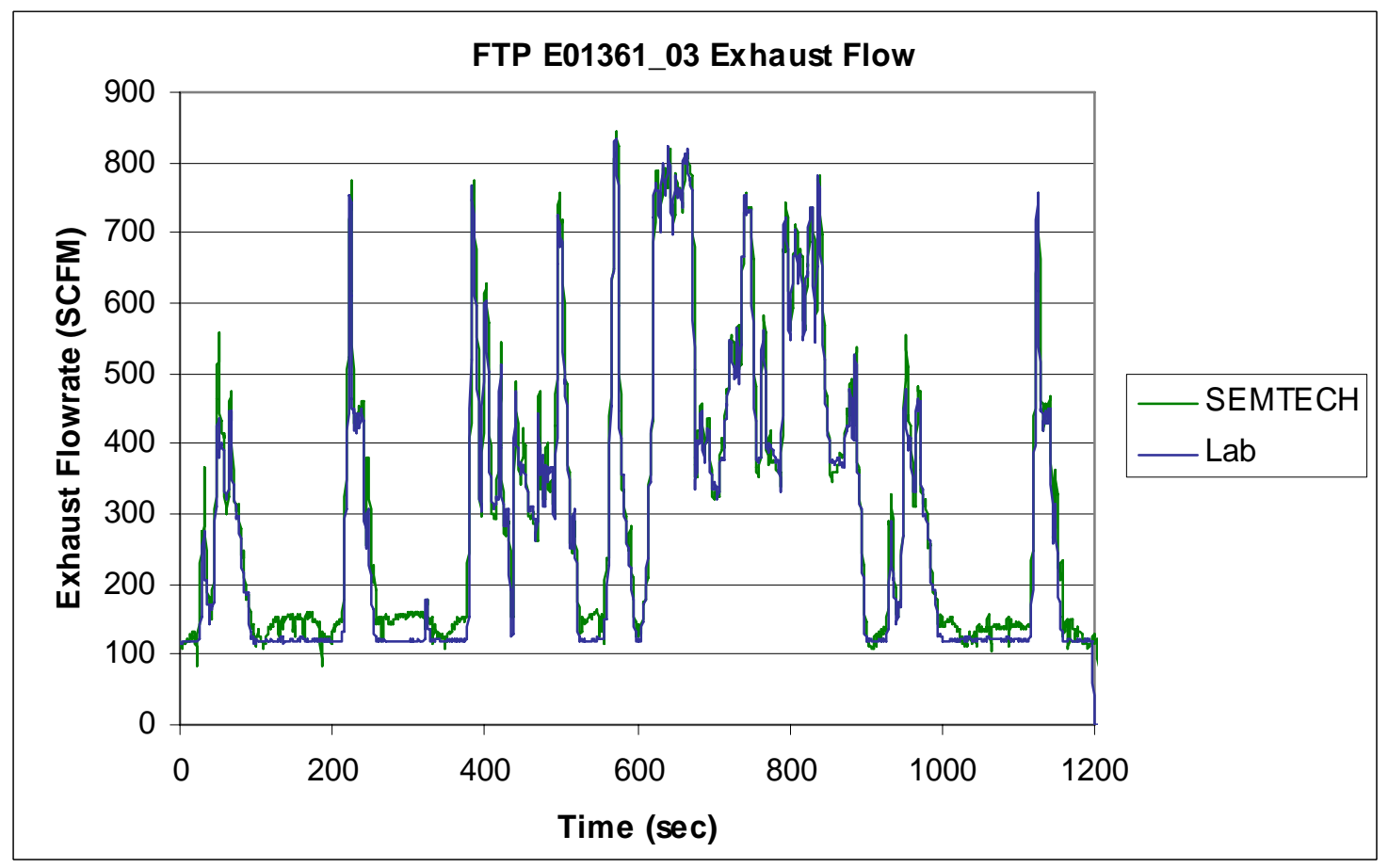

Figure 9.20 Exhaust Flowrate for FTP E01361_03 